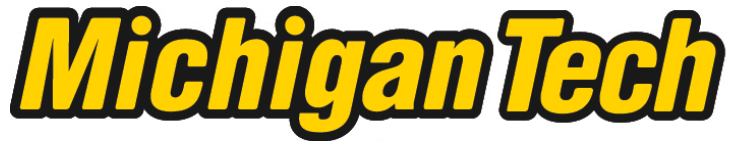 \\ Michigan Technological University Create the Future Digital Commons @ Michigan Tech
}

2013

\section{A STUDY OF THE IMPACTS OF FREEZE-THAW ON CLIFF RECESSION AT THE CALVERT CLIFFS IN CALVERT COUNTY, MARYLAND}

Bonnie Elizabeth Zwissler

Michigan Technological University

Follow this and additional works at: https://digitalcommons.mtu.edu/etds

Part of the Civil Engineering Commons, Geology Commons, and the Geotechnical Engineering Commons

Copyright 2013 Bonnie Elizabeth Zwissler

\section{Recommended Citation}

Zwissler, Bonnie Elizabeth, "A STUDY OF THE IMPACTS OF FREEZE-THAW ON CLIFF RECESSION AT THE CALVERT CLIFFS IN CALVERT COUNTY, MARYLAND", Master's Thesis, Michigan Technological University, 2013.

https://doi.org/10.37099/mtu.dc.etds/491

Follow this and additional works at: https://digitalcommons.mtu.edu/etds

Part of the Civil Engineering Commons, Geology Commons, and the Geotechnical Engineering Commons 


\section{A STUDY OF THE IMPACTS OF FREEZE-THAW ON CLIFF RECESSION AT THE CALVERT CLIFFS IN CALVERT COUNTY, MARYLAND}

By

Bonnie E. Zwissler

\section{A THESIS}

Submitted in partial fulfillment of the requirements for the degree of MASTER OF SCIENCE

In Civil Engineering

MICHIGAN TECHNOLOGICAL UNIVERSITY

2013

(C) 2013 Bonnie E. Zwissler 

This thesis has been approved in partial fulfillment of the requirements for the Degree of MASTER OF SCIENCE in Civil Engineering.

Civil and Environmental Engineering

\author{
Thesis Advisor: $\quad$ Thomas Oommen \\ Committee Member: Stanley Vitton \\ Committee Member: $\quad$ Gregory Waite \\ Department Chair: $\quad$ David Hand
}





\section{Table of Contents}

List of Tables ................................................................................................... vii

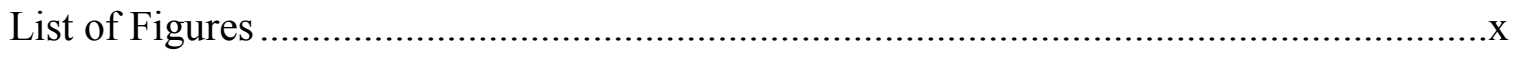

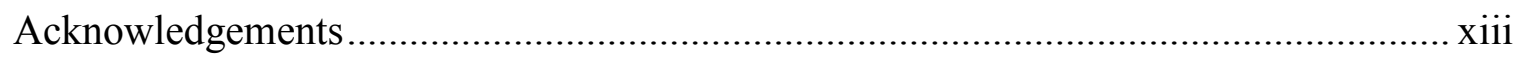

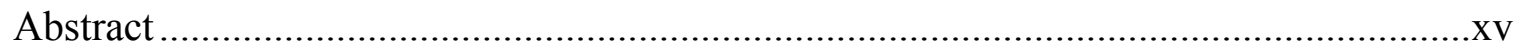

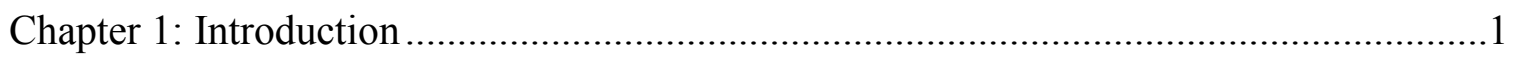

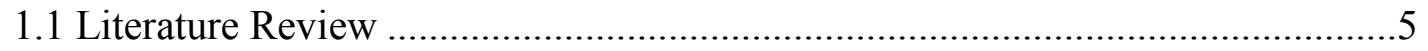

1.1.1 Cliff Instability, Recession, and Erosion Processes ...........................6

1.1.2 Previous Studies on Instability and Recession of the Calvert Cliffs .....10

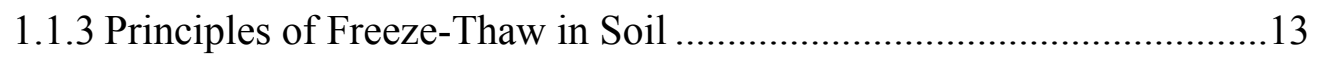

1.1.4 Freeze-Thaw Impacts on Slopes...................................................16

Chapter 2: Problem Formation and Objectives..........................................................20

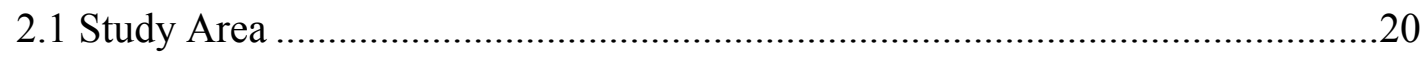

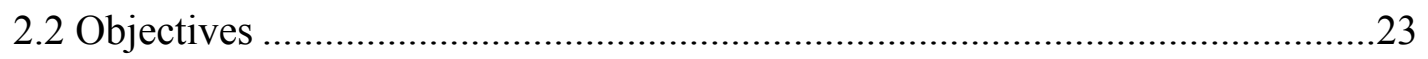

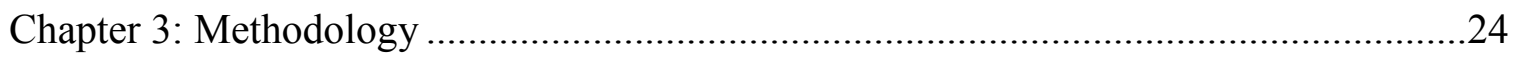

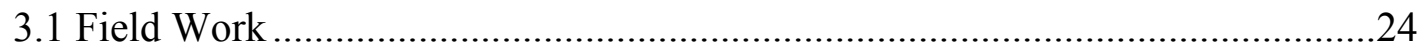

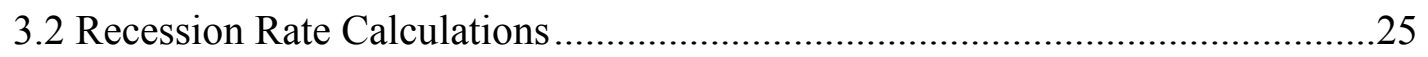

3.3 Freeze-Thaw Behavior and Susceptibility of Calvert Cliffs............................28

3.3.1 Temperature Profile and Frequency of Freeze-Thaw of Cliffs ............28

3.3.2 Soil Layer Identification and Thickness Determination.......................30

3.3.3 Moisture Conditions of Soil Layers ..................................................37

3.3.4 Freeze-Thaw Susceptibility of Soil Layers ........................................39

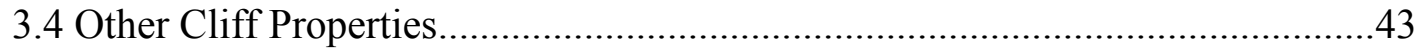

3.4.1 Cliff Height and Slope Angle ......................................................43

3.4.2 Weighted Shear Strength ............................................................45 


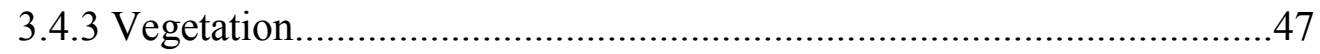

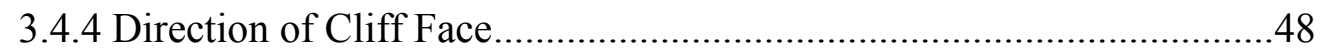

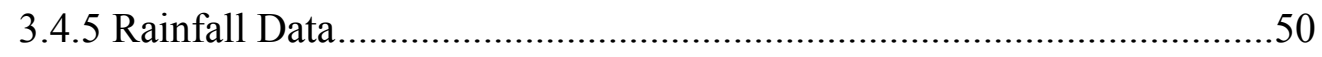

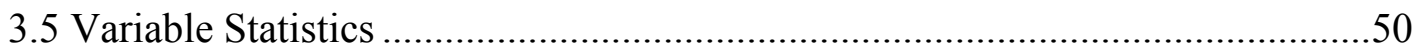

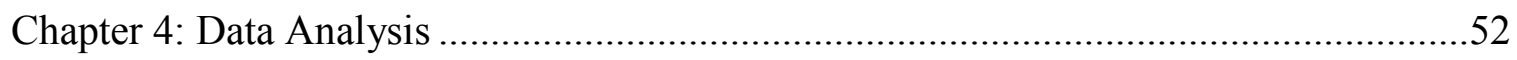

4.1 Spatial and Temporal Trends in Recession Rate ................................................52

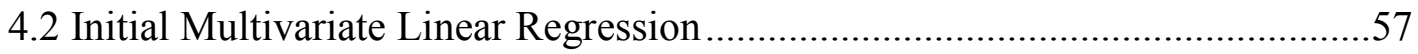

4.2.2 Statistical Significance of the Initial Model ...........................................59

4.2.2 Significance of the Variables Considered in the Initial Model .............63

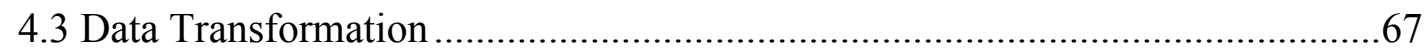

4.4 Relationship between Freeze-Thaw and Recession Rate of the Calvert Cliffs 102

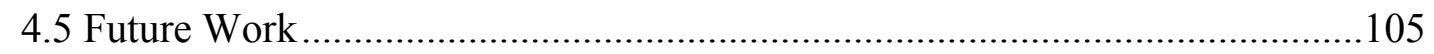

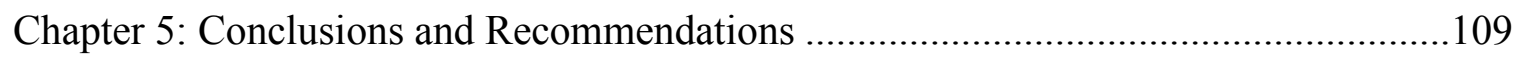

Appendix A: Measurements (in meters) Used in Recession Rate Calculations ................A1

Appendix B: Kriging for Spatial Trends in Temperature Data......................................... B1

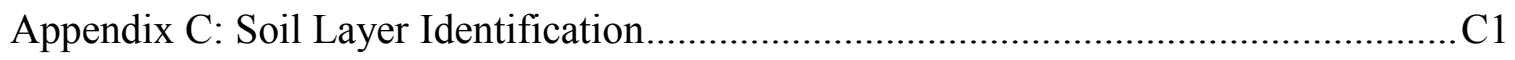

Appendix D: Soil Classification Information ............................................................

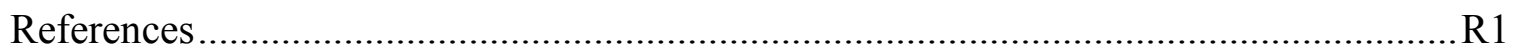




\section{List of Tables}

Table 1: Study Site Names Used in this Study and Previous Studies..............................21

Table 2: Geographic Coordinates of Study Sub-Sites .................................................22

Table 3: Calculated Recession Rates for Each Sub-site .............................................27

Table 4: Average Number of Days of Freezing and Freeze-Thaw Cycles for each

Recession Rate Time Interval ..............................................................29

Table 5: Stratigraphy of the Calvert Cliffs, Comparing Names Used in Past Work to Names Used in This Study..................................................................31

Table 6: Soil Layer Thicknesses for SCN Sub-Sites ...................................................33

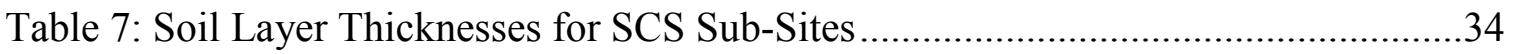

Table 8: Soil Layer Thicknesses for CB Sub-Sites.................................................. 35

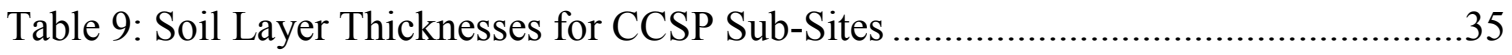

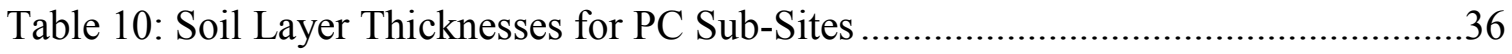

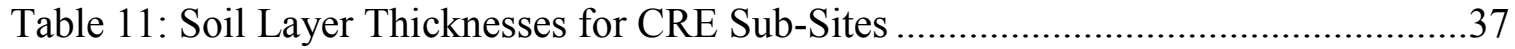

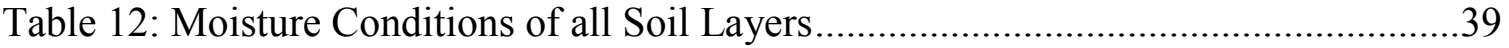

Table 13: U.S. Army Corps of Engineers Frost Susceptibility Based on USCS Classification (Adapted from Department of the Army Corps of Engineers Office of the Chief of Engineers 1984) ....................................................4

Table 14: Percent of Total Cliff Height Composed of Each Freeze-Thaw Susceptibility

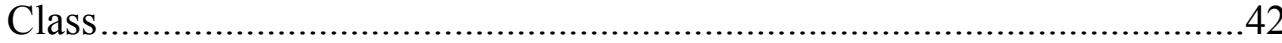

Table 15: Cliff height and slope angle for all sub-sites ...........................................44

Table 16: Weight shear strength for each sub-site ..................................................46

Table 17: Vegetation ranking for each sub-site .........................................................48

Table 18: Direction of cliff face for all study sites ................................................49

Table 19: Average yearly rainfall for time intervals considered ..................................50 
Table 20: Statistical Information for all Variables with Continuous Data

Table 21: Statistical Information for all Variables with Categorical Data

Table 22: Variables Considered for Multivariate Linear Regression .....

Table 23: Summary of Model-Assessment Statistics for Initial Multivariate Regression Model.....

Table 24: Summary of Variable-Assessment Statistics for Initial Multivariate Regression Model .....

Table 25: Summary of Model-Assumption Statistics for Intermediate Multivariate Linear Regressions

Table 26: Details about Slope Angle and Recession Rate Outliers .90

Table 27: Summary of Model-Assumption Statistics for Search for Final Multivariate Linear Regressions.

Table 28: Summary of Variable-Assessment Statistics for Multivariate Linear Regression-Freeze-Thaw Cycles.

Table 29: Summary of Variable-Assessment Statistics for Multivariate Linear Regression-Days of Freezing.

Table 30: Average Freezing Index, Days of Freezing, and Freeze-Thaw Cycles per Time Interval.

Table 31: Summary of Model-Assumption Statistics for Final Multivariate Linear Regression..

Table 32: Summary of Variable-Assessment Statistics for Multivariate Linear Regression-Freezing Index. 100

Table 33: SCN Recession Rate Measurements (in meters)

Table 34: SCS Recession Rate Measurements (in meters)

Table 35: CB Recession Rate Measurements (in meters)

Table 36: CCSP Recession Rate Measurements (in meters) A2

Table 37: PC Recession Rate Measurements (in meters)

Table 38: CRE Recession Rate Measurements (in meters) 
Table 39: Soil Layer Thicknesses, Shear Strength, Vegetation Conditions, and FreezeThaw Susceptibility for $\mathrm{SCN}$................................................................. 2

Table 40: Soil Layer Thicknesses, Shear Strength, Vegetation Conditions, and FreezeThaw Susceptibility for SCS..................................................................... 6

Table 41: Soil Layer Thicknesses, Shear Strength, Vegetation Conditions, and Freeze-

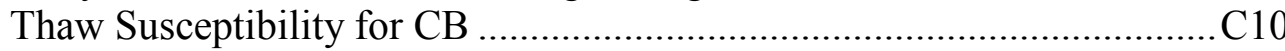

Table 42: Soil Layer Thicknesses, Shear Strength, Vegetation Conditions, and FreezeThaw Susceptibility for CCSP

Table 43: Soil Layer Thicknesses, Shear Strength, Vegetation Conditions, and FreezeThaw Susceptibility for PC

Table 44: Soil Layer Thicknesses, Shear Strength, Vegetation Conditions, and FreezeThaw Susceptibility for CRE ................................................................... 20

Table 45: USCS Classification of Collected Samples .....................................................D1

Table 46: Geotechnical Data for Soil Layers (Adapted from Table 3.11, Miller (1995)) D3

Table 47: USCS Classification for Freeze-Thaw Susceptibility of All Soil Layers..........D4 


\section{List of Figures}

Figure 1: (a) Map of Calvert County, MD, and (b) Aerial Photography Showing Study Site (data source: Calvert County Government 2012) ...................................2

Figure 2: Typical Slope Terminology and Failure Types (adapted from Edil 2010; Miller 1995)

Figure 3: Theoretical Slope Stabilization of the Calvert Cliffs, Assuming a Fixed Slope

Toe 12

Figure 4: Schematic of Freeze-Thaw Behavior in Soil..... 15

Figure 5: Location of Study Sites within Calvert County (map data source: Calvert County Government 2012)

Figure 6: Recession Rate Calculation Demonstration (image data source: Calvert

County Government 2012) 26

Figure 7: Soil Layers Identified for CRE2 in Order for Soil Layer Thicknesses to be

Calculated (image data source: Calvert County Government 2012)... .32

Figure 8: Digital Image and Corresponding FLIR Thermal IR Image of a Portion of a Slope 38

Figure 9: Spatial and Temporal Trends for Northern Study Sites SCN, SCS, and CB

(map data source: Calvert County Government 2012).

Figure 10: Spatial and Temporal Trends for Northern Study Sites CCSP, PC, and CRE (map data source: Calvert County Government 2012) ..............................56

Figure 11: Predicted versus Observed Plot for initial Multivariate Linear Regression ......58

Figure 12: Visualization of Residuals for Initial Multivariate Linear Regression - (a) Scatterplot of Residual Errors vs. Fitted Values, (b) Scatterplot of Standardized Residual Errors vs. Fitted Values, (c) Normal Q-Q Plot, and (d) Cook's Distance Plot

Figure 13: Histograms for Cliff Height (Height), Slope Angle (Angle), Weighted Shear Strength $(\mathrm{Su})$, and Cliff Face Direction (Face).

Figure 14: Histograms for Percent of Total Cliff Height Composed of Freeze-Thaw Susceptibility Classes F4 (Height_L4), F3 (Height_L3), F2 (Height_L2), and F1 (Height_L1) 
Figure 15: Histograms for Vegetation Condition of Soil with Freeze-Thaw

Susceptibility Class F4 (Veg_L4), F3 (Veg_L3), F2 (Veg_L2), and F1

(Veg_L1)....

Figure 16: Histograms for Number of Days of Freeze-Thaw (Ftday), Number of Freeze-

Thaw Cycles (Ftcycle), and Amount of Rainfall (Rain).

Figure 17: Q-Q Plots for Cliff Height (Height), Slope Angle (Angle), and Weighted Shear Strength $(\mathrm{Su})$

Figure 18: Q-Q Plots for Percent of Total Cliff Height Composed of Freeze-Thaw Susceptibility Classes F4 (Height_L4), F3 (Height_L3), F2 (Height_L2), and F1 (Height_L1)

Figure 19: Histograms for Data Transformation of Cliff Height...................................78

Figure 20: Q-Q Plots for Data Transformation of Cliff Height ....................................79

Figure 21: Histograms for Data Transformation of Percent of Total Height of Soil with F3 Freeze-Thaw Susceptibility.

Figure 22: Q-Q Plots for Data Transformation of Percent of Total Height of Soil with F3 Freeze-Thaw Susceptibility.

Figure 23: Histograms and Q-Q Plots for Data Transformation of Percent of Total Height of Soil with F2 Freeze-Thaw Susceptibility

Figure 24: Histograms and Q-Q Plots for Data Transformation of Weighted Shear Strength

Figure 25: Histograms for Data Transformation of Slope Angle .84

Figure 26: Q-Q Plots for Data Transformation of Slope Angle.

Figure 27: Histograms for Data Transformation of Slope Angle WITH OUTLIERS

REMOVED.

Figure 28: Q-Q Plots for Data Transformation of Slope Angle WITH OUTLIERS REMOVED

Figure 29: Predicted versus Observed Plots for Intermediate Multivariate Simple Linear Regression.

Figure 30: Predicted versus Observed Plot for Multivariate Linear Regression-Freeze-

Thaw Cycles

Figure 31: Visualization of Residuals for Multivariate Linear Regression-Freeze-

Thaw Cycles 
Figure 32: Predicted versus Observed Plot for Multivariate Linear Regression-Days of

Freezing

Figure 33: Visualization of Residuals for Multivariate Linear Regression-Days of Freezing

Figure 34: Method for Determining Freezing Index (Adapted from Joint Departments of the Army and Air Force 1987) ..............................................................97

Figure 35: Cumulative Degree Day Plots for Two Winter Seasons

Figure 36: Spatial Interpolation of Temperature Using Kriging for 8/1/2010 -

Exponential Model.

Figure 37: Spatial Interpolation of Temperature Using Kriging for 10/15/2010 -

Exponential Model.

Figure 38: Spatial Interpolation of Temperature Using Kriging for 1/1/2011 -

Exponential Model. B5

Figure 39: Spatial Interpolation of Temperature Using Kriging for 4/15/2011 -

Spherical Model. B6

Figure 40: Spatial Interpolation of Temperature Using Kriging for 8/1/2011 Exponential Model.

Figure 41: Soil Layers Identified for SCN1 (image data source: Calvert County Government 2012)

Figure 42: Soil Layers Identified for SCS5 (image data source: Calvert County Government 2012) C5

Figure 43: Soil Layers Identified for CB1 (image data source: Calvert County Government 2012)

Figure 44: Soil Layers Identified for CCSP4 (image data source: Calvert County Government 2012)

Figure 45: Soil Layers Identified for PC3 (image data source: Calvert County Government 2012)

Figure 46: Soil Layers Identified for CRE2 (image data source: Calvert County Government 2012). 


\section{Acknowledgements}

This project would not have been possible without the generosity and support of many people and groups.

I first must thank Dr. David Brownlee and the rest of the Calvert County Department of Community Planning and Building. They allowed me to "work" for them as an intern in exchange for having access to county data and a place to work for the summer while not in the field. I am very thankful to have had the opportunity to work with such a friendly and positive team.

I also need to thank Erick Pate, a GIS Analyst from the Calvert County Department of Technology Services. He helped me figure out what data I actually needed, provided me with a way to get it, and answered all the questions I could throw at him. Without the data he helped me obtain, my project would not have been remotely possible.

I am grateful that the members of the Cliff Stabilization Advisory Committee (CSAC) allowed me to attend meetings, participate, and share my preliminary findings with them. Being able to work with those most directly affected by the recession of the Calvert Cliffs helped keep the project tied closely to reality for me.

Additionally, I must thank the CSAC members (and other community members) that granted me access to the cliffs on their property or in their communities (while sharing their observations of the cliffs that date back in many instances to before I was born). In Scientist's Cliffs, that was Norman Prince, Tina Bryan, and Dan Head. In Calvert Beach, 
that was Pat McKnett. In Park Chesapeake, that was Bill Brier. In the Chesapeake Ranch Estates, that was Joan Sweeney, Tony Vajda, and Ginger Haskell. Others included Ella Ennis, Tom Cratty, Sandra Bell, and George Tornell. Similarly, Patrick Bright and the Maryland DNR gave me access to the cliffs in Calvert Cliffs State Park that are not accessible to the general public.

I also must thank the local experts who patiently worked with me, shared what they knew, and provided me with guidance from the beginning to the end of this project. I am especially grateful to Dr. Curt Larsen, Dr. Peter Vogt, Dr. Stephen Godfrey, and Dr. Ralph Eshelman.

I am thankful to have had such a good team of advisors (both formal and informal) while working on this project. I am especially grateful for Dr. Oommen's support from the time when this was just a class design project. He helped to keep me levelheaded and focused through the highs and lows, and I would not have been able to reach this final product without him.

Lastly, I am thankful to my family and friends, especially those from the east coast who kept in touch and kept me grounded and sane (especially through the U.P winters). Their unwavering support over the miles is what allowed me to have the confidence and courage to persevere. 


\section{Abstract}

The Calvert Cliffs, which form much of the western coastline of the Chesapeake Bay in Calvert County, Maryland, are actively eroding and destabilizing, resulting in a critical situation for many homes in close proximity to the slope's crest. Past studies have identified that where waves directly interact with the toe of the slope, wave action controls cliff recession; however, where waves do not regularly interact with the slope toe, the past work identified that freeze-thaw controls recession. This study investigated the validity of this second claim by analyzing the recession rate and freeze-thaw behavior of six study sites along the Calvert Cliffs that are not directly affected by waves. While waves do remove failed material from the toe, in these regions freeze-thaw is believed to be the dominant factor driving recession at the Calvert Cliffs. Past recession rates were calculated using historical aerial photographs and were analyzed together with a number of other variables selected to represent the freeze-thaw behavior of the Calvert Cliffs. The investigation studied sixteen independent variables and found that over $65 \%$ of recession at these study sites can be represented by the following five variables: (1) cliff face direction, (2 and 3) the percent of total cliff height composed of soil with freeze-thaw susceptibility F4 and F2, (4) the number of freeze-thaw cycles, and (5) the weighted shear strength. Future mitigation techniques at these sites should focus on addressing these variables and might include vegetation or addressing the presence of water along the face of the slope. Unmitigated, the Calvert Cliffs will continue to recede until a stable slope angle is reached and maintained. 



\section{Chapter 1: Introduction}

The Calvert Cliffs are a geologic feature occurring in Calvert County, Maryland. These coastal bluffs occur along the western coastline of the Chesapeake Bay in Calvert County. This coastline is 45 kilometers long, and the Calvert Cliffs compose almost 30 kilometers (Wilcock et al. 1993). The location of Calvert County in Maryland with respect to the Chesapeake Bay is shown in Figure 1(a).

The Calvert Cliffs are composed of steep Miocene age sediments, 11 to 35 meters high (Wilcock et al. 1993). The stratigraphy of the Calvert Cliffs is complex, featuring the Calvert, Choptank, and St. Mary's formations as well as post-Miocene deposits; this consists primarily of poorly-consolidated and interbedded sands, silts, and clays intermixed with shells and fossils. The cliffs are actively eroding, with recent recession rates published to be as high as 1.2 meters/year (Miller 1995). The recession of the Calvert Cliffs significantly affects a number of homes located at the top of the slope throughout Calvert County, as shown in Figure 1(b). As of 2010, there was one home that was overhanging the Calvert Cliffs. There were also nineteen homes that were within 1.5 meters of the top of the slope, twenty homes within three meters of the top of the slope, and forty-three homes within six meters of the top of the slope (Calvert County et al. 2010). Ten of the most critical homes were approved for a FEMA hazard mitigation grant in 2012 .

The proximity of these homes to the crest of the Calvert Cliffs is what makes the situation so critical. However, recession of the Calvert Cliffs is a natural process that has been 

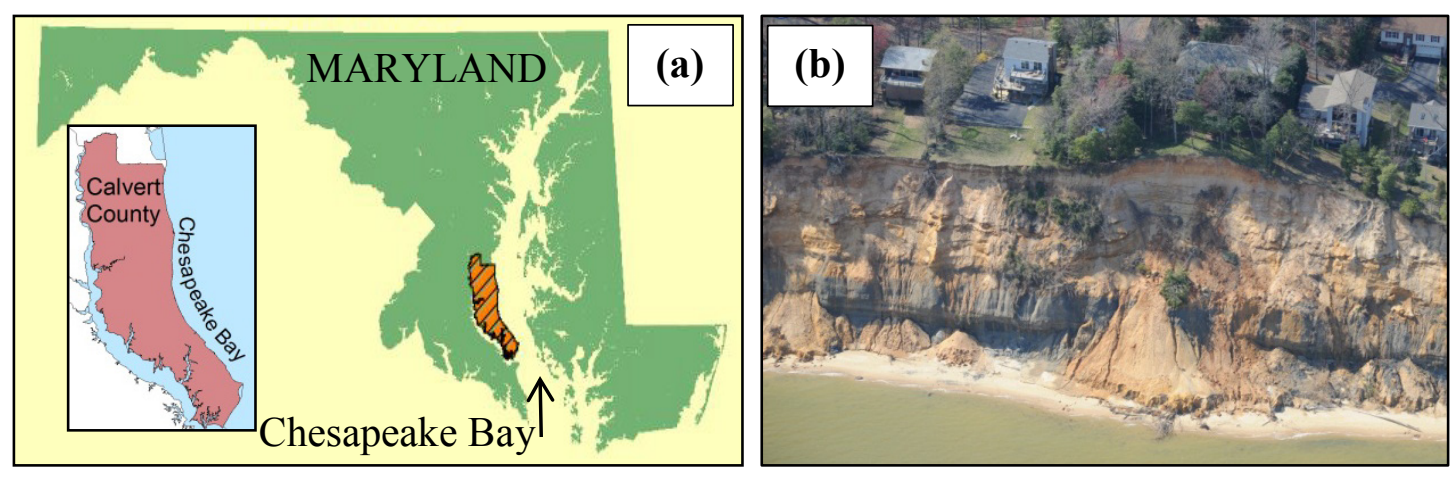

Figure 1: (a) Map of Calvert County, MD, and (b) Aerial Photography Showing Study Site (data source: Calvert County Government 2012)

occurring for thousands of years. The modern Calvert Cliffs were formed as the Laurentide ice sheet melted after the most recent glacial period, the Wisconsinan glaciation. The water from the melting ice sheets flowed down the Susquehanna River channel. Sea level rise due to the increase in water flow caused the channel to widen into the current Chesapeake Bay starting about 7000 years ago. When the Chesapeake Bay widened enough to reach slopes that were remnants of previous glacial periods, the slopes began to erode which formed the Calvert Cliffs. Since they were created, the Calvert Cliffs have been receding due to a number of factors including waves, freeze-thaw, seepage, wind, rain, and desiccation (Leatherman 1986; Scientists' Cliffs History Book Committee 2010). The reason that recession of the Calvert Cliffs is viewed to be a critical issue today is not that this is a new process. Rather, it is because human interaction with the cliffs has changed recently, at least in geologic time.

Evidence of the first humans living in what is now Calvert County has been found dating back at least 10,000 years. The first written record of humans in the region came during John Smith's exploration of the Chesapeake Bay in 1608; John Smith's description of the 
Calvert Cliffs is the only known record of the cliffs before European settlers came to the area around 1650. Tobacco-based agriculture prevailed along the Calvert Cliffs through the mid-1900's, which lead to the destruction of all old-growth vegetation but did not involve significant interaction between humans and the cliffs themselves (Scientists' Cliffs History Book Committee 2010). The WWII military build-up led to a population increase in Calvert County. This population increase, coupled with the desire of government workers in Washington D.C. to have a beach house to visit on the weekends, meant that the farms on cliff-front property were slowly replaced by the homes of people seeking scenic views. The homes built along the cliff were presumably placed far enough away from the crest to be deemed "safe". However, as cliff recession has continued, the homes that were once "safe" are now dangerously close to the top of the Calvert Cliffs, leading to the need to better understand the critical nature of the cliff recession.

There are multiple factors contributing to recession of the Calvert Cliffs. Previous studies (Miller 1995; Wilcock et al. 1998) identified that recession along the Calvert Cliffs has one of two primary driving mechanisms: 1) wave undercutting or 2) freeze-thaw induced soil strength reduction. These studies found that, where waves directly interact with the toe of the Calvert Cliffs, wave action controls recession; however, where waves do not regularly interact with the toe of the Calvert Cliffs, freeze-thaw events likely control recession. Both studies examined the relationship between cliff recession and the interaction between the waves and the cliffs to validate their claims. However, there was little work done to explain how or why it was established that freeze-thaw drives recession rate along the Calvert Cliffs where wave action did not. 
While these studies indicated that one of two factors (either wave action or freeze-thaw) is the driving force behind cliff recession, there are other processes also contributing to cliff recession like seepage, rain, wind, and desiccation. Besides the complexity of the factors affecting recession along the Calvert Cliffs, there are also a number of other complicating factors that make addressing cliff recession more challenging. The first complicating factor is that there are two species of beetle that are federally listed as threatened and state listed as endangered that live along portions of the Calvert Cliffs. The two beetles are called the Puritan Tiger Beetle (see U.S. Fish \& Wildlife Service Service 2011) and the Northeastern Beach Tiger Beetle (see Chesapeake Bay Program 2012). The beetles require two distinct habitats: a sandy beach for foraging and an exposed sandy cliff face for burrowing and larvae development. Any attempt to stop cliff recession where these beetles reside is seen as a threat to the threatened/endangered species (Knisley 2011) and must be addressed (Maryland Department of Natural Resources 2011). Additionally, there are many environmental concerns being so close to the Chesapeake Bay, a body of water that is well-valued and well-protected by regulation. Lastly, there are individuals who believe that the natural process of cliff recession along the Calvert Cliffs should be allowed to continue unaltered. Examples of individuals who share these views are archeologists and paleontologists, who gain insight into the past through fossils and historical artifacts that are uncovered as the cliffs recede. 


\subsection{Literature Review}

The Calvert Cliffs are a geologic feature occurring in Calvert County, Maryland. These steep coastal bluffs, standing 11 to 35 meters high (Wilcock et al. 1993), form $19 \mathrm{~km}$ of the western coastline of the Chesapeake Bay in Calvert County. The Calvert Cliffs are composed of primarily Miocene-aged sediments from the Calvert, Choptank, and St. Mary's formations, as well as post-Miocene deposits; the strigraphy of the cliffs consists primarily of poorly-consolidated and interbedded sands, silts, and clays intermixed with shells and fossils (Ward and Andrews 2008).

The terms "coastal cliffs" and "coastal bluffs" both need to be defined. Some sources differentiate between the terms "cliffs" and "bluffs". The typical distinction is that cliffs are slopes primarily composed of rock, while bluffs are slopes primarily composed of soil (see American Geological Institute 1974). If this definition is accepted, then "Calvert Cliffs" is a misnomer because of the soil composition of these bluffs. However, other sources use the terms interchangeably (Hampton et al. 2004b). This second definition is what will be used in this study, as referring to the Calvert Cliffs exclusively as "bluffs" rather than "cliffs" would be very cumbersome. The term "coastal" means that the slopes are in close proximity to a body of water, typically an ocean or a lake. The Calvert Cliffs are "coastal" because they are located along the western shore of the Chesapeake Bay. 


\subsubsection{Cliff Instability, Recession, and Erosion Processes}

Now that coastal cliffs have been defined as slopes, the stability of these slopes needs to be defined. It is impossible to do a complete review of all topics related to slope stability, as entire textbooks have been dedicated to this topic. What will be addressed here are the background fundamentals governing slope stability, with emphasis on the aspects of slope stability that are related to the recession at the Calvert Cliffs.

While all slopes are variable in factors such as composition and geometry, there are features that are present in all slopes: the slope toe or base, the slope face or midslope, and the slope top or crest. These features are show inFigure 1. The stability of a slope is a measure of how much resistance it has against erosion, mass wasting, and other destabilizing forces. Soil's resistance to these forces, or shear strength, must be greater than the shear forces required to satisfy equilibrium with the destabilizing forces (Duncan and Wright 2005). This is simple enough in principle, but identifying and quantifying the destabilizing forces and determining the soil's shear strength are challenging.

A list of some of the main destabilizing forces that act on coastal cliffs follows: gravity, coastal water level change (sea level) coupled with land subsidence, wave action, surface water runoff, groundwater seepage, water table fluctuations, freeze-thaw, wind erosion, desiccation, seismic forces, and construction activities near the slope toe are all destabilizing forces that can act of coastal cliffs (Budhu 2007; Hampton et al. 2004a). Human activities can also destabilize slopes, including construction activities and undetected pipe leaks (Budhu 2007). When these destabilizing forces, working together 


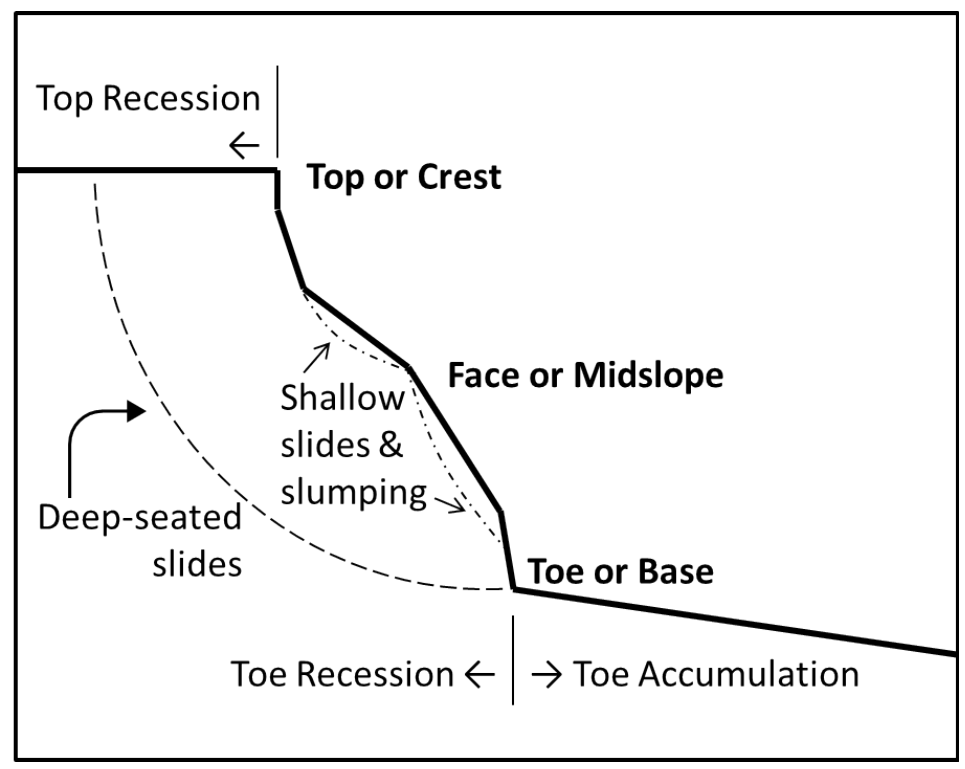

Figure 2: Typical Slope Terminology and Failure Types (adapted from Edil 2010; Miller 1995)

or independently, exceed the shear strength of the materials composing a cliff, a number of different modes of failure can occur. Some of these modes of failure include: rotational sliding (deep-seated or shallow), translational sliding, flow sliding, block or wedge sliding, slumping or sloughing, solifluction, and face degradation (Budhu 2007; Miller 1995).

Coastal cliff instability leads to slope failure and consequently cliff recession, which over time can be measured as a recession rate because coastal cliff recession occurs cyclically. First, one or more destabilizing mechanism acts on the slope (for waves, this is at the toe; for wind, this is along the face; for runoff, this is at the top). When the slope is no longer able to resist the destabilizing mechanism(s), some sort of failure occurs and delivers slope material to the toe of the cliff. This material is removed by waves, exposing the slope toe once again, and they cycle repeats (Edil 2010; Hampton et al. 2004a). As this 
cycle repeats, material is lost from the top and face of the coastal cliffs and transported to the toe. As waves remove the failed material, more material is lost from the cliff and the process continues. Measured horizontally, this episodic loss of soil averaged over a period of time, or cliff recession, is particularly critical to structures constructed in close proximity to the top of coastal cliffs, which often leads to a desire to monitor recession rates.

One of the most common ways to monitor cliff recession is by using aerial photography. According to Hapke (2004), historical aerial photographs are available from a number of sources for as far back as the 1920's, which allows for more of a long-term analysis. Aerial photographs also provide good spatial coverage, especially when compared to field methods such as ground-based surveys. However, there are inaccuracies that get introduced into the analysis when aerial photographs are used, both from the internal workings of the camera system and also from the positions of the camera in relation to the terrain being photographed. If this uncertainty is not rectified, small errors in the camera are translated to large errors in the ground scale in the images. Additionally, some recession rate analyses choose to track the change in position of the top of the cliff, while others choose to use the toe of the cliff. In both instances, the feature of interest (top or toe of cliff) may be obscured from view due to vegetative cover at the top of the cliff or failed material gathered at the base of the cliff. Newer technologies like LiDAR are being used and developed to overcome some of these obstacles, but data is not often readily available and is expensive to obtain (Hapke 2004). 
Historical recession rates are often determined—using methods like ground-based surveys, aerial photographs, or LiDAR — with the goal of predicting future recession rates. Historical long-term recession rates (those averaged over a number of years of observation and measurement) have been successfully correlated with factors associated with cliff recession; factors include storm events (Carter and Guy 1988; Hapke 2004), wave impact (Amin and Davidson-Arnott 1997; Swenson et al. 2006), shear strength resistance to waves (Wilcock et al. 1998), and moisture content/water levels (Manson 2002). Long-term recession rates have proven to be consistent with seasonal recession rates. These long-term recession rates can be used for general and long-term planning purposes. However, neither seasonal recession rates nor long-term recession rates can be used to predict the specific magnitude, location, or time when a given section of cliff will fail, making shorter-term planning very difficult (Hapke 2004).

As mentioned previously, there are a number of factors that affect the rate of coastal cliff recession. Besides the destabilizing factors acting upon the cliffs, recession rates are also a function of the shear strength of the cliff material and the internal stability of the slope. Soil shear strength is a function of the soil's cohesion and internal friction angle, as well as the (effective) normal stress the soil is experiencing; soil shear strength varies based on sediment composition differs for each soil strata. Shear strength can be assessed by a number of laboratory and field tests to varying degrees of accuracy (Duncan and Wright 2005; Holtz et al. 2011). The internal stability of a slope depends on not only the shear strength of the soil(s) but also depends on the geometry of the slope and the presence (or absence) of groundwater table(s). Slopes with greater heights and/or steeper slope angles will have more unstable conditions than slopes with lower heights and/or shallower slope 
angles (Edil and Vallejo 1980). Investigations on the height of coastal cliffs have found no direct relationship with their recession rates (Buckler and Winters 1983; Kamphuis 1987), but the slope angles of coastal bluffs at one site along the Calvert Cliffs has been found to have a relationship with recession rates (Schweitzer 1993). The location of groundwater within a slope, as well as groundwater flow (seepage) is also critical to the slope's stability. As the water level rises within a slope, the stability decreases (Edil and Vallejo 1980; Sterrett and Edil 1982). Seepage, or water flow through soil, becomes a problem for slopes when there are soil strata with varying hydraulic conductivities, forcing the water out of the face of the cliff. It has been observed that, as the height of a cliff increases, the impact of groundwater seepage on that slope's stability also increases (Buckler and Winters 1983).

\subsubsection{Previous Studies on Instability and Recession of the Calvert Cliffs}

Now that some of the basic aspects of coastal cliff recession have been explored, the specifics of previous studies on the Calvert Cliffs will be discussed. The Calvert Cliffs are coastal bluffs composed of steep Miocene age sediments, 11 to 35 meters high (Wilcock et al. 1993). The stratigraphy of the Calvert Cliffs is complex, consisting of the Calvert, Choptank, and St. Mary's formations as well as post-Miocene deposits. These deposits consist primarily of poorly-consolidated and interbedded sands, silts, and clays intermixed with shells and fossils. The material properties of these sediments, including hydraulic and strength properties, vary greatly throughout the cliff (Miller 1995; Ward and Andrews 2008). In some locations along the Calvert Cliffs, slopes can reach nearvertical as they erode and evolve - angles in this study were measured as steep as 88 
degrees. However, field surveys by Clark et al. (2004) indicated that the slopes are stable at angles of 30 to 35 degrees $^{1}$. If the toe of the slopes along the Calvert Cliffs is protected, stable slope angles can be achieved in 30 to 40 years. This reality does not bode well for the structures in close proximity to the top of the Calvert Cliffs, as illustrated in Figure 3.

According to Miller (1995), the slope failure mechanisms that act along the Calvert Cliffs all involve failure within the outer few meters of the cliff face. Spalling, which can be represented as an undercut block failures, and shallow slides, which can be represented as infinite slope failures, are the primary failure mechanisms that occur along the Calvert Cliffs. Deep seated slides do not commonly occur. These failure mechanisms can be triggered by internal instability or erosion forces overcoming the slope's resisting forces. Clark et al. (2004) noted that wave undercutting, freeze-thaw, and groundwater

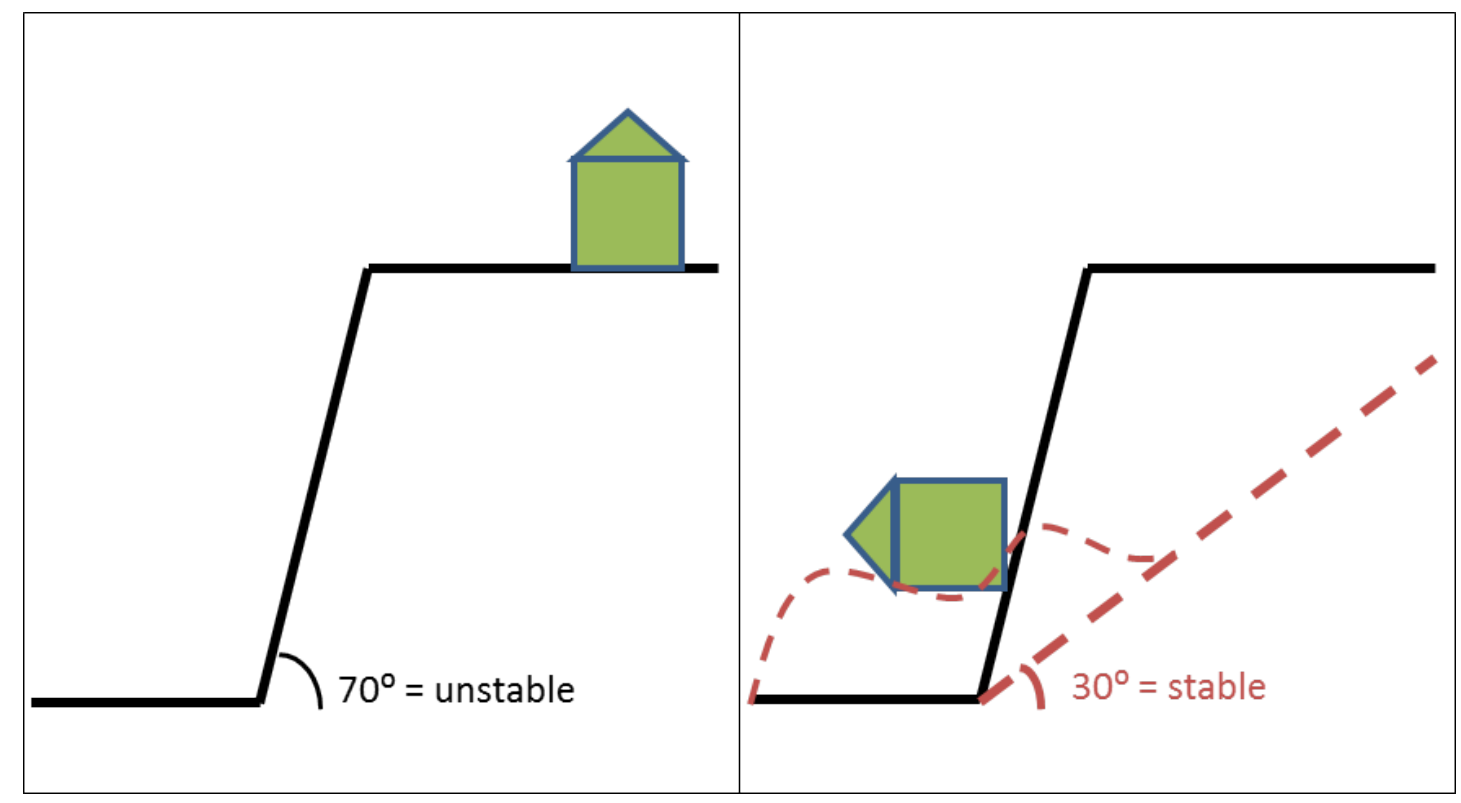

\footnotetext{
${ }^{1}$ Stability at 30 to 35 degrees assumes that wave action is not affecting the toe of the slope.
} 
Figure 3: Theoretical Slope Stabilization of the Calvert Cliffs, Assuming a Fixed Slope Toe

movement all contribute to cliff recession along the Calvert Cliffs. After rigorous studies at multiple locations of the wave activity along the Calvert Cliffs, Miller (1995) and Wilcock et al. (1998) concluded that where waves interact with the toe of a slope (meaning that wave strength exceeds the soil shear strength), wave action controls recession rate. They also stated that, where waves did not interact with the toe of the slope, freeze-thaw controls recession rate. Recession rates for the slopes with recession driven by wave undercutting were higher than those for slopes with recession driven by freeze-thaw, but the recession rates for freeze-thaw controlled slopes were still measureable and significant. However, no study of the relationship between freeze-thaw and cliff recession for more than one or two locations along the Calvert Cliffs has ever been conducted.

There have been several limited studies of the relationship between freeze-thaw and cliff recession. Schweitzer (1993) conducted a study in which erosion pins and catchment basins were installed and monitored for one year at two slopes in close proximity to each other (located at Calvert Cliffs State Park). This study concluded that freeze-thaw was important to the recession rate of the Calvert Cliffs, but did not quantify how freeze-thaw contributed to recession. Miller (1995) expanded this study by installing and monitoring erosion pins for two years in several locations (at Scientists' Cliffs and Calvert Cliffs State Park, identified in this study in Table 1 and Figure 5). The freeze-thaw erosion measured using the erosion pins was found to contribute to a large percent of the recession rates. However, only a short time-period was analyzed and only the freeze-thaw at the base of the slopes was considered. After observing the erosion pins at one of these 
locations (Scientists' Cliffs) for over 10 years, Miller et al. (2006) recommended that freeze-thaw drives cliff recession; however, only qualitative (rather than quantitative) evidence was presented to support these claims. It was also noted in their research that vegetated slopes were insulated in the winter, preventing cyclic freezing, and reducing recession rates compared to un-vegetated slopes.

\subsubsection{Principles of Freeze-Thaw in Soil}

Since freeze-thaw was identified as one of the driving factors for cliff recession along the Calvert Cliffs, the impacts of freeze-thaw on soil need to be investigated further. Freezethaw occurs when soil loses enough heat for the pore water to freeze. This freezing occurs from the ground surface (so for the Calvert Cliffs, from the cliff face) to a depth which is controlled by the magnitude of soil heat loss; the soil heat loss depends on the thermal properties of the soil (Gatto 1995). Freezing of the pore water leads to expansion, as water expands about nine percent by volume when it is frozen to ice (American Concrete Pavement Institute 2008). Ice lenses can form if the freezing front propagates slowly enough for water to be transported to the cliff face (Michalowski and Zhu 2006a). Ice needles will form instead if there is a faster moving freezing front due to a high temperature gradient between the soil and the air (Gatto 1995).

For soils to experience freeze-thaw, pore water must be present. The soils that are the most susceptible to freeze-thaw are silts. Silts have high capillarity, which pulls water to the freezing front; silts also have a high enough hydraulic conductivity to allow water to flow through. Fine sands and clays can also experience freeze-thaw, but usually to a lesser degree (Gatto 1995; Michalowski and Zhu 2006a). The freezing behavior of soil 
with varying particle-size distribution and mineralogy also varies. While different minerals tend to have different thermal conductivities, particle-size distribution is what tends to control soil freezing behavior. Technically, soil is considered to be "frozen" when it is below $0^{\circ} \mathrm{C}\left(32^{\circ} \mathrm{F}\right)$, regardless of the phase condition of the water-solid (ice), liquid, or intermediate. At what point the "frozen" soil becomes solid ice depends on the particle size distribution. The freezing of sands and silts is a function of the pore diameter-finer pore spaces have more capillarity, or the surface tension of water present within the voids. However, the freezing of clays is more complex. Clay particles are colloidal with very large surface areas compared to the particle thickness, which means that the negatively charged particles have the potential for a large amount of adsorption, resulting in a thick diffused double layer. Adsorbed water cannot readily freeze; any water present outside of the diffused double layer, or "free water", is what would freeze. Additionally, because of the small size of clay particles (diameter of less than 2 micrometers), the voids are small enough that surface tension between the particles and the water, or capillarity, prevents the water from freezing at $0^{\circ} \mathrm{C}$ (Andersland and Anderson 1978). This is why silts are considered to be the soils most susceptible to freeze-thaw.

For those soils that experience freeze-thaw, the destabilizing effects develop during freezing. When thawing occurs, larger voids are present in the soil matrix and the soil structure is disturbed due to the ice expansion during freezing. After thawing, there is also a higher moisture content present at the surface. These factors lead to a reduction in shear strength - there can be as much as a 50 percent reduction in shear strength after a 
single freeze-thaw cycle (Gatto 1995). A schematic of the freeze-thaw process can be seen in Figure 4.

The most common problem associated with freeze-thaw events in soils is when accounting for frost heave in roadways. Most methods have therefore been developed for this application. Several methods to account for freeze-thaw and the depth of freezing include using the Federal Highway Administration (FHWA) E-FROST research analyst tool (Selezneva et al. 2008), the use of thermal conductivity and other thermal properties of the soil (including the methods presented by Black 1995; Gatto 1995), and freezing index (Andersland and Anderson 1978). Freezing index is a measure of the duration and magnitude of freezing during a given winter or "freezing season". Typical values for freezing index are normally used, and are provided in contour maps (Joint Departments of the Army and Air Force 1987) or tables (see NCDC/NOAA 2002a; NCDC/NOAA 2002b; NCDC/NOAA 2002c). Freezing index can also be calculated (Joint Departments of the Army and Air Force 1987). Freezing index will be discussed more thoroughly in

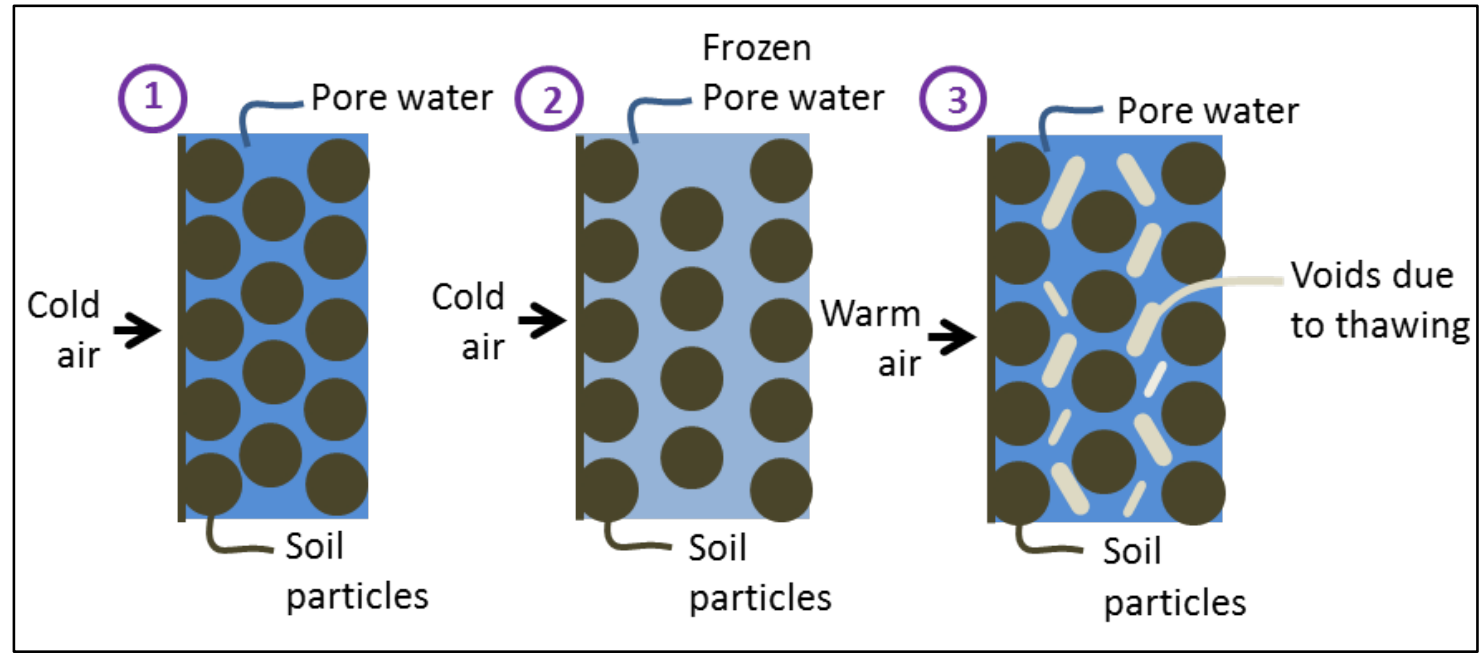

Figure 4: Schematic of Freeze-Thaw Behavior in Soil 
Section 4.3. It should be noted that the anisotropy of soil technically are not included in these methods, which have been developed for vertical freezing. Therefore, adjustments should be made to assess freezing events normal to slopes.

\subsubsection{Freeze-Thaw Impacts on Slopes}

Numerous studies have been conducted in which the interaction between freeze-thaw and soil has been investigated (including Kim and Daniel 1992; Konrad and Morgenstern 1980; Michalowski and Zhu 2006a; Michalowski and Zhu 2006b; Zheng et al. 1993). However, not as much work has been conducted on the freeze-thaw behavior of soil slopes.

Gatto (1995) provides a rather comprehensive overview on how freeze-thaw affects soils (discussed more thoroughly in Section 1.1.3). Suggestions are offered as to the factors that control freeze-thaw in stream banks, which are can be viewed as a smaller version of coastal cliffs. Suggestions are also made on how to conduct field studies of freeze-thaw for banks and how to estimate the depth of the freeze-thaw weakened zone. It is noted that if freeze-thaw does not cause a slope failure directly, it has caused a decrease in shear strength which means that the slope will be more susceptible to other erosion forces. The sequence of freeze-thaw in banks is separated into fall, winter, and spring. The level of freeze-thaw that is experienced at the Calvert Cliffs is most similar to Gatto's fall freezing and thawing, which is indicated to have intermediate effects (compared to minimum and maximum effects) on soil erodability. 
Vallejo (1980) developed a method to represent freeze-thaw mass movements in terms of unit weights, residual friction angles, and grain concentration ratio rather than using increases in pore water pressure- bulk properties of soil are much easier to measure than pore water pressures. However, this method was developed for solifluction. Solifluction is the slow and fluid-like flow of blocks of saturated soil suspended in a soil slurry-a result of exposure to freezing and thawing - down a slope. The Calvert Cliffs do not experience solifluction, but rather ice wedging and spalling are the typical failure mechanisms observed due to freeze-thaw (Miller 1995). Vallejo's (1980) method of analysis was also designed for "very low" slope angles, which are not representative of the Calvert Cliffs.

Harris et al. (2001) performed scaled-down laboratory tests of frozen soil in a centrifuge. The aim of the testing was to analyze the mechanism of thaw consolidation; in consolidation, pore water pressures increase which means that effective stresses decrease. The centrifuge was used to apply a stress history to the lab samples used that is equivalent to stress history observed in the field. The specific parameters that were used in this study were pore water pressure and the pore pressure parameter $r_{u}$, as well as soil displacement. Samples were prepared at 12-24 degree slopes. Similar to Vallejo (1980), this study was trying to specifically assess solifluction, which is not a process that occurs at the Calvert Cliffs. The slope angles considered by this study are also not representative of the Calvert Cliffs.

Ferrick and Gatto (2005) also performed a laboratory experiment investigating the erosion of freeze-thaw susceptible soils on shallow slopes (8 and 15 degrees). The study 
concluded that soil erosion due to freeze-thaw was independent of slope angle, but that it was very much influenced by soil moisture. Another study performed by Higashi and Corte (1971) found that slope angle was more influential than soil moisture conditions. However, it is unclear how these results would translate to the steeper slopes that are present along the Calvert Cliffs.

A field study by Harris and Lewkowicz (2000) was conducted on 5-27 degree slopes in a permafrost region. In permafrost zones, slope failure was found to be a result of thawed material sliding over material that is still frozen. Material properties and the shear strength parameters for the slope materials were determined in the lab, and then used with pore water pressures measure in the field to conduct an effective stress stability analysis. It was observed that during the displacement that occurs during thawing, the shear strength parameters tend to move from peak to residual values, leading to slope instability. While interesting, this study is also not directly applicable to the Calvert Cliffs due to the low slope angles used and the failure mechanism being related to permafrost.

Another field study conducted by Kawamura and Miura (2011) assessed the freeze-thaw behavior of slopes composed of volcanic soils in Japan. The aim of this study was to develop a way to predict slope failures using monitoring techniques. It was found that monitoring moisture content may be a good way to predict failure due to freeze-thaw. The study assessed slope angles up to 40 degrees, which is closer to the conditions at the Calvert Cliffs than any other study assessed in this literature review. However, these slopes experience seasonal freezing, rather than the short-term cyclic freezing experienced by the Calvert Cliffs. 
No previous studies that were encountered during this literature review investigated freeze-thaw on slopes that are nearly as steep as the Calvert Cliffs. Also, most work was conducted on slopes located in permafrost regions, or at least regions that experience seasonal freezing, rather than the short-term cyclic freezing that occurs at the Calvert Cliffs. 


\section{Chapter 2: Problem Formation and Objectives}

Clearly, cliff recession is a complex issue. The impact of waves on coastal bluffs, including those at the Calvert Cliffs, has been thoroughly studied and defined. However, the impacts of freeze-thaw on the recession of coastal bluffs, especially the Calvert Cliffs, need to be thoroughly investigated. Freeze-thaw is not a directly measurable quantity, as it is a function of moisture conditions, grain size, relative density, soil thermal conductivity, and a number of other factors. Freeze-thaw can instead be studied indirectly by investigating a number of variables that are related to freeze-thaw and comparing the variables to recession rate.

\subsection{Study Area}

The study area for the project lies within a $30 \mathrm{~km}$ section of the Calvert Cliffs coastline, which includes $19 \mathrm{~km}$ of cliffs. Six study sites were selected for investigation in this study, as identified in Figure 5. From north to south, these sites are: SCN (Scientists' Cliffs North), SCS (Scientists' Cliffs South), CB (Calvert Beach), CCSP (Calvert Cliffs State Park), PC (Park Chesapeake), and CRE. The Calvert Cliffs do not have uniform material or geometric properties along their length; rather, they vary in height, composition, and a number of other variables. This variation along the length of the Calvert Cliffs does not make it possible to analyze them as a single system with uniform properties. These study sites were selected for a number of reasons. For each study site selected, historical data were available and/or and the study sites was accessible for observation from the beach. Accessibility from the beach enabled field visits to be 
conducted, and availability of data enabled a reasonable analysis to be carried out.

Additionally, past work (Miller 1995; Wilcock et al. 1998) indicated that the cliff recession at four of these sites (SCN, SCS, CCSP, and CRE) is driven by freeze-thaw action and not regularly affected by waves. The other two sites were selected because, observationally, waves do not interact with the cliff toe during regular weather events (although waves do gradually remove failed material from the slope toe). For the sake of comparison to past work, Table 1 indicates the name of all study sites used in this study and the name used (if applicable) in past work. The position of all study sites, with respect to the Calvert County shoreline, can be seen in Figure 5.

At least four sub-sites were identified at each study site so that the variation of properties within each site could be explored. The latitude and longitude of each sub-site, determined using Google Earth, is shown in Table 2.

\section{Table 1: Study Site Names Used in this Study and Previous Studies}

\begin{tabular}{|l|c|l|c|l|c|}
\hline \multicolumn{2}{|c|}{ This Study } & \multicolumn{2}{c|}{ Wilcock et. al (1998) } & \multicolumn{2}{c|}{ Miller (1995) } \\
\hline Name & Symbol & \multicolumn{1}{|c|}{ Name } & Symbol & Name & Symbol \\
\hline $\begin{array}{l}\text { Scientists' Cliffs } \\
\text { North }\end{array}$ & SCN & Scientists Cliffs & SC & $\begin{array}{l}\text { Scientists' Cliffs } \\
\text { North }\end{array}$ & $\begin{array}{c}\text { SC- } \\
\text { SCN }\end{array}$ \\
\cline { 1 - 4 } $\begin{array}{l}\text { Scientists' Cliffs } \\
\text { South }\end{array}$ & SCS & $\begin{array}{l}\text { Scientists' Cliffs } \\
\text { South }\end{array}$ & $\begin{array}{c}\text { SC- } \\
\text { SCS }\end{array}$ \\
\hline Calvert Beach & CB & - & - & - & - \\
\hline $\begin{array}{l}\text { Calvert Cliffs } \\
\text { State Park }\end{array}$ & CCSP & $\begin{array}{l}\text { Gray's Creek } \\
\text { South }\end{array}$ & GYCS & $\begin{array}{l}\text { Gray's Creek } \\
\text { South }\end{array}$ & $\begin{array}{l}\text { CCSP- } \\
\text { GYCS }\end{array}$ \\
\hline Park Chesapeake & PC & - & - & - & - \\
\hline $\begin{array}{l}\text { Chesapeake } \\
\text { Ranch Estates }\end{array}$ & CRE & Laramie Lane & LL & Laramie Lane & $\begin{array}{c}\text { CRE- } \\
\text { LL }\end{array}$ \\
\hline
\end{tabular}




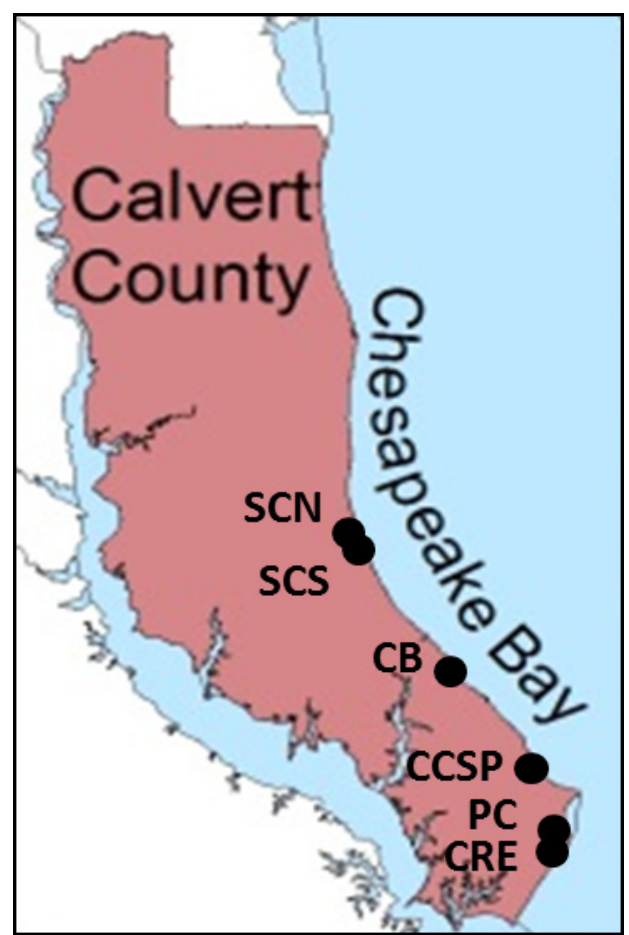

Figure 5: Location of Study Sites within Calvert County (map data source: Calvert County Government 2012)

Table 2: Geographic Coordinates of Study Sub-Sites

\begin{tabular}{|c|c|c|c|}
\hline Study Site & Sub-site & Latitude & Longitude \\
\hline \multirow{4}{*}{ SCN } & SCN1 & $38.5249 \mathrm{~N}$ & $76.5148 \mathrm{~W}$ \\
\cline { 2 - 4 } & SCN2 & $38.5242 \mathrm{~N}$ & $76.5146 \mathrm{~W}$ \\
\cline { 2 - 4 } & SCN3 & $38.5224 \mathrm{~N}$ & $76.5138 \mathrm{~W}$ \\
\cline { 2 - 4 } & SCN4 & $38.5204 \mathrm{~N}$ & $76.5131 \mathrm{~W}$ \\
\hline \multirow{4}{*}{ SCS } & SCS5 & $38.5121 \mathrm{~N}$ & $76.5100 \mathrm{~W}$ \\
\cline { 2 - 4 } & SCS6 & $38.5115 \mathrm{~N}$ & $76.5098 \mathrm{~W}$ \\
\cline { 2 - 4 } & SCS7 & $38.5083 \mathrm{~N}$ & $76.5084 \mathrm{~W}$ \\
\cline { 2 - 4 } & SCS8 & $38.5050 \mathrm{~N}$ & $76.5068 \mathrm{~W}$ \\
\cline { 2 - 4 } & SCS9 & $38.5045 \mathrm{~N}$ & $76.5066 \mathrm{~W}$ \\
\hline \multirow{4}{*}{ CB } & CB1 & $38.4760 \mathrm{~N}$ & $76.4873 \mathrm{~W}$ \\
\cline { 2 - 4 } & CB2 & $38.4678 \mathrm{~N}$ & $76.4769 \mathrm{~W}$ \\
\cline { 2 - 4 } & CB3 & $38.4672 \mathrm{~N}$ & $76.4761 \mathrm{~W}$ \\
\cline { 2 - 4 } & CB4 & $38.4670 \mathrm{~N}$ & $76.4758 \mathrm{~W}$ \\
\hline \multirow{4}{*}{ CCSP } & CCSP1 & $38.4018 \mathrm{~N}$ & $76.4075 \mathrm{~W}$ \\
\cline { 2 - 4 } & CCSP2 & $38.4010 \mathrm{~N}$ & $76.4074 \mathrm{~W}$ \\
\hline
\end{tabular}




\begin{tabular}{|c|c|c|c|}
\hline \multirow{4}{*}{} & CCSP3 & $38.4008 \mathrm{~N}$ & $76.4071 \mathrm{~W}$ \\
\cline { 2 - 4 } & CCSP4 & $38.4004 \mathrm{~N}$ & $76.4070 \mathrm{~W}$ \\
\hline \multirow{4}{*}{ PC } & PC_G & $38.3687 \mathrm{~N}$ & $76.3899 \mathrm{~W}$ \\
\cline { 2 - 4 } & PC1 & $38.3682 \mathrm{~N}$ & $76.3899 \mathrm{~W}$ \\
\cline { 2 - 4 } & PC2 & $38.3671 \mathrm{~N}$ & $76.3899 \mathrm{~W}$ \\
\cline { 2 - 4 } & PC3 & $38.3667 \mathrm{~N}$ & $76.3899 \mathrm{~W}$ \\
\cline { 2 - 4 } & PC4 & $38.3663 \mathrm{~N}$ & $76.3901 \mathrm{~W}$ \\
\hline \multirow{4}{*}{ CRE } & CRE1 & $38.3577 \mathrm{~N}$ & $76.3904 \mathrm{~W}$ \\
\cline { 2 - 4 } & CRE2 & $38.3567 \mathrm{~N}$ & $76.3912 \mathrm{~W}$ \\
\cline { 2 - 4 } & CRE3 & $38.3558 \mathrm{~N}$ & $76.3916 \mathrm{~W}$ \\
\cline { 2 - 4 } & CRE4 & $38.3549 \mathrm{~N}$ & $76.3925 \mathrm{~W}$ \\
\hline
\end{tabular}

\subsection{Objectives}

The objective of this study is to determine if a meaningful relationship does exist between freeze-thaw and cliff recession rate in areas where waves do not directly interact with the base of the Calvert Cliffs. If such a relationship does exist, this work will identify the specific variables that control recession rate. These critical variables can be used to develop mitigation strategies to address the key factors in freeze-thaw controlled recession. 


\section{Chapter 3: Methodology}

The Calvert Cliffs compose 19 kilometers of the Calvert County shoreline. Since the cliffs vary in height, composition, and a number of other geologic and geometric variables along their length, there is no way to accurately analyze them as a single system with uniform properties. Each study site, and even sub-site, has unique slope geometry, soil layer profiles, and freeze-thaw susceptibility (among other properties), so it was necessary to study each sub-site individually to account for these differences. Due to the large distance of cliffs and the short amount of time available for field work-June to August 2012 - six study sites were selected in order to analyze small portions of the Calvert Cliffs and to see if general trends hold true for the entirety of the cliffs. These study sites and sub-sites were identified as explained previously in Section 2.1.

\subsection{Field Work}

Field work was conducted from June to August in 2012. The study sites were accessed from the beach below so that the entire face of the cliffs could be observed. Digital images were collected using a Kodak EasyShare ZD15 camera to record what was observed. Thermal IR images at all sites were also collected using a FLIR ThermaCAM SC640. Due to the instability of the cliffs, no invasive soil sampling or testing was performed on the cliffs. Rather, samples of failed material (where available) were collected from the base of the cliff for laboratory testing and classification. The impact of waves on each site was also noted to ensure that none of the sites had regular wave action potentially contributing to cliff recession. 


\subsection{Recession Rate Calculations}

Once the study sites were identified and it was verified — visually and anecdotally—that none of the sites were directly affected by wave action ${ }^{2}$, the recession rate at each of the sub-sites was calculated. High-resolution aerial images of the cliffs from 2003, 2006, 2007, and 2011 were used in the analysis. The 2003 and 2006 have $30.5 \mathrm{~cm} /$ pixel resolution, while the 2007 and 2011 images have $15.25 \mathrm{~cm} / \mathrm{pixel}$ resolution. The dates the images were collected are: April 6-7, 2003; March 18, 2006; March 20, 2007; and March 25, 2011 (Calvert County Government 2012). These images were used to calculate the amount of recession, in meters, that occurred between the years the images were taken for each sub-site. Since the images were all taken at the same time of year, after the freezethaw season was over, the slight variations from whole years in the dates of the images were neglected. The recession rate analysis was performed using ArcMap 10 for each sub-site. For each sub-site, the distance from a permanent structure to the crest of the cliff was measured for each aerial image; the change in this distance between images was the recession for the time interval between the images. This process is demonstrated in Figure 6. Line 1 shows the measured distance from a permanent structure to the crest of the cliff; the change in this distance between images was the recession for the time interval between the images. The measured distance was calibrated by measuring a permanent structure, line 2, and scaling the measured distances by it; the building correction factor was used to account for the slight variation in image scale that resulted from slightly different flight paths while the images were being collected. The

\footnotetext{
${ }^{2}$ While no wave action was noted during the normal wave climate present during field exploration, storm events can bring storm surges. Anecdotally, these infrequent storm surges can be in excess of 2 meters.
} 

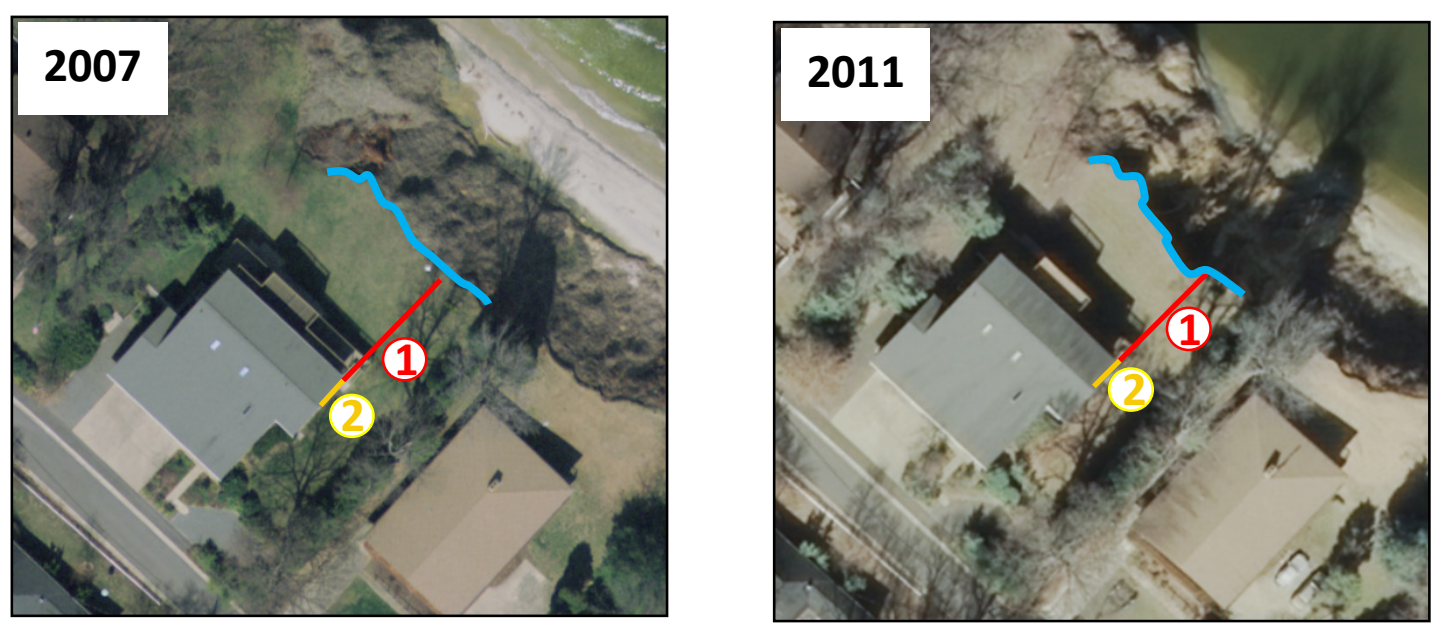

Figure 6: Recession Rate Calculation Demonstration (image data source: Calvert County Government 2012)

measurements used in the recession rate calculations, as well as sample calculations for recession rate determination, can be found in Appendix A. If the calculated total recession for a particular sub-site and time interval was smaller than the image resolution, the recession rate was assumed to be zero; these values are marked with an asterisk in Table 3. The calculated recession rates are shown in Table 3. 
Table 3: Calculated Recession Rates for Each Sub-site

\begin{tabular}{|c|c|c|c|c|}
\hline Study Site & Sub-site & $\begin{array}{c}\text { Recession } \\
\text { Rate }(\mathrm{m} / \mathrm{yr}) \\
2003-2006\end{array}$ & $\begin{array}{c}\text { Recession } \\
\text { Rate }(\mathrm{m} / \mathrm{yr}) \\
2006-2007\end{array}$ & $\begin{array}{c}\text { Recession } \\
\text { Rate }(\mathrm{m} / \mathrm{yr}) \\
2007-2011\end{array}$ \\
\hline \multirow{4}{*}{$\mathrm{SCN}$} & SCN1 & $0.00 *$ & $0.00 *$ & $0.18^{*}$ \\
\hline & SCN2 & $0.00^{*}$ & 0.00 & $0.07 *$ \\
\hline & SCN3 & 0.00 & $0.00 *$ & 0.00 \\
\hline & SCN4 & $0.00 *$ & $0.00 *$ & $0.00 *$ \\
\hline \multirow{5}{*}{ SCS } & SCS5 & 0.22 & 0.26 & 0.17 \\
\hline & SCS6 & 0.58 & 0.57 & 1.37 \\
\hline & SCS7 & 0.12 & $0.00 *$ & 0.07 \\
\hline & SCS8 & 0.18 & $0.00 *$ & 0.41 \\
\hline & SCS9 & 0.13 & 0.71 & 0.56 \\
\hline \multirow{4}{*}{$\mathrm{CB}$} & CB1 & 0.27 & 1.58 & 0.42 \\
\hline & $\mathrm{CB} 2$ & 0.00 & $0.00 *$ & 0.00 \\
\hline & CB3 & $0.00 *$ & $0.00 *$ & 0.70 \\
\hline & CB4 & 0.67 & 0.26 & $0.00 *$ \\
\hline \multirow{4}{*}{ CCSP } & CCSP1 & 0.27 & 0.52 & 0.55 \\
\hline & CCSP2 & 0.70 & 0.95 & 0.88 \\
\hline & CCSP3 & 0.56 & 0.50 & 0.66 \\
\hline & CCSP4 & 0.35 & 1.50 & 0.45 \\
\hline \multirow{5}{*}{$\mathrm{PC}$} & PC_G & $0.00^{*}$ & $0.00^{*}$ & 0.21 \\
\hline & $\mathrm{PC} 1$ & 0.21 & $0.00 *$ & 1.02 \\
\hline & PC2 & 0.44 & $0.00 *$ & 0.23 \\
\hline & PC3 & 0.17 & $0.00 *$ & 0.19 \\
\hline & PC4 & 0.15 & 0.31 & 0.45 \\
\hline \multirow{4}{*}{ CRE } & CRE1 & 0.37 & 0.76 & 1.56 \\
\hline & CRE2 & 1.17 & 0.92 & 0.25 \\
\hline & CRE3 & 0.28 & 0.27 & 1.44 \\
\hline & CRE4 & 0.55 & 0.65 & 0.36 \\
\hline
\end{tabular}

*Calculated recession values (meters) lower than the image resolution were assumed to be 0 . 


\subsection{Freeze-Thaw Behavior and Susceptibility of Calvert Cliffs}

After the recession rates were calculated, the freeze-thaw behavior of the Calvert Cliffs was analyzed.

\subsubsection{Temperature Profile and Frequency of Freeze-Thaw of Cliffs}

The thermal properties of soil affect the rate at which the temperature of the air interacts with the temperature of the soil, and therefore the pore water. The frequency and depth of the freezing pore water is what defines the freeze-thaw behavior of soil. Since the thermal properties of the layers of the Calvert Cliffs were not known, simplifying assumptions were made. A single "day of freezing" was defined as one day in which the average temperature remained below $0{ }^{\circ} \mathrm{C}$. A single "freeze-thaw cycle" was defined as a single day in which the average temperature remained below $0^{\circ} \mathrm{C}$, or (when applicable) a group of days in which the maximum temperature remained consecutively below $0^{\circ} \mathrm{C}$. These two measures of freeze-thaw occurrence were chosen to assess if the amount of time the soil stays frozen (days of freezing) has more or less of an effect on recession rate than the number of times the soil freezes and thaws (freeze-thaw cycles).

Once these freeze-thaw metrics - days of freezing and freeze-thaw-cycles - were defined, the temperature profile of the cliffs was investigated. Temperature can vary greatly from one location to another, even over small distances and especially with elevation variations; being in close proximity to a body of water can also magnify these temperature variations. Therefore, the spatial and temporal variations in temperature were investigated, as no temperature data was available for any of the study sites. Historical 
temperature data from 19 locations was obtained online from the National Climatic Data Center, or NCDC (NCDC/NOAA 2012a). Ordinary kriging was performed using the statistical computing program R 2.15.0 (R Core Team 2012) to attempt to find a suitable model to represent the spatial trends in temperature. However, it was found that the spatial interpolation using kriging was no more accurate than using temperature data from an individual location, as discussed more thoroughly in Appendix B. Because of this, temperature data (average, minimum, and maximum daily temperature) was used from the NCDC for Patuxent River Naval Air Station, the closest location with available data, which is located approximately $6.5 \mathrm{~km}$ southwest of CRE (southernmost site) and $26 \mathrm{~km}$ southeast from SCN (northernmost site). This temperature data was assumed to be representative of all study sites. The temperature data was used to calculate the days of freezing and the number of freeze thaw cycles for the time intervals between the images used in the recession rate determination; the results of this analysis are show in Table 4.

As discussed in Section 3.2, the amount of time between images was treated as whole years; the analysis was run from April 1 from the first year to March 31 of the last year in the time interval. These metrics - days of freezing and freeze thaw cycles-were then used to not only identify potential differences between the freeze-thaw instances in a given time interval, but to also determine if the number of instances of freezing and

\section{Table 4: Average Number of Days of Freezing and Freeze-Thaw Cycles for each Recession Rate Time Interval}

\begin{tabular}{|c|c|c|}
\hline Time Interval & $\begin{array}{c}\text { Average Number of } \\
\text { Days of Freezing }\end{array}$ & $\begin{array}{c}\text { Average Number of } \\
\text { Freeze-Thaw Cycles }\end{array}$ \\
\hline $2003-2006$ & 21 & 18 \\
\hline $2006-2007$ & 26 & 22 \\
\hline $2007-2011$ & 25.75 & 24.5 \\
\hline
\end{tabular}


thawing or the amount of time the soil stays frozen in a given time interval was more influential in cliff recession.

\subsubsection{Soil Layer Identification and Thickness Determination}

In addition to the number of days of freezing and the number of freeze-thaw cycles, which were assumed to be uniform for the entire length of the Calvert Cliffs, the freezethaw susceptibility of the different stratigraphic units (henceforth called soil layers) composing the cliffs at the different study sites was also investigated. Before freeze-thaw susceptibility of the soil layers could be assessed, the layers present at each study sub-site were identified. Digital images taken at each sub-site were studied and compared to a subset of the previous studies conducted (Miller 1995; Shattuck 1904) to determine what each layer that was visually observed corresponded to in previous work. Shattuck (1904) describes the soil stratigraphic units in terms of "soil zones", while Miller (1995) uses the term "unit". Table 5 identifies the stratigraphy of each study site and indicates what name was used for each soil layer in previous work. While not all of the sites selected for this work were studied previously, the cliffs are formed primarily of Miocene deposits dipping gently to the southeast (Kidwell 1997), which means that all layers appear in sequence and the stratigraphy at the previously unstudied sites can still be generally determined through interpolation.

Once the layers at each study site were identified, the thickness of each layer at each subsite was measured using digital imagery. The actual height of the cliff at each sub-site was computed using topographic data in the form of 2 foot elevation contours from 2003; 
Table 5: Stratigraphy of the Calvert Cliffs, Comparing Names Used in Past Work to Names Used in This Study

\begin{tabular}{|c|c|c|c|c|c|c|c|}
\hline \multirow{2}{*}{$\begin{array}{c}\text { Soil Zone } \\
\text { (based on } \\
\text { Shattuck } \\
1904 \text { ) }\end{array}$} & \multirow{2}{*}{$\begin{array}{c}\text { Soil Units } \\
\text { (based on Miller 1995) }\end{array}$} & \multicolumn{6}{|c|}{$\begin{array}{c}\text { Present at Study Sites? } \\
\text { If so, name used in this study: }\end{array}$} \\
\hline & & $\mathrm{SCN}$ & SCS & $\mathrm{CB}$ & CCSP & $\mathrm{PC}$ & CRE \\
\hline Zone 13 & Chione-Glossus* & $\mathrm{SC} 1 *$ & $\mathrm{SC} 1 *$ & & & & \\
\hline Zone 14 & KBSB** & SC 2 & $\mathrm{SC} 2$ & & & & \\
\hline Zone 15 & Turritella-Pandora & $\mathrm{SC} 3$ & $\mathrm{SC} 3$ & & & & \\
\hline Zone 16 & Turritella-Pandora & $\mathrm{SC} 4$ & $\mathrm{SC} 4$ & & & & \\
\hline Zone 17 & Governor's Run Sand & $\mathrm{SC} 5$ & $\mathrm{SC} 5$ & CB 1 & & & \\
\hline Zone 17 & $\mathrm{DCSB}^{* * *}$ & $\mathrm{SC} 6$ & $\mathrm{SC} 6$ & $\mathrm{CB} 2$ & & & \\
\hline Zone 18 & Mytilus & $\mathrm{SC} 7$ & $\mathrm{SC} 7$ & $\mathrm{CB} 3$ & & & \\
\hline Zone 18 & Mytilus & $\mathrm{SC} 7$ & $\mathrm{SC} 7$ & $\mathrm{CB} 3$ & & & \\
\hline Zone 19 & Anadara Sand & $\mathrm{SC} 8$ & $\mathrm{SC} 8$ & & & & \\
\hline Zone 19 & $\mathrm{BCSB} * * * *$ & SC 9 & SC 9 & $\mathrm{CB} 4$ & $\mathrm{BCSB}$ & & \\
\hline Zone 20 & Unnamed N. of Rocky Point & $\mathrm{SC} 10$ & $\mathrm{SC} 10$ & CB 5 & CCSP 1 & & \\
\hline Zone 20 & Unnamed N. of Rocky Point & $\mathrm{SC} 10$ & $\mathrm{SC} 10$ & & & & \\
\hline Post-Miocene & N/A & & & CB 6 & & & \\
\hline Zone 21 & Zone 21 & & & & CCSP 2 & & \\
\hline Zone 22 & Zone 22 & & & & CCSP 3 & PC 1 & CRE 1 \\
\hline Zone 22 & Zone 22 & & & & & PC 2 & CRE 2 \\
\hline Zone 23 & Zone 23 Lower & & & & $\operatorname{CCSP} 4$ & PC 3 & CRE 3 \\
\hline Zone 23 & Zone 23 Upper & & & & CCSP 5 & $\mathrm{PC} 4$ & CRE 4 \\
\hline Zone 23 & Zone 23 Upper & & & & CCSP 6 & PC 5 & CRE 5 \\
\hline Zone 23 & CRE Clay & & & & & PC 6 & CRE 6 \\
\hline Zone 23 & CRE Clay & & & & & PC 7 & CRE 7 \\
\hline Post-Miocene & CRE-Sand & & & & CCSP 7 & PC 8 & CRE 8 \\
\hline Post-Miocene & CRE-Sand & & & & CCSP 7 & PC 9 & CRE 9 \\
\hline Post Miocene & CRE Sand & & & & & PC 10 & CRE 10 \\
\hline Post Miocene & CRE Soil & & & & & PC 11 & CRE 11 \\
\hline
\end{tabular}

*This stratigraphic unit is often referred to as "Blue Marl" by community members of Scientist's Cliffs

**KBSB=Kenwood Beach Shell Bed

$* * * \mathrm{DCSB}=$ Drumcliff Shell Bed

$* * *$ BCSB$=$ Boston Cliffs Shell Bed

the contours have $16 \mathrm{~cm} /$ pixel resolution (Calvert County Government 2012). Using

oblique aerial digital images from 2011 (Calvert County Government Government 2012), which show the entire cliff height from a single reference point, the thickness of each 
layer and the total cliff height were measured using ArcMap 10. These thicknesses were then scaled by using the actual cliff height at each sub-site. Figure 7 shows an example of how each layer was identified in order to be measured. Table 6 through Table 11 show the calculated layer thicknesses for each sub-site. Appendix C contains figures showing how the layers were identified for each study site in order to be measured, the measured layer thicknesses, and sample calculations.

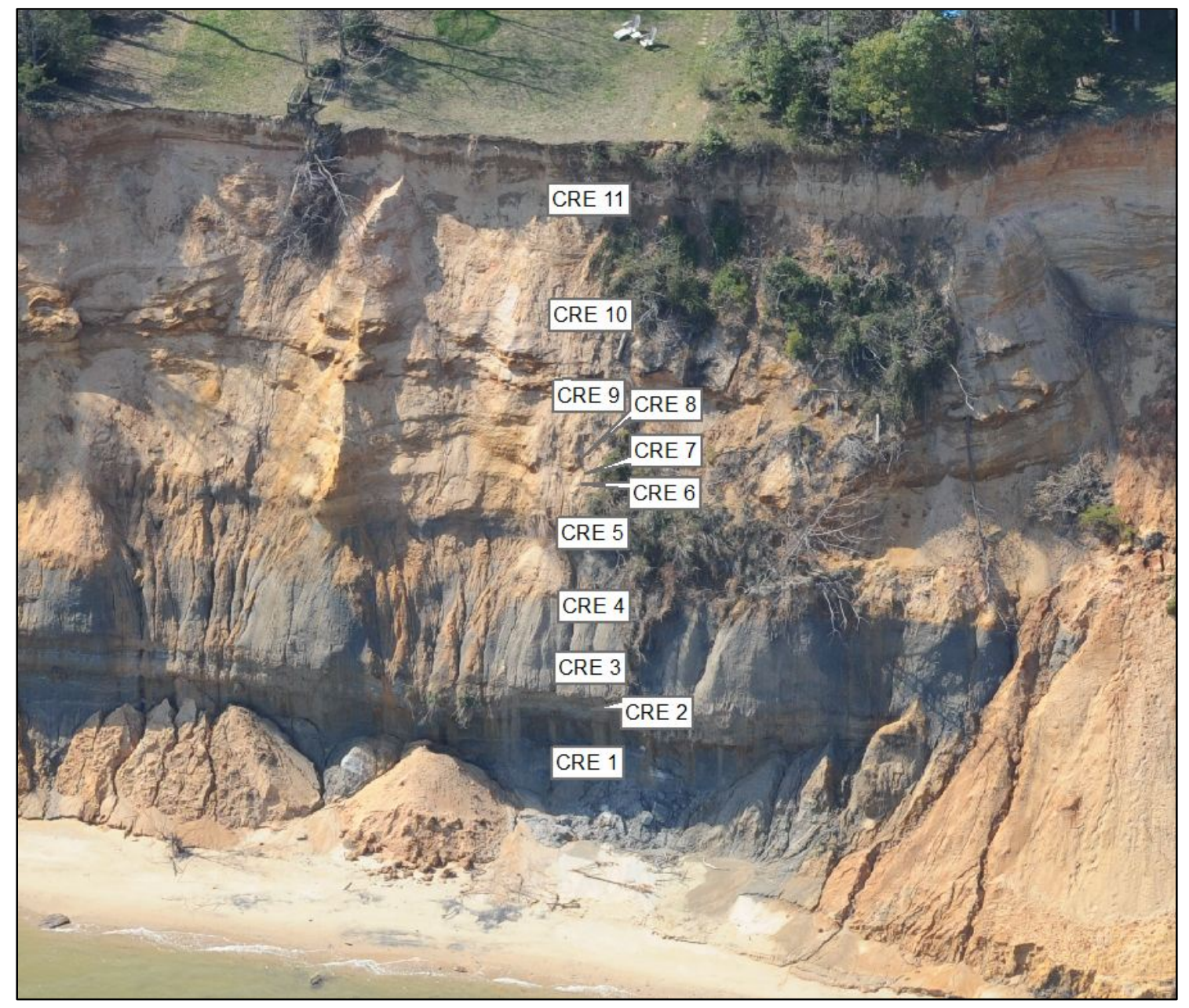

Figure 7: Soil Layers Identified for CRE2 in Order for Soil Layer Thicknesses to be Calculated (image data source: Calvert County Government 2012) 
Table 6: Soil Layer Thicknesses for SCN Sub-Sites

\begin{tabular}{|c|c|c|}
\hline Sub-site & Layer & $\begin{array}{l}\text { Actual Layer } \\
\text { Thickness (m) }\end{array}$ \\
\hline \multirow{12}{*}{ SCN1 } & $\mathrm{SC} 1$ & 3.9 \\
\hline & $\mathrm{SC} 2$ & 1.1 \\
\hline & $\mathrm{SC} 3$ & 1.1 \\
\hline & $\mathrm{SC} 4$ & 1.1 \\
\hline & SC 5 & 5.8 \\
\hline & SC 6 & 3.8 \\
\hline & SC 7 & 3.0 \\
\hline & $\mathrm{SC} 7$ & 1.9 \\
\hline & SC 8 & 0.1 \\
\hline & SC 9 & 2.3 \\
\hline & $\mathrm{SC} 10$ & 4.3 \\
\hline & SC 10 & 2.1 \\
\hline \multirow{12}{*}{ SCN2 } & $\mathrm{SC} 1$ & 3.8 \\
\hline & SC 2 & 1.0 \\
\hline & SC 3 & 1.0 \\
\hline & $\mathrm{SC} 4$ & 1.0 \\
\hline & SC 5 & 5.6 \\
\hline & SC 6 & 3.6 \\
\hline & SC 7 & 2.9 \\
\hline & SC 7 & 1.5 \\
\hline & SC 8 & 0.0 \\
\hline & SC 9 & 0.0 \\
\hline & SC 10 & 0.0 \\
\hline & SC 10 & 0.1 \\
\hline
\end{tabular}

\begin{tabular}{|c|c|c|}
\hline Sub-site & Layer & $\begin{array}{l}\text { Actual Layer } \\
\text { Thickness (m) }\end{array}$ \\
\hline \multirow{12}{*}{$\mathrm{SCN} 3$} & $\mathrm{SC} 1$ & 1.2 \\
\hline & $\mathrm{SC} 2$ & 0.3 \\
\hline & SC 3 & 0.3 \\
\hline & $\mathrm{SC} 4$ & 0.3 \\
\hline & SC 5 & 2.7 \\
\hline & SC 6 & 0.0 \\
\hline & SC 7 & 0.0 \\
\hline & SC 7 & 0.0 \\
\hline & SC 8 & 0.0 \\
\hline & SC 9 & 0.0 \\
\hline & SC 10 & 0.0 \\
\hline & SC 10 & 1.9 \\
\hline \multirow{12}{*}{ SCN4 } & SC 1 & 1.3 \\
\hline & SC 2 & 0.3 \\
\hline & SC 3 & 0.3 \\
\hline & SC 4 & 0.3 \\
\hline & SC 5 & 3.2 \\
\hline & SC 6 & 0.0 \\
\hline & SC 7 & 0.0 \\
\hline & SC 7 & 0.0 \\
\hline & SC 8 & 0.0 \\
\hline & SC 9 & 0.0 \\
\hline & SC 10 & 0.0 \\
\hline & SC 10 & 1.9 \\
\hline
\end{tabular}


Table 7: Soil Layer Thicknesses for SCS Sub-Sites

\begin{tabular}{|c|c|c|}
\hline Sub-site & Layer & $\begin{array}{l}\text { Actual Layer } \\
\text { Thickness (m) }\end{array}$ \\
\hline \multirow{12}{*}{ SCS5 } & SC 1 & 0.6 \\
\hline & SC 2 & 0.6 \\
\hline & $\mathrm{SC} 3$ & 0.5 \\
\hline & $\mathrm{SC} 4$ & 0.5 \\
\hline & SC 5 & 3.5 \\
\hline & SC 6 & 4.1 \\
\hline & SC 7 & 4.3 \\
\hline & SC 7 & 2.7 \\
\hline & SC 8 & 2.2 \\
\hline & SC 9 & 2.3 \\
\hline & SC 10 & 2.7 \\
\hline & SC 10 & 2.2 \\
\hline \multirow{12}{*}{ SCS6 } & SC 1 & 0.7 \\
\hline & SC 2 & 0.7 \\
\hline & SC 3 & 1.1 \\
\hline & SC 4 & 1.1 \\
\hline & SC 5 & 2.4 \\
\hline & SC 6 & 3.6 \\
\hline & SC 7 & 4.2 \\
\hline & SC 7 & 3.3 \\
\hline & SC 8 & 0.6 \\
\hline & SC 9 & 3.7 \\
\hline & SC 10 & 3.9 \\
\hline & SC 10 & 2.7 \\
\hline \multirow{12}{*}{ SCS7 } & SC 1 & 0.8 \\
\hline & SC 2 & 0.8 \\
\hline & SC 3 & 1.1 \\
\hline & SC 4 & 1.1 \\
\hline & SC 5 & 1.6 \\
\hline & SC 6 & 2.6 \\
\hline & SC 7 & 1.8 \\
\hline & SC 7 & 1.6 \\
\hline & SC 8 & 2.8 \\
\hline & SC 9 & 2.1 \\
\hline & SC 10 & 4.7 \\
\hline & SC 10 & 1.3 \\
\hline
\end{tabular}

\begin{tabular}{|c|c|c|}
\hline Sub-site & Layer & $\begin{array}{l}\text { Actual Layer } \\
\text { Thickness (m) }\end{array}$ \\
\hline \multirow{12}{*}{ SCS8 } & $\mathrm{SC} 1$ & 0.0 \\
\hline & SC 2 & 1.3 \\
\hline & SC 3 & 0.7 \\
\hline & $\mathrm{SC} 4$ & 0.7 \\
\hline & SC 5 & 3.7 \\
\hline & SC 6 & 2.4 \\
\hline & SC 7 & 2.1 \\
\hline & SC 7 & 1.9 \\
\hline & SC 8 & 0.6 \\
\hline & SC 9 & 2.5 \\
\hline & SC 10 & 1.6 \\
\hline & SC 10 & 1.6 \\
\hline \multirow{12}{*}{ SCS9 } & $\mathrm{SC} 1$ & 0.0 \\
\hline & SC 2 & 1.3 \\
\hline & SC 3 & 0.4 \\
\hline & SC 4 & 0.4 \\
\hline & SC 5 & 5.5 \\
\hline & SC 6 & 3.6 \\
\hline & SC 7 & 4.1 \\
\hline & SC 7 & 2.8 \\
\hline & SC 8 & 1.1 \\
\hline & SC 9 & 2.2 \\
\hline & SC 10 & 0.3 \\
\hline & SC 10 & 1.3 \\
\hline
\end{tabular}


Table 8: Soil Layer Thicknesses for CB Sub-Sites

\begin{tabular}{|c|c|c|}
\hline \multirow{4}{*}{ Sub-site } & Layer & $\begin{array}{c}\text { Actual Layer } \\
\text { Thickness (m) }\end{array}$ \\
\hline \multirow{5}{*}{ CB1 } & CB 1 & 6.4 \\
\cline { 2 - 3 } & CB 2 & 4.1 \\
\cline { 2 - 3 } & CB 3 & 8.3 \\
\cline { 2 - 3 } & CB 4 & 2.1 \\
\cline { 2 - 3 } & CB 5 & 3.2 \\
\hline & CB 6 & 3.4 \\
\hline \multirow{5}{*}{ CB2 } & CB 1 & 0.0 \\
\cline { 2 - 3 } & CB 2 & 0.0 \\
\cline { 2 - 3 } & CB 3 & 3.1 \\
\cline { 2 - 3 } & CB 4 & 3.5 \\
\cline { 2 - 3 } & CB 5 & 6.8 \\
\cline { 2 - 3 } & CB 6 & 1.2 \\
\hline
\end{tabular}

\begin{tabular}{|c|c|c|}
\hline \multirow{4}{*}{ Sub-site } & Layer & $\begin{array}{c}\text { Actual Layer } \\
\text { Thickness (m) }\end{array}$ \\
\hline \multirow{5}{*}{ CB3 } & CB 1 & 0.0 \\
\cline { 2 - 3 } & CB 2 & 0.0 \\
\cline { 2 - 3 } & CB 3 & 1.9 \\
\cline { 2 - 3 } & CB 4 & 2.9 \\
\hline & CB 5 & 5.4 \\
\hline & CB 6 & 0.7 \\
\hline \multirow{5}{*}{ CB4 } & CB 1 & 0.0 \\
\hline & CB 2 & 0.0 \\
\cline { 2 - 3 } & CB 3 & 1.7 \\
\cline { 2 - 3 } & CB 4 & 2.6 \\
\hline & CB 5 & 5.4 \\
\cline { 2 - 3 } & CB 6 & 0.7 \\
\hline
\end{tabular}

Table 9: Soil Layer Thicknesses for CCSP Sub-Sites

\begin{tabular}{|c|c|c|}
\hline \multirow{5}{*}{ Sub-site } & Layer & $\begin{array}{c}\text { Actual Layer } \\
\text { Thickness (m) }\end{array}$ \\
\hline & BCSB & 1.4 \\
\cline { 2 - 3 } & CCSP 1 & 2.7 \\
\cline { 2 - 3 } CCSP1 1 CCSP 2 & 1.1 \\
\cline { 2 - 3 } & CCSP 3 & 4.0 \\
\cline { 2 - 3 } & CCSP 4 & 4.0 \\
\cline { 2 - 3 } & CCSP 5 & 3.6 \\
\cline { 2 - 3 } & CCSP 6 & 2.3 \\
\cline { 2 - 3 } & CCSP 7 & 1.1 \\
\cline { 2 - 3 } & CCSP 7 & 1.1 \\
\hline \multirow{5}{*}{ CCSP2 } & BCSB & 0.5 \\
\cline { 2 - 3 } & CCSP 1 & 3.3 \\
\cline { 2 - 3 } & CCSP 2 & 0.7 \\
\cline { 2 - 3 } & CCSP 3 & 2.7 \\
\cline { 2 - 3 } & CCSP 4 & 4.5 \\
\cline { 2 - 3 } & CCSP 5 & 2.4 \\
\cline { 2 - 3 } & CCSP 6 & 2.2 \\
\cline { 2 - 3 } & CCSP 7 & 1.1 \\
\cline { 2 - 3 } & CCSP 7 & 0.3 \\
\hline
\end{tabular}

\begin{tabular}{|c|c|c|}
\hline \multirow{5}{*}{ Sub-site } & Layer & $\begin{array}{c}\text { Actual Layer } \\
\text { Thickness (m) }\end{array}$ \\
\hline & BCSB & 0.5 \\
\cline { 2 - 3 } & CCSP 1 & 3.4 \\
\cline { 2 - 3 } CCSP3 & CCSP 2 & 1.0 \\
\cline { 2 - 3 } & CCSP 3 & 3.0 \\
\cline { 2 - 3 } & CCSP 4 & 2.6 \\
\cline { 2 - 3 } & CCSP 5 & 5.7 \\
\cline { 2 - 3 } & CCSP 6 & 3.1 \\
\cline { 2 - 3 } & CCSP 7 & 1.9 \\
\cline { 2 - 3 } & CCSP 7 & 1.9 \\
\hline \multirow{5}{*}{ CCSP4 } & BCSB & 0.5 \\
\cline { 2 - 3 } & CCSP 1 & 3.0 \\
\cline { 2 - 3 } & CCSP 2 & 0.4 \\
\cline { 2 - 3 } & CCSP 3 & 3.4 \\
\cline { 2 - 3 } & CCSP 4 & 3.8 \\
\cline { 2 - 3 } & CCSP 5 & 6.2 \\
\cline { 2 - 3 } & CCSP 6 & 3.5 \\
\cline { 2 - 3 } & CCSP 7 & 1.2 \\
\cline { 2 - 3 } & CCSP 7 & 1.2 \\
\hline
\end{tabular}


Table 10: Soil Layer Thicknesses for PC Sub-Sites

\begin{tabular}{|c|c|c|}
\hline Sub-site & Layer & $\begin{array}{l}\text { Actual Layer } \\
\text { Thickness (m) }\end{array}$ \\
\hline \multirow{11}{*}{ PC_G } & PC 1 & 0.8 \\
\hline & PC 2 & 2.2 \\
\hline & PC 3 & 1.4 \\
\hline & PC 4 & 1.4 \\
\hline & PC 5 & 1.1 \\
\hline & PC 6 & 0.4 \\
\hline & PC 7 & 0.4 \\
\hline & PC 8 & 0.4 \\
\hline & PC 9 & 3.4 \\
\hline & PC 10 & 10.1 \\
\hline & PC 11 & 2.4 \\
\hline \multirow{11}{*}{ PC1 } & PC 1 & 2.0 \\
\hline & PC 2 & 2.2 \\
\hline & PC 3 & 0.9 \\
\hline & PC 4 & 2.0 \\
\hline & PC 5 & 0.7 \\
\hline & PC 6 & 0.3 \\
\hline & PC 7 & 0.3 \\
\hline & PC 8 & 0.3 \\
\hline & PC 9 & 1.5 \\
\hline & PC 10 & 1.7 \\
\hline & PC 11 & 0.9 \\
\hline \multirow{11}{*}{ PC2 } & PC 1 & 1.8 \\
\hline & PC 2 & 2.5 \\
\hline & PC 3 & 0.7 \\
\hline & PC 4 & 2.5 \\
\hline & PC 5 & 2.1 \\
\hline & PC 6 & 0.5 \\
\hline & PC 7 & 0.5 \\
\hline & PC 8 & 0.5 \\
\hline & PC 9 & 3.9 \\
\hline & PC 10 & 0.0 \\
\hline & PC 11 & 0.2 \\
\hline
\end{tabular}

\begin{tabular}{|c|c|c|}
\hline Sub-site & Layer & $\begin{array}{l}\text { Actual Layer } \\
\text { Thickness (m) }\end{array}$ \\
\hline \multirow{11}{*}{ PC3 } & PC 1 & 1.2 \\
\hline & PC 2 & 1.5 \\
\hline & PC 3 & 0.3 \\
\hline & PC 4 & 1.5 \\
\hline & PC 5 & 2.1 \\
\hline & PC 6 & 0.3 \\
\hline & PC 7 & 0.3 \\
\hline & PC 8 & 0.3 \\
\hline & PC 9 & 7.6 \\
\hline & PC 10 & 10.6 \\
\hline & PC 11 & 2.5 \\
\hline \multirow{11}{*}{ PC4 } & PC 1 & 1.2 \\
\hline & $\mathrm{PC} 2$ & 1.5 \\
\hline & PC 3 & 0.3 \\
\hline & PC 4 & 1.5 \\
\hline & PC 5 & 2.0 \\
\hline & PC 6 & 0.3 \\
\hline & PC 7 & 0.3 \\
\hline & PC 8 & 0.3 \\
\hline & PC 9 & 7.6 \\
\hline & PC 10 & 10.5 \\
\hline & PC 11 & 1.5 \\
\hline
\end{tabular}


Table 11: Soil Layer Thicknesses for CRE Sub-Sites

\begin{tabular}{|c|c|c|}
\hline Sub-site & Layer & $\begin{array}{l}\text { Actual Layer } \\
\text { Thickness (m) }\end{array}$ \\
\hline \multirow{11}{*}{ CRE1 } & CRE 1 & 3.6 \\
\hline & CRE 2 & 2.0 \\
\hline & CRE 3 & 1.3 \\
\hline & CRE 4 & 5.4 \\
\hline & CRE 5 & 1.8 \\
\hline & CRE 6 & 0.4 \\
\hline & CRE 7 & 0.4 \\
\hline & CRE 8 & 0.4 \\
\hline & CRE 9 & 4.1 \\
\hline & CRE 10 & 2.1 \\
\hline & CRE 11 & 1.6 \\
\hline \multirow{11}{*}{ CRE2 } & CRE 1 & 5.2 \\
\hline & CRE 2 & 1.0 \\
\hline & CRE 3 & 1.9 \\
\hline & CRE 4 & 4.2 \\
\hline & CRE 5 & 2.2 \\
\hline & CRE 6 & 0.9 \\
\hline & CRE 7 & 0.9 \\
\hline & CRE 8 & 0.9 \\
\hline & CRE 9 & 4.3 \\
\hline & CRE 10 & 4.8 \\
\hline & CRE 11 & 4.6 \\
\hline
\end{tabular}

\begin{tabular}{|c|c|c|}
\hline Sub-site & Layer & $\begin{array}{l}\text { Actual Layer } \\
\text { Thickness (m) }\end{array}$ \\
\hline \multirow{11}{*}{ CRE3 } & CRE 1 & 2.3 \\
\hline & CRE 2 & 1.2 \\
\hline & CRE 3 & 1.0 \\
\hline & CRE 4 & 3.5 \\
\hline & CRE 5 & 2.8 \\
\hline & CRE 6 & 0.7 \\
\hline & CRE 7 & 0.7 \\
\hline & CRE 8 & 0.7 \\
\hline & CRE 9 & 4.8 \\
\hline & CRE 10 & 10.4 \\
\hline & CRE 11 & 2.4 \\
\hline \multirow{11}{*}{ CRE4 } & CRE 1 & 2.1 \\
\hline & CRE 2 & 1.2 \\
\hline & CRE 3 & 1.5 \\
\hline & CRE 4 & 4.3 \\
\hline & CRE 5 & 3.1 \\
\hline & CRE 6 & 0.4 \\
\hline & CRE 7 & 0.4 \\
\hline & CRE 8 & 0.4 \\
\hline & CRE 9 & 8.3 \\
\hline & CRE 10 & 3.8 \\
\hline & CRE 11 & 2.6 \\
\hline
\end{tabular}

\subsubsection{Moisture Conditions of Soil Layers}

Moisture conditions of the soil layers were noted from historical data (Miller 1995), and were supplemented by analysis of digital and FLIR thermal IR images when historical data was not available. For study sites also investigated by Miller (1995), a geotechnical profile originating from soil boring information was available. This geotechnical profile noted soil moisture conditions. However, not all study sites were previously investigated. For those sites not previously investigated, if seepage out of the cliff face was noticeable, the soil was considered saturated. If no noticeable seepage was present, Miller's (1995) 
historical data for the soil strata at different study sites was verified with digital images and the FLIR thermal IR images. Figure 8 demonstrates how moisture not detectable in digital images can be detected using the FLIR thermal IR images. The image to the left is a digital image, and no noticeable moisture can be detected. The image to the right, a FLIR thermal IR image, shows a band of lower temperature with respect to the temperature of the surrounding soil, which is associated with moisture, near the top of the slope (Price 1980). Table 12 gives the moisture condition of all soil layers present at each study site.
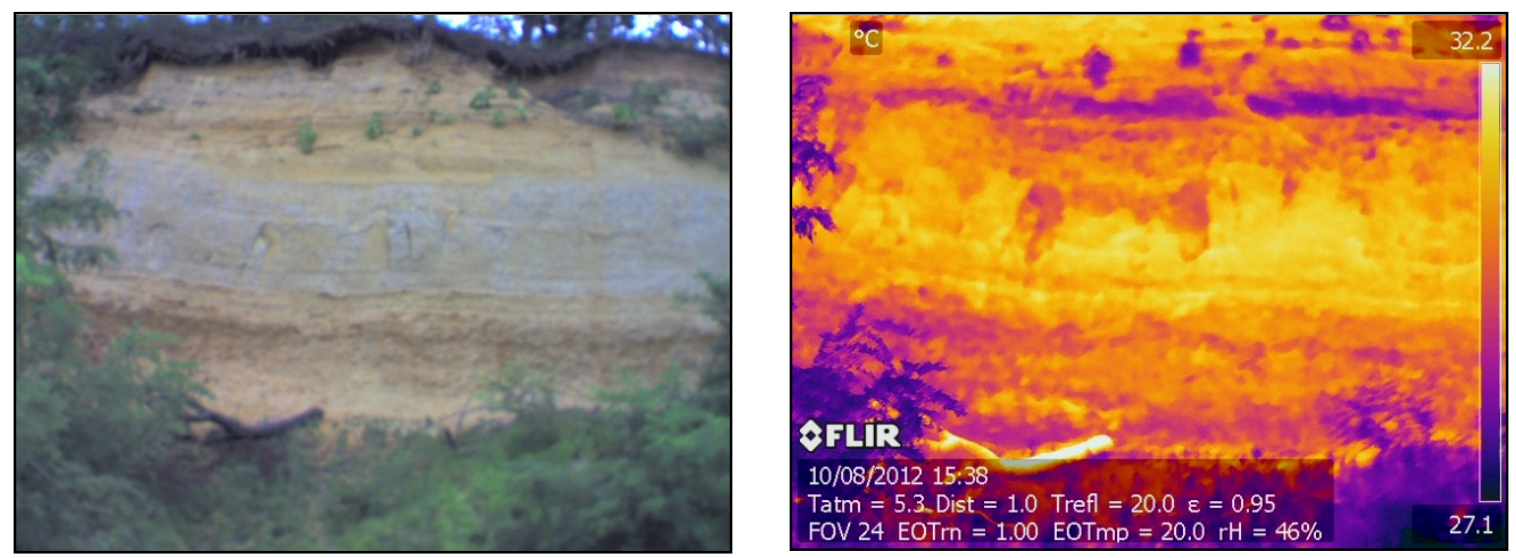

Figure 8: Digital Image and Corresponding FLIR Thermal IR Image of a Portion of a Slope 
Table 12: Moisture Conditions of all Soil Layers

\begin{tabular}{|c|c|c|}
\hline $\begin{array}{l}\text { Study } \\
\text { Site }\end{array}$ & Layer & Layer Moisture \\
\hline \multirow{12}{*}{$\begin{array}{c}\mathrm{SCN} \\
\& \\
\mathrm{SCS}\end{array}$} & $\mathrm{SC} 1$ & Wet \\
\hline & SC 2 & Wet \\
\hline & SC 3 & Wet \\
\hline & $\mathrm{SC} 4$ & Wet \\
\hline & SC 5 & Moist; saturated at base \\
\hline & SC 6 & Moist \\
\hline & $\mathrm{SC} 7$ & Dry \\
\hline & $\mathrm{SC} 7$ & Dry \\
\hline & SC 8 & Dry \\
\hline & SC 9 & Moist to dry \\
\hline & SC 10 & Moist \\
\hline & SC 10 & Moist \\
\hline \multirow{6}{*}{$\mathrm{CB}$} & CB 1 & Moist \\
\hline & CB 2 & Moist \\
\hline & CB 3 & Moist; seeps at top \\
\hline & CB 4 & Moist to dry \\
\hline & $\mathrm{CB} 5$ & Moist to dry \\
\hline & CB 6 & Moist \\
\hline \multirow{9}{*}{ CCSP } & BCSB & Moist to dry \\
\hline & CCSP 1 & Moist \\
\hline & CCSP 2 & Dry/moist \\
\hline & CCSP 3 & Moist \\
\hline & CCSP 4 & Saturated \\
\hline & CCSP 5 & Moist; saturated at base \\
\hline & CCSP 6 & Slightly moist \\
\hline & CCSP 7 & Slightly moist \\
\hline & $\operatorname{CCSP} 7$ & Slightly moist \\
\hline
\end{tabular}

\begin{tabular}{|c|c|c|}
\hline $\begin{array}{l}\text { Study } \\
\text { Site }\end{array}$ & Layer & Layer Moisture \\
\hline \multirow{11}{*}{$\mathrm{PC}$} & PC 1 & Saturated \\
\hline & PC 2 & Saturated \\
\hline & PC 3 & Saturated \\
\hline & $\mathrm{PC} 4$ & Moist \\
\hline & PC 5 & Moist \\
\hline & PC 6 & Saturated \\
\hline & PC 7 & Moist \\
\hline & PC 8 & Saturated \\
\hline & PC 9 & Saturated \\
\hline & PC 10 & Moist; saturated at base \\
\hline & PC 11 & Moist \\
\hline \multirow{11}{*}{ CRE } & CRE 1 & Saturated \\
\hline & CRE 2 & Saturated \\
\hline & CRE 3 & Saturated \\
\hline & CRE 4 & Moist \\
\hline & CRE 5 & Moist \\
\hline & CRE 6 & Saturated \\
\hline & CRE 7 & Moist \\
\hline & CRE 8 & Saturated \\
\hline & CRE 9 & Saturated \\
\hline & CRE 10 & Moist; saturated at base \\
\hline & CRE 11 & Moist \\
\hline
\end{tabular}

\subsubsection{Freeze-Thaw Susceptibility of Soil Layers}

After the layers present at each study site and sub-site were identified, their freeze-thaw susceptibility was analyzed. The soil samples collected during field work were tested in one of Michigan Technological University's graduate geotechnical engineering research 
laboratories (Dillman Hall Room B010b) in order to be classified using the Unified Soil Classification System (USCS). Testing of these samples included moisture content, specific gravity, grain size analysis, Atterberg limits, and USCS classification. These tests were performed, without deviation, according to the following standards:

- ASTM D2216 - 10: Standard Test Methods for Laboratory Determination of Water (Moisture) Content of Soil and Rock by Mass

- Micromeritics AccuPyc 1330 Helium Pycnometer User Manual (specific gravity)

- ASTM D422 - 63 (2007): Standard Test Method for Particle-Size Analysis of Soils

- ASTM D4318 - 10: Standard Test Methods for Liquid Limit, Plastic Limit, and Plasticity Index of Soils

- ASTM D2487 - 11: Standard Practice for Classification of Soils for Engineering Purposes (Unified Soil Classification System)

For the soil layers that were not represented by any of the soil samples analyzed in the laboratory (see Appendix D), historical data was used (Miller 1995). While this data did not provide a USCS classification or enough data to obtain one, it did contain soil descriptions and data on percent sand, silt, and clay. The soil classification data can be found in Appendix D.

Using the classification data for the soil layers, the freeze-thaw susceptibility of each layer could be assessed. This was analyzed using Table 13, developed by the U.S. Army Corps of Engineers. This system identifies four freeze-thaw susceptibility categories, from F1 (least susceptible) to F4 (most susceptible). For the soil layers that had a USCS classification associated with them, the criteria in columns 3 and 4 of Table 13 was used to determine the freeze-thaw susceptibility. For the soil layers lacking a USCS classification, the soil description and the percent silt/clay were used to determine the freeze-thaw susceptibility. Traditionally, the percent of soil that is finer than $0.02 \mathrm{~mm}$ is 
Table 13: U.S. Army Corps of Engineers Frost Susceptibility Based on USCS Classification (Adapted from Department of the Army Corps of Engineers Office of the Chief of Engineers 1984)

\begin{tabular}{|c|c|c|c|}
\hline Group & Type of Soil & $\begin{array}{c}\text { Percent } \\
\text { Finer } \\
\text { than } \\
0.075 \\
\mathrm{~mm}^{1}\end{array}$ & USCS Group Symbols \\
\hline $\begin{array}{l}\text { F1 (least } \\
\text { susceptible) }\end{array}$ & Gravels & $3-10$ & GW, GP, GW-GM, GP-GM \\
\hline \multirow{2}{*}{$\mathbf{F 2}$} & a. Gravels & $10-20$ & GM, GW-GM, GP-GM \\
\hline & b. Sands & $3-15$ & SW, SP, SM, SW-SM, SP-SM \\
\hline \multirow{3}{*}{ F3 } & a. Gravels & $>20$ & GM, GC \\
\hline & $\begin{array}{l}\text { b. Sands, except for very fine silty } \\
\text { sands }\end{array}$ & $>15$ & $\mathrm{SM}, \mathrm{SC}$ \\
\hline & c. Clays with plasticity index $>12$ & - & $\mathrm{CL}, \mathrm{CH}$ \\
\hline \multirow{4}{*}{$\begin{array}{c}\text { F4 (most } \\
\text { susceptible) }\end{array}$} & a. Silts and sandy silts & - & ML, MH \\
\hline & b. Fine silty sands & $>15$ & SM, SC \\
\hline & $\begin{array}{l}\text { c. Lean clays with } \\
\text { plasticity index }<12\end{array}$ & - & CL, CL-ML \\
\hline & $\begin{array}{l}\text { d. Varved clays and other fine } \\
\text { grained, banded sediments }\end{array}$ & - & $\begin{array}{l}\text { CL \& ML; CL, ML, \& SM; CL, } \\
\text { CH, \& ML; CL, CH, ML, \& SM }\end{array}$ \\
\hline
\end{tabular}

${ }^{1}$ The U.S. Army Corps of Engineers uses $0.02 \mathrm{~mm}$ as the critical size for freeze-thaw susceptibility, but due to data limitations, $0.075 \mathrm{~mm}$ was used in this study.

used in analyzing freeze-thaw susceptibility. However, since the percent of material that is finer than $0.02 \mathrm{~mm}$ was not available for any soil layer classified using historical data, it was adjusted so that all of the soil could be classified. The particle size of $0.075 \mathrm{~mm}$ was selected because this is the size that differentiates between coarse-grained materials (gravel and sand) and fine-grained materials (silt and clay) according to USCS, and thus data were available for all soil layers present at all study sites.

Once a freeze-thaw susceptibility of F1 to F4 was assigned to all soil layers, these classifications were adjusted to account for soil moisture conditions; if there is no moisture present, no freeze-thaw can occur regardless of particle size, so soil layers that 
had no moisture (Table 12) were given a freeze-thaw susceptibility of F1. After these adjustments were made, the total height of each freeze-thaw susceptibility class that is present at each sub-site was calculated. These heights were used to calculate the percent of the total cliff height composed of each freeze-thaw susceptibility class. Table 14 shows the percent of the total cliff height composed of each freeze-thaw susceptibility class for each sub-site. Appendix C contains all original data and sample calculations.

Table 14: Percent of Total Cliff Height Composed of Each Freeze-Thaw Susceptibility Class

\begin{tabular}{|c|c|c|c|c|c|}
\hline Study Site & Sub-site & $\begin{array}{c}\text { \% of Total } \\
\text { Height - F4 } 4\end{array}$ & $\begin{array}{c}\text { \% of Total } \\
\text { Height - F3 }\end{array}$ & $\begin{array}{c}\text { \% of Total } \\
\text { Height - F2 } 2\end{array}$ & $\begin{array}{c}\text { \% of Total } \\
\text { Height - F1 }\end{array}$ \\
\hline \multirow{5}{*}{ SCN } & SCN1 & $0 \%$ & $24.7 \%$ & $51.1 \%$ & $24.2 \%$ \\
\cline { 2 - 6 } & SCN2 & $0 \%$ & $15.1 \%$ & $63.7 \%$ & $21.3 \%$ \\
\cline { 2 - 6 } & SCN3 & $0 \%$ & $14.5 \%$ & $85.5 \%$ & $0.0 \%$ \\
\cline { 2 - 6 } & SCN4 & $0 \%$ & $13.3 \%$ & $86.7 \%$ & $0.0 \%$ \\
\hline \multirow{5}{*}{ SCS } & SCS5 & $0 \%$ & $16.7 \%$ & $39.2 \%$ & $44.2 \%$ \\
\cline { 2 - 6 } & SCS6 & $0 \%$ & $24.0 \%$ & $33.9 \%$ & $42.1 \%$ \\
\cline { 2 - 6 } & SCS7 & $0 \%$ & $34.8 \%$ & $28.3 \%$ & $37.0 \%$ \\
\cline { 2 - 6 } & SCS8 & $0 \%$ & $23.1 \%$ & $40.0 \%$ & $36.9 \%$ \\
\cline { 2 - 6 } & SCS9 & $0 \%$ & $9.9 \%$ & $45.4 \%$ & $44.7 \%$ \\
\hline \multirow{5}{*}{ CB } & CB1 & $11.6 \%$ & $30.3 \%$ & $58.1 \%$ & $0.0 \%$ \\
\cline { 2 - 6 } & CB2 & $46.4 \%$ & $21.5 \%$ & $32.2 \%$ & $0.0 \%$ \\
\cline { 2 - 6 } & CB3 & $49.6 \%$ & $17.2 \%$ & $33.2 \%$ & $0.0 \%$ \\
\cline { 2 - 6 } & CB4 & $52.3 \%$ & $16.2 \%$ & $31.5 \%$ & $0.0 \%$ \\
\hline \multirow{5}{*}{ CCSP } & CCSP1 & $58.7 \%$ & $34.7 \%$ & $6.7 \%$ & $0 \%$ \\
\cline { 2 - 6 } & CCSP2 & $60.0 \%$ & $36.9 \%$ & $3.1 \%$ & $0 \%$ \\
\cline { 2 - 6 } & CCSP3 & $65.8 \%$ & $32.1 \%$ & $2.2 \%$ & $0 \%$ \\
\cline { 2 - 6 } & CCSP4 & $69.7 \%$ & $28.1 \%$ & $2.2 \%$ & $0 \%$ \\
\hline \multirow{5}{*}{ PC } & PC_G & $3.4 \%$ & $29.6 \%$ & $66.9 \%$ & $0 \%$ \\
\cline { 2 - 6 } & PC1 & $15.3 \%$ & $52.4 \%$ & $32.3 \%$ & $0 \%$ \\
\cline { 2 - 6 } & PC2 & $12.1 \%$ & $60.6 \%$ & $27.3 \%$ & $0 \%$ \\
\cline { 2 - 6 } & PC3 & $4.2 \%$ & $22.0 \%$ & $73.8 \%$ & $0 \%$ \\
\cline { 2 - 6 } & PC4 & $4.3 \%$ & $22.8 \%$ & $72.8 \%$ & $0 \%$ \\
\hline \multirow{5}{*}{ CRE } & CRE1 & $15.5 \%$ & $50.6 \%$ & $33.9 \%$ & $0 \%$ \\
\cline { 2 - 6 } & CRE2 & $16.8 \%$ & $38.9 \%$ & $44.2 \%$ & $0 \%$ \\
\cline { 2 - 6 } & CRE3 & $7.5 \%$ & $34.8 \%$ & $57.7 \%$ & $0 \%$ \\
\cline { 2 - 6 } & CRE4 & $7.6 \%$ & $40.0 \%$ & $52.4 \%$ & $0 \%$ \\
\hline
\end{tabular}


While these freeze-thaw metrics - days of freezing, number of freeze-thaw cycles, and freeze-thaw susceptibility — do not directly account for the depth of freezing, they can still be used to indirectly represent depth of freezing. Since no spatial variation with temperature is being represented in this analysis, all study sites are assumed to have the same number of days of freezing and freeze-thaw cycles per winter season. Therefore, those soil layers with high freeze-thaw susceptibility (F4 or F3) should have greater depths of freezing in a given winter season than those soil layers with low freeze-thaw susceptibility (F2 or F1) for the same winter season.

\subsection{Other Cliff Properties}

While the recession rate and the freeze-thaw behavior of the cliffs were essential components of this analysis, there were a number of other variables that were also considered for their potential impacts on the recession rate of the Calvert Cliffs.

\subsubsection{Cliff Height and Slope Angle}

Cliff height and slope angle were both analyzed for each sub-site. These variables were considered because, as discussed in Section 1.1.1, increasing slope height and slope angle lead to an increase in the likelihood of slope failure. It makes sense, then, that in increased likelihood of slope failure might also lead to an increased recession rate. Both cliff height and slope angle were analyzed using ArcMap 10. Data containing contours derived from 2003 LiDAR data (Calvert County Government 2012) was used to calculate both the cliff height and the slope angle of the cliffs at each sub-site. While the slope angle changes every time there is a slope failure, a single slope angle was used for each 
sub-site due to the lack of data from all years of interest. Additionally, different sections of the cliff face at each sub-site often have different slopes (Miller 1995); however, the average slope over the entire height of the cliff was used and assumed to be representative of the slope. Table 15 shows the cliff height and slope angle for all subsites.

Table 15: Cliff height and slope angle for all sub-sites

\begin{tabular}{|c|c|c|c|}
\hline $\begin{array}{c}\text { Study } \\
\text { Site }\end{array}$ & $\begin{array}{c}\text { Sub- } \\
\text { site }\end{array}$ & $\begin{array}{c}\text { Cliff Height } \\
(\mathrm{m})\end{array}$ & $\begin{array}{c}\text { Slope Angle } \\
\text { (Degrees) }\end{array}$ \\
\hline \multirow{4}{*}{ SCN } & SCN1 & 30.5 & 53 \\
\cline { 2 - 4 } & SCN2 & 20.7 & 46 \\
\cline { 2 - 4 } & SCN3 & 6.7 & 45 \\
\cline { 2 - 4 } & SCN4 & 7.3 & 54 \\
\hline \multirow{5}{*}{ SCS } & SCS5 & 23.2 & 46 \\
\cline { 2 - 4 } & SCS6 & 22.6 & 39 \\
\cline { 2 - 4 } & SCS7 & 20.1 & 41 \\
\cline { 2 - 4 } & SCS8 & 19.2 & 53 \\
\cline { 2 - 4 } & SCS9 & 22.9 & 55 \\
\hline \multirow{5}{*}{ CB } & CB1 & 27.4 & 88 \\
\cline { 2 - 4 } & CB2 & 14.6 & 43 \\
\cline { 2 - 4 } & CB3 & 11.0 & 37 \\
\cline { 2 - 4 } & CB4 & 10.4 & 38 \\
\hline \multirow{5}{*}{ CCSP } & CCSP1 & 21.3 & 54 \\
\cline { 2 - 4 } & CCSP2 & 17.7 & 53 \\
\cline { 2 - 4 } & CCSP3 & 23.2 & 43 \\
\cline { 2 - 4 } & CCSP4 & 23.2 & 39 \\
\hline \multirow{5}{*}{ PC } & PC_G & 23.8 & 35 \\
\cline { 2 - 4 } & PC1 & 12.8 & 46 \\
\cline { 2 - 4 } & PC2 & 15.2 & 35 \\
\cline { 2 - 4 } & PC3 & 28.0 & 41 \\
\cline { 2 - 4 } & PC4 & 26.8 & 38 \\
\hline \multirow{5}{*}{ CRE } & CRE1 & 23.2 & 45 \\
\cline { 2 - 4 } & CRE2 & 31.1 & 45 \\
\cline { 2 - 4 } & CRE3 & 30.5 & 44 \\
\cline { 2 - 4 } & CRE4 & 28.0 & 43 \\
\hline \multirow{4}{*}{} & & & \\
\hline \multirow{5}{*}{} & & & 43 \\
\hline
\end{tabular}




\subsubsection{Weighted Shear Strength}

Shear strength was analyzed for the slope face at each sub-site. At the face of the cliff, there is little overburden stress acting. Using the Mohr-Coulomb failure criterion

$$
\tau=c+\sigma \tan (\varphi)
$$

(Holtz et al. 2011), where $\tau=$ shear strength, $\mathrm{c}=$ cohesion, $\sigma=$ normal stress, and $\varphi=$ internal friction angle, it can be assumed that the soil shear strength at the face of the cliff can be modeled as being primarily cohesive. Therefore, in this work, soil shear strength is assumed to be entirely composed of cohesive strength. Historical data from Miller (1995) was used to determine the shear strength of all but one soil layer. In this data set, cohesion (c) was determined using Torvane shear tests, Unconsolidated Undrained "Quick" triaxial tests, and Unconfined Compression triaxial tests. When a range of cohesive strengths was given, the average value was used. When a cohesive strength value was given for an indurated sample, that value was not used in the average cohesive strength calculation, since no samples were observed to be indurated at the study sites. One soil layer (Zone 23, CRE Clay; more information can be found in Section 3.3 and Appendix D) did not have cohesive strength data available. For this layer, Standard Penetration Test (SPT) data was available (Miller 1995). This was used along with Table 7.5 from Budhu (2007) to approximate the soil's shear strength. In order to have a single value to represent the shear strength of each sub-site, weighted shear strength was calculated. The weighted shear strength of a sub-site was developed by weighting the shear strength of each layer present by the thickness of the layer. Table 16 shows the 
weighted shear strength of the material present at each sub-site. The shear strength data for each soil layer and sample calculation can be found in Appendix C, and the cohesion values used to obtain shear strength can be found in Appendix D.

Table 16: Weight shear strength for each sub-site

\begin{tabular}{|c|c|c|}
\hline Study Site & Sub-site & Weighted Shear Strength $(\mathrm{kPa})$ \\
\hline \multirow{4}{*}{$\mathrm{SCN}$} & SCN1 & 43.7 \\
\hline & $\mathrm{SCN} 2$ & 40.6 \\
\hline & $\mathrm{SCN} 3$ & 48.3 \\
\hline & SCN4 & 45.5 \\
\hline \multirow{5}{*}{ SCS } & SCS5 & 33.3 \\
\hline & SCS6 & 40.8 \\
\hline & SCS7 & 43.6 \\
\hline & SCS8 & 33.5 \\
\hline & SCS9 & 24.2 \\
\hline \multirow{4}{*}{$\mathrm{CB}$} & CB1 & 26.6 \\
\hline & $\mathrm{CB} 2$ & 29.5 \\
\hline & CB3 & 28.0 \\
\hline & CB4 & 28.0 \\
\hline \multirow{4}{*}{ CCSP } & CCSP1 & 49.4 \\
\hline & CCSP2 & 51.4 \\
\hline & CCSP3 & 42.5 \\
\hline & CCSP4 & 43.8 \\
\hline \multirow{5}{*}{$\mathrm{PC}$} & PC_G & 22.3 \\
\hline & $\mathrm{PC} 1$ & 47.0 \\
\hline & $\mathrm{PC} 2$ & 43.2 \\
\hline & $\mathrm{PC} 3$ & 16.0 \\
\hline & $\mathrm{PC} 4$ & 16.5 \\
\hline \multirow{4}{*}{ CRE } & CRE1 & 39.0 \\
\hline & CRE2 & 34.3 \\
\hline & CRE3 & 22.8 \\
\hline & CRE4 & 24.1 \\
\hline
\end{tabular}




\subsubsection{Vegetation}

The amount of vegetation was determined for each soil layer present in the slopes at each sub-site. Vegetation was investigated for two reasons: (1) the root system from vegetative cover on a slope often helps to stabilize it from shallow failure, and (2) vegetation can serve to insulate the slope from air temperature fluctuations, affecting the slope's freezethaw behavior. The vegetation was analyzed by looking at digital images of the slopes. The following qualitative rankings were given based on the vegetation present: a ranking of 1 meant no vegetation was present; a ranking of 2 meant that there was some vegetation, either sparsely covered or seasonally variable; a ranking of 3 meant full vegetation was present. Each soil layer present at each sub-site was given a qualitative ranking of 1-3. When the percent of the total cliff height composed of each freeze-thaw susceptibility class was determined (as described in Section 3.3), each freeze-thaw susceptibility class was also assigned a qualitative vegetation ranking of 1-3 based on the ranking of all layers contributing to that class. If there were no soil layers belonging to a particular freeze-thaw susceptibility class, no vegetation ranking was assigned. Table 17 shows the vegetation rankings for each freeze-thaw susceptibility class at each sub-site. 
Table 17: Vegetation ranking for each sub-site

\begin{tabular}{|c|c|c|c|c|c|}
\hline \multirow{2}{*}{$\begin{array}{l}\text { Study } \\
\text { Site }\end{array}$} & \multirow[t]{2}{*}{ Sub-site } & \multicolumn{4}{|c|}{$\begin{array}{l}\text { Vegetation Ranking for Each } \\
\text { Freeze-Thaw Susceptibility Clas }\end{array}$} \\
\hline & & F4 & F3 & F2 & F1 \\
\hline \multirow{4}{*}{$\mathrm{SCN}$} & SCN1 & - & 1 & 1 & 1 \\
\hline & SCN2 & - & 3 & 2 & 3 \\
\hline & SCN3 & - & 3 & 2 & - \\
\hline & SCN4 & - & 3 & 2 & - \\
\hline \multirow{5}{*}{ SCS } & SCS5 & - & 2 & 2 & 2 \\
\hline & SCS6 & - & 2 & 2 & 2 \\
\hline & SCS7 & - & 3 & 2 & 2 \\
\hline & SCS8 & - & 2 & 2 & 2 \\
\hline & SCS9 & - & 2 & 2 & 2 \\
\hline \multirow{4}{*}{$\mathrm{CB}$} & CB1 & 2 & 1 & 2 & - \\
\hline & CB2 & 3 & 2 & 2 & - \\
\hline & CB3 & 1 & 2 & 1 & - \\
\hline & CB4 & 1 & 2 & 1 & - \\
\hline \multirow{4}{*}{ CCSP } & CCSP1 & 1 & 1 & 1 & - \\
\hline & CCSP2 & 1 & 1 & 1 & - \\
\hline & CCSP3 & 1 & 1 & 1 & - \\
\hline & CCSP4 & 1 & 1 & 1 & - \\
\hline \multirow{5}{*}{ PC } & PC_G & 3 & 3 & 1 & - \\
\hline & PC1 & 1 & 1 & 1 & - \\
\hline & PC2 & 1 & 1 & 1 & - \\
\hline & PC3 & 1 & 1 & 1 & - \\
\hline & PC4 & 1 & 1 & 1 & - \\
\hline \multirow{4}{*}{ CRE } & CRE1 & 1 & 1 & 1 & - \\
\hline & CRE2 & 1 & 1 & 1 & - \\
\hline & CRE3 & 1 & 1 & 1 & - \\
\hline & CRE4 & 1 & 1 & 1 & - \\
\hline
\end{tabular}

\subsubsection{Direction of Cliff Face}

The cardinal direction that the cliff faces was analyzed for each study site. This variable was also considered for two reasons. The first was to account for winter sun exposure. Due to the geographical location of the Calvert Cliffs, those cliffs facing the south 
generally receive more sun exposure during the winter than cliffs facing the north. Sun exposure indirectly affects the freeze-thaw behavior of the cliffs (Harlan and Nixon 1978); greater sun exposure leads to higher daily temperature variations and more freezethaw cycles, whereas less sun exposure leads to more uniform daily temperatures and less freeze-thaw cycles (Gatto 1995). The second reason to consider the direction the cliffs face is to account for wind direction. Wind direction varies along the Calvert Cliffs due to their proximity to the Chesapeake Bay and because the cliffs face a variety of cardinal directions along the bay (Miller 1995). Storms that could affect cliff recession at locations not typically affected by waves (i.e. the study sites selected) may vary their effects depending on the direction the cliff is facing, as could potential wind erosion effects. The direction that the cliffs face at each study site was determined from a map. The slope face direction varied from NE to SE for the study sites. Values were assigned to each study site to represent the slope face direction: 1 was assigned to all sites facing NE; 2 was assigned to all sites facing NE to ENE; 3 was assigned to all sites facing ENE; 4 was assigned to all sites facing ENE to E; and 5 was assigned to all sites facing SE. The slope directions for all study sites are shown in Table 18.

\section{Table 18: Direction of cliff face for all study sites}

\begin{tabular}{|c|c|c|}
\hline Study Site & Cliff Face Direction & Cliff Face Direction Value \\
\hline SCN & ENE & 3 \\
\hline SCS & ENE & 3 \\
\hline CB & NE & 1 \\
\hline CCSP & NE to ENE & 2 \\
\hline PC & ENE to E & 4 \\
\hline CRE & SE & 5 \\
\hline
\end{tabular}




\subsubsection{Rainfall Data}

Rainfall data was analyzed for the Calvert Cliffs as a whole. This variable was used, in addition to the direction of the cliff face (Section 3.4.5), to attempt to represent the effect that storms may have on recession rate. Rainfall data was obtained from the NCDC for Baltimore Washington International Airport, the closest location with available data, which is located approximately $73.5 \mathrm{~km}$ north-northwest of SCN (northernmost site) and $94 \mathrm{~km}$ north-northwest of CRE (southernmost site). The average yearly rainfall was calculated during each time intervals between the images used in the recession rate determination. Any missing data was assumed to be negligible. Just like for days of freezing and freeze-thaw cycles (described in Section 3.3), average yearly rainfall was calculated starting on April 1 of the first year and ending on March 31 of the last year of the time interval being studied. Table 19 shows the average yearly rainfall values for the time intervals used for recession rate determination.

Table 19: Average yearly rainfall for time intervals considered

\begin{tabular}{|c|c|}
\hline Time Interval & Average yearly rainfall $(\mathrm{mm} / \mathrm{yr})$ \\
\hline $2003-2006$ & 1272 \\
\hline $2006-2007$ & 1122 \\
\hline $2007-2011$ & 1147 \\
\hline
\end{tabular}

\subsection{Variable Statistics}

After the data for the variables being considered to explain recession rate was compiled, the variable statistics were analyzed. Table 20 shows the statistical information for all variables composed of continuous data, while Table 21 shows the statistical information 
for all variables composed of categorical data. These two tables contain all variables that were used to try to relate freeze-thaw and recession rate.

Table 20: Statistical Information for all Variables with Continuous Data

\begin{tabular}{|c|c|c|c|c|c|}
\hline Variable & Mean & Median & Min. & Max. & $\begin{array}{c}\text { Standard } \\
\text { Deviation }\end{array}$ \\
\hline Cliff Height (m) & 20.82 & 22.71 & 6.71 & 31.09 & 6.97 \\
\hline Slope Angle (degrees) & 46.04 & 44.30 & 35.10 & 88.30 & 10.40 \\
\hline Weighted Shear Strength (kPa) & 35.29 & 36.65 & 16.00 & 51.30 & 10.41 \\
\hline $\begin{array}{c}\text { \% of Total Height of F-T Susceptible } \\
\text { Layers - F4 (represented as a decimal) }\end{array}$ & 0.19 & 0.08 & 0.00 & 0.70 & 0.24 \\
\hline $\begin{array}{c}\text { \% of Total Height of F-T Susceptible } \\
\text { Layers - F3 (represented as a decimal) }\end{array}$ & 0.29 & 0.27 & 0.10 & 0.61 & 0.13 \\
\hline $\begin{array}{c}\text { \% of Total Height of F-T Susceptible } \\
\text { Layers - F2 (represented as a decimal) }\end{array}$ & 0.42 & 0.40 & 0.02 & 0.87 & 0.24 \\
\hline $\begin{array}{c}\text { \% of Total Height of F-T Susceptible } \\
\text { Layers - F1 (represented as a decimal) }\end{array}$ & 0.10 & 0.00 & 0.00 & 0.45 & 0.17 \\
\hline Number of Days of Freezing per Year & 24.25 & 25.75 & 21.00 & 26.00 & 2.32 \\
\hline Number of Freeze-Thaw Cycles per Year & 21.50 & 22.00 & 18.00 & 24.50 & 2.69 \\
\hline Rainfall per Year (mm) & 1180 & 1147 & 1122 & 1272 & 66.04 \\
\hline Recession Rate (m/year) & 0.38 & 0.26 & 0.00 & 1.58 & 0.41 \\
\hline
\end{tabular}

Table 21: Statistical Information for all Variables with Categorical Data

\begin{tabular}{|c|c|c|c|c|c|}
\hline \multirow{2}{*}{ Variable } & \multicolumn{5}{|c|}{ Frequency of Value } \\
\cline { 2 - 6 } & 1 & 2 & 3 & 4 & 5 \\
\hline${\text { Vegetation for F-T Susceptible Layers }-\mathrm{F} 4^{1}}^{1}$ & 14 & 1 & 2 & N/A & N/A \\
\hline${\text { Vegetation for F-T Susceptible Layers }-\mathrm{F} 3^{1}}^{1}$ & 14 & 7 & 5 & N/A & N/A \\
\hline${\text { Vegetation for F-T Susceptible Layers }-\mathrm{F} 2^{1}}^{1}$ & 16 & 10 & 0 & N/A & N/A \\
\hline${\text { Vegetation for F-T Susceptible Layers }-\mathrm{F} 1^{1}}^{2}$ & 1 & 5 & 1 & N/A & N/A \\
\hline Direction of Cliff Face $^{2}$ & 4 & 4 & 9 & 5 & 4 \\
\hline
\end{tabular}

${ }^{1}$ For vegetation: $1=$ no vegetation present; $2=$ some vegetation, sparsely covered or seasonally variable; 3 = full vegetation present.

${ }^{2}$ For cliff face direction: $1=\mathrm{NE} ; 2=\mathrm{NE}$ to ENE; $3=\mathrm{ENE} ; 4=\mathrm{ENE}$ to E; $5=\mathrm{SE}$. 


\section{Chapter 4: Data Analysis}

Once the data for all of the variables was complied, the relationship between the variables (described in detail in Section 3) and recession rate was studied.

\subsection{Spatial and Temporal Trends in Recession Rate}

Before a relationship between recession rate and freeze-thaw could be analyzed, the spatial and temporal trends in recession rate were analyzed. Figure 9 and Figure 10 provide a way to visualize the recession rates calculated for each sub-site during each time interval. As a general trend for all study sites, as seen in Figure 9 and Figure 10, it can be said that 2003-2006 had smaller recession rates than 2006-2007 or 2007-2011 did. The recession rates for 2006-2007 and 2007-2011 were similar for both time intervals at each study site, with slight variations between the time intervals for each study site and sub-site. As a general trend with some exceptions, the recession rates in the southern study sites are larger than those in the northern study sites for each time interval.

Figure 9 shows spatial and temporal trends of recession rate for the northern study sitesSCN, SCS, and CB. Looking at this figure, several trends become apparent. SCN consistently shows low recession rates for all sub-sites. While the 2003-2006 time interval has the lowest recession rates for $\mathrm{SCN}$, all time intervals shows similar recession rates for all sub-sites in each time interval. Spatially, all of these sub-sites are close together. There is a significant variation in slope height for the $\mathrm{SCN}$ sub-sites $(6.7 \mathrm{~m}$ to $20.7 \mathrm{~m}$ ), but the other sub-site specific variables (slope angle, weighted shear strength, 
percent height of freeze-thaw susceptible layers) are all consistent; this could explain the uniform nature of recession at SCN. For SCS and $\mathrm{CB}$, there is more spatial variation in recession rate for each sub-site, and there is also more significant temporal recession rate variation. For SCS, recession is generally lowest in 2003-2006, higher in 2006-2007, and highest in 2007-2011. Each sub-site maintains the same relative trends throughout the time interval - those with low recession compared to the other sub-sites in one time interval are also low in the other time intervals, and those with higher recession compared to the other sub-sites in one time interval are also higher in the other time intervals. The same can be said for CB; however, there is one sub-site that shows a significantly higher recession rate in 2006-2007 than any other sub-sites in any other time interval. If this value correctly represents the measured and calculated recession rate for that sub-site in that time interval, it could be a reflection of the episodic recession that occurs along the cliffs; this time interval reflects a single year and could have captured a larger failure event that may be otherwise damped when considering multiple years of recession. It could also be a reflection of the uncertainty of the recession rate measurement and calculation procedure, since much of the process of interpreting aerial photography is subjective and may be introducing human error into the analysis. The CB sub-site with the high recession rate does have a significantly higher height and slope angle and lower weighted shear strength than the other CB sub-sites, which could help to explain the higher recession rate; if this were the only part of the explanation, however, the recession rate for this sub-site should be higher in all time intervals, not just one.

Figure 10 shows spatial and temporal trends of recession rate for the southern study sites - CCSP, PC, and CRE. Several trends can also be noted for these study sites from 
this figure. For CCSP, recession rate is relatively constant for all sub-sites across the time intervals. Recession was lowest in 2003-2006, higher in 2007-2011, and highest in 20062007. For PC, recession rate is consistently low for 2003-2006 and 2006-2007. For 20072011, there is a slight increase in recession rate for most sub-sites. However, in 20072011, there is one sub-site with a recession rate significantly higher than all other subsites in all other time intervals. There is no significant variation in any sub-site specific variable for this sub-site from the rest of the PC sub-sites. As discussed previously for one of the CB sub-sites, it could be a representation of episodic cliff recession or a reflection of the uncertainty of the recession rate measurement and calculation procedure. The sub-site dependent variables do not differ significantly for any of the PC sub-sites, so that should not have an impact on the recession rate differences. CRE consistently has some of the highest recession rates of all the study sites for all time intervals. There is no direct relationship between the CRE sub-sites experiencing high recession rates and the sub-site specific variables. Three of the four CRE sub-sites experience recession rates above 1 meter per year in a time interval, with two of those three above 1.5 meters per year. This again could represent episodic failures or uncertainty in recession rate determination. 


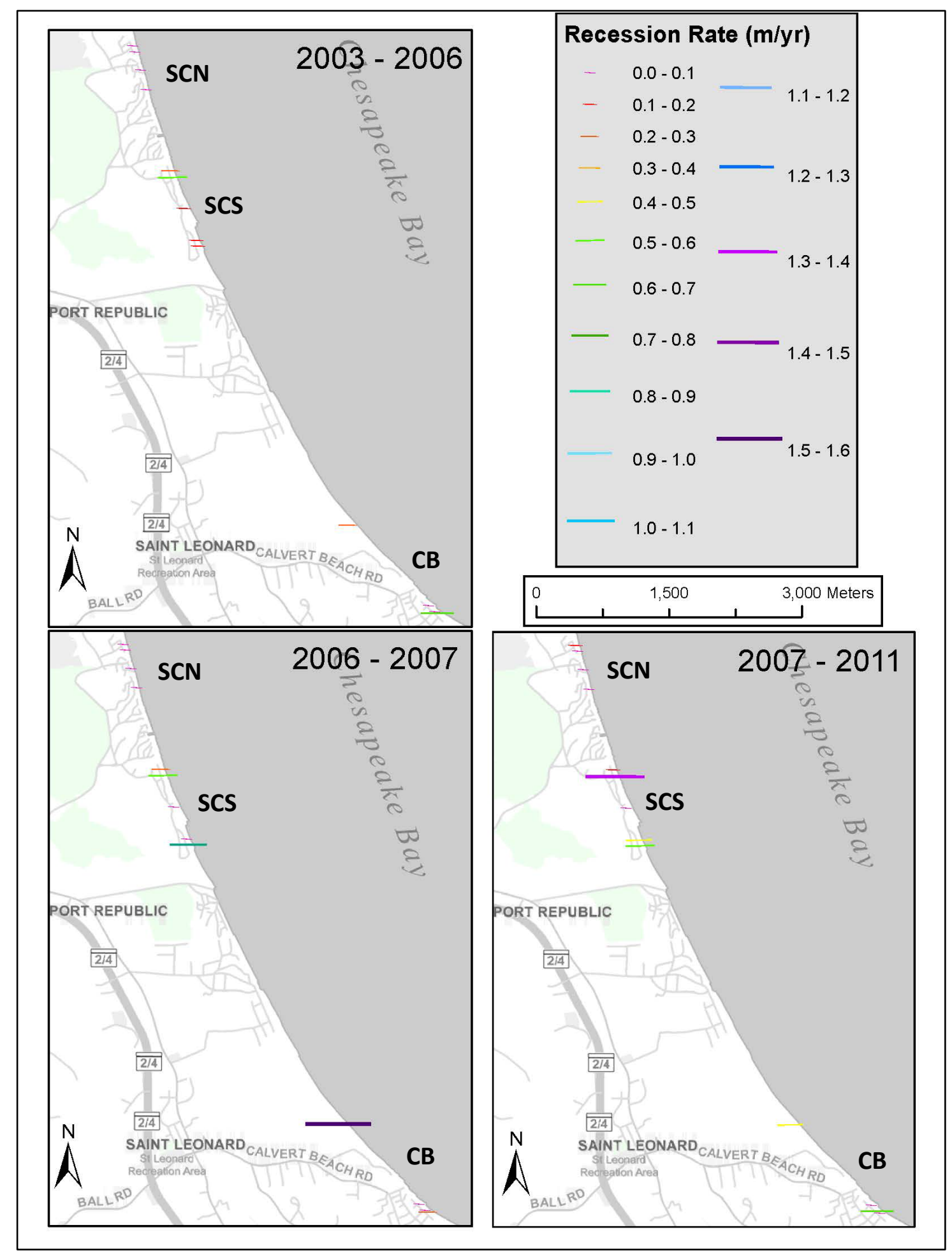

Figure 9: Spatial and Temporal Trends for Northern Study Sites SCN, SCS, and CB (map data source: Calvert County Government 2012) 


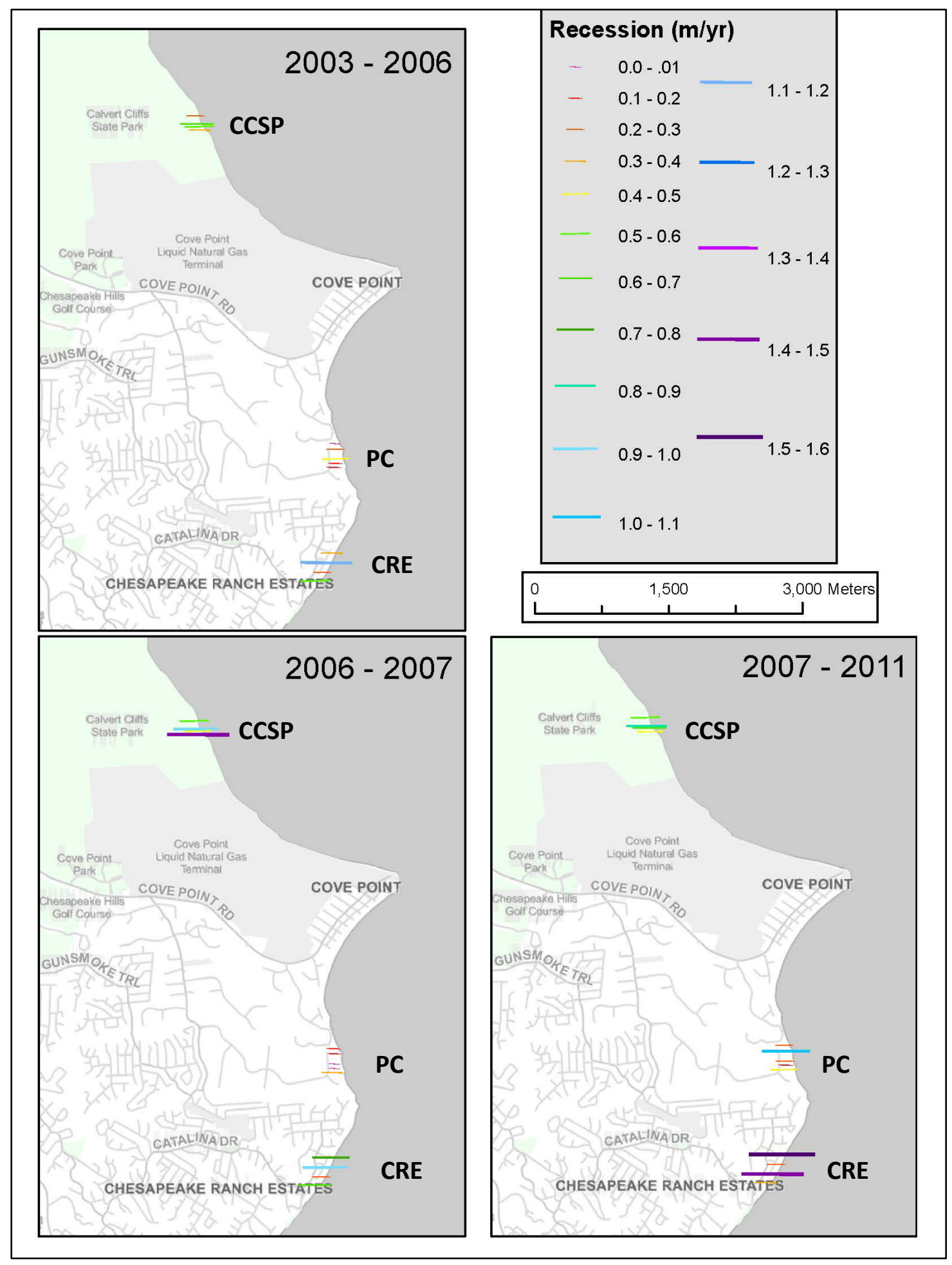

Figure 10: Spatial and Temporal Trends for Northern Study Sites CCSP, PC, and CRE (map data source: Calvert County Government 2012) 


\subsection{Initial Multivariate Linear Regression}

After the spatial and temporal trends of recession rate were investigated, the relationship between recession rate and all other variables was explored. The goal of this data exploration was to find a multivariate linear regression to represent the relationship between recession rate and the independent variables. A summary of the variables considered to explain recession rate are shown in Table 22

Table 22: Variables Considered for Multivariate Linear Regression

\begin{tabular}{|l|}
\hline Variables Considered \\
\hline Cliff Height \\
\hline Slope Angle \\
\hline Days of Freezing \\
\hline Number of Freeze-Thaw Cycles \\
\hline $\begin{array}{l}\text { Soil Layer Freeze-Thaw Susceptibility } \\
\text { (\% Height F1 through F4) }\end{array}$ \\
\hline Weighted Soil Shear Strength (Su) \\
\hline Cliff Face Direction \\
\hline Vegetation (F1 through F4) \\
\hline Rainfall \\
\hline
\end{tabular}

The program R 2.15.0 was used to explore the relationships between the variables and recession rate and to determine a multivariate simple linear regression for recession rate and for statistical analysis of the regression model. The initial regression generated was:

$$
\begin{aligned}
\text { Recession Rate }= & 0.0160 * \text { Slope Angle }-1.0684 * \% \text { Height F3 }-1.2867 * \% \text { Height F2 } \\
& -0.1162 * \text { Vegetation F1 }+0.2057 * \text { Face Direction } \\
& +0.0279 * \text { F-T Cycles }-0.6698
\end{aligned}
$$

A way to visualize this regression is using an observed versus predicted plot. The observed values are the recession rates determined for each sub-site using the aerial 
photographs. The predicted values are the recession rates determined using the regression equation. For a perfect regression, the predicted values would equal the observed values, which can be represented by a 1:1 line. The predicted versus observed plot for this regression can be found in Figure 11. From this plot, it can be seen that some of the data lies close to the 1:1 line, but there is also a good deal of scatter from this line for much of the data.

The validity of this regression can be assessed using statistical evaluations, as well as looking at what the selection of certain variables and their significance in the regression means. The statistical evaluation will be discussed first.

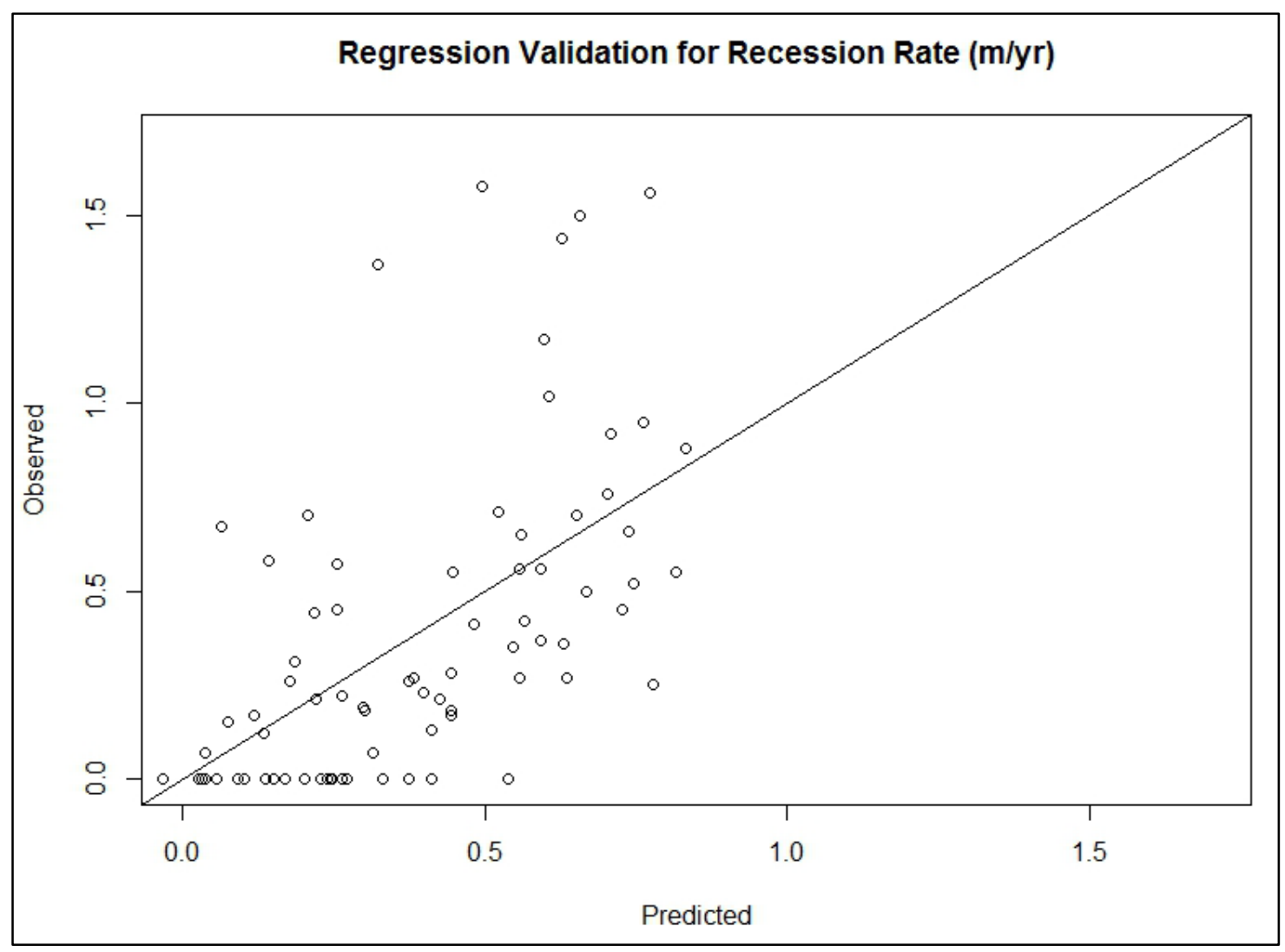

Figure 11: Predicted versus Observed Plot for initial Multivariate Linear Regression 


\subsubsection{Statistical Significance of the Initial Model}

There are several statistical measures that can be used to evaluate a regression model.

Some of these statistics assess the regression model, while others assess the individual variables considered in the regression model. Table 23 presents a summary of the modelassessment statistics for the initial regression model, and Table 24 presents a summary of the variable-assessment statistics for the initial regression model.

Table 23: Summary of Model-Assessment Statistics for Initial Multivariate Regression Model

\begin{tabular}{|c|c|c|c|}
\hline Sample Size & $\mathrm{R}^{2}$ & Adjusted $\mathrm{R}^{2}$ & RMSE \\
\hline 78 & 0.35 & 0.30 & 0.33 \\
\hline
\end{tabular}

Table 24: Summary of Variable-Assessment Statistics for Initial Multivariate Regression Model

\begin{tabular}{|c|c|c|c|c|c|}
\hline Variable & $\begin{array}{c}\text { Coefficient } \\
\text { Estimate }\end{array}$ & $\begin{array}{c}\text { Std. } \\
\text { Error }\end{array}$ & t-value & $\operatorname{Pr}(>|\mathrm{t}|)$ & Significance Level $^{\text {a }}$ \\
\hline (Intercept) & -0.6698 & 0.3993 & -1.677 & $9.79 \%$ &. \\
\hline Slope Angle & 0.0160 & 0.0044 & 3.618 & $0.06 \%$ & $* * *$ \\
\hline \% Height F3 & -1.0684 & 0.5968 & -1.790 & $7.77 \%$ &. \\
\hline$\%$ Height F2 & -1.2867 & 0.2857 & -4.503 & $0.003 \%$ & $* * *$ \\
\hline Vegetation F1 & -0.1163 & 0.0507 & -2.295 & $2.50 \%$ & $*$ \\
\hline Face Direction & 0.2057 & 0.0587 & 3.508 & $0.08 \%$ & $* * *$ \\
\hline F-T Cycles & 0.0279 & 0.0147 & 1.906 & $6.07 \%$ &. \\
\hline
\end{tabular}

One statistical method of regression model analysis is root mean squared error (RMSE).

RMSE serves as an estimate of the standard deviation of the random errors in the regression. A small RMSE indicates a more fitting model (Pardoe 2012). For this initial regression, the RMSE value was 0.33 , as seen in Table 23. This RMSE can be compared to the RMSE of other regression models to determine which model is the most fitting. 
Another measure of model evaluation is the coefficient of determination $\left(R^{2}\right) . R^{2}$ is a way to compare the model to a situation where no independent variables are available. The regression model, which takes into account the independent variables, should be able to predict recession rate more accurately than the random generation of recession rate values that results when no independent variables are used. The farther the recession rates predicted using the regression model are from the recession rates predicted using no independent variables, the higher the $\mathrm{R}^{2}$ value is. The lower bound of $\mathrm{R}^{2}$ is 0 , which indicates that the regression model is no better at predicting recession rate than random generation is. The upper bound of $\mathrm{R}^{2}$ is 1 , which indicates a perfect model where the observed values equal the predicted values. $\mathrm{R}^{2}$ also serves as a way to compare models to determine which is the most fitting, as there is no definite "reference value" for $\mathrm{R}^{2}$ that indicates a good or bad model. However, it should be noted that as more variables are added to the regression model, $\mathrm{R}^{2}$ will increase regardless of if the model improves with the addition of the new variable or not; this is an effect of the way that $\mathrm{R}^{2}$ is calculated (Pardoe 2012). For this initial regression, the $\mathrm{R}^{2}$ value was 0.35 , as seen in Table 23. Having an $\mathrm{R}^{2}$ of 0.35 indicates that about $35 \%$ of the recession rate can be explained by the variables utilized in this regression model.

Adjusted $\mathrm{R}^{2}$ is another way to assess the validity of the regression model. Since $\mathrm{R}^{2}$ cannot assess if the addition of additional variables improves the model, as discussed previously, it would be useful to have another way to assess the value of adding variables. Adjusted $\mathrm{R}^{2}$ does exactly that. As independent variables are added to a model, if the adjusted $\mathrm{R}^{2}$ value increases, it means that the model was improved by the addition of the variables; however, if the adjusted $\mathrm{R}^{2}$ decreases, it means that the variables added to the model were 
insignificant and did not add value to the model (Pardoe 2012). For the initial regression the adjusted $R^{2}$ was 0.30 , as seen in Table 23 . This adjusted $R^{2}$ value can be compared to regression models considering different independent variables to determine which model is most fitting without considering insignificant variables.

Another way to consider the importance of independent variables used by the regression model to predict recession rate is by using the regression parameter hypothesis test. This involves performing a hypothesis test on all variables used in the regression model. Each individual variable included in the regression is tested to see, when all other variables are held constant, if there is a linear relationship between that variable and recession rate. A null hypothesis is stated for each variable, which sets the variable equal to zero, to check for this linear relationship; if the null hypothesis is not rejected, it indicates that there is no linearity between the variable and recession rate. The t-statistic is calculated and then compared to the t-distribution at a particular significance level, called the critical value; if the absolute value of the t-statistic is greater than the critical value, then the null hypothesis is rejected and the variable is considered significant for the considered significance level. The sum of the area under the t-distribution for absolute values greater than the t-statistic gives the observed significance level, also called the p-value or the $\operatorname{Pr}$ $(>|t|)($ Pardoe 2012). The t-statistics and $\operatorname{Pr}(>|t|)$ can be seen in Table 24 for all variables used in the initial regression. This shows that slope angle, \% Height F2, and face direction reject the null hypothesis in much lower significance levels than $\%$ Height F3, Vegetation F1, and freeze-thaw cycles, indicating that they are more significant. This also indicates that the intercept has little significance. Those variables that were not included 
in this regression model rejected the null hypothesis for any significance level, proving to be insignificant.

A final way to analyze the regression model is to look at the model residuals. Residuals are a measure of how each predicted value deviates from the corresponding observed value. For a well-fitting linear regression model, the residuals should be random values that are normally distributed (Fox and Weisberg 2011). Figure 12 provides a way to visually analyze the residuals for the initial multivariate linear regression. For a perfect regression, the plot in the upper left, Figure 12 (a), should show the residuals being randomly distributed with respect a horizontal line; this line represents a residual error of zero. Since the line is not perfectly horizontal, it indicates that there is some trend to the data, which means that the residuals are not all random. The upper right plot, Figure 12 (b), should also show data randomly distributed around a horizontal line and not have any clear trend; the red line in this plot also indicates that the residuals do have some trend, meaning that the residuals are not all random. The bottom left plot, Figure 12 (c), is a QQ plot (which is discussed more thoroughly in Section 4.3). If the data were normally distributed, they would fall along the 1:1 line; since a good amount of the data deviates from the 1:1 line, it is not fully normally distributed. The bottom right plot, Figure 12 (d), shows Cook's Distance, a measure to identify potential outliers. Any data with a Cook's Distance greater than 1 indicates that either the data are outliers or the regression model does not represent the data well. While no data falls above 1 , there are still some data that indicate that either outliers need to be addressed or the model needs to be improved. 


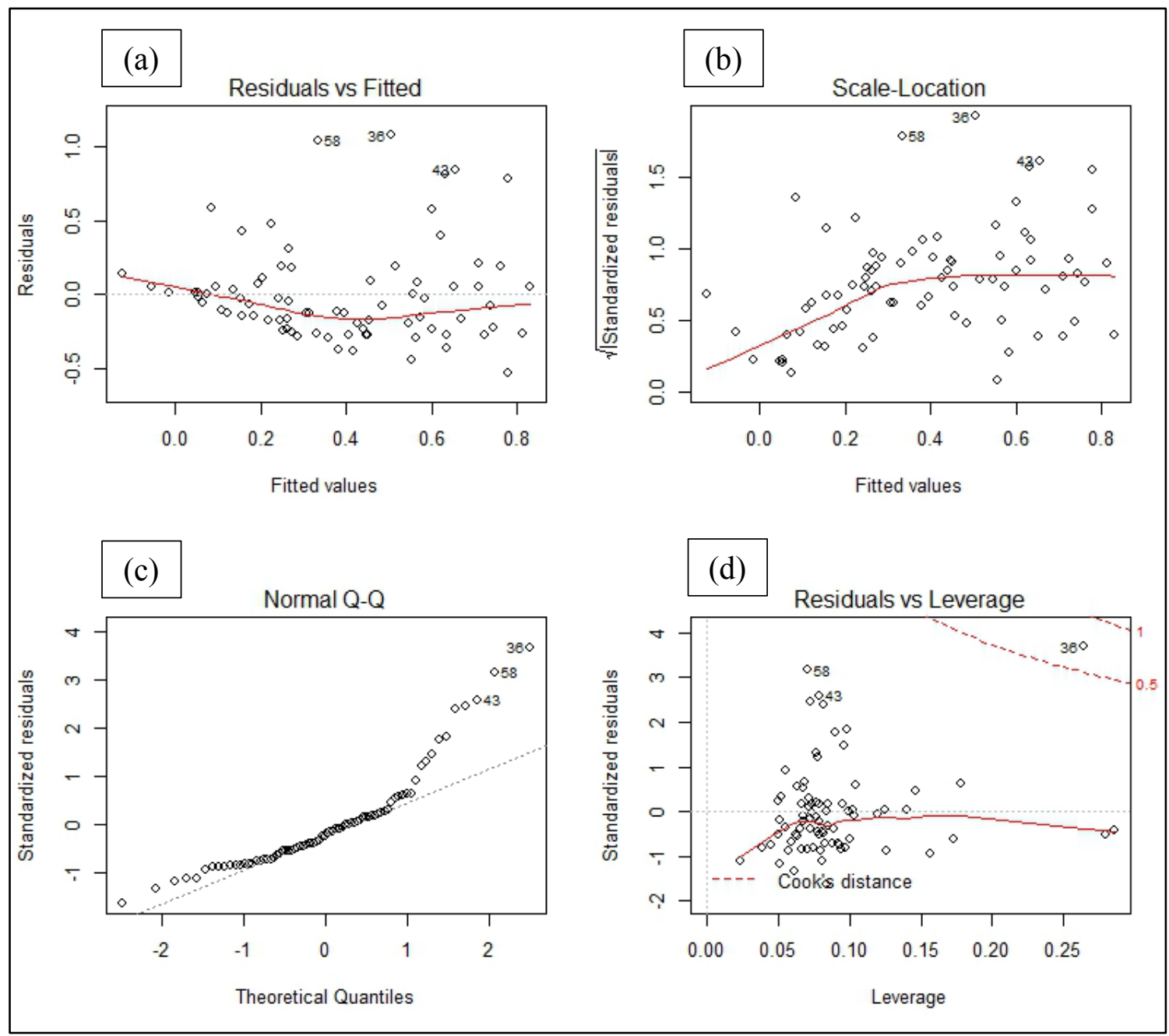

Figure 12: Visualization of Residuals for Initial Multivariate Linear Regression - (a) Scatterplot of Residual Errors vs. Fitted Values, (b) Scatterplot of Standardized Residual Errors vs. Fitted Values, (c) Normal Q-Q Plot, and (d) Cook's Distance Plot

\subsubsection{Significance of the Variables Considered in the Initial Model}

The variables that were selected to explain recession rate in the initial multivariate linear regression were the slope angle, number of freeze-thaw cycles, cliff face direction, percent of total height of soil layers with F3 freeze-thaw susceptibility, percent of total height of soil layers with F2 freeze-thaw susceptibility, and the vegetation condition for 
the soil layers with F1 freeze-thaw susceptibility. Once these variables were selected, the significance of these variables was studied.

The variables that had the highest significance to the initial regression were slope angle, percent of total height of soil with freeze-thaw susceptibility F2, and cliff face direction, based on having the lowest observed significance levels of $0.06 \%, 0.003 \%$, and $0.08 \%$, respectively. The coefficient assigned to slope angle was 0.0160 , indicating a positive correlation with recession rate. As slope angle increases, it makes sense that the recession rate should also increase. The coefficient assigned to the percent of height of soil with freeze-thaw susceptibility F2 was -1.2867 . Freeze-thaw susceptibility class F2 is one of the least susceptible classes of soil. It makes sense, then, for it to have a negative relationship with recession rate; as the percent of height of F2 soils increases, it makes sense that recession rate should decrease. The coefficient assigned to cliff face direction was 0.2057 , indicating a positive relationship with recession rate. Cliff face is a categorical variable, so the trend in the relationship between cliff face and recession rate is not telling. All that it indicates is that cliff face direction has an impact on recession rate.

Vegetation conditions for the soil layers with F1 freeze-thaw susceptibility had moderate significance to the initial regression, with an observed significance level of $2.5 \%$. The coefficient assigned to vegetation conditions of F1 soil was -0.1137 . While F1 is the least susceptible soil class, increasing vegetative cover anywhere along the cliff face should decrease recession. The negative relationship that vegetation conditions of F1 soil has with recession rate is reasonable. 
The number of freeze-thaw cycles and the percent of total height of soil with freeze-thaw susceptibility F3 had little significance to the initial regression, with observed significance levels of $6.07 \%$ and $7.77 \%$, respectively. The coefficient assigned to the number of freeze-thaw cycles was 0.0279 . The positive relationship that this coefficient indicates exists with recession rate is significant. As the number of freeze-thaw cycles increases, the recession rate should increase, which indicates that this relationship is reasonable. The coefficient assigned to the percent of total height of F3 soil was -1.0684. The negative relationship with recession rate that it indicates is troubling. Freeze-thaw susceptibility class F3 is one of the most susceptible soil classes. It would make sense that as the height of a highly freeze-thaw susceptible layer increases, the recession rate would also increase. However, this coefficient indicates a negative relationship with recession rate, which represents the opposite trend. This warrants more investigation.

The intercept also had significance to the initial regression, since it had an observed significance level of $9.79 \%$. If freeze-thaw is the only factor controlling recession rate, which is what this study is trying to analyze, then if there is no freeze-thaw, there should not be any recession. The low significance that the intercept provided, as well as little reason to believe that there should be one, provides rationale for setting the intercept to zero.

It is also important to assess why, other than statistically, the remaining variables may not have been included in the initial multivariate regression model. Cliff height seems critical, as taller cliffs that are evolving due to destabilizing forces reach instability faster than shorter cliffs evolving due to the same destabilizing forces (Edil and Vallejo 1980). 
There was no noted uncertainty in the determination of cliff height. Cliff height should be analyzed further. Since the number of freeze-thaw cycles was included in the initial regression, it is not concerning that days of freezing was not; freeze-thaw cycles still provides a metric of the amount of freeze-thaw occurring to the regression. Rainfall being omitted from the regression is not surprising. While rainfall was considered in an attempt to quantify storm activity that could potentially cause recession that is not freeze-thaw related, the average rainfall per year amounts for each time interval were within 150 millimeters of each other, which was likely too close to provide any value to the regression. The vegetation for soil in freeze-thaw susceptibility classes F4, F3, and F2 being omitted from the regression is also not surprising. Vegetation is a categorical variable with only three categories (full vegetation, partial vegetation, no vegetation), and may not provide enough variation to provide value to the regression. Additionally, the method used for determining vegetation was very subjective and may not be representing the actual conditions as accurately as other variables are, so having these variables omitted is not concerning. The percent height of soil with freeze-thaw susceptibility of F1 and F4 seem to be critical variables, especially F4. Not all study sites contained F1 or F4 soils in their slopes. Soil with an F4 susceptibility class is the most freeze-thaw susceptible, which means that presence of F4 soil should lead to higher recession. While not present at all sites, this is likely a critical variable that should be investigated further. Soil with an F1 susceptibility class is the least freeze-thaw susceptible, which means that the presence of F1 should lead to lower recession rates. However, having the higher freeze-thaw susceptibility classes represented in the regression model would likely mean that the lower freeze-thaw susceptibility classes are redundant. Lastly, shear strength is 
another variable that is likely critical. The shear strength of the soil is a measure of the magnitude of driving forces, especially freeze-thaw, that the soil can withstand before failing. Lower shear strength should lead to a higher recession rate, so this variable should be investigated further.

In addition to investigating the significance of the variables used and not used in the regression model, the recession rate predicted using these variables in the initial regression should be analyzed. Returning to Figure 11, the observed versus predicted plot for the initial multivariate linear regression, several items should be noted. The first trend that should be noted is that much of the data falls below the 1:1 line, indicating that it is being over-predicted. This is counteracted significantly by five data points that are significantly under-predicted. While the highest predicted value for these five data points is about 0.8 meters per year, the observed values are all larger than 1.3 meters per year. These data are clearly outliers, which will be discussed more in Section 4.3. The last item to note is that the regression model fails to predict any recession rate above 0.83 meters per year, while observed recession rates are as high as 1.58 meters per year. This demonstrates a limitation to this initial multivariate linear regression that will also be addressed more thoroughly in Section 4.3.

\subsection{Data Transformation}

Even though a meaningful relationship was found between recession rate and some of the variables considered, this relationship does not include all variables, nor do all of the 
trends make sense (as discussed previously in Section 4.2). For this reason, data transformation of the variables was explored. This was conducted using R 2.15.0.

The variables that were used to explain recession rate in the initial multivariate linear regression were the slope angle, number of freeze-thaw cycles, cliff face direction, percent of total height of soil layers with F2 freeze-thaw susceptibility, and the vegetation condition for the soil layers with F1 freeze-thaw susceptibility. The one variable that was included in the initial multivariate linear regression that could not be explained is the percent of total height of soil layers with F3 freeze-thaw susceptibility. This variable requires further exploration. There were other variables that were excluded from the initial regression that seem too important to be ignored, as discussed in Section 4.2. These variables were weighted shear strength, cliff height, and percent of total height of soil layers with F4 freeze-thaw susceptibility. These variables were explored to determine if data transformation could help fit them into the multivariate linear regression.

The histograms of all of the variables considered can be seen in Figure 13 through Figure 16. The histogram for each variable shows the distribution of the data. Normally distributed data do not need to be transformed. Data that is not normally distributed can potentially benefit from transformation attempting to reach normality, as an assumption of any linear regression, as well as most other statistical procedures, is that all data is normally distributed (Thode 2002). Multivariate linear regressions, like those being used in this study, can tolerate minor deviations from the assumption of normality; only distinct violations to normality, which are difficult to clearly define, should be concerning (Pardoe 2012). Still, all variables containing data that are not normally distributed should 
go through the transformation process to attempt to re-express the variables to satisfy the normality assumption.

Another way to qualitatively visualize normality is by using quantile-quantile (Q-Q) plots. Data that are normally distributed will follow the diagonal line plotted with the data; if the data deviates from this line, it is not normally distributed. The Q-Q plots for the continuous variables are shown in Figure 17 through Figure 18. Q-Q plots are not shown for the categorical variables or the variables with only three distinct values, as these plots cannot represent these variables in a meaningful way.

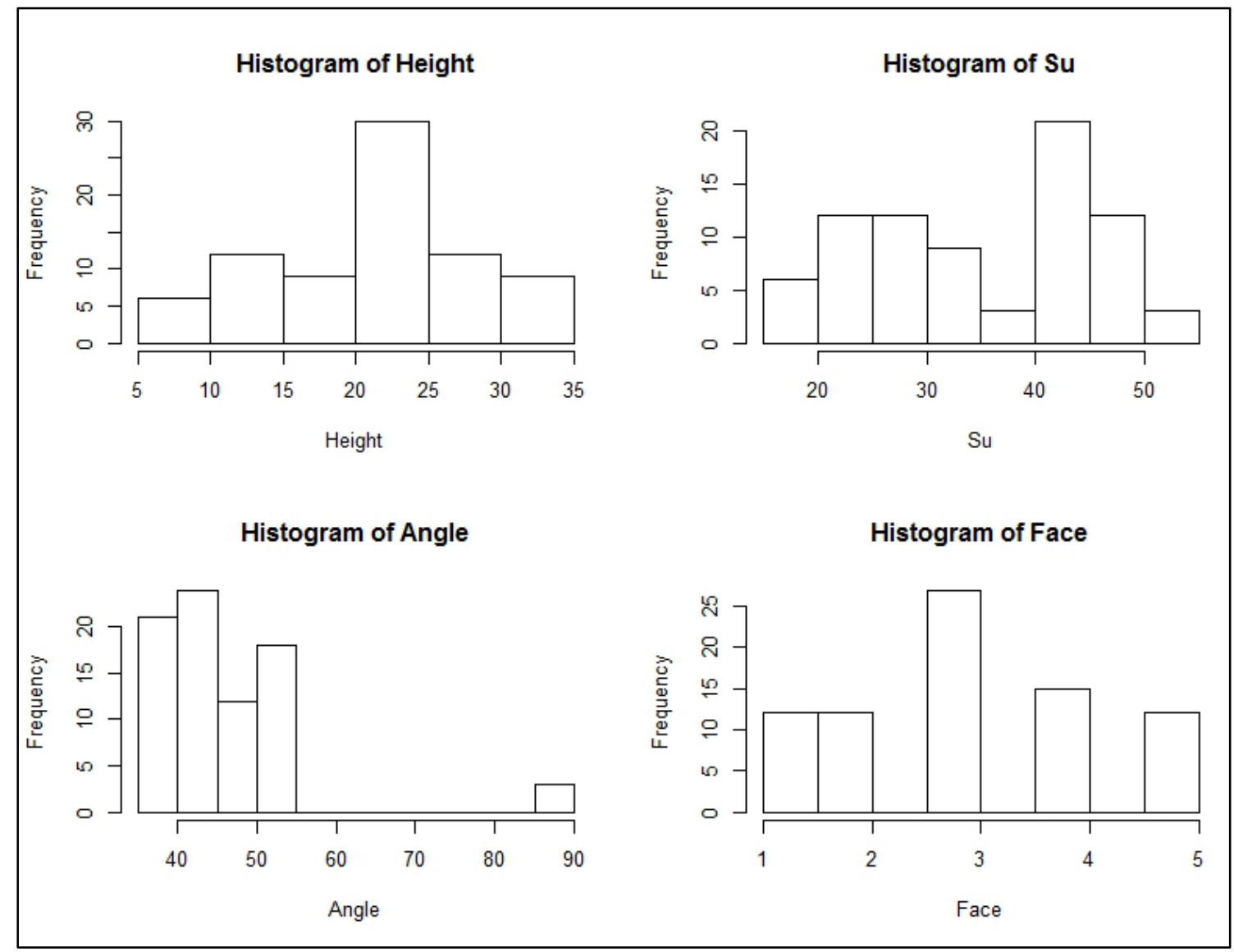

Figure 13: Histograms for Cliff Height (Height), Slope Angle (Angle), Weighted Shear Strength (Su), and Cliff Face Direction (Face) 


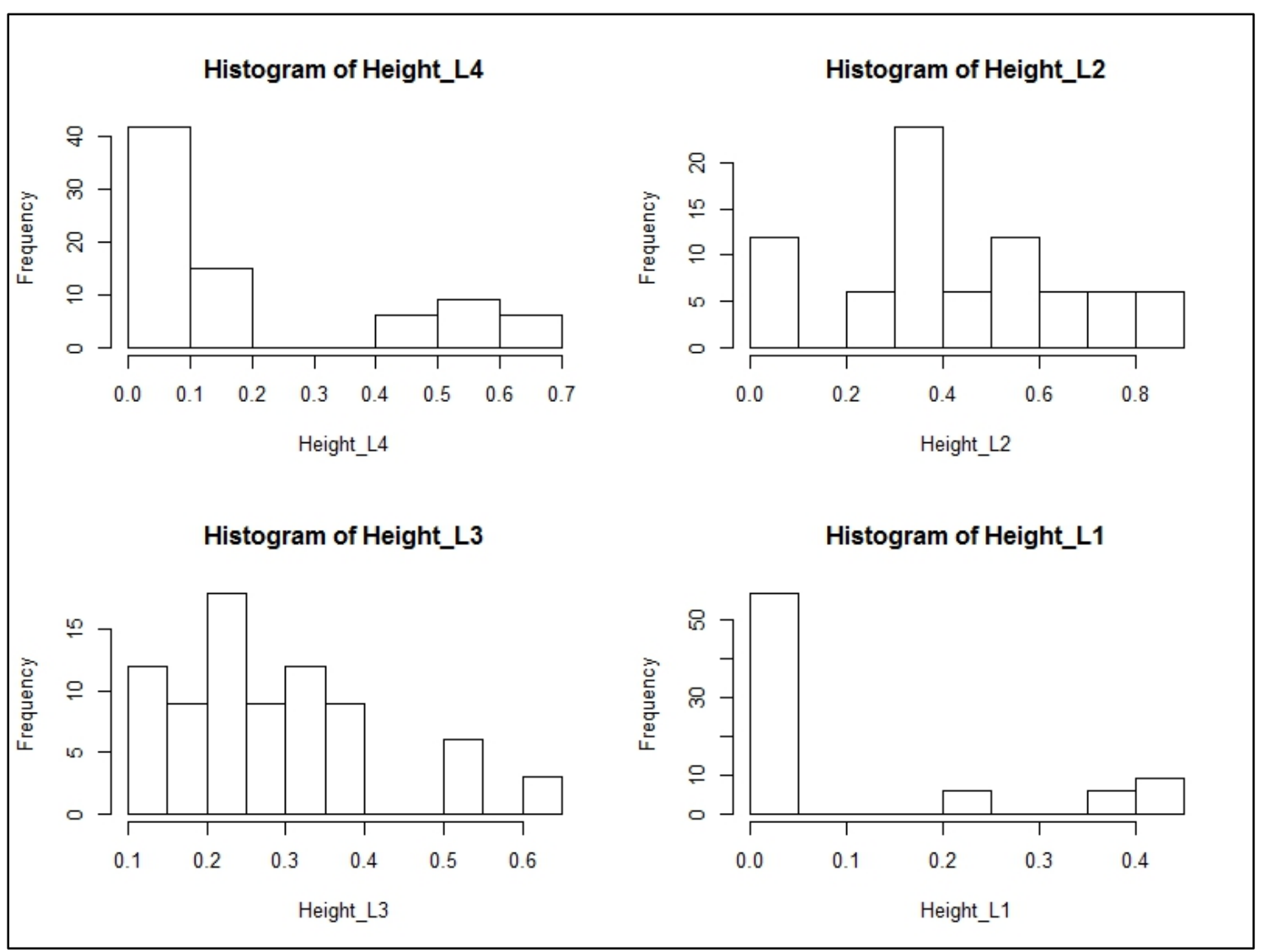

Figure 14: Histograms for Percent of Total Cliff Height Composed of Freeze-Thaw Susceptibility Classes F4 (Height_L4), F3 (Height_L3), F2 (Height_L2), and F1 (Height_L1) 


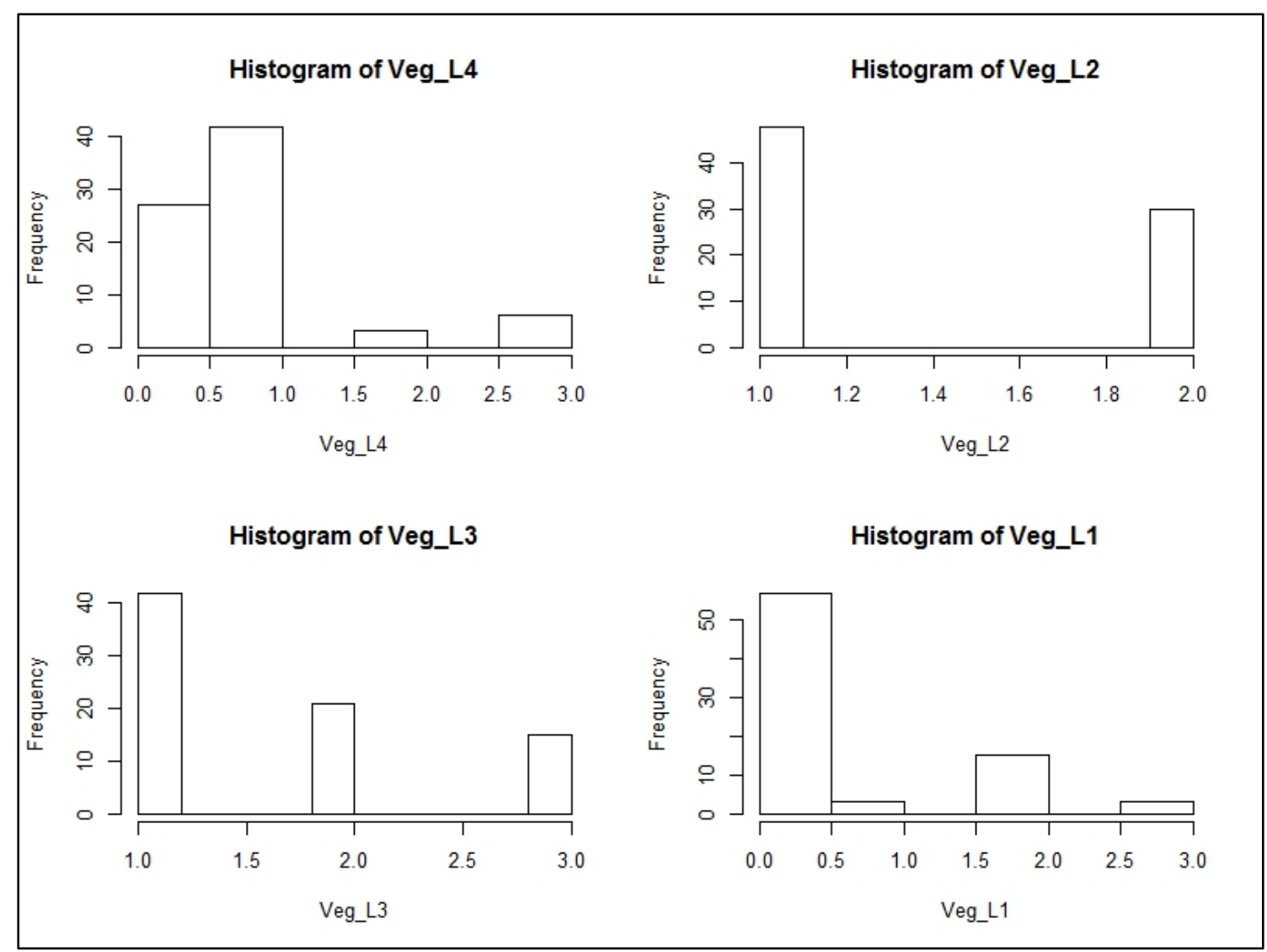

Figure 15: Histograms for Vegetation Condition of Soil with Freeze-Thaw Susceptibility Class F4 (Veg_L4), F3 (Veg_L3), F2 (Veg_L2), and F1 (Veg_L1) 


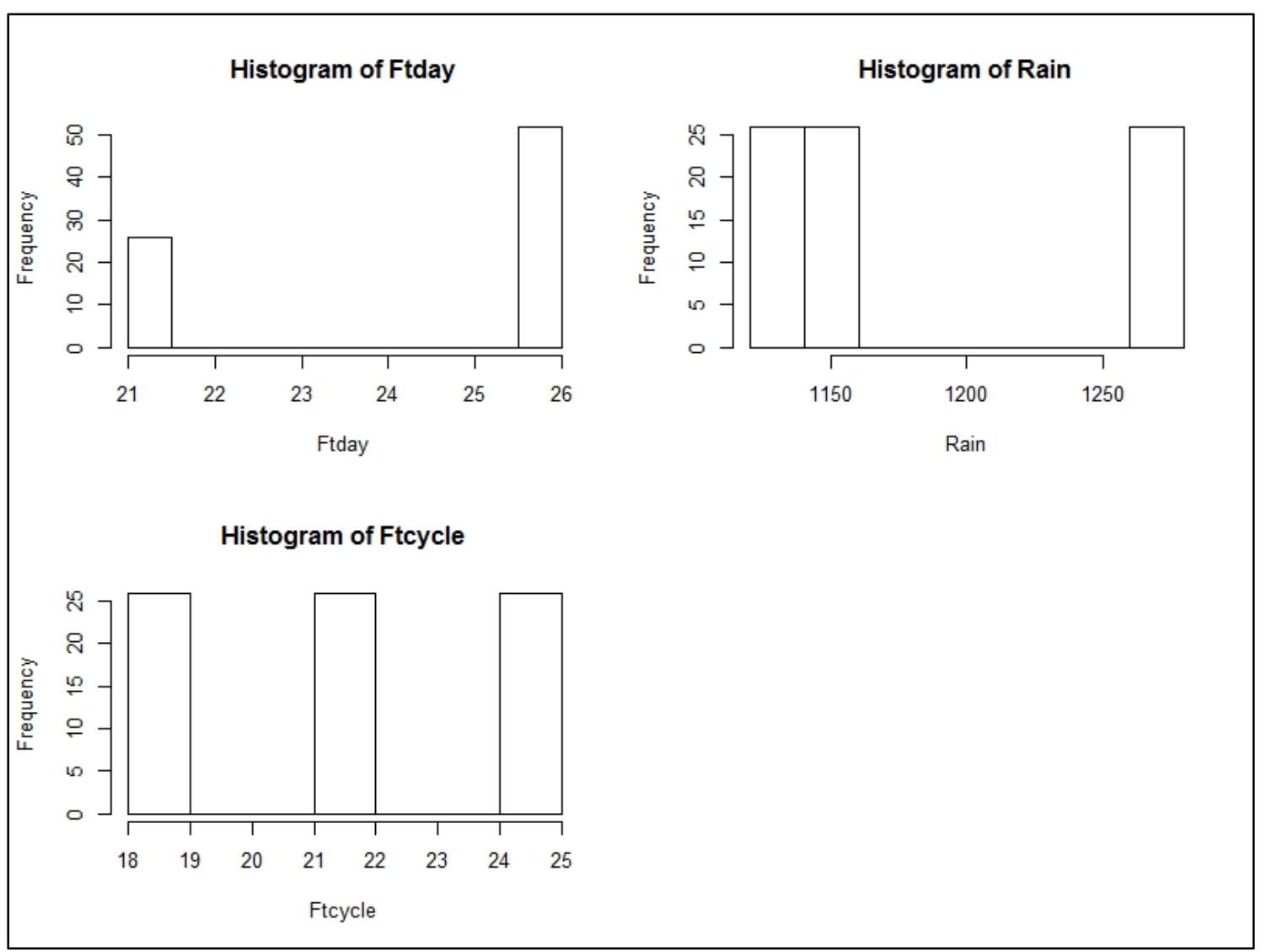

Figure 16: Histograms for Number of Days of Freeze-Thaw (Ftday), Number of Freeze-Thaw Cycles (Ftcycle), and Amount of Rainfall (Rain) 


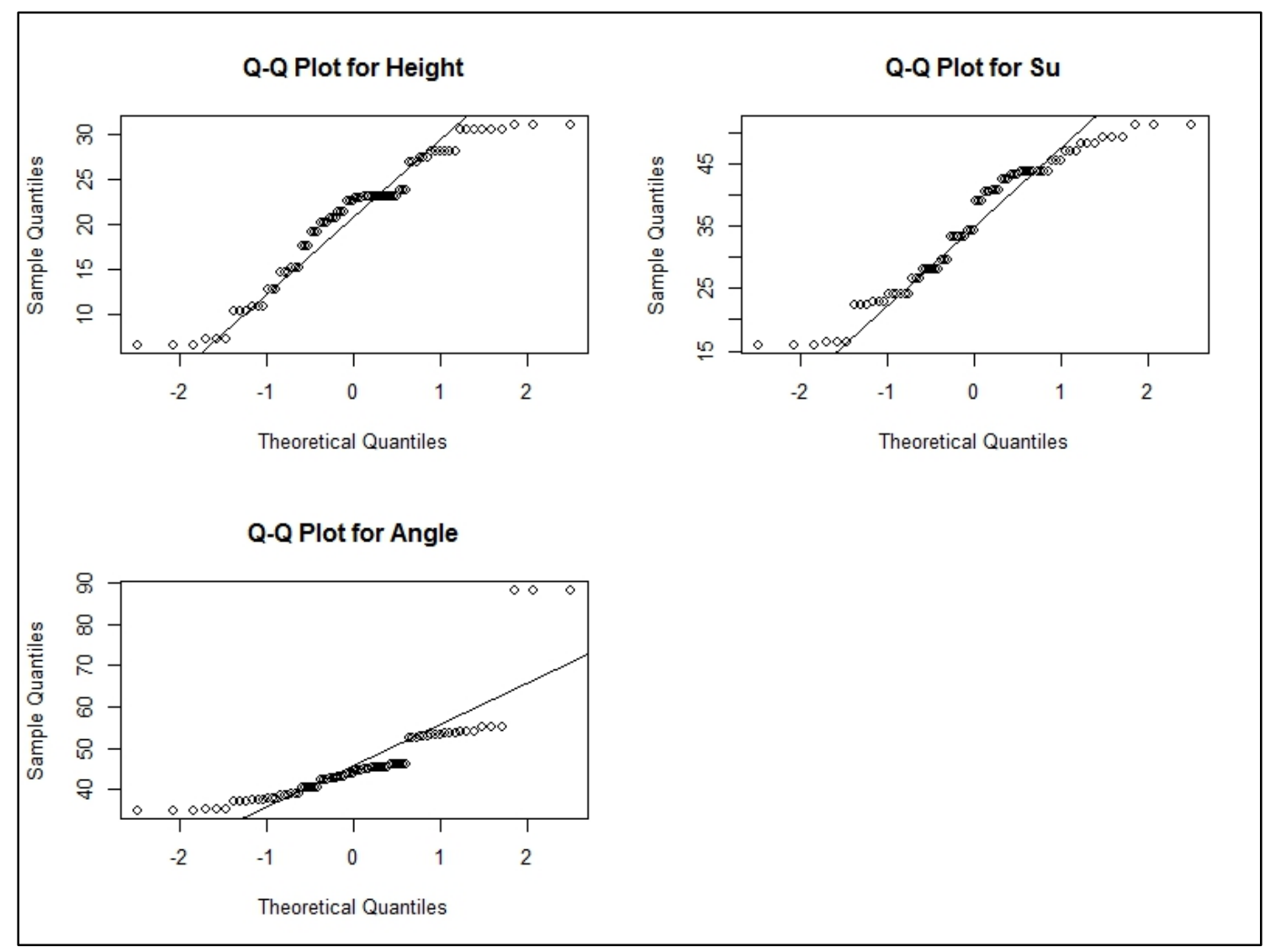

Figure 17: Q-Q Plots for Cliff Height (Height), Slope Angle (Angle), and Weighted Shear Strength (Su) 


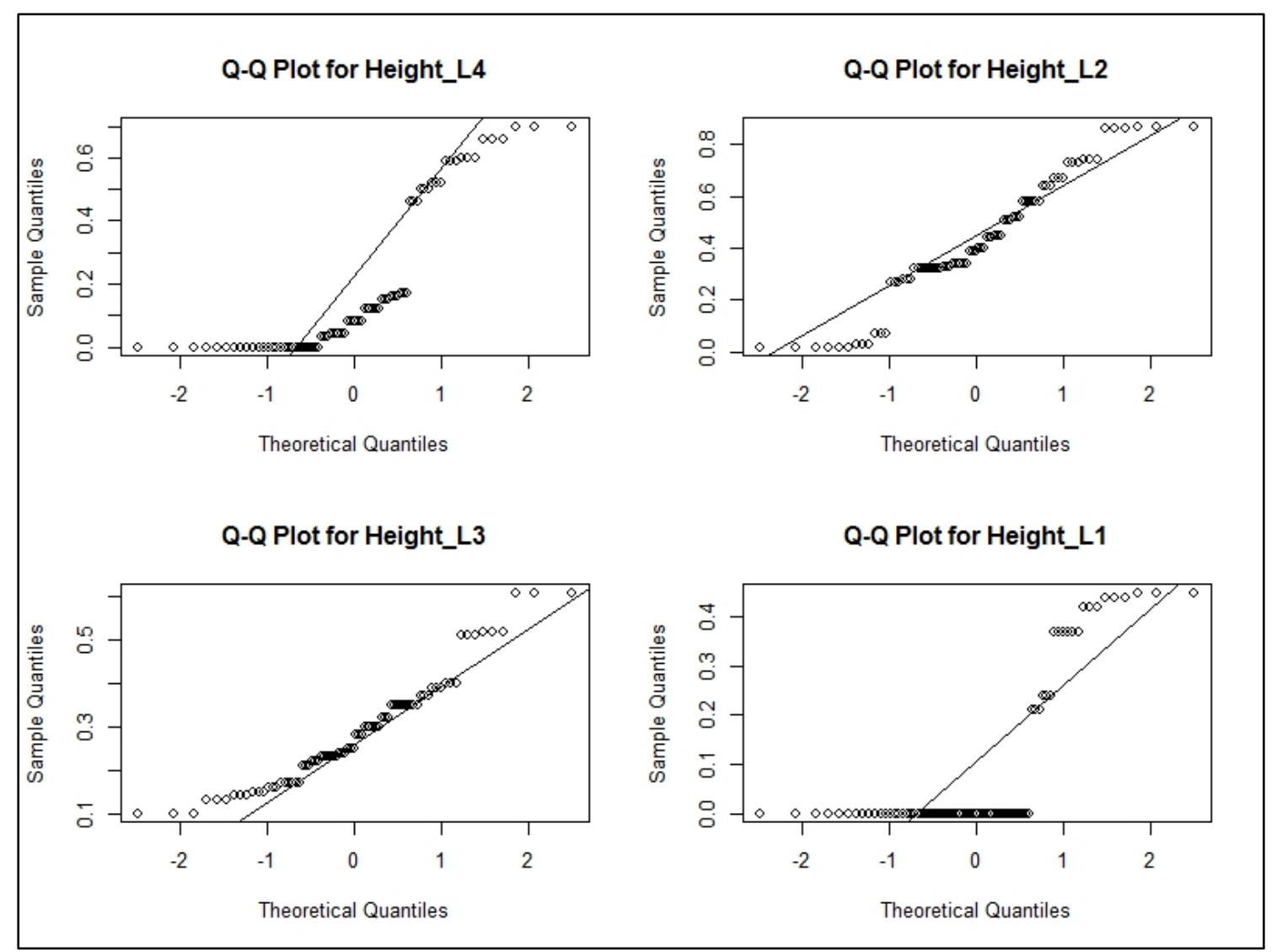

Figure 18: Q-Q Plots for Percent of Total Cliff Height Composed of Freeze-Thaw Susceptibility Classes F4 (Height_L4), F3 (Height_L3), F2 (Height_L2), and F1 (Height_L1)

Normality can be assessed for each variable using Figure 13 through Figure 18. The normality of the variables used in the initial multivariate linear regression was evaluated first. Slope angle is clearly not normally distributed based on the histogram and the Q-Q plot. There appear to be several large slope angles skewing the data in the histogram, and very little of the Q-Q plot aligns with the Q-Q line. This variable could benefit from data transformation. Cliff face direction has no clear violations to normality. The histogram looks relatively normally distributed. While this variable is not perfectly normally distributed, it is unlikely that data transformation will benefit the variable's normality. 
The number of freeze-thaw cycles is not normally distributed. Since this variable contains only three distinct values, one number for each time interval considered, it is not possible to be normally distributed, nor can it benefit from data transformation. The percent of total height of soil layers with F3 freeze-thaw susceptibility data do not have any clear violations to normality based on the histogram and the Q-Q plot. However, since this variable had an unexplainable negative relationship with recession rate in the initial regression, transformation could be beneficial to more appropriately include F3 soils in future regressions. The percent of total height of soil layers with $F 2$ freeze-thaw susceptibility data do not have any clear violations to normality based on the histogram and the Q-Q plot. However, it is worth exploring data transformation for this variable in case a more perfect normal distribution can be achieved. The vegetation condition for the soil layers with F1 freeze-thaw susceptibility data is clearly not normally distributed based on the histogram. A large number of the data do not have any F1 soils, which skews the plot. However, this data cannot be omitted, and data transformation would not be able to improve normality.

The variables not included in the initial regression that still seem critical were assessed next. Cliff height appears to be close to normally distributed from the histogram and Q-Q plots. While there is some deviation from the Q-Q line at extreme values, much of the data aligns well. The histogram is not a perfect example of normality, but it has no clear violations. Since the variable was not considered in the initial regression, it may benefit from data transformation to more closely approach normality in attempts to be included in future regressions. Weighted shear strength has no clear violations to normality, but both the histogram and the Q-Q plot show deviations from a normal distribution. Because 
the variable was not considered in the initial regression, it might benefit from data transformation to improve normality; the potential improved normality of transforming shear strength could allow it to be included in future regressions. The percent of total height of soil layers with F4 freeze-thaw susceptibility is not normally distributed based on both the histogram and the Q-Q plot. Based on the histogram, the data is skewed by a large number of data that do not have F4 soils and then some data that have a high percentage of F4 soils, with little in the middle. These data cannot be removed as they are representative of the conditions, and would likely not benefit from data transformation.

The variables not included in the initial regression and not alarming in their omission were assessed for normality last. While their normality was assessed, no attempt at transforming the data was made to improve these variables. Days of freezing and rainfall are clearly not normally distributed from their respective histograms and Q-Q plots. Both of these variables only have three distinct values, one for each time interval, so it is not possible for them to be normally distributed. Percent of total height of soil layers with F1 freeze-thaw susceptibility is also clearly not normally distributed based on the histogram and Q-Q plot. A large number of the data do not have any F1 soils, which skews both plots. Similarly, vegetation condition for the soil layers with F4, F3, and F2 freeze-thaw susceptibility are not normally distributed based on both the histogram. This data is categorical, with only three categories, which does not readily allow for normality to be achieved. 
The variables identified to potentially benefit from data transformation by assessing normality - percent of total height of soil with F3 and F4 freeze-thaw susceptibility, weighted shear strength, cliff height, and slope angle — were then analyzed.

The first variable explored was cliff height. The histogram and Q-Q plot for slope height demonstrated that the data were normally distributed. However, it seemed that cliff height should have an impact on cliff recession, so data transformations were performed on this variable to attempt to improve normality. Figure 19 and Figure 20 show the histograms and Q-Q plots for several attempts at transforming the data, using both logarithm and power transformations. These figures show that, while transformation makes subtle changes in the data trends, none of the transformations provide significant improvement to cliff height's normality. Therefore, cliff height should be used without any data transformation.

The next variable explored was the percent of total height of soil with F3 freeze-thaw susceptibility. The histogram and Q-Q plot for percent height of F3 soil indicated that the data was normally distributed. However, since this variable had an unexplained negative correlation with recession rate, data transformations were performed in order to attempt to improve normality and potentially encourage a positive correlation with recession rate. Both logarithm and power transformations were performed. Figure 21 and Figure 22 show the histograms and Q-Q plots for the transformations that showed improvement, logarithm and square root transformations. Both transformations indicate improvements, but the logarithm transformation appears to show more improvement. Both the original 
variable and the log transformation of the variable should be considered for the regression.

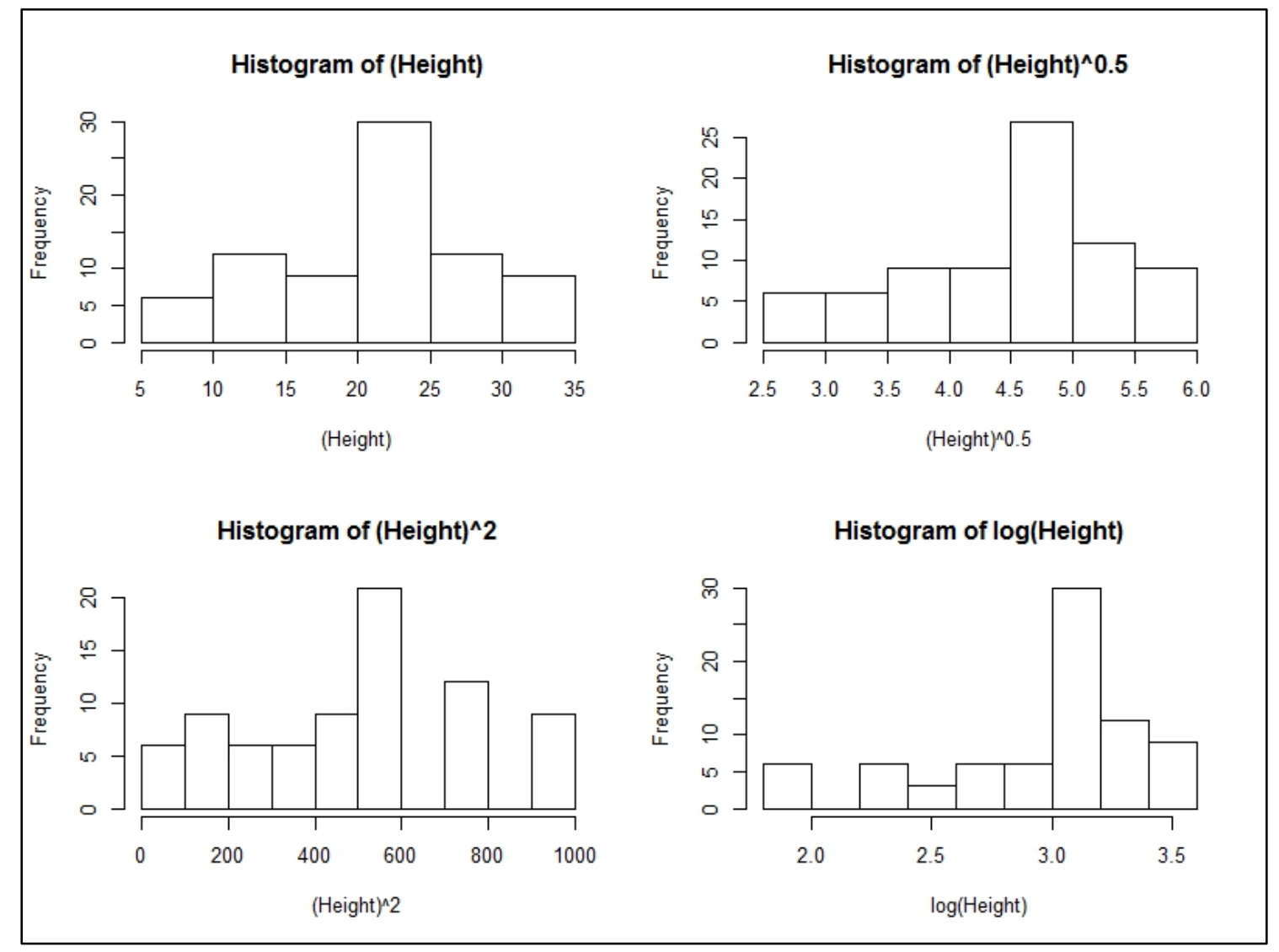

Figure 19: Histograms for Data Transformation of Cliff Height 


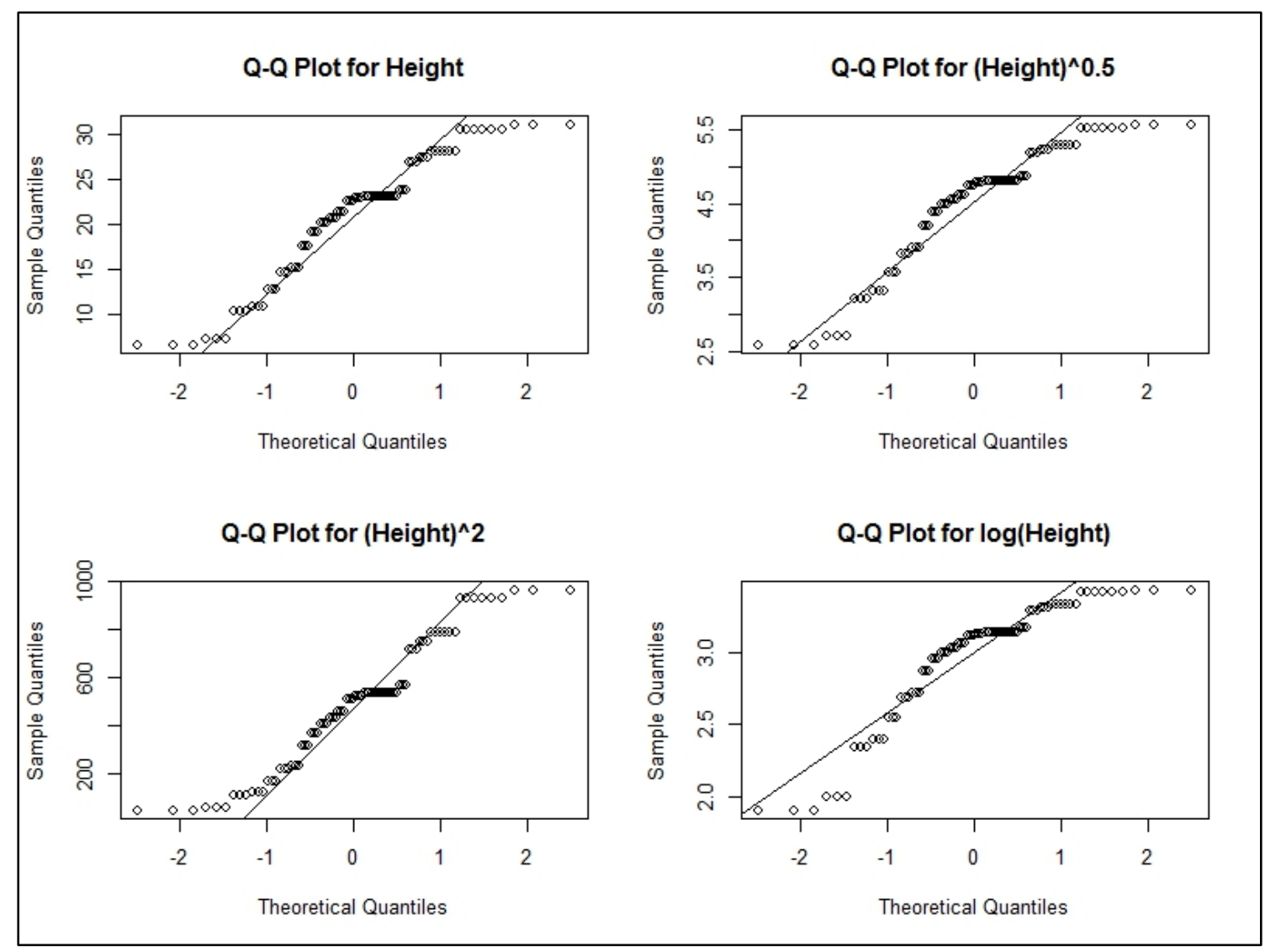

Figure 20: Q-Q Plots for Data Transformation of Cliff Height 


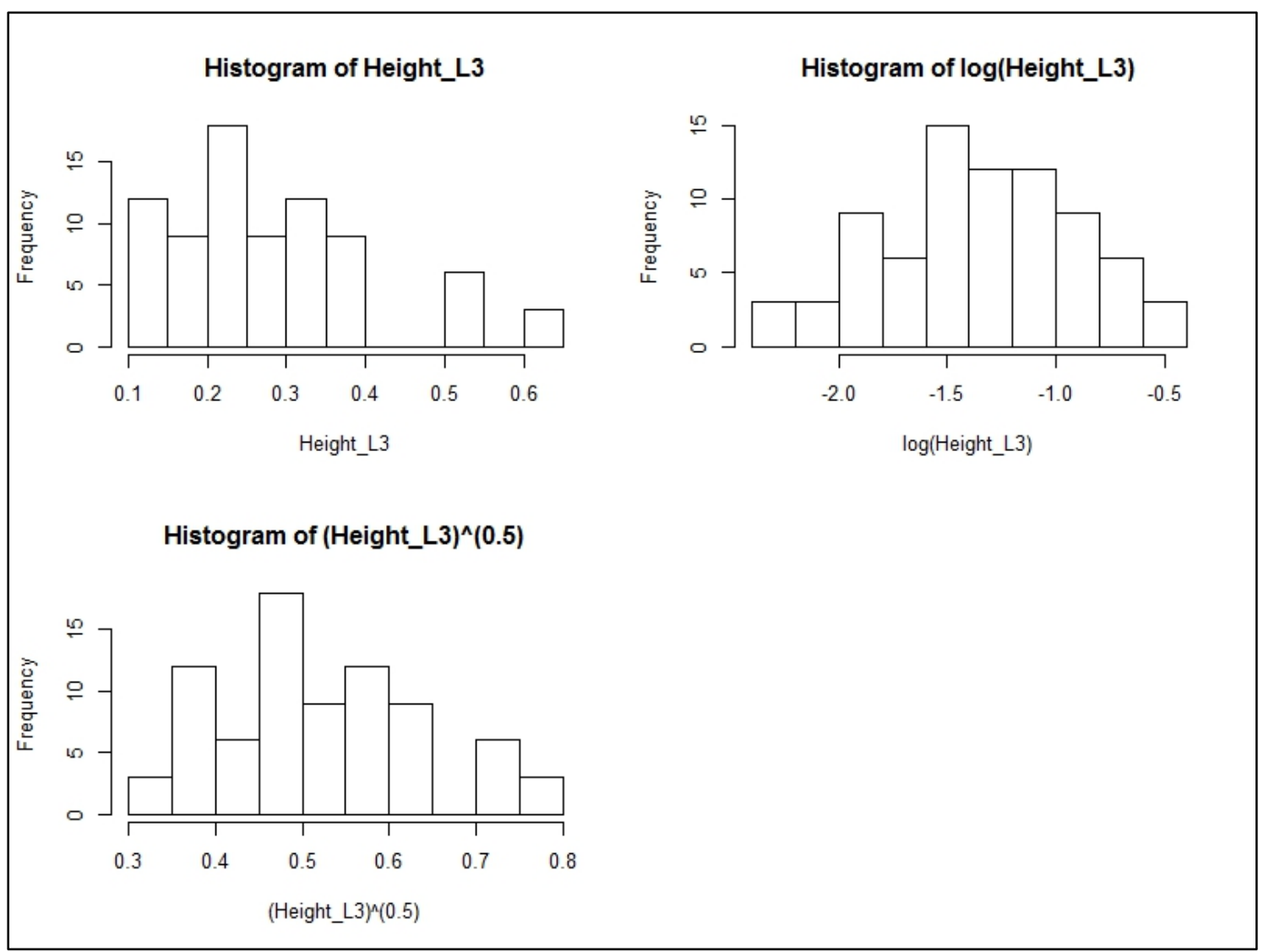

Figure 21: Histograms for Data Transformation of Percent of Total Height of Soil with F3 Freeze-Thaw Susceptibility 


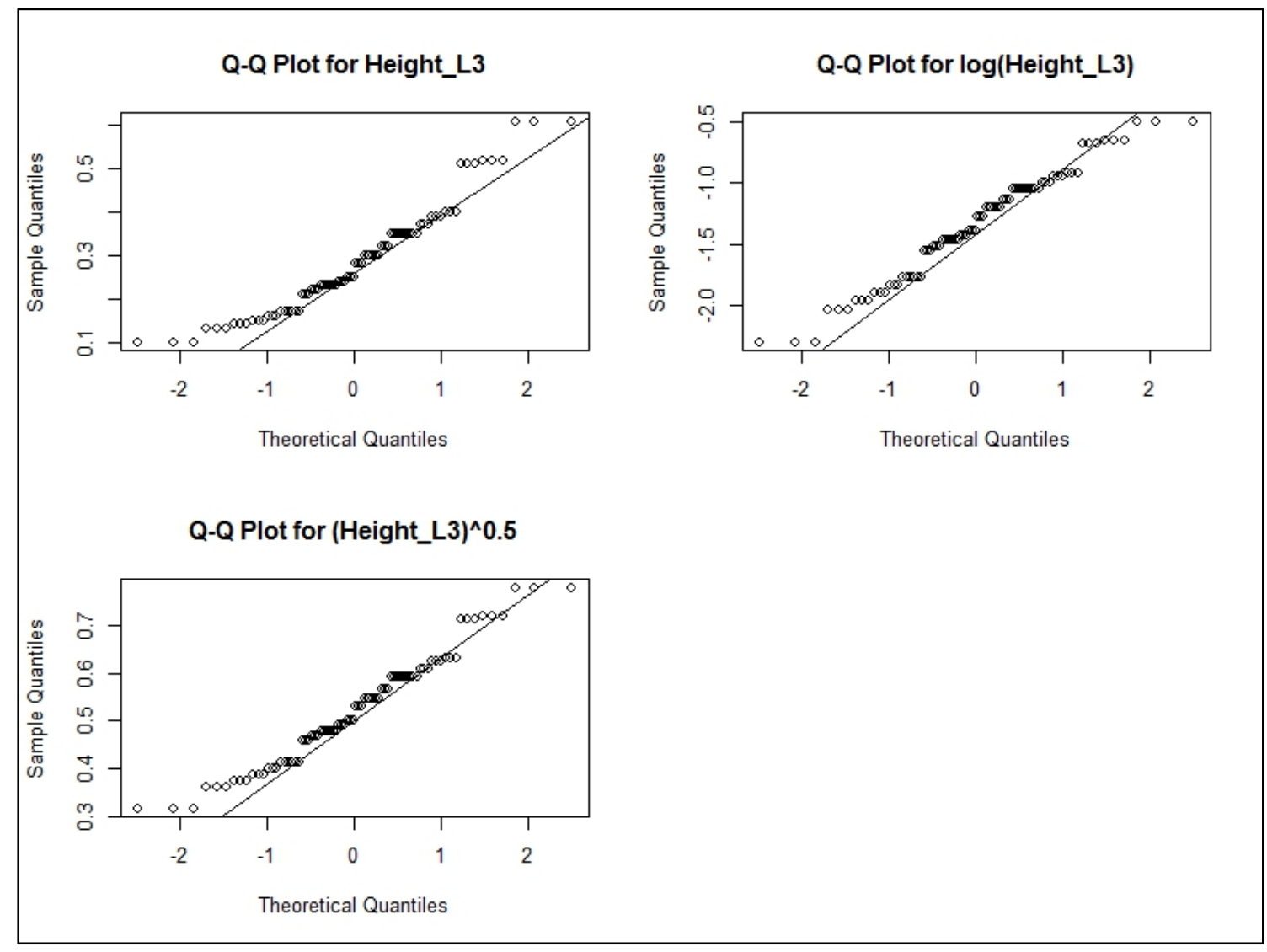

Figure 22: Q-Q Plots for Data Transformation of Percent of Total Height of Soil with F3 Freeze-Thaw Susceptibility

The next variable explored was the percent of total height of soil with F2 freeze-thaw susceptibility. The histogram and Q-Q plot for percent height of F2 soil indicated that the data was close to normally distributed. However, since this variable was considered in the initial regression and did not perfectly satisfy the normality assumption, data transformations were performed in order to attempt to improve normality. Both logarithm and power transformations were performed. Figure 23 shows the histograms and Q-Q plots for the transformation that showed improvement, a square root transformation. Both the original variable and the log transformation of the variable should be considered in future regressions. 


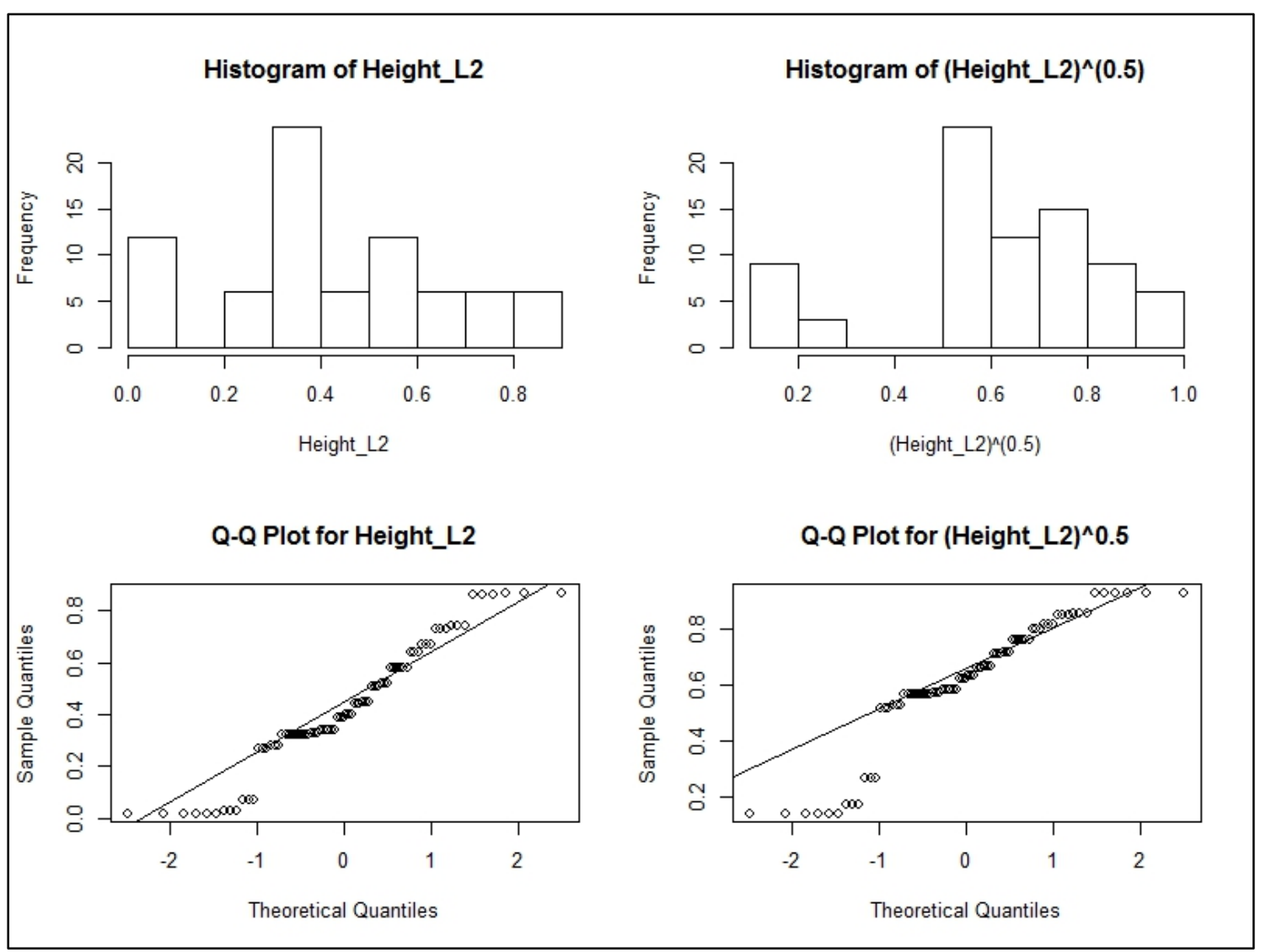

Figure 23: Histograms and Q-Q Plots for Data Transformation of Percent of Total Height of Soil with F2 Freeze-Thaw Susceptibility

Weighted shear strength was the next variable considered. The histogram and Q-Q plot for weighted shear strength both deviated from normality. Since this seemingly important variable was not considered in the initial regression, data transformations were performed in order to attempt to improve normality to increase the chances of having it included in future regressions. Both logarithm and power transformations were performed. Figure 24 shows the histograms and Q-Q plots for the transformation that showed the most improvement in both the histogram and the Q-Q plot, a power transformation of two. The power transformation of two of weighted shear strength should be considered in future regressions. 

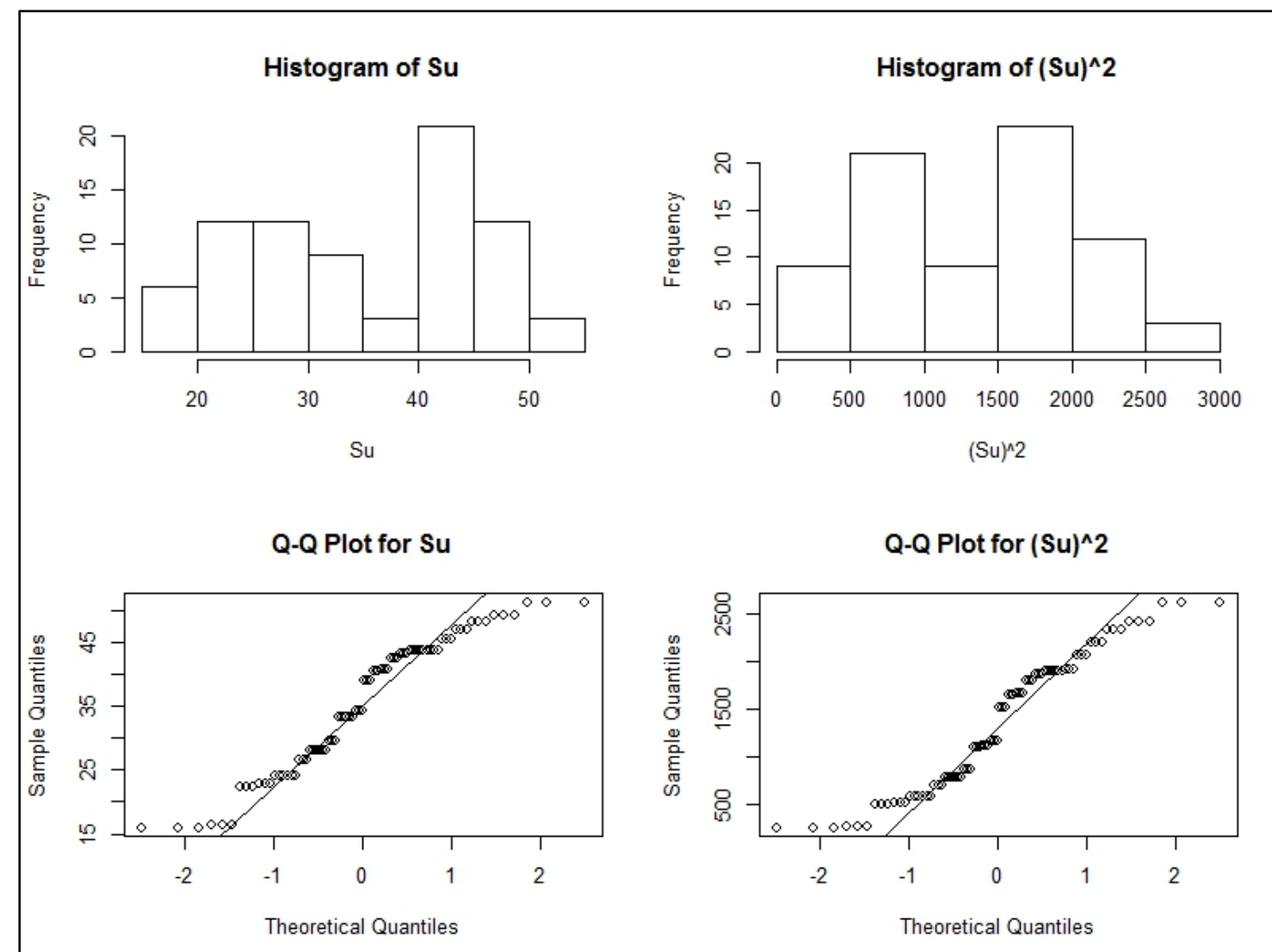

Figure 24: Histograms and Q-Q Plots for Data Transformation of Weighted Shear Strength

The last variable to be considered was slope angle. The histogram and Q-Q plot for slope angle both deviated from normality. Since this variable was considered in the initial regression despite its lack of normality, data transformations were performed in order to attempt to improve normality and potentially future regressions. Both logarithm and power transformations were performed. Figure 25 and Figure $\mathbf{2 6}$ show the histograms and Q-Q plots for the transformations that showed the most improvement. While there is improvement, there are also still clearly some significant outliers that are especially evident in the histograms. If slope angle was to be considered in future regressions, the outliers needed to be addressed. 


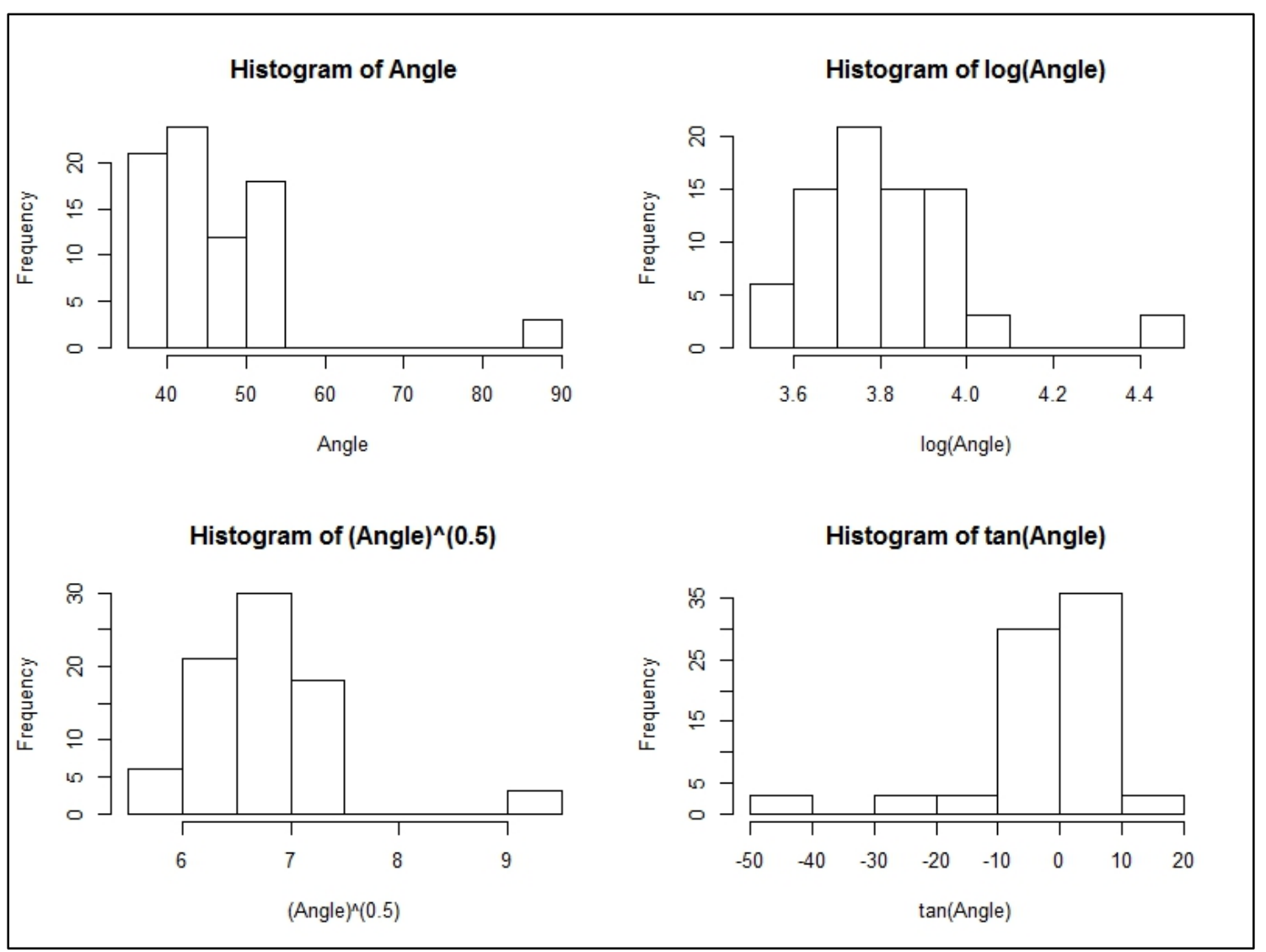

Figure 25: Histograms for Data Transformation of Slope Angle 


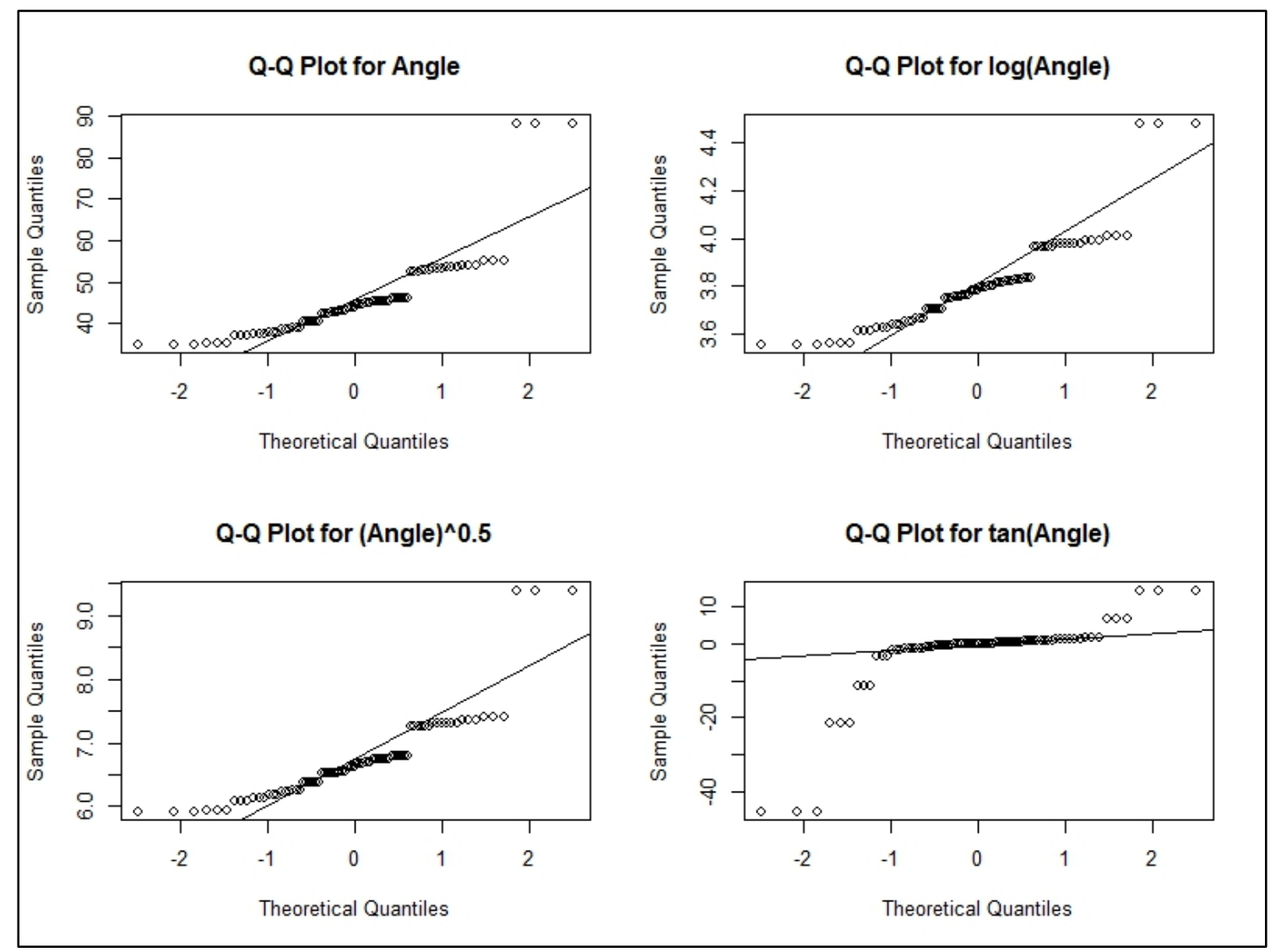

\section{Figure 26: Q-Q Plots for Data Transformation of Slope Angle}

The outliers for slope angle, as mentioned previously, are three data points with slope angles greater than 55 degrees - these three angles are 88 degrees, as this data comes from three time intervals for the same sub-site. While there was no error in the determination of slope angle, there is not enough data being considered with high slope angles to potentially provide a normal distribution. A regression using the current dataset should not be considering these high slope angles if this is a variable utilized in the regression. Therefore, the outliers - slope angles greater than 55 degrees-were removed to see how it impacted the normality of slope angle. Figure 27 and Figure 28 show the 
histograms and Q-Q plots for slope angle with outliers removed for the same data transformations considered previously.

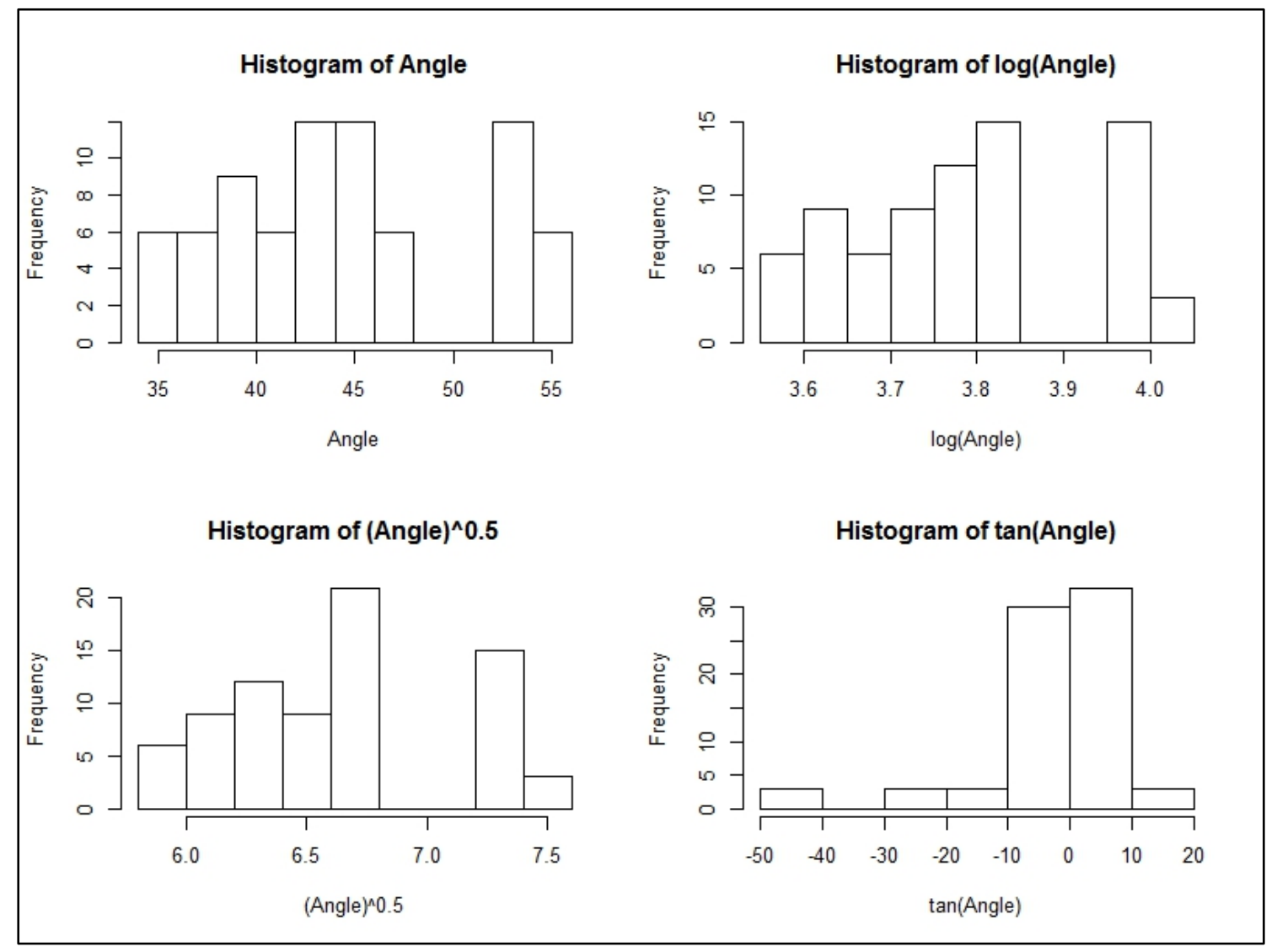

Figure 27: Histograms for Data Transformation of Slope Angle WITH OUTLIERS REMOVED 


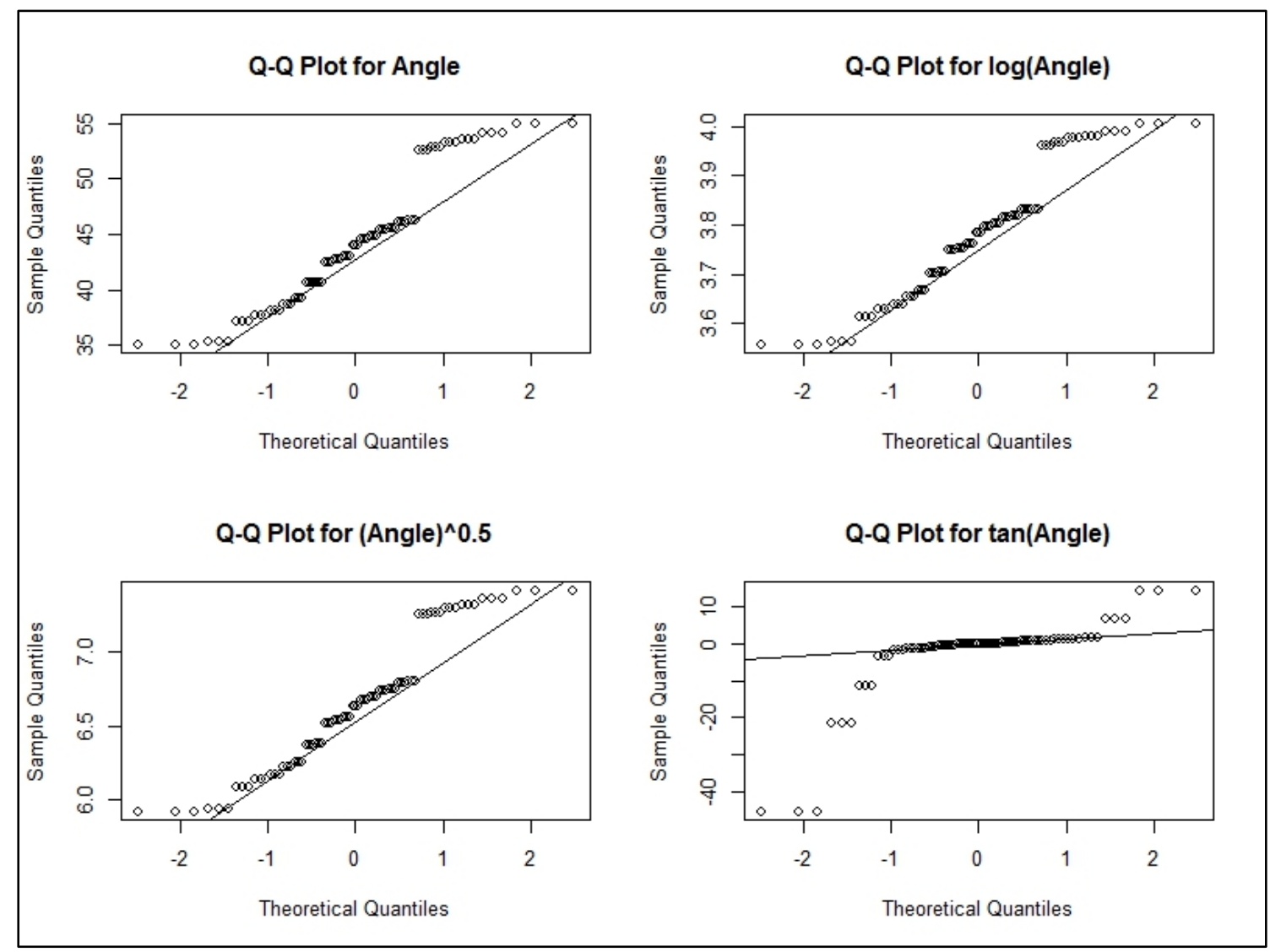

Figure 28: Q-Q Plots for Data Transformation of Slope Angle WITH OUTLIERS REMOVED

With the high slope angles removed, all of the histograms and Q-Q plots in Figure 27 and Figure 28 show improvements in normality. None of considered transformations represents a perfect normal distribution; however, the square root and tangent transformations improved most. These transformations, as well as untransformed slope angle, should be considered in future regressions.

Once the data transformation process was complete, the transformed variables were considered in various multivariate simple linear regressions. Table 25 summarizes the variables used in each regression, as well as the model-assessment statistics. 
Table 25: Summary of Model-Assumption Statistics for Intermediate Multivariate Linear Regressions

\begin{tabular}{|c|c|c|c|c|c|}
\hline $\begin{array}{l}\text { Variables Included* } \\
\text { (listed in order of } \\
\text { decreasing significance) }\end{array}$ & $\begin{array}{c}\text { Sample } \\
\text { Size }\end{array}$ & $\mathrm{R}^{2}$ & $\underset{\mathrm{R}^{2}}{\text { Adjusted }}$ & RMSE & Notes \\
\hline -j, b, f, -o, e, -i, -intercept & 78 & 0.35 & 0.29 & 0.32 & initial regression \\
\hline$-\mathrm{j}, \mathrm{f}, \mathrm{b},-\mathrm{o},-\mathrm{i}, \mathrm{e}$ & 75 & 0.63 & 0.60 & 0.34 & $\begin{array}{l}\text { initial variables, } 0 \text { intercept set, } \\
\text { angle outliers removed }\end{array}$ \\
\hline$-\mathrm{j}, \mathrm{b}, \mathrm{f},-\mathrm{o},-\mathrm{i}, \mathrm{e},-\mathrm{c},-\mathrm{h}, \mathrm{a}$ & 75 & 0.65 & 0.60 & 0.33 & $\begin{array}{l}\text { initial regression variables }+ \\
\text { those considered important }\end{array}$ \\
\hline$-\mathrm{j}, \mathrm{f},-\mathrm{o},(\mathrm{b})^{1 / 2},-\mathrm{i}, \mathrm{e}$ & 75 & 0.61 & 0.57 & 0.35 & investigate transformed angle \\
\hline$e,-j, f,-o,-i, \tan (b)$ & 75 & 0.58 & 0.55 & 0.35 & $\begin{array}{l}\text { investigate transformed angle, } \\
\text { no improvement }\end{array}$ \\
\hline $\mathrm{e},-\mathrm{j}, \mathrm{f},-\mathrm{o},(\mathrm{c})^{2},-\mathrm{i}$ & 75 & 0.59 & 0.55 & 0.36 & $\begin{array}{l}\text { investigate transformed } \mathrm{Su}, \\
\text { slight improvement }\end{array}$ \\
\hline$-\mathrm{j}, \mathrm{e}, \mathrm{f},-\mathrm{o},-\mathrm{i},-\mathrm{h}$ & 75 & 0.58 & 0.55 & 0.36 & $\begin{array}{l}\text { investigate including HF4, no } \\
\text { improvement }\end{array}$ \\
\hline$e,-j, f,-o,-i$ & 75 & 0.58 & 0.55 & 0.36 & $\begin{array}{l}\text { investigate transforming HF3, } \\
\text { still negative correlation }\end{array}$ \\
\hline$-\mathrm{j}, \mathrm{e}, \mathrm{f},-\mathrm{o},-\log (\mathrm{i})$ & 75 & 0.58 & 0.55 & 0.36 & $\begin{array}{l}\text { investigate transforming HF3, } \\
\text { still negative correlation }\end{array}$ \\
\hline$e,-j, f,-o$ & 75 & 0.58 & 0.56 & 0.36 & investigate transforming HF2 \\
\hline$e,-(j)^{1 / 2}, f,-o$ & 75 & 0.58 & 0.56 & 0.36 & $\begin{array}{l}\text { investigate transforming HF2, } \\
\text { improvement }\end{array}$ \\
\hline$e,-(j)^{1 / 2}, f$ & 75 & 0.57 & 0.56 & 0.36 & $\begin{array}{l}\text { omit } \mathrm{V} 1 \text { - no value to } \\
\text { regression }\end{array}$ \\
\hline$e,-(j)^{1 / 2}, f, \tan (b)$ & 75 & 0.57 & 0.55 & 0.36 & $\begin{array}{l}\text { add back variables (not HF3) - } \\
\text { Angle (no improvement) }\end{array}$ \\
\hline$-(\mathbf{j})^{1 / 2}, \mathbf{e}, \mathbf{a}, \mathbf{f}$ & 75 & 0.60 & 0.58 & 0.35 & $\begin{array}{l}\text { add back variables (not HF3) } \\
\text { - Height (improvement) }\end{array}$ \\
\hline$-(j)^{1 / 2}, e, f, i^{2}$ & 75 & 0.58 & 0.56 & 0.36 & $\begin{array}{l}\text { add back variables (not HF3) - } \\
\text { Su2 (no improvement) }\end{array}$ \\
\hline
\end{tabular}

*Variables: $a=$ cliff height; $b=$ slope angle; $c=$ weighted shear strength; $d=$ days of freezing; $\mathrm{e}=$ number of freeze-thaw cycles; $\mathrm{f}=$ cliff face direction; $\mathrm{g}=$ rainfall; $\mathrm{h}=\%$ height of $\mathrm{F} 4$ soil; $\mathrm{i}=\%$ height of $\mathrm{F} 3$ soil; $\mathrm{j}=\%$ height of $\mathrm{F} 2$ soil, $\mathrm{k}=\%$ height of $\mathrm{F} 1$ soil; $1=$ vegetation of F4 soil; $\mathrm{m}=$ =vegetation of $\mathrm{F} 3$ soil; $\mathrm{n}=$ vegetation of $\mathrm{F} 2$ soil; $\mathrm{o}=$ vegetation of $\mathrm{F} 1$ soil

While some of the regressions shown in Table 25 look promising, there are several issues that must be addressed before a final multivariate simple linear regression can be developed. While those regressions including percent height of soil with freeze-thaw susceptibility class F3 have the highest $\mathrm{R}^{2}$ and lowest RMSE values, they all maintain a negative correlation between this variable and recession rate. As discussed previously in 
Section 4.2, this trend does not make sense. Since data transformation was not able to improve this relationship, this variable should not be used in future regressions. Taking that into account, the best regression considered in Table 25 is shown in bold.

Additionally, none of these regressions were able to predict recession rates above about 0.8 meters per year. This is true for all regressions explored in Table 25; the observed versus predicted plot for the best regression, identified in bold, can be seen in Figure 29 as a sample of this trend. This means that all data with observed recession rates above 0.8 meters per year should be omitted due to its sparsity, since it is outside of the predictive capability of the model.

Details about the outliers that were removed for both high slope angles and high recession rates can be seen in Table 26. Outliers do not come exclusively from one study site or from one time interval. There are more recession rates that are higher than 0.8 meters per year in 2006-2007 and 2007-2011, but there is not a single time interval that produced a suspiciously large number of high recession rates. CCSP and CRE have the most high recession rates. It is possible that there is another factor acting on the cliffs at these study sites and sub-sites that is not being accounted for in this study, and that this is causing this high recession rates. It is also possible that these high recession rates are a result of the uncertainty associated with the recession rate calculations. High slope angles only occur at one sub-site. It is probably that something else controls the recession rate of these steep slopes, likely gravity. 


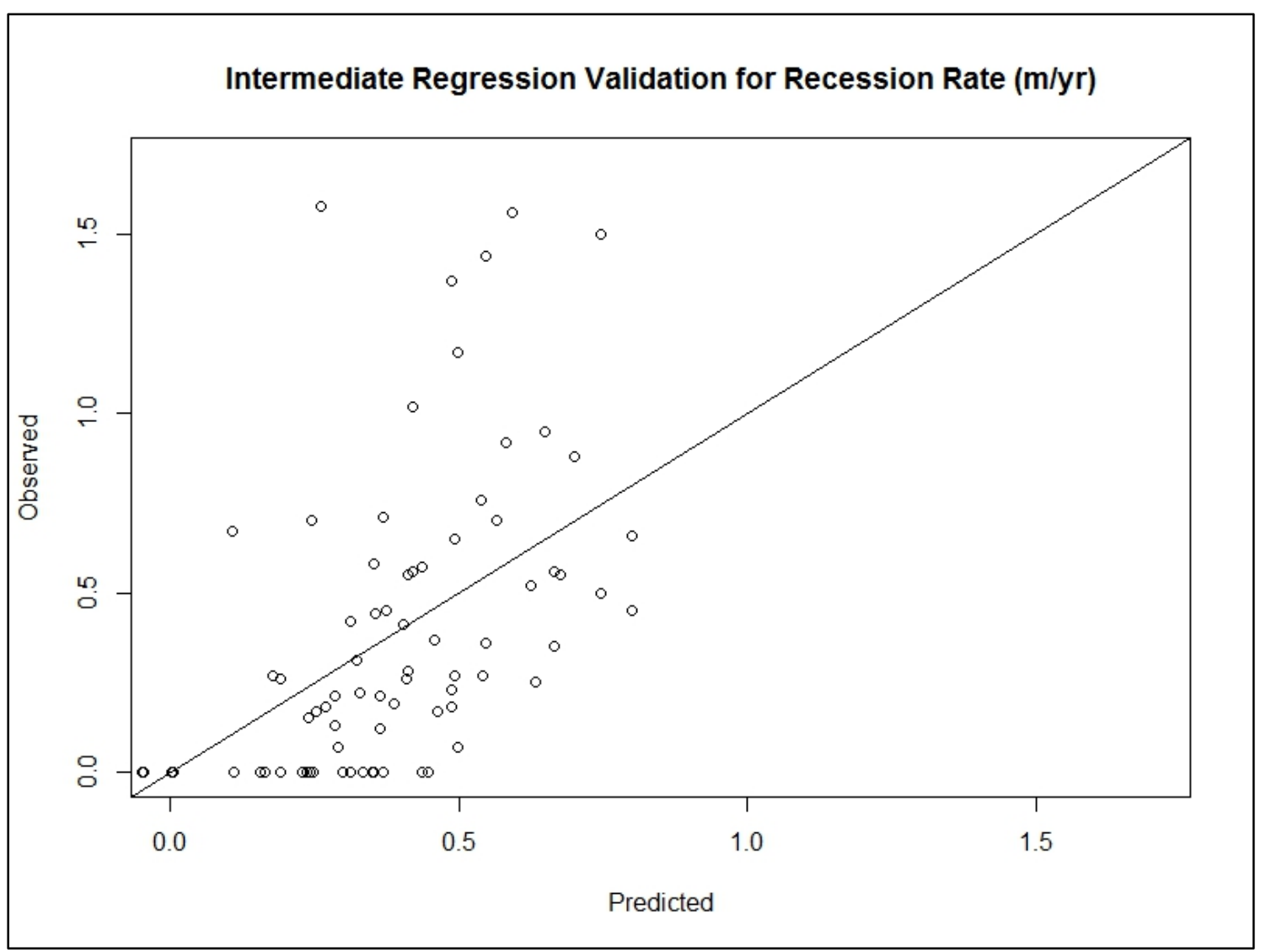

Figure 29: Predicted versus Observed Plots for Intermediate Multivariate Simple Linear Regression

Table 26: Details about Slope Angle and Recession Rate Outliers

\begin{tabular}{|c|c|c|c|}
\hline \multirow{2}{*}{ Sub-site } & \multirow{2}{*}{$\begin{array}{c}\text { Slope Angle } \\
\text { (Angle }>\text { 55 degrees?) }\end{array}$} & Time Interval & (Recession $>0.8 \mathrm{~m} / \mathrm{yr}$ ?) \\
\hline SCS6 & - & $2007-2011$ & 1.37 \\
\hline CB1 & 88 & $2006-2007$ & 1.58 \\
\hline CCSP2 & - & $2006-2007$ & 0.95 \\
\hline CCSP2 & - & $2007-2011$ & 0.88 \\
\hline CCSP4 & - & $2006-2007$ & 1.50 \\
\hline PC1 & - & $2007-2011$ & 1.02 \\
\hline CRE1 & - & $2007-2011$ & 1.56 \\
\hline CRE2 & - & $2003-2006$ & 1.17 \\
\hline CRE2 & - & $2006-2007$ & 0.92 \\
\hline CRE3 & - & $2007-2011$ & 1.44 \\
\hline
\end{tabular}


Once the outliers were removed, the search for a final multivariate simple linear regression commenced. A summary of the regressions considered is show in Table 27.

The two most fitting regression models are shown in bold in Table 27. The only difference between these regression models is that one uses days of freezing and the other uses number of freeze-thaw cycles. These two models were investigated further to determine which relationship should be used as the final multivariate simple linear regression model.

For the multivariate simple linear regression containing the number of freeze-thaw cycles, a summary of the variable-assessment statistics is shown in Table 28 , the observed versus predicted plot is shown in Figure 30, and the residuals can be visualized

\section{Table 27: Summary of Model-Assumption Statistics for Search for Final Multivariate Linear Regressions}

\begin{tabular}{|c|c|c|c|c|c|}
\hline $\begin{array}{l}\text { Variables Included* } \\
\text { (listed in order of } \\
\text { decreasing significance) }\end{array}$ & $\begin{array}{c}\text { Sample } \\
\text { Size }\end{array}$ & $\mathrm{R}^{2}$ & $\begin{array}{l}\text { Adjusted } \\
\mathrm{R}^{2}\end{array}$ & RMSE & Notes \\
\hline$-(\mathrm{j})^{1 / 2}, e, a, f$ & 75 & 0.60 & 0.58 & 0.35 & $\begin{array}{l}\text { most successful intermediate } \\
\text { regression }\end{array}$ \\
\hline$-(\mathrm{j})^{1 / 2}, e, f, a$ & 66 & 0.66 & 0.64 & 0.20 & $\begin{array}{l}\text { removing outliers improves, } \\
\text { height has low significance }\end{array}$ \\
\hline$-(j)^{1 / 2}, e, f$ & 66 & 0.65 & 0.64 & 0.20 & $\begin{array}{l}\text { remove height, agrees that height } \\
\text { contributed little }\end{array}$ \\
\hline$f,-(j)^{1 / 2}, h, e$ & 66 & 0.67 & 0.65 & 0.20 & bring back HL4—improves \\
\hline$e,-(j)^{1 / 2}, f,-\tan (b)$ & 66 & 0.68 & 0.66 & 0.20 & $\begin{array}{l}\text { bring back angle-negative } \\
\text { correlation with angle not logical }\end{array}$ \\
\hline$-(\mathrm{j})^{1 / 2}, \mathrm{e}, \mathrm{f},(\mathrm{c})^{2}$ & 66 & 0.66 & 0.64 & 0.20 & bring back $\mathrm{Su}-$ no improvement \\
\hline$f,-(j)^{1 / 2}, h, e,(c)^{2}$ & 66 & 0.68 & 0.66 & 0.19 & use $\mathrm{HL} 4$ and $\mathrm{Su}$-improvement \\
\hline f, $-(\mathbf{j})^{1 / 2}, \mathrm{~d}, \mathrm{~h},(\mathrm{c})^{2}$ & 66 & 0.68 & 0.65 & 0.20 & $\begin{array}{l}\text { use FT-days rather than FT- } \\
\text { cycles-similar }\end{array}$ \\
\hline
\end{tabular}

*Variables: $a=$ cliff height; $b=$ slope angle; $c=$ weighted shear strength; $d=$ days of freezing; $\mathrm{e}=$ number of freeze-thaw cycles; $\mathrm{f}=$ cliff face direction; $\mathrm{g}=$ rainfall; $\mathrm{h}=\%$ height of $\mathrm{F} 4$ soil; $\mathrm{i}=\%$ height of $\mathrm{F} 3$ soil; $\mathrm{j}=\%$ height of $\mathrm{F} 2$ soil, $\mathrm{k}=\%$ height of $\mathrm{F} 1$ soil; $\mathrm{l}=$ =vegetation of $\mathrm{F} 4$ soil; $\mathrm{m}=$ vegetation of $\mathrm{F} 3$ soil; $\mathrm{n}=$ vegetation of $\mathrm{F} 2$ soil; $\mathrm{o}=$ vegetation of $\mathrm{F} 1$ soil 
in Figure 31. For the multivariate simple linear regression containing the number of days of freezing, a summary of the variable-assessment statistics is shown in Table 29, the observed versus predicted plot is shown in Figure 32, and the residuals can be visualized in Figure 33.

These regressions are very similar, with very subtle differences. While some of the variables considered in each regression have very low significance, their presence leads to an increase in adjusted $\mathrm{R}^{2}$ and a decrease in RMSE, indicating that the variables add value to the regression. The plots of residuals for both regressions (shown in Figure 31 and Figure 33) show improvement from the initial linear regression model (shown in Figure 12). The residuals are more random for both regressions, as indicated by the randomness of the data focused about the horizontal dashed line in the upper left plots and the lack of a distinct trend in the upper right plots in Figure 31 and Figure 33. The data is also more normally distributed, as indicated by the closer fit on the Q-Q plots (bottom left plots) in Figure 31 and Figure 33; the data still does not perfectly fall along the 1:1 line, but these regressions show less deviation than the initial regression did. Finally, the Cook's Distances (bottom right plots) for these regressions do not indicate the presence of any outliers or a poorly-fitting model. 
Table 28: Summary of Variable-Assessment Statistics for Multivariate Linear Regression-Freeze-Thaw Cycles

\begin{tabular}{|c|c|c|c|c|c|}
\hline Variable & Estimate & Std. Error & $\mathrm{t}$ value & $\operatorname{Pr}(>|\mathrm{t}|)$ & Significance $^{\mathrm{a}}$ \\
\hline Height_L4 & 0.3088 & 0.1585 & 1.948 & $5.60 \%$ &. \\
\hline$(\mathrm{Su})^{2}$ & $-5.100 \mathrm{E}-05$ & $3.550 \mathrm{E}-05$ & -1.437 & $15.60 \%$ & \\
\hline (Height_L2) $^{1 / 2}$ & -0.5331 & 0.1651 & -3.229 & $0.20 \%$ & $* *$ \\
\hline Face & 0.0959 & 0.0251 & 3.817 & $0.03 \%$ & $* * *$ \\
\hline F-T Cycles & 0.0139 & 0.0072 & 1.941 & $5.69 \%$ &. \\
\hline
\end{tabular}

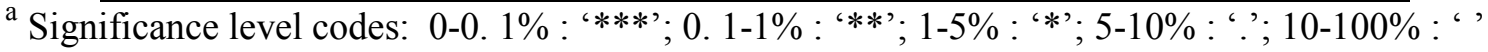

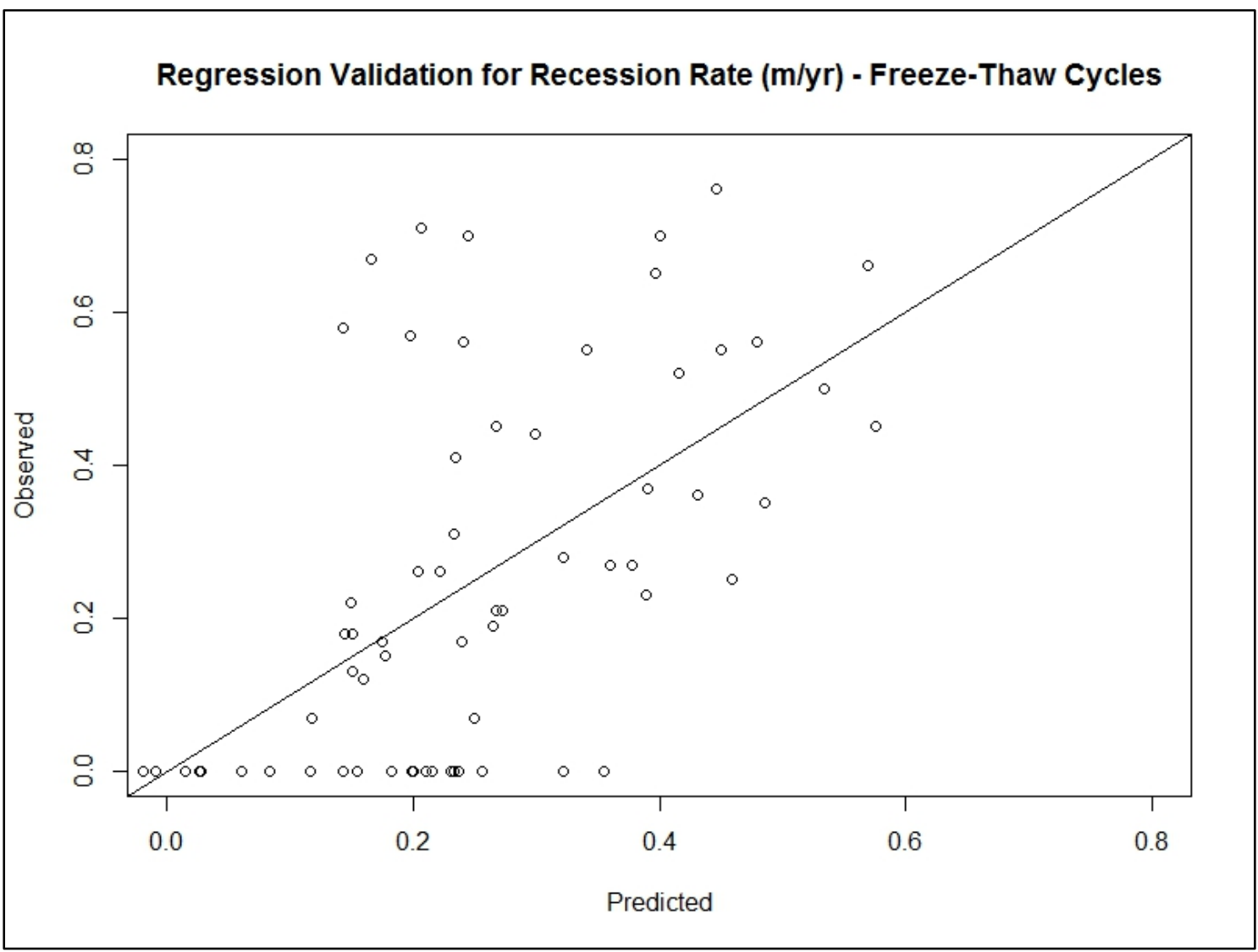

Figure 30: Predicted versus Observed Plot for Multivariate Linear RegressionFreeze-Thaw Cycles 


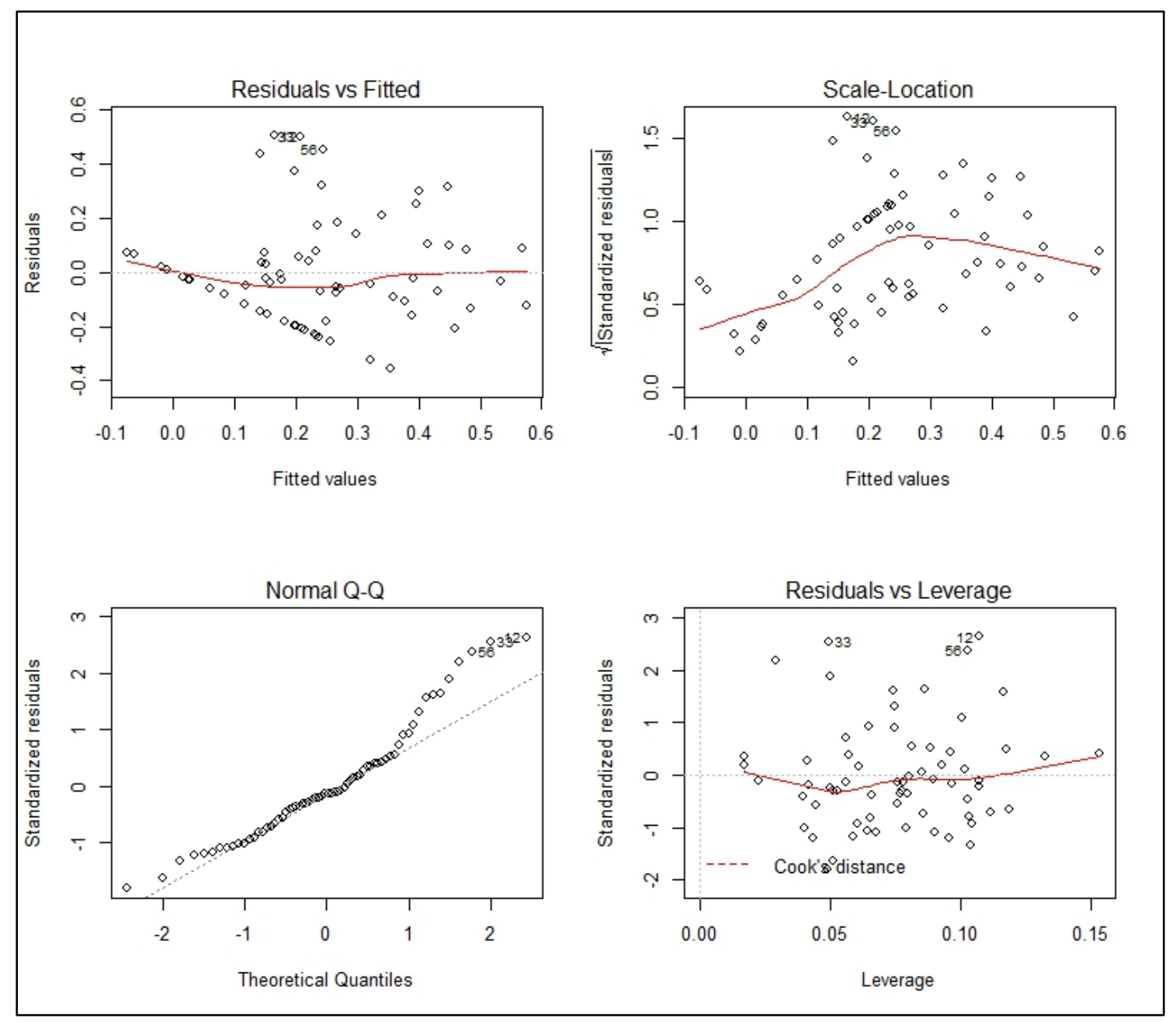

Figure 31: Visualization of Residuals for Multivariate Linear Regression-FreezeThaw Cycles 
Table 29: Summary of Variable-Assessment Statistics for Multivariate Linear Regression-Days of Freezing

\begin{tabular}{|c|c|c|c|c|c|}
\hline Variable & Estimate & Std. Error & $\mathrm{t}$ value & $\operatorname{Pr}(>|\mathrm{t}|)$ & Significance $^{\mathrm{a}}$ \\
\hline Height_L4 & 0.2859 & 0.1705 & 1.677 & $9.88 \%$ & \\
\hline$(\mathrm{Su})^{2}$ & $-5.485 \mathrm{E}-05$ & $3.657 \mathrm{E}-05$ & -1.500 & $13.88 \%$ & \\
\hline (Height_L2) $^{1 / 2}$ & -0.5574 & 0.1779 & -3.133 & $0.27 \%$ & $* *$ \\
\hline Face & 0.0927 & 0.0261 & 3.554 & $0.07 \%$ & $* * *$ \\
\hline F-T Days & 0.0137 & 0.0073 & 1.887 & $6.40 \%$ &. \\
\hline
\end{tabular}

${ }^{a}$ Significance level codes: $0-0.1 \%$ : ‘***'; $0.1-1 \%$ : ‘**’; 1-5\% : ‘*’; 5-10\% : ‘'; 10-100\% : '

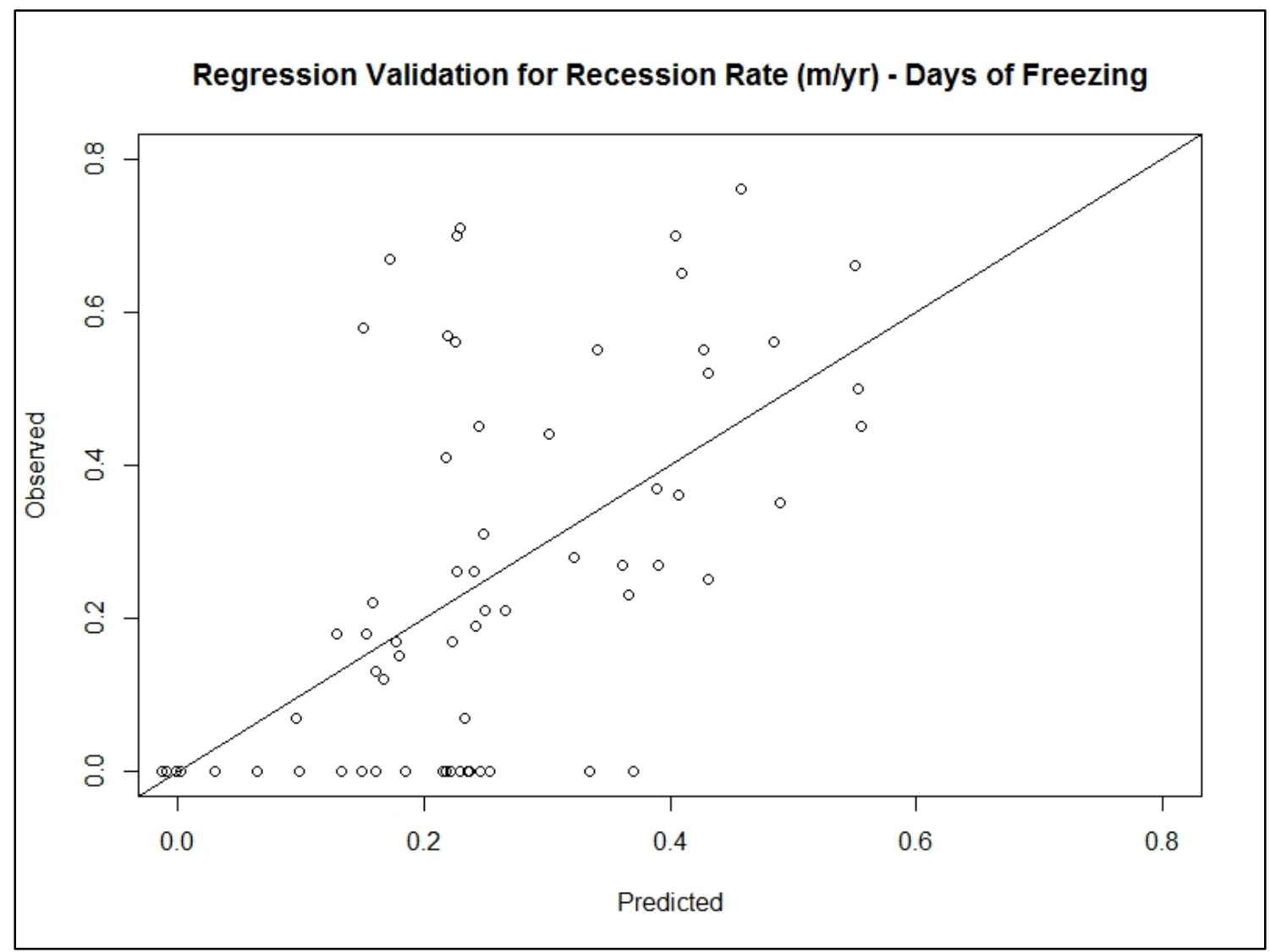

Figure 32: Predicted versus Observed Plot for Multivariate Linear RegressionDays of Freezing 


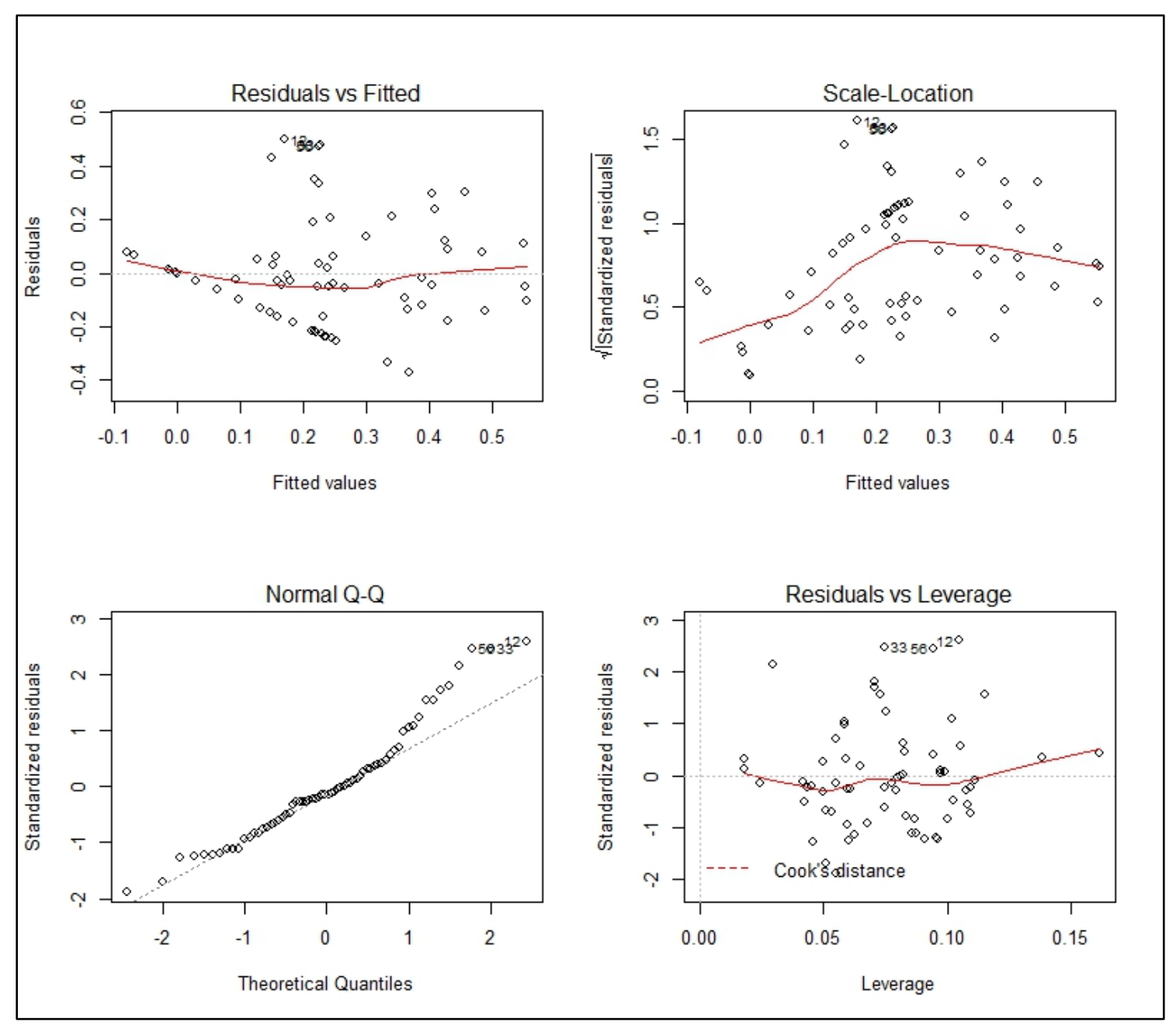

Figure 33: Visualization of Residuals for Multivariate Linear Regression-Days of Freezing

Because these regressions are so similar, it is safe to state that there is not a significant difference between days of freezing and freeze-thaw cycles in this dataset. That is not to say that these metrics would not be more telling with other data, but no distinction can be made with this data.

As mentioned in Section 1.1.3, another way to account for the impact of freeze-thaw is by using freezing index. In most applications, typical values based on years of historical data 
are used to represent freeze-thaw. However, freezing index can also be calculated.

Freezing index is a measure of cumulative degree-days in a freezing season. A single degree-day and cumulative degree-days are defined as:

$$
\begin{gathered}
\text { Degree }- \text { day }=\left(\mathrm{T}_{\text {mean }}-32^{\circ} \mathrm{F}\right) \\
\text { Cumulative degree }- \text { days }=\sum\left(\mathrm{T}_{\text {mean }}-32^{\circ} \mathrm{F}\right)
\end{gathered}
$$

where $\mathrm{T}_{\text {mean }}=$ mean daily temperature $\left({ }^{\circ} \mathrm{F}\right)($ Joint Departments of the Army and Air Force 1987). A plot of cumulative degree days can then be created, and freezing index can be interpreted as the largest negative deviation of cumulative degree-days from freezing, as described in Figure 34.

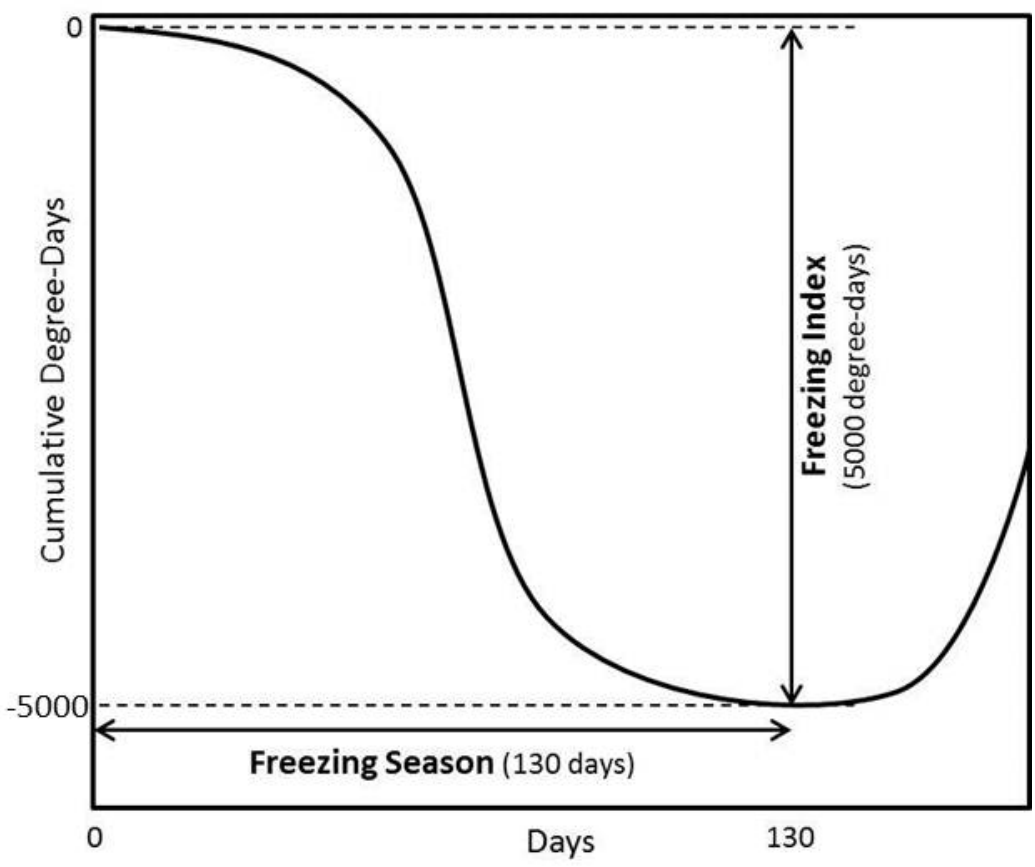

Figure 34: Method for Determining Freezing Index (Adapted from Joint Departments of the Army and Air Force 1987) 
While this procedure is not complicated in theory, it is intended for regions with a clearly defined freezing season, or a distinct period of time when the average daily temperature generally remains below freezing. One source (Gatto 1995) recommends that the freezing season begins when the mean air temperature is below $32^{\circ} \mathrm{F}$ for at least five consecutive days. For the Calvert Cliffs, there were some winter seasons that had clearly defined freezing seasons; there were others that had a great deal of fluctuation between period of freezing and thawing. There were three winter seasons that did not have five consecutive days below freezing for the entire winter (2005-2006, 2007-2008, and 2008-2009) but still likely experienced some level of freezing and thawing.

An example of the cumulative degree-day plots for two winters where a freezing season was difficult to define is shown in Figure 35. Depending on when the start of the freezing season was defined, the resulting freezing index could be higher or lower based on how many above-freezing periods occurred after the first below-freezing period. In order to analyze the temperature data to determine the average freezing index for each recession rate time interval, the start of the freezing season for a given winter was assigned to the first time that two or more consecutive days had degree-days below 0 (mean temperature at or below $32^{\circ} \mathrm{F}$ ). Using this definition, the average freezing index for each recession rate time interval was calculated and can be seen in Table 30 . Table 30 also shows the days of freezing and number of freeze-thaw cycles for the same time intervals. 


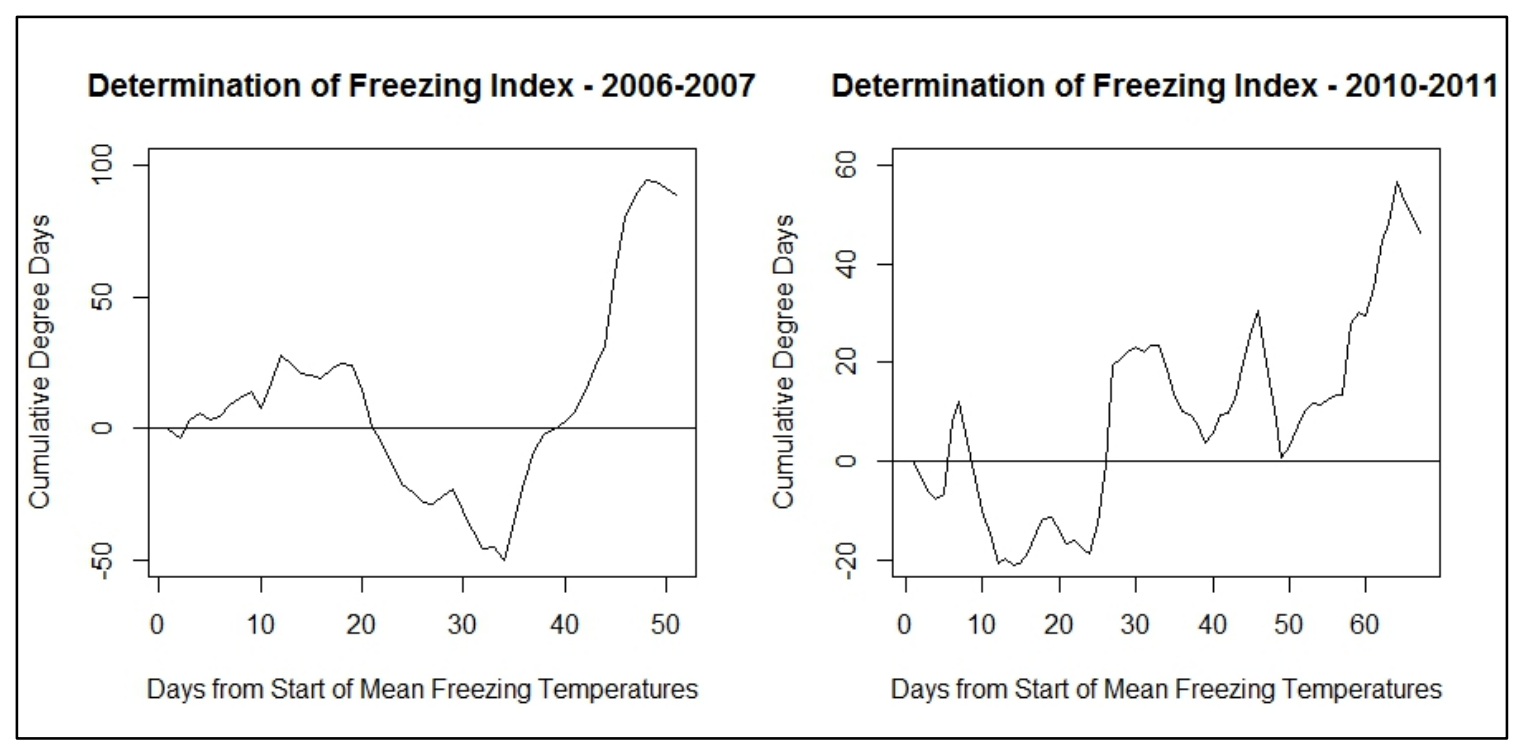

Figure 35: Cumulative Degree Day Plots for Two Winter Seasons

Table 30: Average Freezing Index, Days of Freezing, and Freeze-Thaw Cycles per Time Interval

\begin{tabular}{|c|c|c|c|}
\hline Time Interval & $\begin{array}{c}\text { Average } \\
\text { Freezing Index } \\
\text { (degree-days) }\end{array}$ & $\begin{array}{c}\text { Days of } \\
\text { Freezing }\end{array}$ & $\begin{array}{c}\text { Freeze-Thaw } \\
\text { Cycles }\end{array}$ \\
\hline $2003-2006$ & 69.4 & 21 & 18 \\
\hline $2006-2007$ & 49.9 & 26 & 22 \\
\hline $2007-2011$ & 25.45 & 25.75 & 24.5 \\
\hline
\end{tabular}

It is apparent that there is deviation in the values for freezing index compared to the days of freezing and freeze-thaw cycles. The values for 2007-2011 are very similar for all three freeze-thaw metrics. While freezing index for 2006-2007 is higher than days of freezing and number of freeze-thaw cycles, it follows the same trend of being higher than 2007-2011. What is striking is that for 2003-2006, freezing index is highest out of all time intervals considered, while days of freezing and number of freeze-thaw cycles are the lowest out of the time intervals. This could be due to the fact that freezing index accounts for not only the duration of freezing but also the magnitude, whereas the other 
metrics focus solely on duration. It is possible - though not apparent after studying the data - that there were periods of deep freeze (the degree part of "degree-days") in 20032006 that the other metrics could not account for. What is more likely is that freezing index is not meant to be applied in locations where clear freezing seasons cannot be defined.

Still, it was worth studying the relationship that freezing index had with recession rate and the other variables considered. The final regression analyzed in Table 27 was reanalyzed using freezing index instead of freeze-thaw cycles or days of freezing. The results are shown in Table 31 and Table 32. Using freezing index decreases the value of the regression model and has minimal significance to the regression. Additionally, freezing index has a negative correlation with recession rate while it should have a positive correlation, since increasing freezing index should increase recession rate.

Table 31: Summary of Model-Assumption Statistics for Final Multivariate Linear Regression

\begin{tabular}{|c|c|c|c|c|l|}
\hline $\begin{array}{c}\text { Variables Included* } \\
\text { (listed in order of } \\
\text { decreasing significance) }\end{array}$ & $\begin{array}{c}\text { Sample } \\
\text { Size }\end{array}$ & $\mathrm{R}^{2}$ & $\begin{array}{c}\text { Adjusted } \\
\mathrm{R}^{2}\end{array}$ & $\mathrm{RMSE}$ & \multicolumn{1}{|c|}{ Notes } \\
\hline $\mathrm{f},-(\mathrm{j})^{1 / 2}, \mathrm{~h}, \mathrm{e},(\mathrm{c})^{2}$ & 66 & 0.68 & 0.66 & 0.19 & Uses freeze-thaw cycles \\
\hline $\mathrm{f},-(\mathrm{j})^{1 / 2}, \mathrm{~d}, \mathrm{~h},(\mathrm{c})^{2}$ & 66 & 0.68 & 0.65 & 0.20 & Uses days of freezing \\
\hline $\mathrm{f}, \mathrm{h},-(\mathrm{j})^{1 / 2},(\mathrm{c})^{2},-\mathrm{p}$ & 66 & 0.66 & 0.63 & 0.20 & Uses freezing index \\
\hline
\end{tabular}

*Variables: $a=$ cliff height; $b=$ slope angle; $c=$ weighted shear strength; $d=$ days of freezing; $\mathrm{e}=$ number of freeze-thaw cycles; $\mathrm{f}=$ cliff face direction; $\mathrm{g}=$ rainfall; $\mathrm{h}=\%$ height of $\mathrm{F} 4$ soil; $\mathrm{i}=\%$ height of $\mathrm{F} 3$ soil; $\mathrm{j}=\%$ height of $\mathrm{F} 2$ soil, $\mathrm{k}=\%$ height of $\mathrm{F} 1$ soil; $1=$ vegetation of F4 soil; $\mathrm{m}=$ =vegetation of F3 soil; $\mathrm{n}=$ vegetation of F2 soil; $\mathrm{o}=$ vegetation of F1 soil; $\mathrm{p}=$ freezing index

Table 32: Summary of Variable-Assessment Statistics for Multivariate Linear Regression-Freezing Index 


\begin{tabular}{|c|c|c|c|c|c|}
\hline Variable & Estimate & Std. Error & $\mathrm{t}$ value & $\operatorname{Pr}(>|\mathrm{t}|)$ & Significance $^{\mathrm{a}}$ \\
\hline Height_L4 & 0.5409 & 0.1195 & 4.52 & $0.003 \%$ & $* * *$ \\
\hline$(\mathrm{Su})^{2}$ & $-2.397 \mathrm{E}-05$ & $3.465 \mathrm{E}-05$ & -0.687 & $49.5 \%$ & \\
\hline (Height_L2) $^{1 / 2}$ & -0.2901 & 0.1207 & -2.404 & $1.93 \%$ & $*$ \\
\hline Face & 0.1172 & 0.0242 & 4.838 & $0.0009 \%$ & $* * *$ \\
\hline Freezing Index & $-4.649 \mathrm{E}-05$ & 0.0014 & -0.033 & $97.3 \%$ & \\
\hline
\end{tabular}

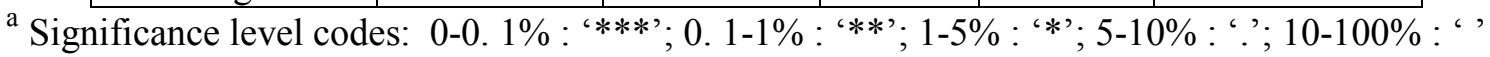

Freezing index would likely be a very useful metric for freeze-thaw in regions where there is a clearly defined freezing season, since it accounts for both duration and magnitude of freezing. It is clear that freezing index is not applicable in this situation. For the Calvert Cliffs, counting the distinct freeze-thaw cycles and days of freezing is more useful.

This means that the final regression to be used to describe the relationship between freeze-thaw and recession rate should use either the number of freeze-thaw cycles of the days of freezing. While either metric could be used for this dataset, because using days of freeze-thaw yields a slightly higher adjusted $\mathrm{R}^{2}$ value and a slightly lower RMSE, that will be the final regression presented. Therefore, recession rate can be defined by the following equation:

$$
\begin{aligned}
\text { Recession Rate }= & 0.0940 * \text { Face Direction }-0.5002 *(\% \text { Height F2 })^{1 / 2} \\
& +0.3081 * \% \text { Height F4 }+0.0135 * \text { Freeze-Thaw Cycles } \\
& -4.528 \mathrm{E}-5 *(\text { Weighted Shear Strength })^{2}
\end{aligned}
$$




\subsection{Relationship between Freeze-Thaw and Recession Rate of the Calvert Cliffs}

As identified at the end of Section 4.3, recession rate can be explained as a function of cliff face direction, percent height of freeze-thaw susceptibility classes F4 and F2, number of freeze-thaw cycles, and weight shear strength. While there are specific coefficients associated with each of the variables, the variables themselves are the most important factor. Statistically, these variables were included in the final regression equation because they led to the highest $R^{2}$ and adjusted $R^{2}$ values while maintaining low $\operatorname{Pr}(>|t|)$ values. However, the selection of these variables and the omission of the other variables can also be assessed qualitatively.

It is first important to consider the variables included in the final regression equation. Based on the $\operatorname{Pr}(>|t|)$ values, the variables that have the highest significance to this final regression equation are cliff face direction, followed by percent height of freeze-thaw susceptibility class F2, percent height of freeze-thaw susceptibility class F4, and number of freeze-thaw cycles. These variables are all directly related to freeze-thaw. The fact that they are considered significant variables in explaining recession rate indicates that freeze thaw is a dominant process in cliff recession. The least significant variable is shear strength. While including shear strength does improve both the $\mathrm{R}^{2}$ and adjusted $\mathrm{R}^{2}$ values for the regression, this variable has very low significance based on the $\operatorname{Pr}(>|t|)$ value. In typical slope stability problems, shear strength is a very important variable (as well as cliff height and slope angle, two variables not included in this regression). The fact that the variables directly related to freeze-thaw are more significant than shear strength also 
indicates that freeze-thaw processes may have more of an effect on cliff recession than typical slope stability processes.

It is also important to consider the variables not included in the final regression equation. These variables were either not directly related to freeze-thaw or did not have much certainty in the way that they were defined. The variables that were not included in the final regression equation are percent height of freeze-thaw susceptibility class F3 and F1, days of freezing, cliff height, slope angle, rainfall, and vegetation. It is not surprising that not all freeze-thaw susceptibility classes were included in the final regression, as they are related (as the percent height of one freeze-thaw susceptibility class goes up, the others go down). As discussed in Section 4.3, there was little difference between the number of freeze-thaw cycles and the number of days of freezing, so including both variables would not add any value to the regression. Vegetation can be related to freeze-thaw processes, but the variable was not defined in a way that added value to the regression. The remaining variables—cliff height, slope angle, and rainfall—are not related to freezethaw, but were rather selected to represent other processes that could be contributing to recession rate. The fact that these variables were not included in the final regression provides further validation that the recession rate at the study sites considered along the Calvert Cliffs is dominated by freeze-thaw processes.

This final multivariate linear regression utilizing cliff face direction, percent height of freeze-thaw susceptibility classes F4 and F2, number of freeze-thaw cycles, and weight shear strength is able to explain over $65 \%$ of recession rate (based on an $\mathrm{R}^{2}$ value of 0.68). Because of the variables used in this regression, it can be said that freeze-thaw is 
the dominant erosion mechanism where waves do not control recession along the Calvert Cliffs. The predicted versus observed plot for this regression-Figure 30 - as well as the regression equation, can be found in Section 4.3. There is certainly some scatter from the 1:1 line in Figure 30. However, due to the complex nature of this problem, further study would be needed to try to reduce the uncertainty in the inputs and evaluate other critical variables. While fifteen variables were considered to explain recession rate (sixteen with the inclusion of freezing index), there are quite likely other factors that contribute to recession rate. The main goal of this research was to assess if freeze-thaw controls recession where waves do not interact with the cliff toe at the Calvert Cliffs. If the goal was to be able to explain $100 \%$ of cliff recession, other factors such as seepage, wind erosion, and even animal burrowing would need to be considered.

It should also be noted that, due to the removal of outliers from the dataset, this relationship between freeze-thaw and recession rate cannot be applied to slopes greater than 55 degrees or sites with measured recession rate higher than 0.8 meters per year. Higher angles could potentially be reintroduced into the model if more data was collected for slopes with these higher slope angles. Sub-sites with high measured recession rates could likely not be reintroduced into this model. They were not omitted due to a lack of data; rather, they were omitted because no linear regression using the variables considered was able to predict recession rates above 0.8 meters per year. It is likely that other factors that were not considered were the cause for these high recession rates. This means that, short of trying to introduce new variables to the dataset, these high recession rates cannot be explained by freeze-thaw alone. There was not a distinct spatial or 
temporal trend to the data points considered outliers, as seen in Table 26, so nothing about any specific study site or time interval can be used to explain this.

\subsection{Future Work}

This work does successfully establish a relationship between freeze-thaw and recession rate. However, more could be done to further understand some aspects of the research.

One area that could benefit from additional work is the thermal modeling of the cliffs. Freeze-thaw was quantified in a number of ways (freeze-thaw susceptibility, number of freeze thaw cycles, vegetation, etc.), but the thermal properties of the materials composing the Calvert Cliffs were never studied or included in the work. Rather than trying to find an indirect relationship between recession rate and a variety of variables selected to represent freeze-thaw in one way or another, knowing the thermal properties of the soil would allow for a more direct relationship. Knowing thermal properties, like thermal conductivity, would enable the determination of the depth of freeze-thaw penetration, which could then directly be related to recession rate. In-situ testing or laboratory testing would enable the thermal properties of the cliffs to be more completely understood. Having temperature measurements for each study site would also improve the thermal modeling of the cliffs. Rather than assuming temperature is constant for the entire length of the Calvert Cliffs, it would enable the potential microclimate of each study site to be included in the analysis.

Additionally, soil sampling of all soil layers present in the cliffs, specifically those that produce "non-disturbed" samples, could be beneficial. Laboratory testing on freezing 
behavior of the soils could be studied. Additionally, having a full grain size analysis run for all soil samples would enable the use of the original Army Corps freeze-thaw susceptibility rankings, rather than having to adjust grain size ranges to accommodate the historical data that was used.

The recession rate determination methods could also be improved. Recession rate data spanning more than eight winter seasons would certainly provide a more comprehensive understanding of the recession rate trends present at the Calvert Cliffs, especially due to the episodic nature of the cliff recession. The aerial photographs used in this analysis had high resolution, but in some instances the measured recession rate was lower than the image resolution, so those small recession rates were assumed to be zero. Methods with higher recession rates would enable the incorporation of these smaller recession rates into future models. Additionally, in many cases the study sub-sites were selected because the top of the cliff was not obscured from vegetation (so that recession of the cliff top could be measured). There are emerging methods of mapping, like LiDAR, that enable features like vegetation to be trimmed from the dataset, revealing the ground surface below. This data processing is more rigorous than simply analyzing aerial photographs, but can also be more powerful (National Oceanic and Atmospheric Administration (NOAA) Coastal Services Center 2012). LiDAR data was collected for the Calvert County shoreline (i.e. the Calvert Cliffs) in 2003 and 2011; however, the data only had \pm 5 meter accuracy due to the point spacing used in the data collection, which is not high enough resolution for studying cliff recession meaningfully. In the future, using recession rate determination methods with higher accuracy could be used to more precisely monitor cliff recession at both the top of the cliff and the toe of the cliff. For portions of the Calvert Cliffs not 
affected by waves, the toe of the slope should remain constant, and therefore tracking cliff top recession could be used to monitor slope stabilization over time as the cliff approaches a stable angle.

There is also a debate as to the source of the beach sand along the Calvert Cliffs. Some believe that the beach is primarily fed from eroding cliff material. If this is the case, then stabilizing the Calvert Cliffs will stop the replenishment of the beach material. Homeowners and vacationers alike utilize the beach for recreational activities. While stabilizing the cliffs would increase the safety of these recreational beach activities, a lack of natural beach replenishment would limit these activities. Sand from other sources could be brought in for beach replenishment, but this is often a costly option. However, others believe that the beach sand comes primarily from streams feeding the bay and is deposited along the Calvert Cliffs due to littoral drift. If this is the case, then cliff stabilization would have no impact on the future of the beaches along the Calvert Cliffs. It would be beneficial for a study of the source of the beach sand along the Calvert Cliffs to be conducted so that the impacts (or lack thereof) of cliff stabilization on the future of the beaches along the Calvert Cliffs could be assessed.

Lastly, the critical variables identified in the relationship developed between freeze-thaw and recession rate could be used to address future cliff recession. Using the key variables identified, all regions of the Calvert Cliffs could be assessed to determine the areas that have the highest freeze-thaw susceptibility and therefore the highest risk of future cliff recession. Potential solutions to address these key variables could be considered as remediation techniques. A brief discussion on potential remediation follows in Chapter 5. 
Similar analyses could also be conducted for other coastal cliffs, as coastal cliff erosion is hardly a problem that is unique to the Calvert Cliffs. 


\section{Chapter 5: Conclusions and Recommendations}

Freeze-thaw driven cliff recession is clearly a problem at the six study sites analyzed where waves do not control recession. Based on the variables considered (specifically cliff face direction, the percent of total cliff height composed of soil with freeze-thaw susceptibility F4 and F2, the number of freeze-thaw cycles, and the weighted shear strength), over $65 \%$ of the cliff recession that occurred between 2003 and 2011 can be explained by freeze-thaw-related factors.

As discussed in Section 4.4, the variables that were included in the final regression equation are related to freeze-thaw processes, while those that were not included in the final regression are not directly related to freeze-thaw processes. Literature supports these conclusions. The Army Corps of Engineers' frost susceptibility classification is a widely used method to represent the freezing potential of different soils (Department of the Army Corps of Engineers Office of the Chief of Engineers 1984); the depth of freezing experienced dictates the depth of the weakened zone of soil (Gatto 1995), which leads to slope failure and cliff recession. Soil shear strength is also widely accepted to be a key factor in slope stability (Duncan \& Wright 2005). Cliff face direction, which is used to represent differences in winter sun exposure, has been shown to have an effect of the freeze-thaw behavior of slopes (Gatto 1995; Harlan and Nixon 1978); this has also anecdotally been observed along the Calvert Cliffs. Gatto (1995) suggested indirectly that the number of freeze-thaw cycles - similar to fall freezing conditions - may be more critical to cliff recession than the number of days of freezing — similar to spring thawing conditions. While cliff height and slope angle have been shown to affect slope instability 
(Edil and Vallejo 1980), they have not been shown to directly relate to cliff recession (Buckler and Winters 1983; Kamphuis 1987). Vegetation will be discussed later in this section, but it should have an effect on the freeze-thaw behavior of slopes. The last variable to consider is rainfall. While soil moisture has been proven to be very important to the freeze-thaw behavior of soil, especially soil slopes (Gatto 1995; Kawamaura and Miura 2011; Michalowski and Zhu 2006a), rainfall was used to try to represent storm activity. In any case, there was not enough variation in the average rainfall amounts for the time periods being considered for it to add value to the regression.

The study conducted was only aiming to assess the freeze-thaw behavior of the Calvert Cliffs and to determine if a meaningful relationship exists between freeze-thaw and recession rate at study sites not affected by waves. This was shown to be true. The study was not aiming to account for $100 \%$ of cliff recession. Due to the complex nature of the cliffs, accounting for all factors contributing to cliff recession would be very difficult if not impossible. However, to account for more than $65 \%$ of cliff recession, other potential recession-driving factors like seepage, wind erosion, and soil desiccation would need to be considered.

Freeze-thaw processes have proven to be the dominating factor controlling coastal cliff erosion where waves do not regularly interact with the Calvert Cliffs. Other analyses on coastal cliff erosion in regions that experience some level of freezing and thawingwhether it is seasonal freezing or short-term cyclic freezing like the Calvert Cliffsshould assess the contributions of freeze-thaw, especially where waves do not regularly interact with the slope toe. Freezing index would likely be a very useful metric for freeze- 
thaw in regions where there is seasonal freezing, since it accounts for both duration and magnitude of freezing. However, it is clear that freezing index is not applicable in this situation. For the Calvert Cliffs and other locations experiencing short-term cyclic freezing, counting the distinct freeze-thaw cycles and days of freezing is more useful.

It should also be considered that the factors affecting cliff recession at the Calvert Cliffs are likely to change with time. Significant changes in precipitation loads would cause changes in the groundwater table elevation, affecting slope stability. Additionally, sea level rise in the Chesapeake Bay has been observed to increase in recent years; one estimate is that the average sea level rise in the 1900's was three millimeters per year, while the current average sea level rise is as high as four millimeters per year. This, coupled with land subsidence, could have long term stability implications, as previous work on similar coastal bluffs along the Great Lakes has shown that an increase in sea level corresponds to an increase in bluff recession (Brown et al. 2005; Vallejo 1988; Zurek et al. 2003). This work on bluff stability along the Great Lakes was looking at sites already affected by wave action; the impact of sea level rise would likely be magnified if waves started impacting slopes that were previously affected by other factors like freezethaw.

In order to mitigate cliff recession at the six study sites considered along the Calvert Cliffs, freeze-thaw needs to be addressed, specifically the five variables identified in the final multivariate linear regression. Cliff face direction and number of freeze-thaw cycles are two variables that cannot be addressed; cliff face direction is a function of geography, and the number of freeze-thaw cycles is a function of the weather, both of which cannot 
be controlled by humans. There are several mitigation approaches that could be utilized to address the remaining variables used to represent freeze-thaw processes.

The recession-mitigations suggestions that follow do not take into account current regulations or permitting procedures, as this is far outside of the scope of this research. Based on a recommendation from the Cliff Stabilization Advisory Committee (for information on the CSAC committee, see: Calvert County 2013), the Calvert County Department of Community Planning and Building has developed the "Calvert Shoreline Development Guide", which outlines the permit process governing all shoreline erosion control projects (including both living shoreline projects and structural control projects) and serves as an aid for community members. The Calvert Shoreline Development Guide outlines the complex process with 102 pages of text and 33 pages of flow-charts; an interactive web-based system is also available (CSAC-Meeting 2012). Any projects being conducted along the Calvert Cliffs generally need a combination of county, state, and/or federal approval due to the proximity to the Chesapeake Bay.

The first potential mitigation solution to address cliff recession caused by freeze-thaw is vegetation. It is well established that vegetation slows recession driven by freeze-thaw processes. Vegetation serves to insulate the soil, which limits the soil's heat loss to the air and reduces the depth of freezing. The deeper the soil freezes, the more surface soil will be susceptible to instability and recession (Gatto 1995). While vegetation condition was one of the variables considered in the multivariate linear regressions, it was one of the variables with the most uncertainty (see Section 4.2.2 for explanation). Despite that vegetation conditions (as defined in this study) did not have a strong correlation to 
recession rate, increasing vegetation on the slopes should prove to decrease recession rate due to the effect of insulation. It should be noted that deciduous vegetation, which is what is often found along the Calvert Cliffs, would not provide as much insulation as yearround vegetation. Vegetation can also help to increase the shear strength of the soil because of the tensile strength of the roots. This shear strength increase only extends to the depth of roots, and is a function of root shape, root diameter, root orientation, and growing environment (Gray and Sotir 1996). According to the Army Corps of Engineers (1981a), slope angle and regional conditions - like climate, soil types and properties, exposure to waves, and salinity - affect the type of vegetation that can grow successfully on cliffs. Cliffs with slopes between $1 \mathrm{~V}: 3 \mathrm{H}$ and $1 \mathrm{~V}: 1 \mathrm{H}$ can be planted with grasses, ground covers, trees, shrubs or combinations that will not require maintenance. Cliffs with slopes steeper than $1 \mathrm{~V}: 1 \mathrm{H}$ tend to impede the successful establishment of vegetation (Department of the Army Corps of Engineers 1981a). However, slopes steeper than this along the Calvert Cliffs were observed with vegetation present, indicating that vegetation could be used. A Best Management Plan was developed in 2006 for the community of Scientists' Cliffs (from this study, sites SCN and SCS) which demonstrated that vegetated slopes suffered less freeze-thaw-driven recession than un-vegetated slopes. All but two of the sub-sites used in this study that are located in Scientists' Cliffs had slopes steeper than $1 \mathrm{~V}: 1 \mathrm{H}$, further validating that vegetation can help slow recession rates along the Calvert Cliffs (Miller et al. 2006). Vegetation is one of the most inexpensive ways to stabilize a slope. While vegetation is not able to singlehandedly resist recession due to heavy wave action or groundwater effects (Department of the Army Corps of Engineers 
1981b), it can be successful in at least slowing recession in slopes predominantly controlled by freeze-thaw processes.

Another mitigation approach that would help address recession caused by freeze-thaw would be infiltration and drainage control. Freeze-thaw cannot occur if there is not water to freeze. While it is improbable to remove all water from the face of the cliffs, controlling the amount of water, especially after periods of heavy rainfall or raised groundwater table levels, can help increase stability (Department of the Army Corps of Engineers 1981a). Drainage of water present in slopes is typically achieved through the use of horizontal or vertical drains, and is almost always effective at stabilizing slopes that cannot be otherwise stabilized by re-grading (Department of the Army Corps of Engineers 1981b). Horizontal wick drains are a relative new technique; installation is less expensive and time-intensive, and durability has been proven to be no less effective than traditional drains (Mininger et al. 2011). Patented methods exist for such horizontal wick drain systems (Jackson 2003). However, they are typically used in locations that experience deep-seated slides, rather than the shallow slides that are typical along much of the Calvert Cliffs. The amount of disturbance that the slopes would need to endure during installation would need to be considered, especially if only surficial failure is expected. Additionally, a potential issue with wick drains is that most of the homes along the Calvert Cliffs utilize water wells and have septic tanks rather than being connected to public water and sewer; dewatering operations would need to keep this in mind. Infiltration and drainage control at the top of the slope, especially diverting runoff away from the slope face, may be just as effective as horizontal wick drains. A more detailed analysis would need to be conducted to fully assess the feasibility of such options. 
While vegetation does serve to increase shear strength of soil through the root zone, one of best ways to mitigate low soil shear strength is through structural soil reinforcement. Some examples of structural reinforcement are soil nailing (see Tanyu et al. 2008) or surficial shotcrete application with weep holes (see Abramson et al. 2002). Soil nailing would be effective against both shallow and deep-seated slides, while shotcrete would only be able to protect against shallow failures typical of freeze-thaw cliff recession. These structural methods are the most expensive, most destructive, and the least likely to get permitted in such an environmentally sensitive area.

Unless the variables related to cliff recession affected by freeze-thaw are addressed and slope stability is achieved through vegetation, soil wick drains, or other mitigation techniques, cliff recession at these six study sites along the Calvert Cliffs will continue to occur until a stable slope angle is achieved and maintained. 


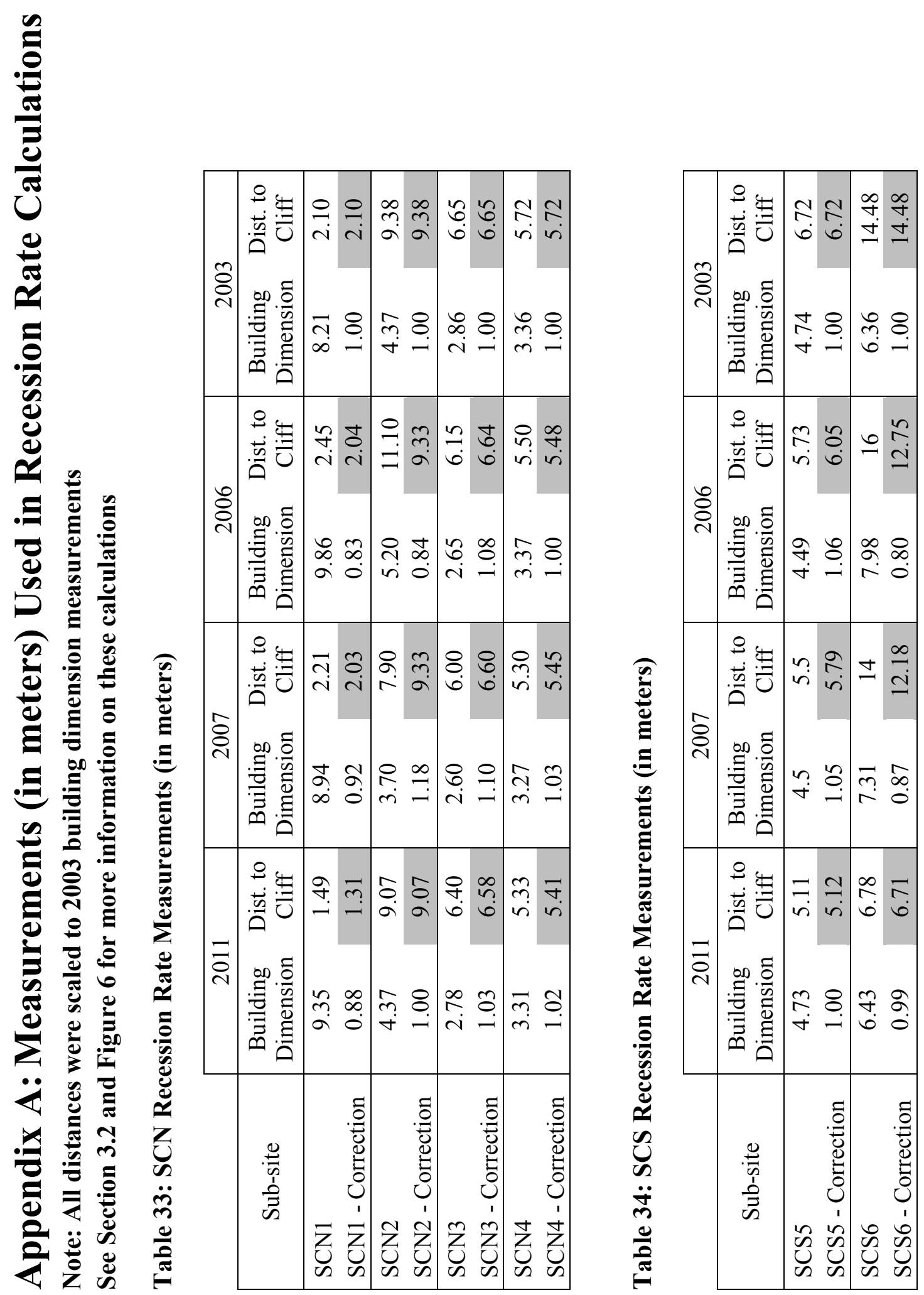

A-1 


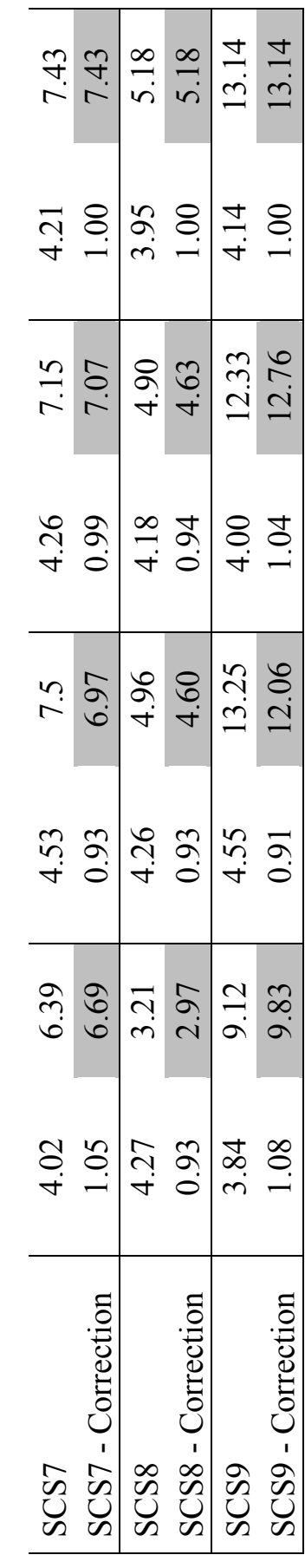
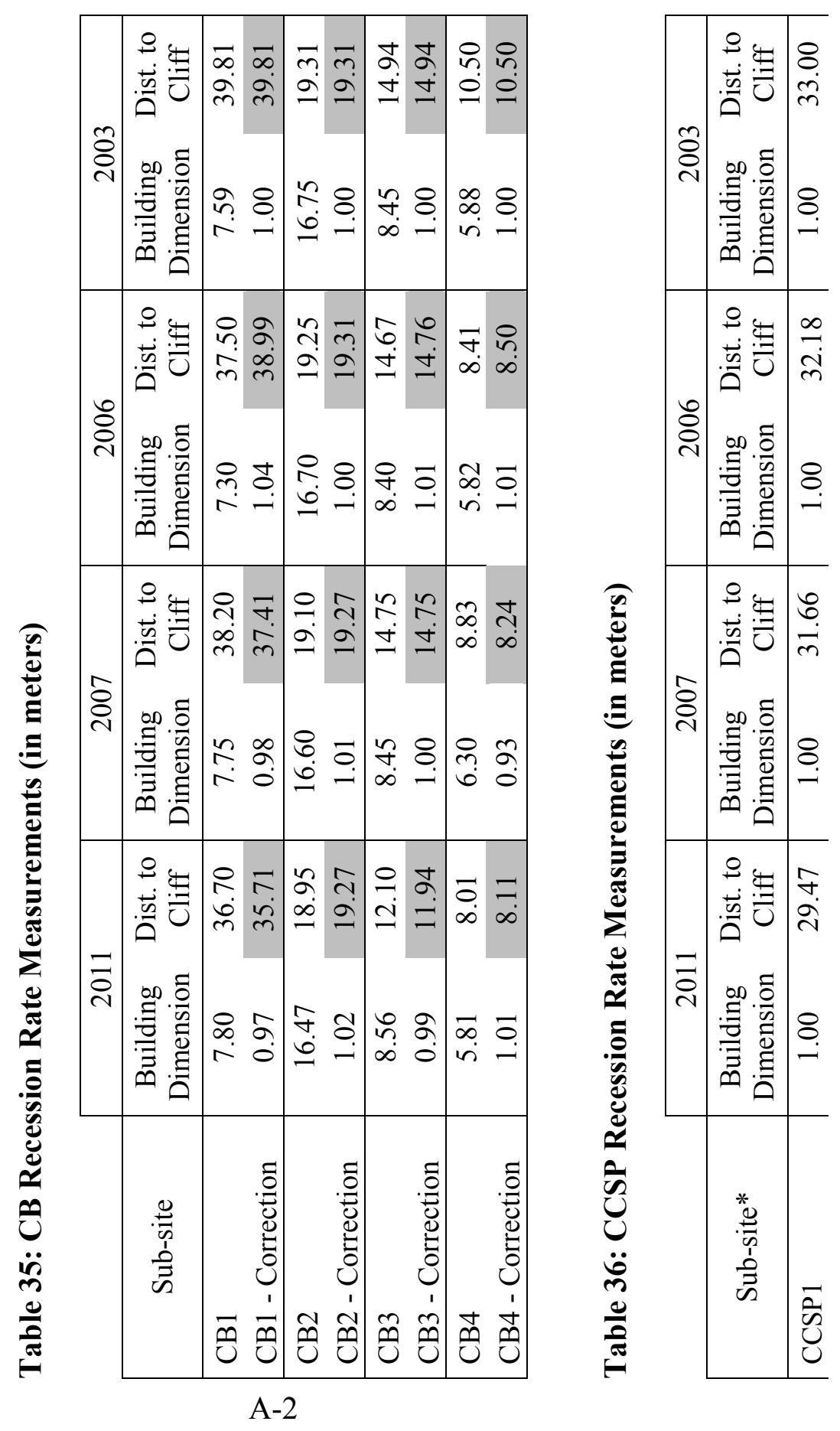

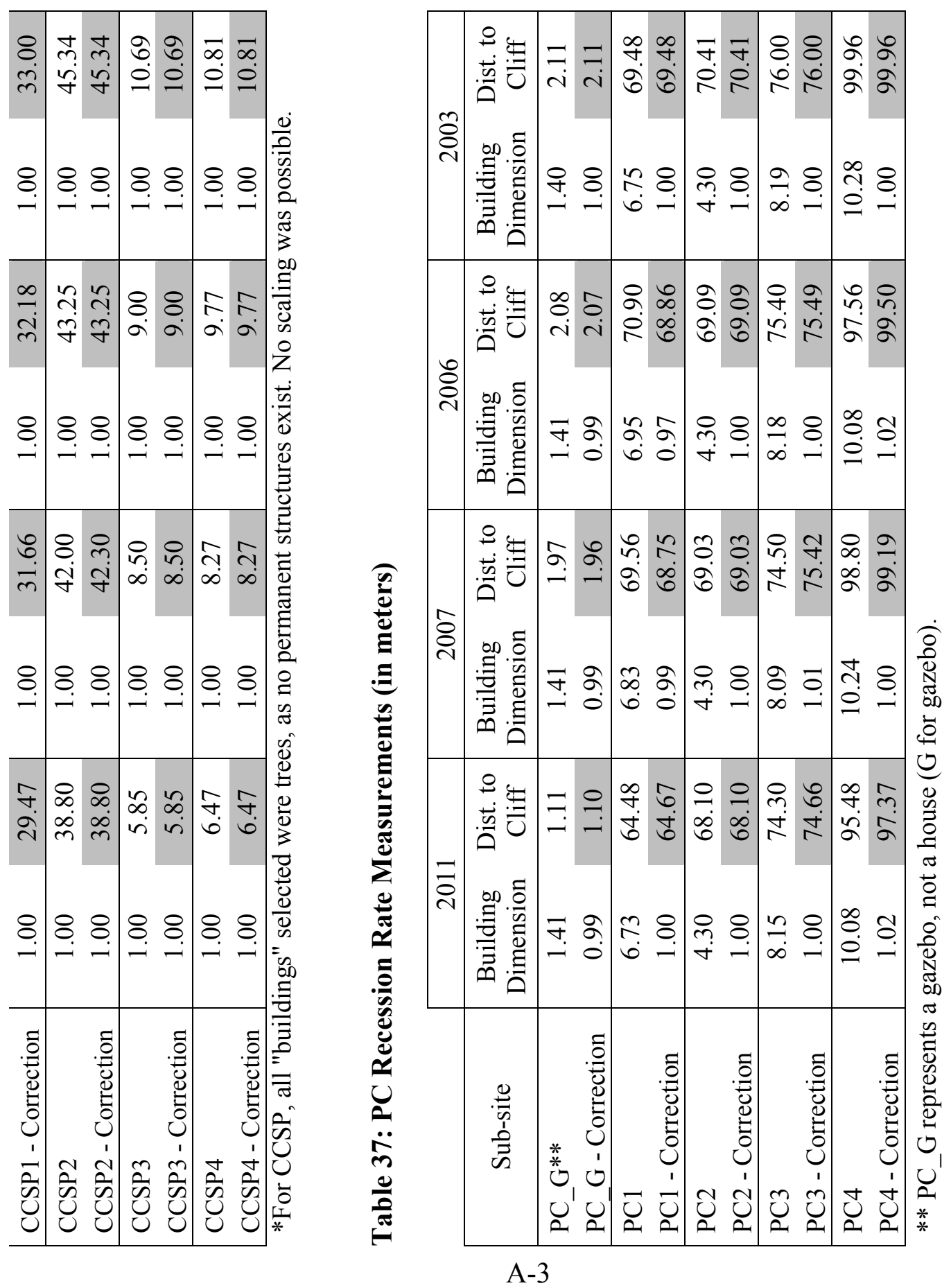

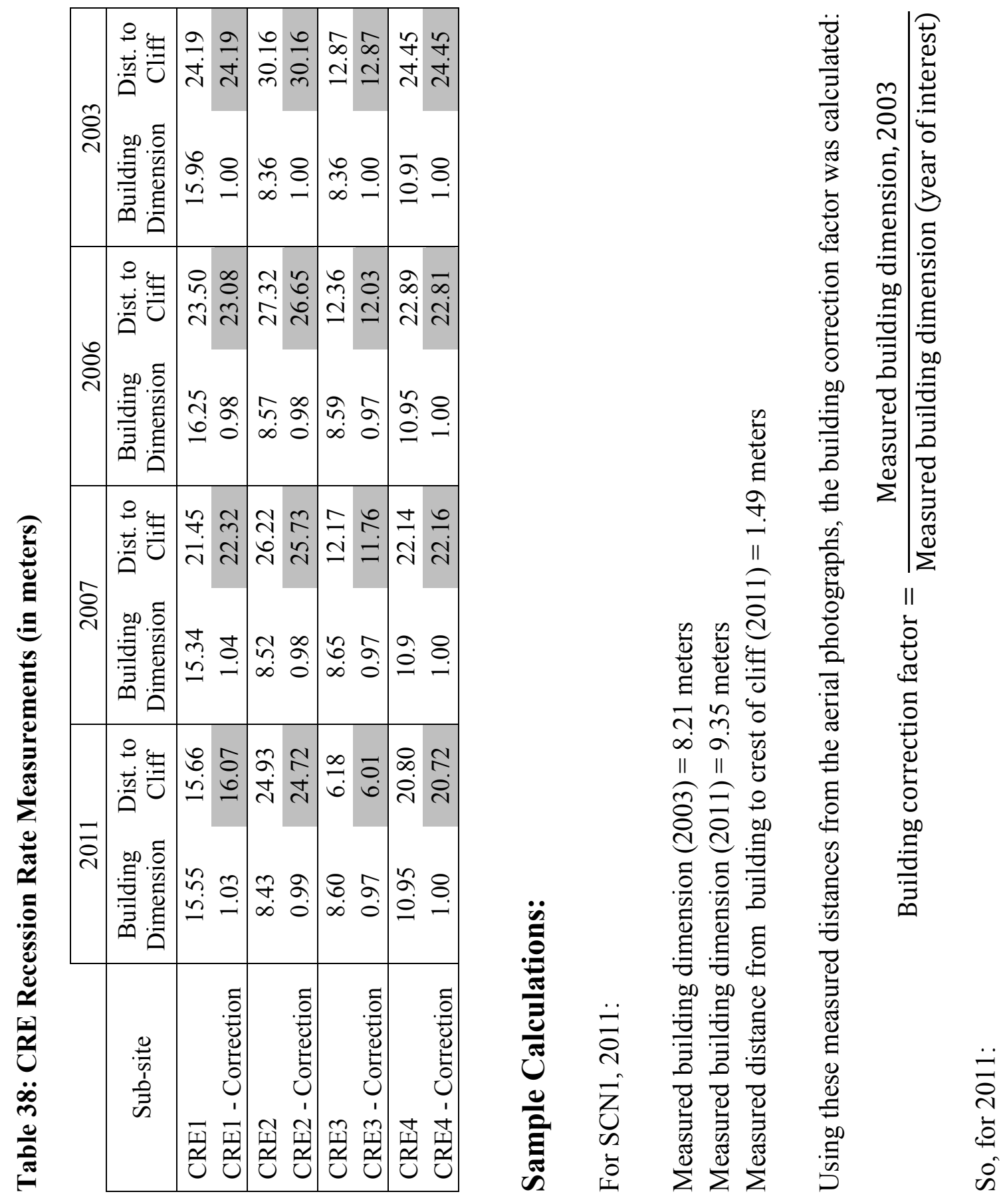

A-4 


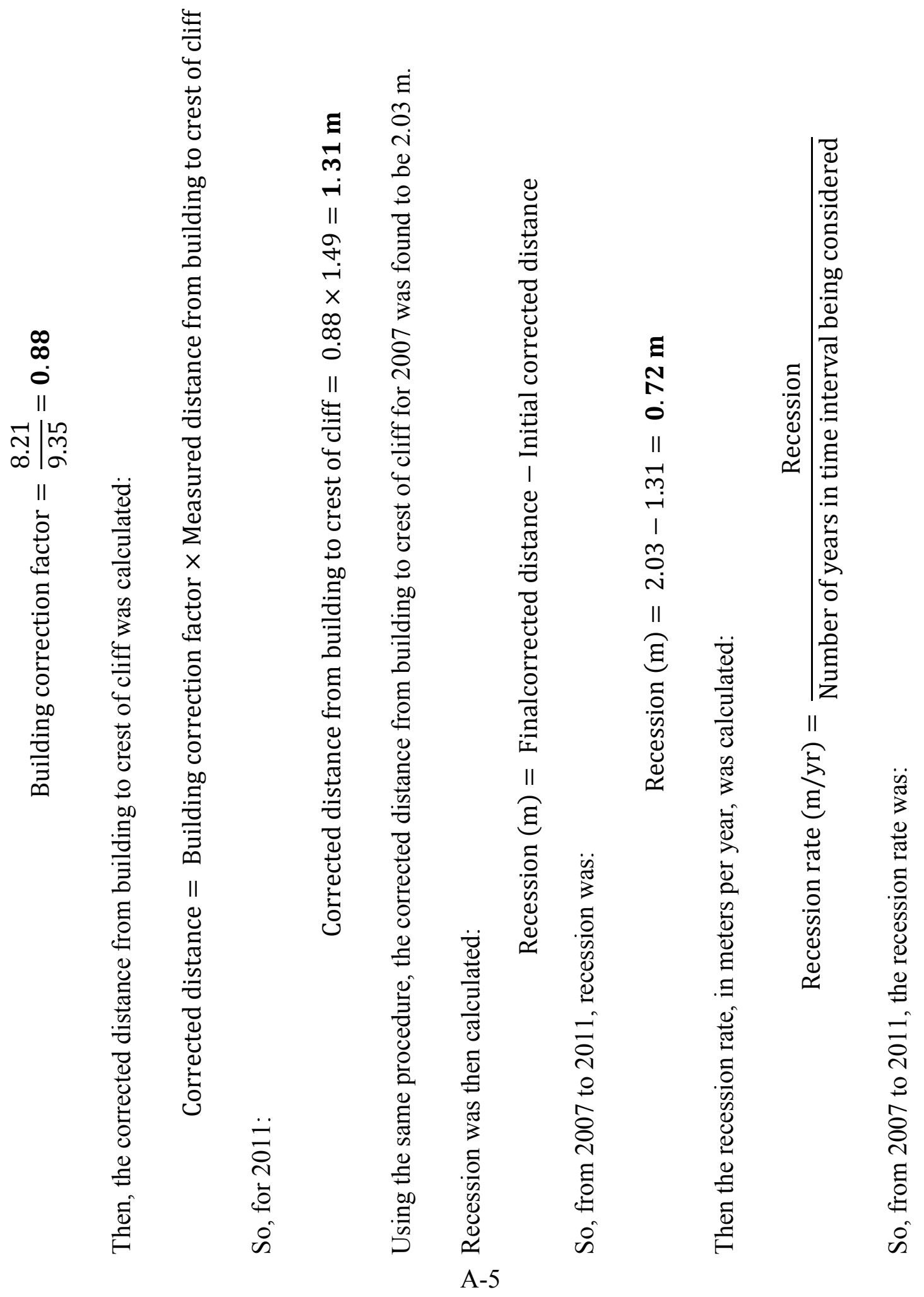




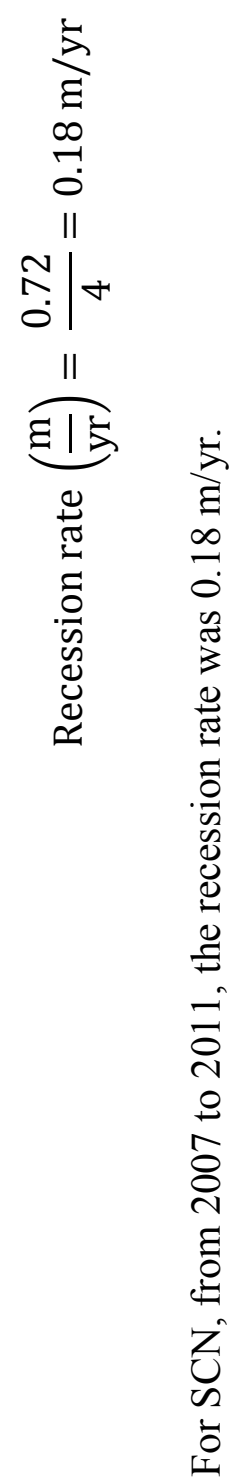

A-6 


\section{Appendix B: Kriging for Spatial Trends in Temperature Data}

Rather than assuming that the temperature profile of the entire Calvert Cliffs was the same and could be represented by using a single weather station, the spatial trends in temperature were assessed. Temperature data was obtained from 19 sites from NCDC/NOAA (2012b). The sites were:

- Andrews Air Force Base

- Annapolis

- Bishops Head

- BWI Airport

- Cambridge/Dorchester

- Cambridge

- College Park

- Cove Point

- Easton

- Francis Scott Key
- Lewisetta

- Patuxent River NAS

- Solomons

- Stevensville

- St. Mary's

- Thomas Point

- Tipton

- Washington National

- Webster

The low daily temperature was used in this analysis, as that is what would control freezing. It was assumed that a UTM coordinate system was used, and that it referenced NAD83. It was also assumed that the elevations stated for each data set (above mean sea level) were at the ground surface at each site; that is, if an elevation was stated as 5 meters, it was assumed that the ground surface elevation was also 5 meters and that the reading was not taken above the ground surface.

For the analysis, all data that was available for the time period of interest was used-not all sites had continuous data for all years. The spatial trends for a single year were assessed first, in order to see if any spatial trends held true. The time period considered was August 1, 2010 to August 1, 2011. Ordinary kriging was performed in order to investigate the spatial and temporal trends in the temperature data. Three models were considered — spherical, exponential, and Gaussian — and the most suitable model was determined using cross validation. For select dates within the time period considered, spatial temperature trends were also plotted so that the spatial trends could be observed.

This analysis was conducted using R 2.15.0, as well as a number of R packages. The packages used are listed below along with a citation for each. 
- maps (Becker et al. 2012)

- sp (Bivand et al. 2008; Pebesma and Bivand 2005)

- $\quad$ spdep (Bivand et al. 2011c)

- gstat (Pebesma 2004)

- splancs (Rowlingson et al. 2012)

- $\quad$ spatstat (Baddeley and Turner 2005)

- pgirmess (Giraudoux 2011)

- RColorBrewer (Neuwirth 2011)

- $\quad$ 1071 (Dimitriadou et al. 2011)

- classInt (Bivand et al. 2011a)

- spgwr (Bivand et al. 2011b)
- RgoogleMaps (Loecher 2011)

- Rgdal (Keitt et al. 2012)

- Geomapdata (Lees 2011)

- Automap (Hiemstra et al. 2008)

- Rpanel (Bowman et al. 2007)

- fields (Furrer et al. 2012)

- RODBC (Ripley and Lapsley 2012)

- intamap (Pebesma et al. 2010)

- plyr (Wickham 2011)

- maptools (Lewin-Koh et al. 2012)

- ape (Paradis et al. 2004)

The first date that was analyzed within the time period considered was August 1, 2010, the first date in the time period. The spatial analysis for this date can be seen in Figure 36. The model that provided the best spatial interpolation for temperature was the exponential model, since it had the lowest RMSE/sd (root mean squared error over standard deviation) value; for the exponential model, the RMSE/sd value was 1.068. However, since the RMSE/sd values for all models considered were close to 1, kriging is not able to explain the temperature data any better than the mean value is. The mean value for the available data for this date was 69.1 degrees Fahrenheit. 


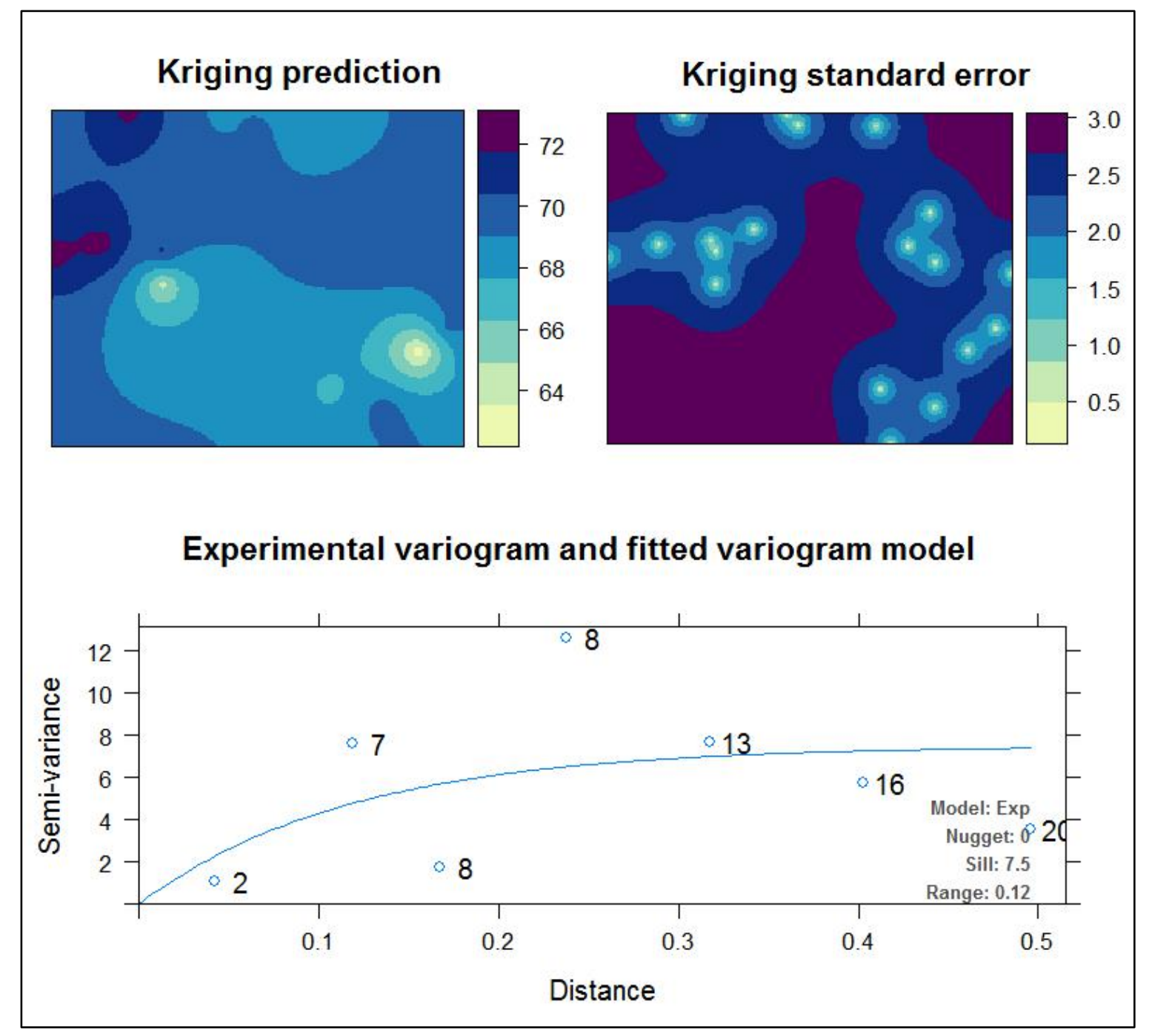

Figure 36: Spatial Interpolation of Temperature Using Kriging for 8/1/2010 Exponential Model

The second date that was analyzed within the time period considered was October 15, 2010. This date was selected to observe fall trends. The spatial analysis for this date can be seen in Figure 37. The model that provided the best spatial interpolation for temperature was also the exponential model, since it had the lowest RMSE/sd (root mean squared error over standard deviation) value; for the exponential model, the RMSE/sd value was 0.8175 . However, since the RMSE/sd values for all models considered were close to 1 , kriging is not able to explain the temperature data better than the mean value is. The mean value for the available data for this date was 50.6 degrees Fahrenheit. 


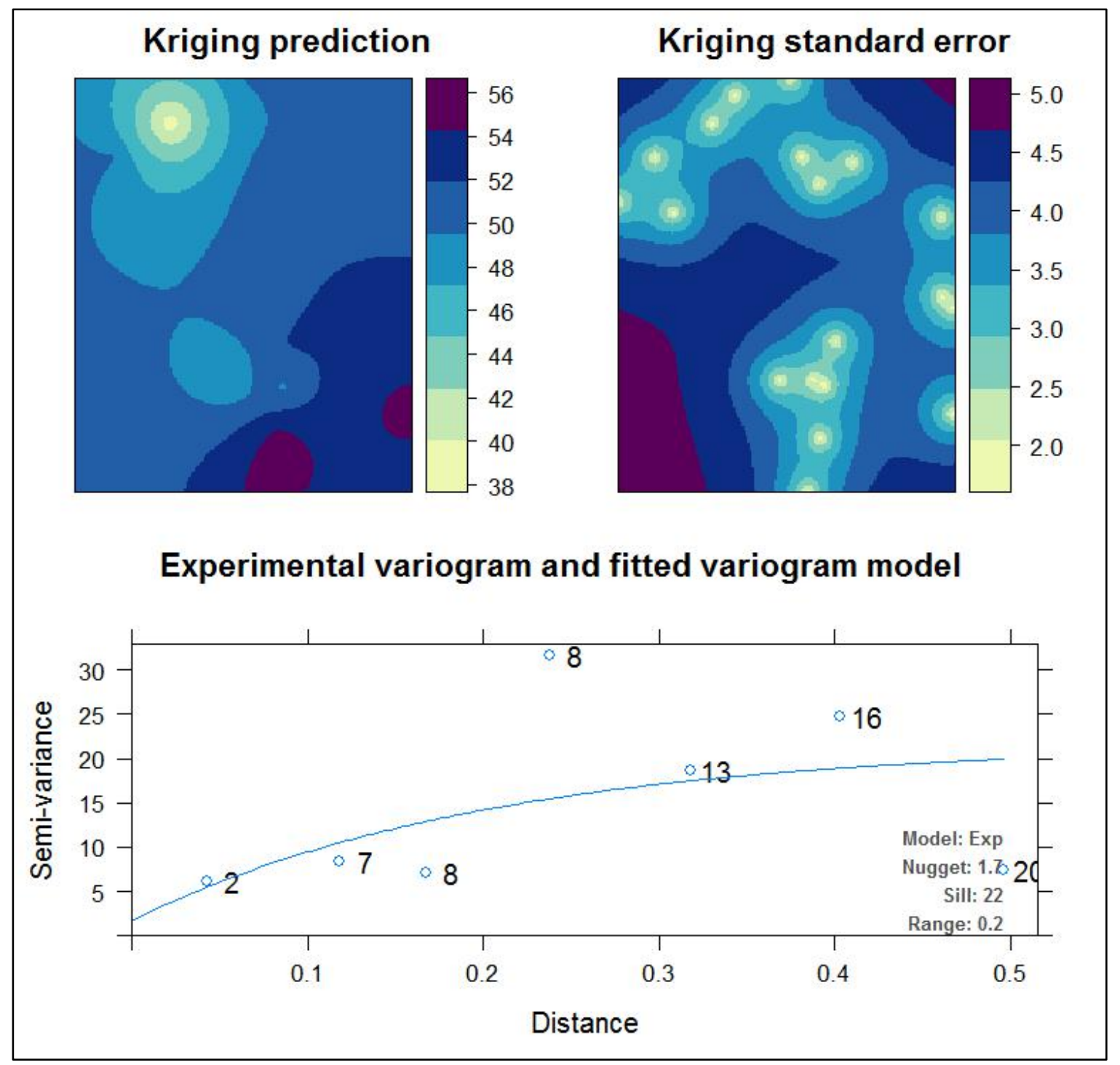

\section{Figure 37: Spatial Interpolation of Temperature Using Kriging for 10/15/2010 - Exponential Model}

The third date that was analyzed within the time period considered was January 1, 2011. This date was selected to observe winter trends. The spatial analysis for this date can be seen in Figure 38. The model that provided the best spatial interpolation for temperature was also the exponential model, since it had the lowest RMSE/sd (root mean squared error over standard deviation) value; for the exponential model, the RMSE/sd value was 0.9398. However, since the RMSE/sd values for all models considered were close to 1 , kriging is not able to explain the temperature data better than the mean value is. The mean value for the available data for this date was 33.7 degrees Fahrenheit. 


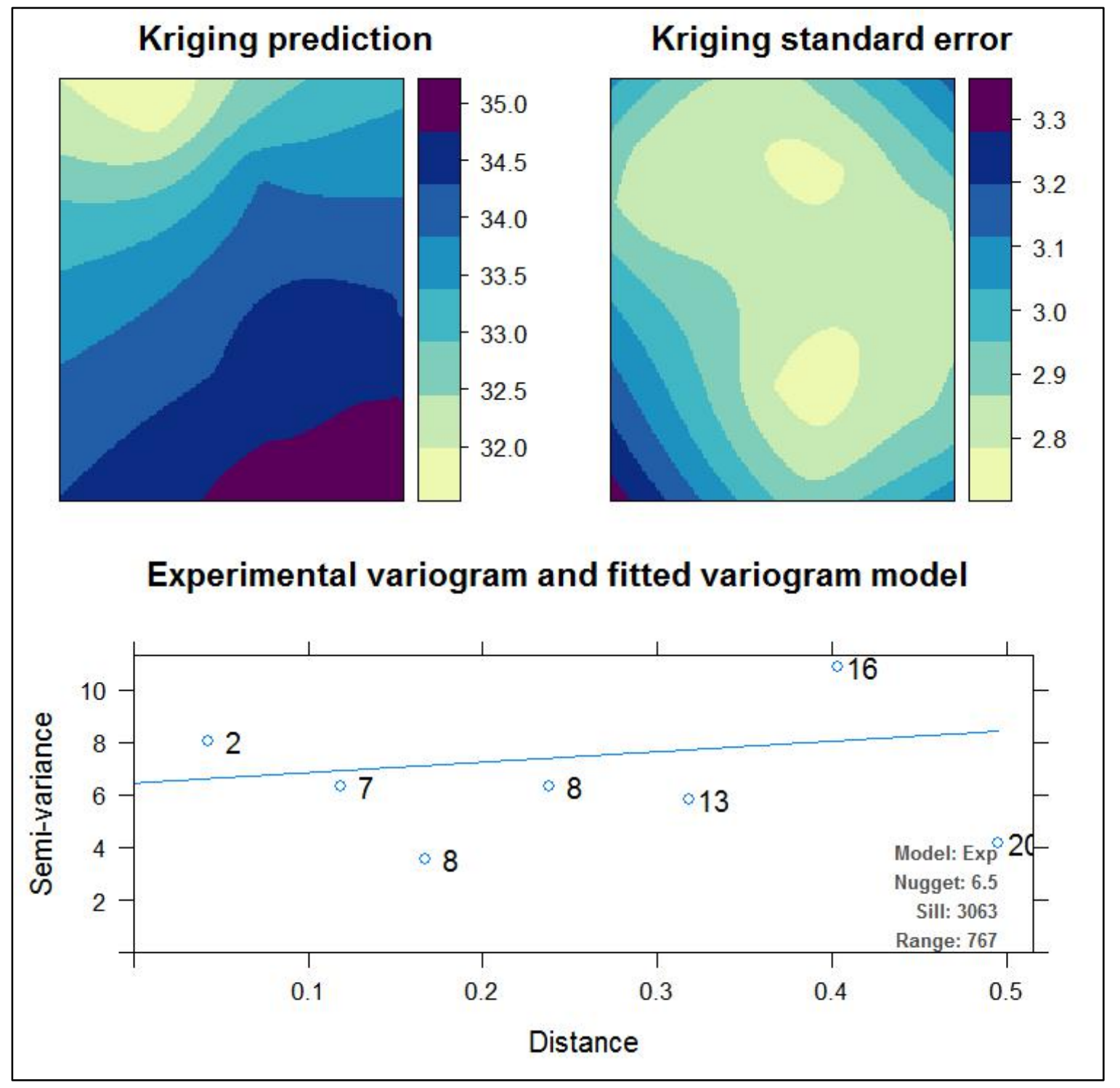

Figure 38: Spatial Interpolation of Temperature Using Kriging for 1/1/2011 Exponential Model

The fourth date that was analyzed within the time period considered was April 15, 2011. This date was selected to observe spring trends. The spatial analysis for this date can be seen in Figure 39. The model that provided the best spatial interpolation for temperature was the spherical model, since it had the lowest RMSE/sd (root mean squared error over standard deviation) value; for the exponential model, the RMSE/sd value was 1.027. However, since the RMSE/sd values for all models considered were close to 1, kriging is not able to explain the temperature data better than the mean value is. The mean value for the available data for this date was 47.6 degrees Fahrenheit. 


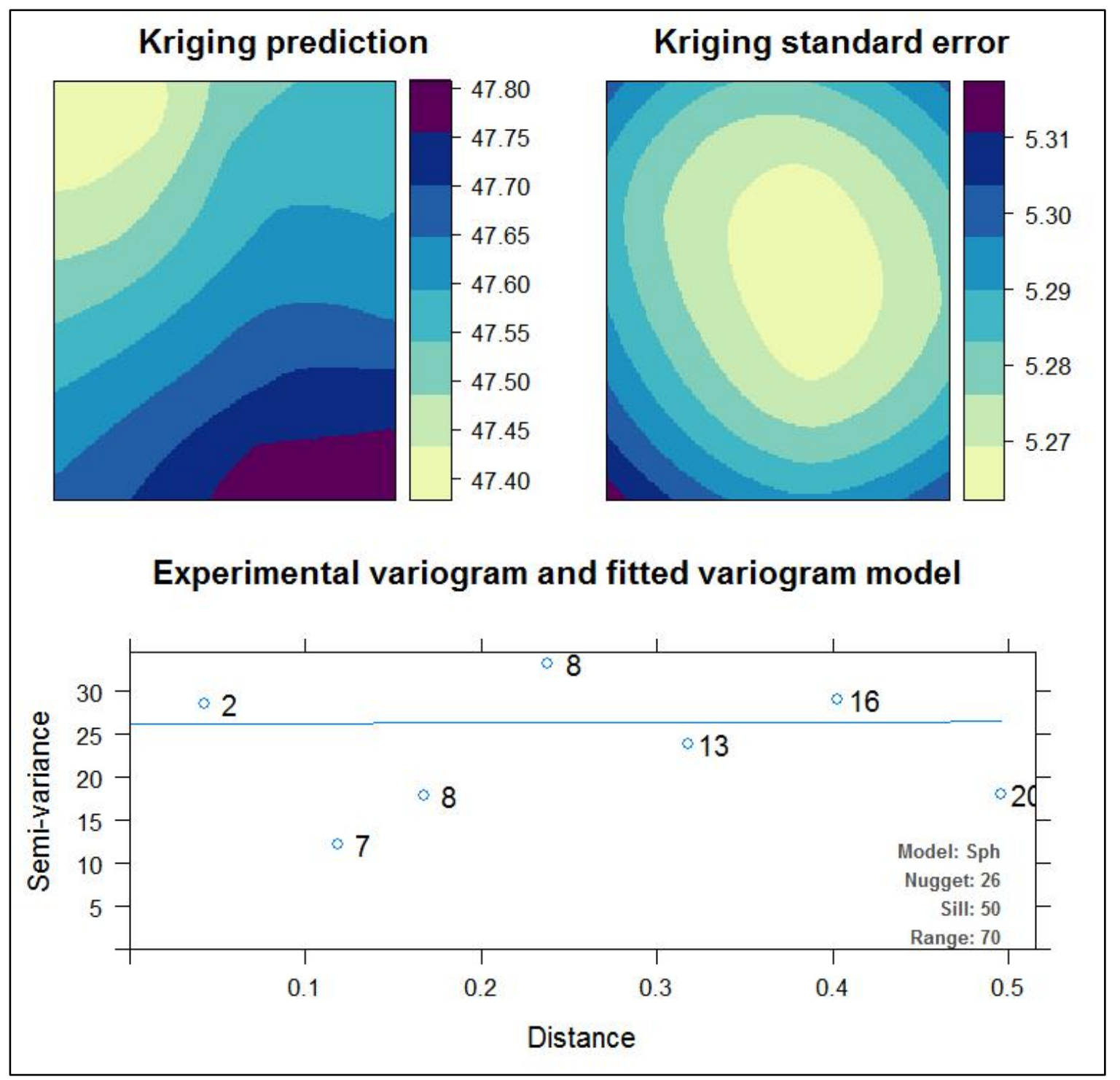

Figure 39: Spatial Interpolation of Temperature Using Kriging for 4/15/2011 Spherical Model

The last date that was analyzed within the time period considered was August 1, 2011, the last date in the time period. The spatial analysis for this date can be seen in Figure 39. The model that provided the best spatial interpolation for temperature was the exponential model, since it had the lowest RMSE/sd (root mean squared error over standard deviation) value; for the exponential model, the RMSE/sd value was 1.030. However, since the RMSE/sd values for all models considered were close to 1 , kriging is not able to explain the temperature data better than the mean value is. The mean value for the available data for this date was 74.11 degrees Fahrenheit. 


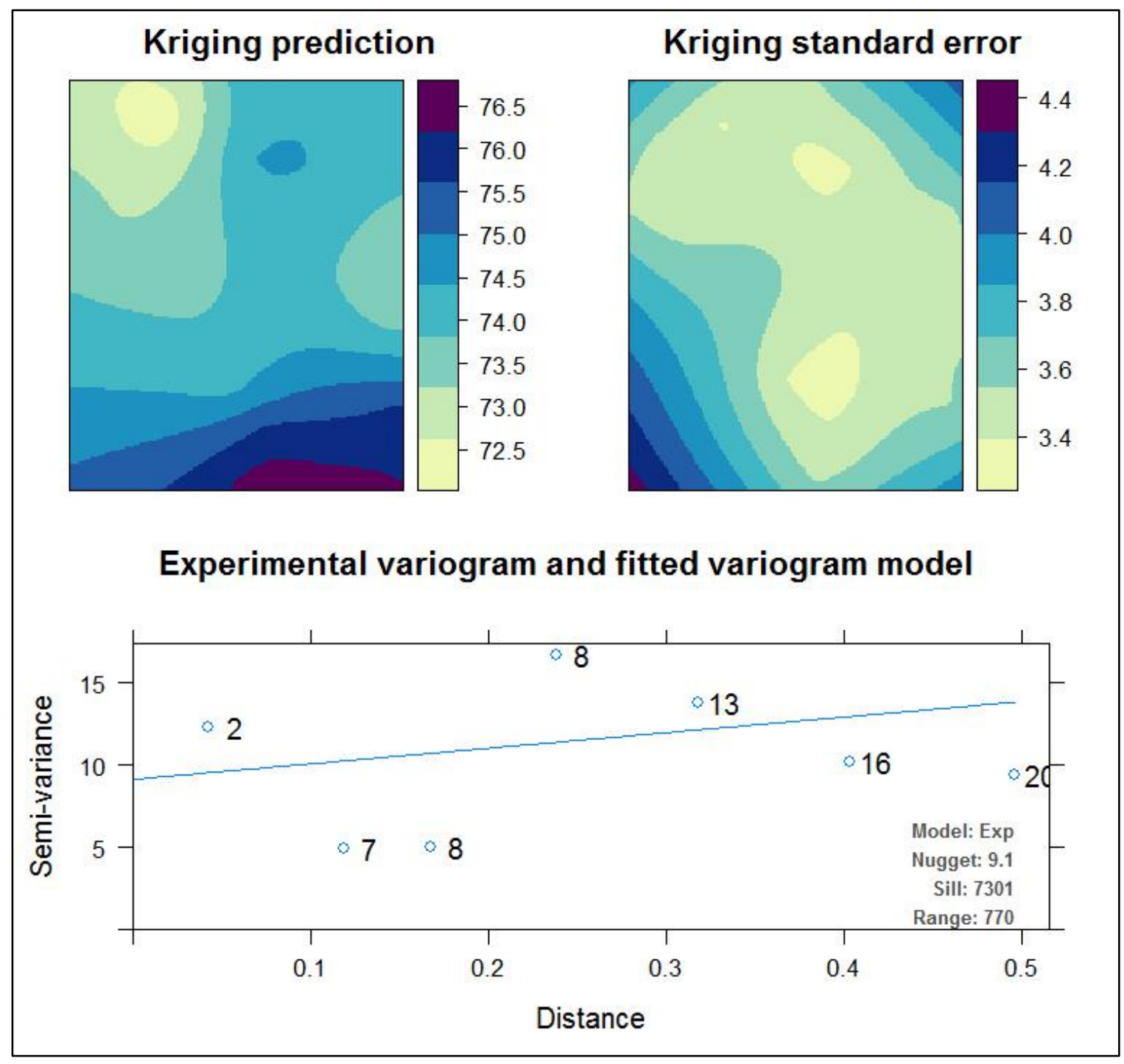

Figure 40: Spatial Interpolation of Temperature Using Kriging for 8/1/2011 Exponential Model

After assessing the spatial and temporal trends of temperature data for a single year, it is clear that kriging is not able to represent the temperature data with any accuracy. Taking the mean of the temperatures would be just as suitable as using kriging. Similar analyses were run to try to improve the model considering only the weather stations closest to the Calvert Cliffs and/or considering only weather stations with elevations less than 40 meters, but the results were similar in that they did not indicate any value in using spatial interpolation.

Since there is a large amount of spatial variability in the weather stations providing temperature data, temperature data from Patuxent River Naval Air Station should be used to represent the temperature along the Calvert Cliffs, as it is located approximately 6.5 
$\mathrm{km}$ southwest of CRE (southernmost site) and $26 \mathrm{~km}$ southeast from SCN (northernmost site). 


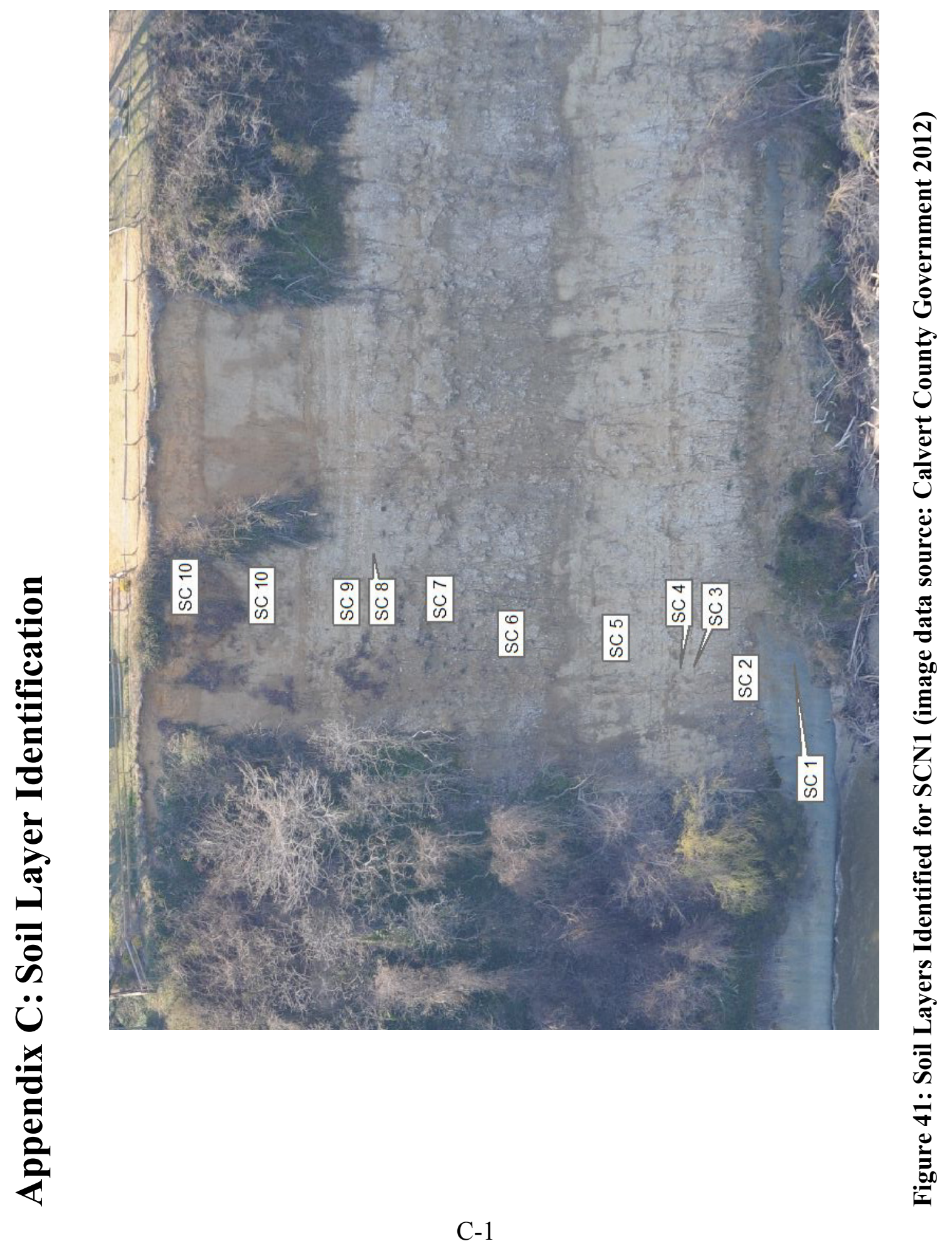




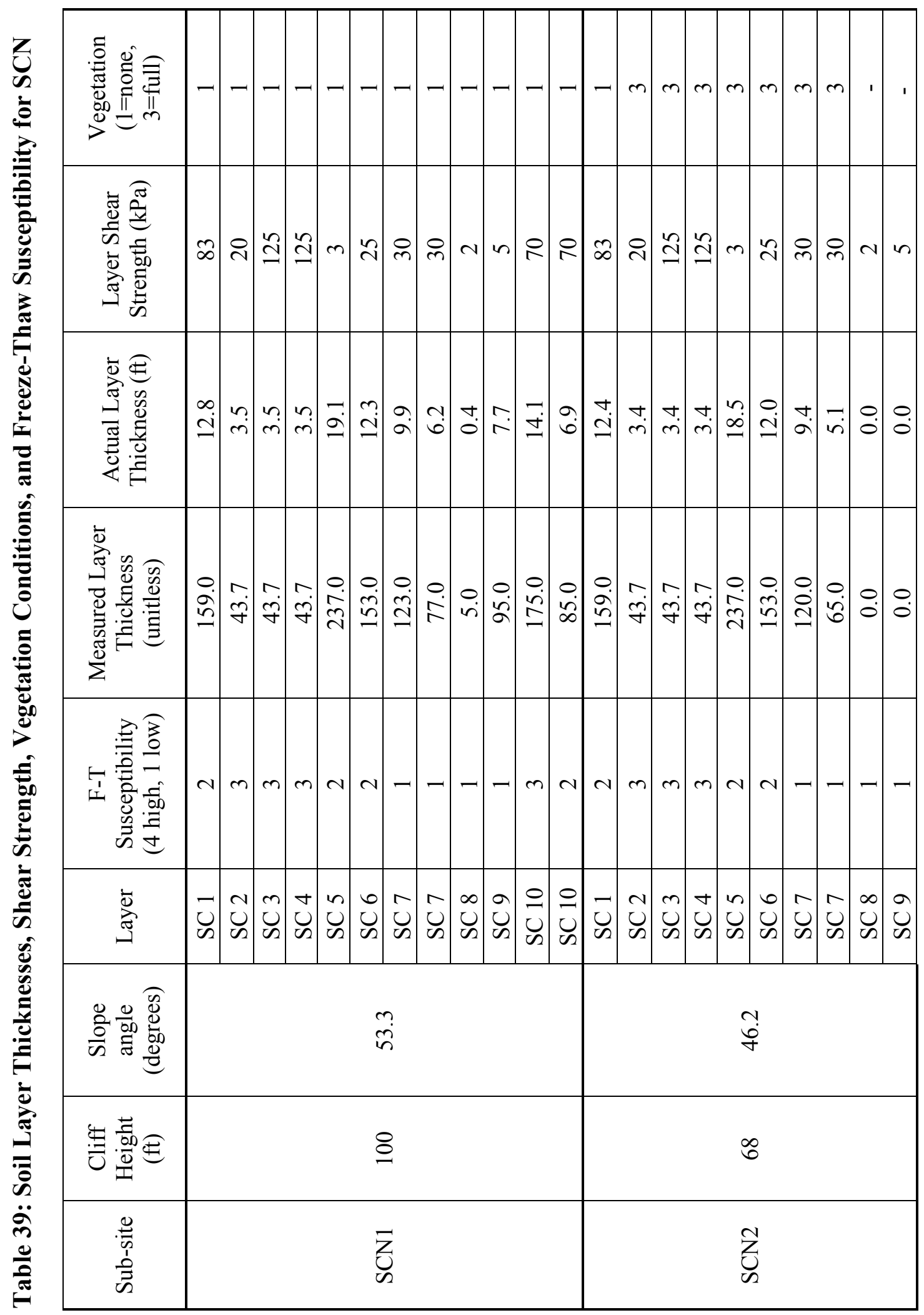

C-2 


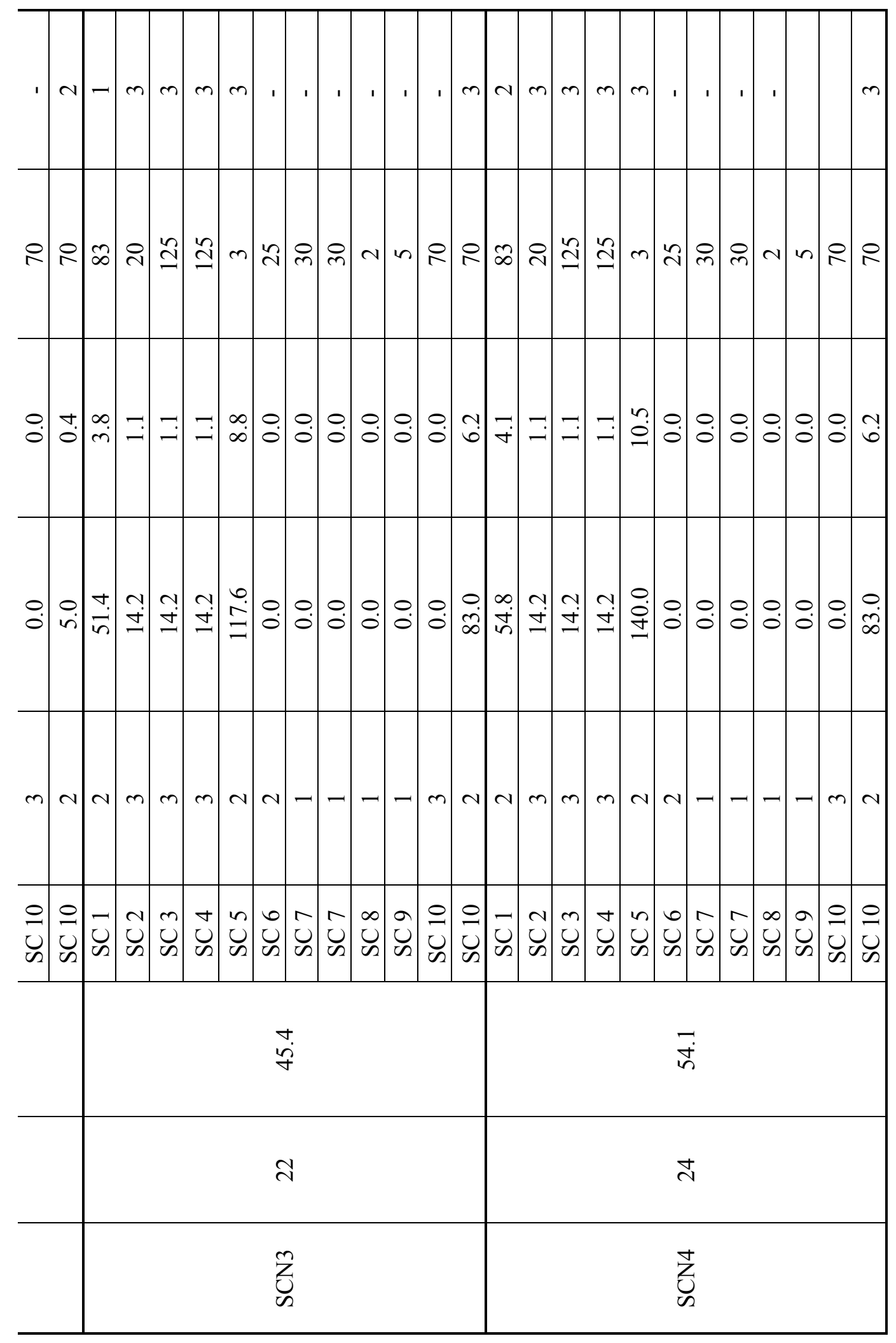

C-3 


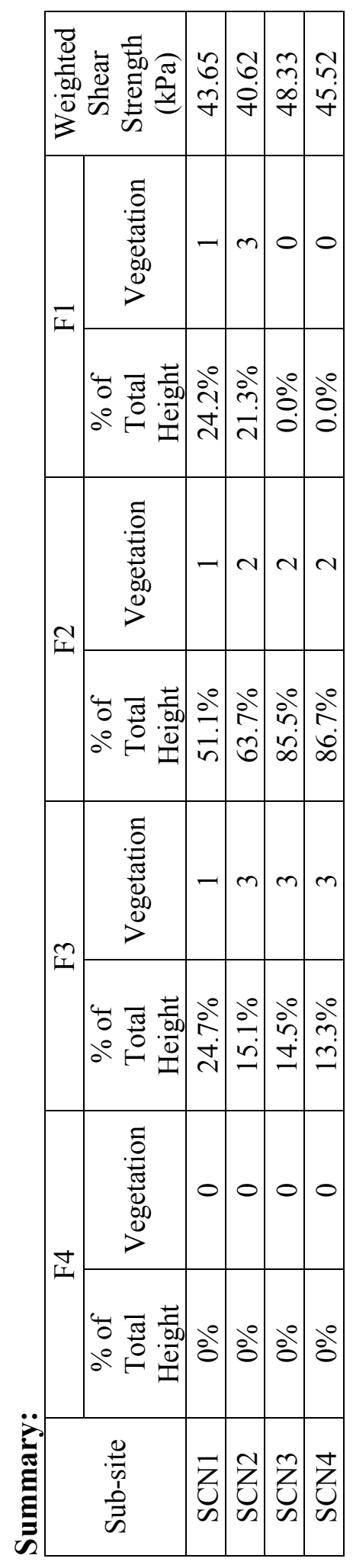




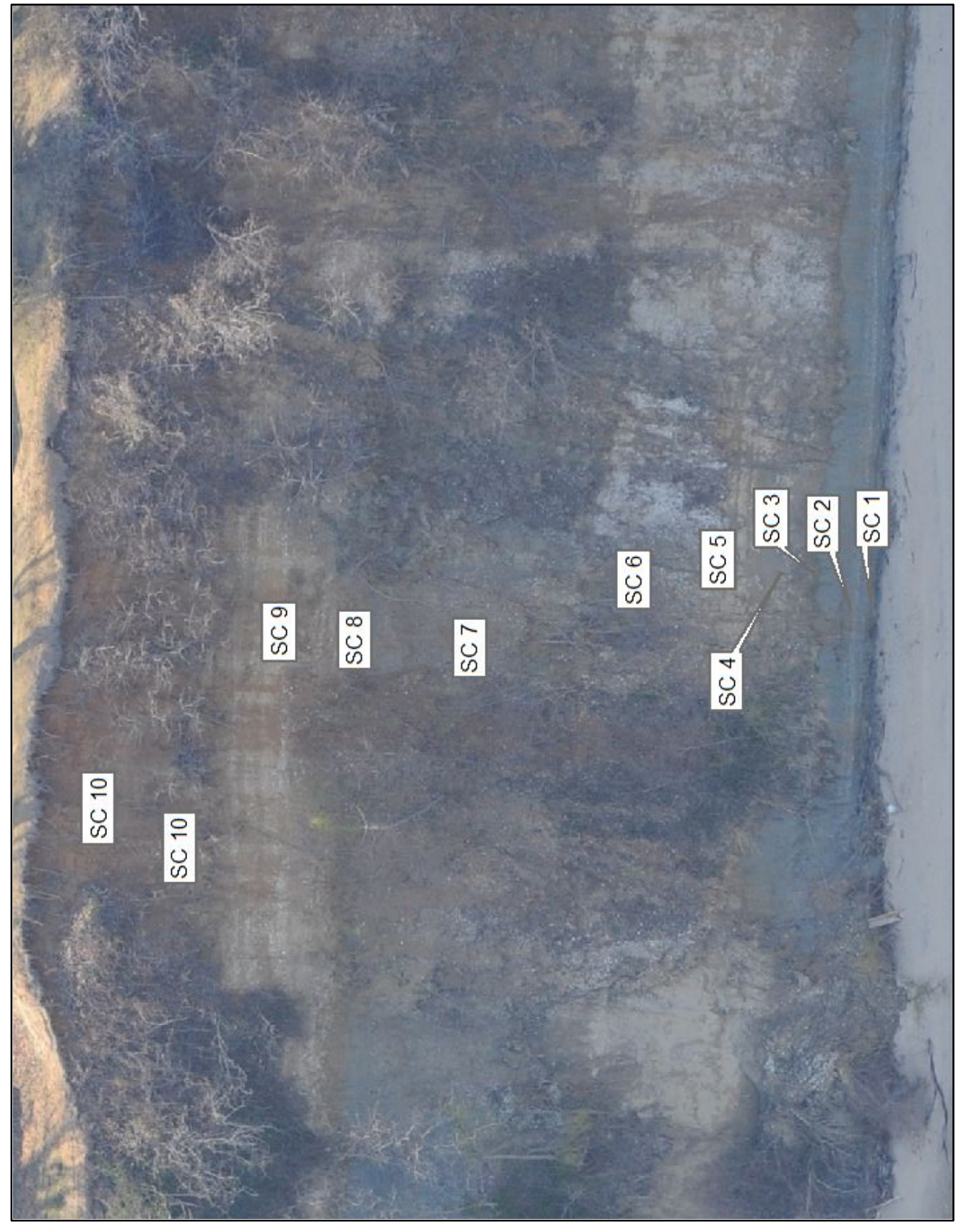

ปิ)

C-5 


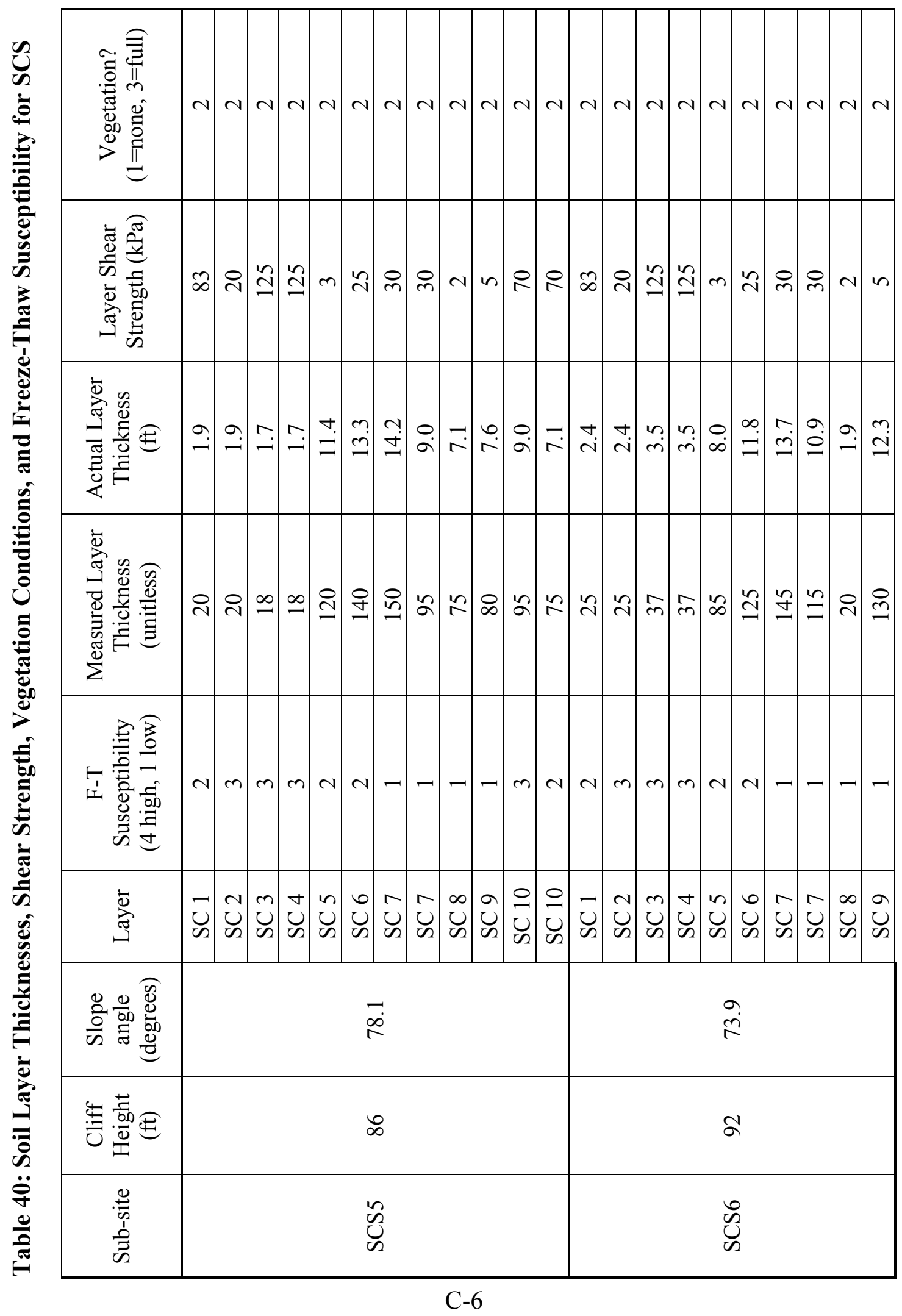




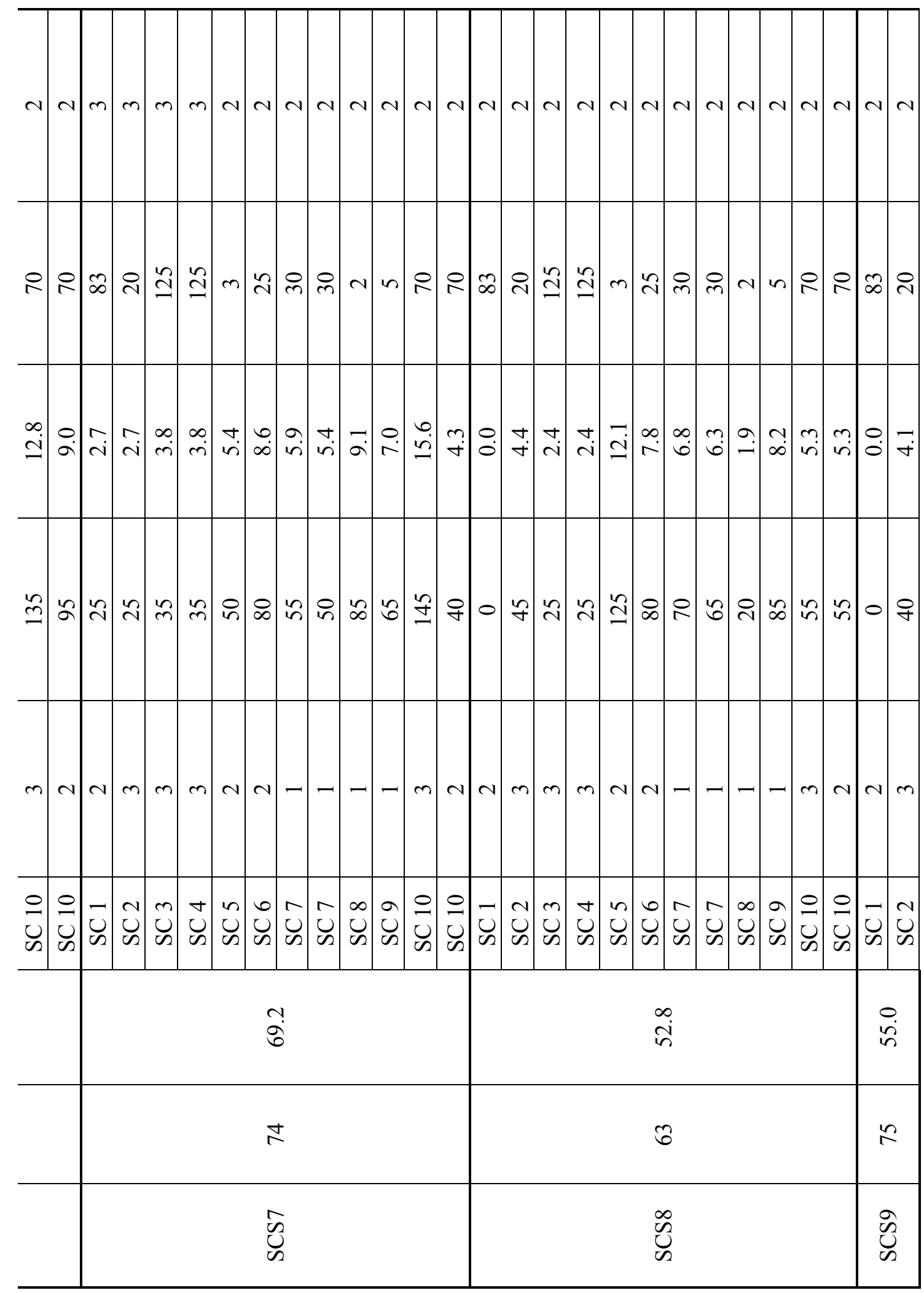

C-7 


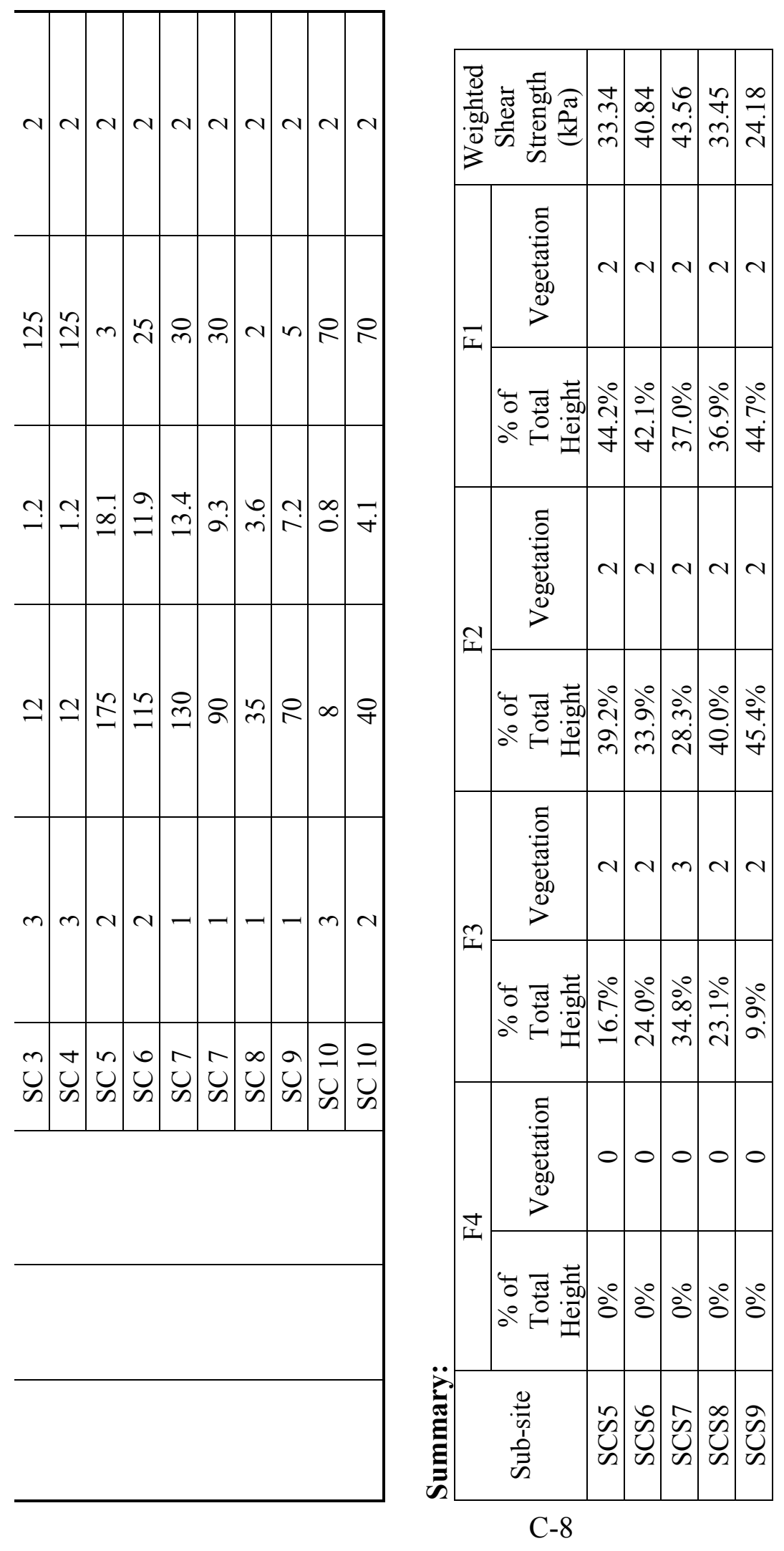




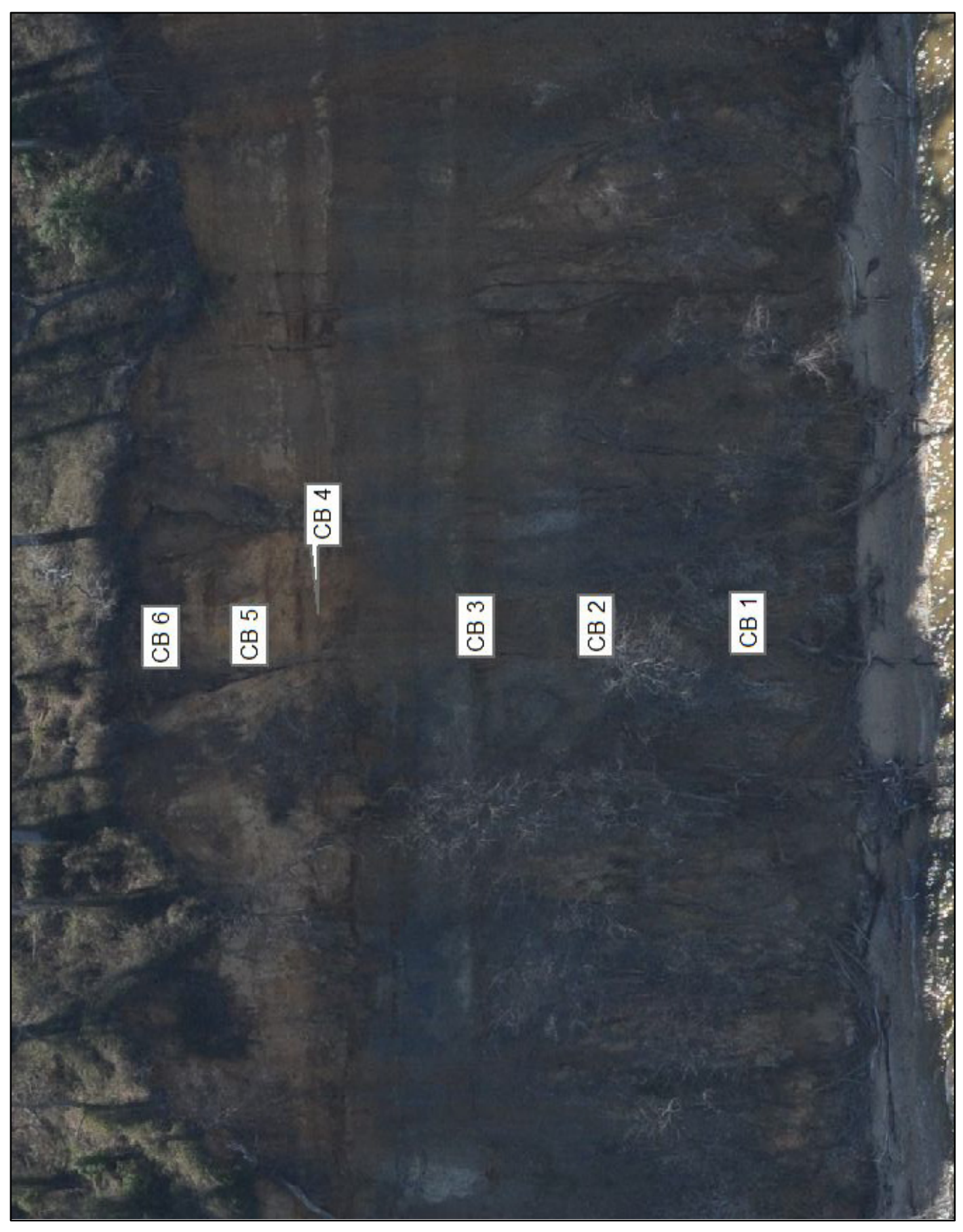

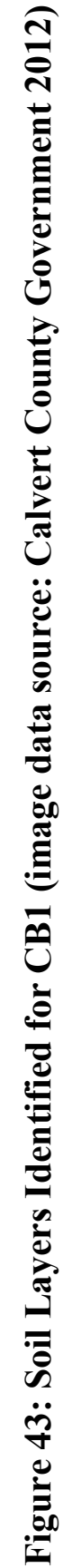
C-9 


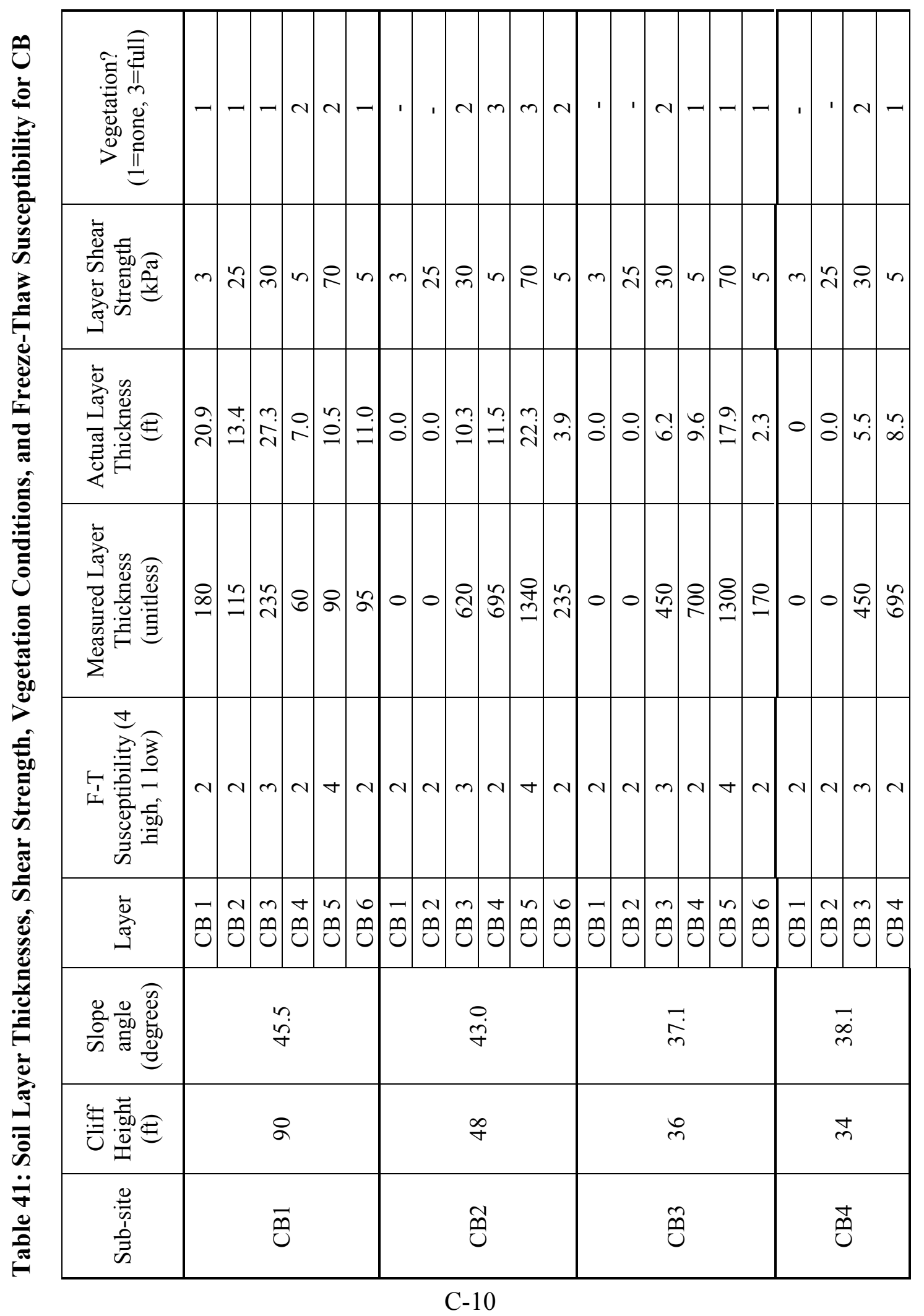




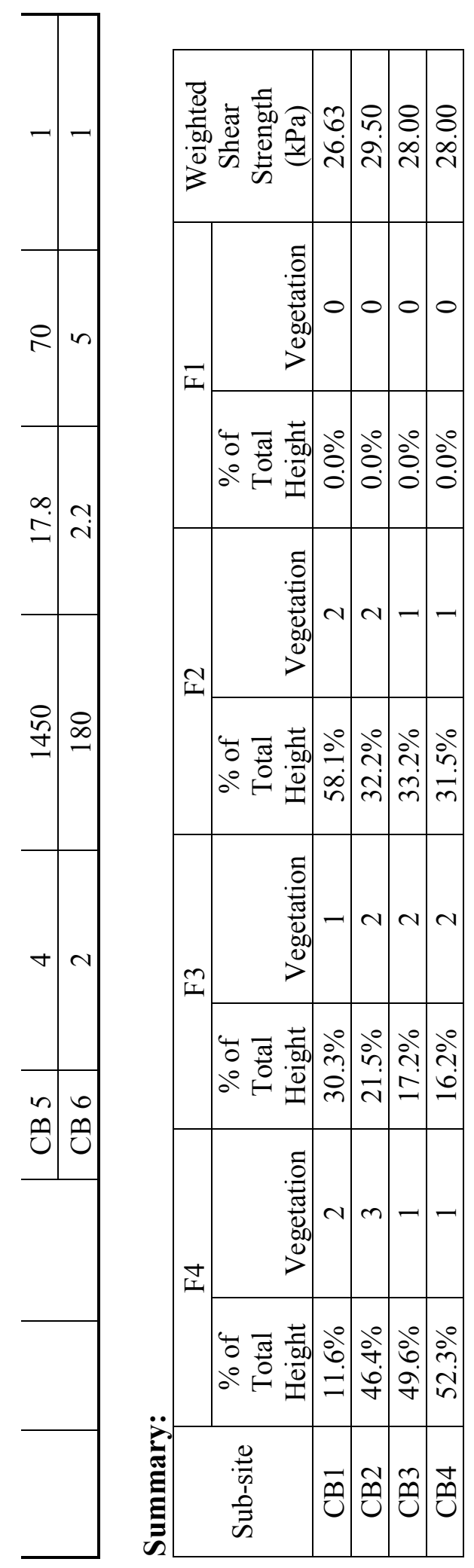




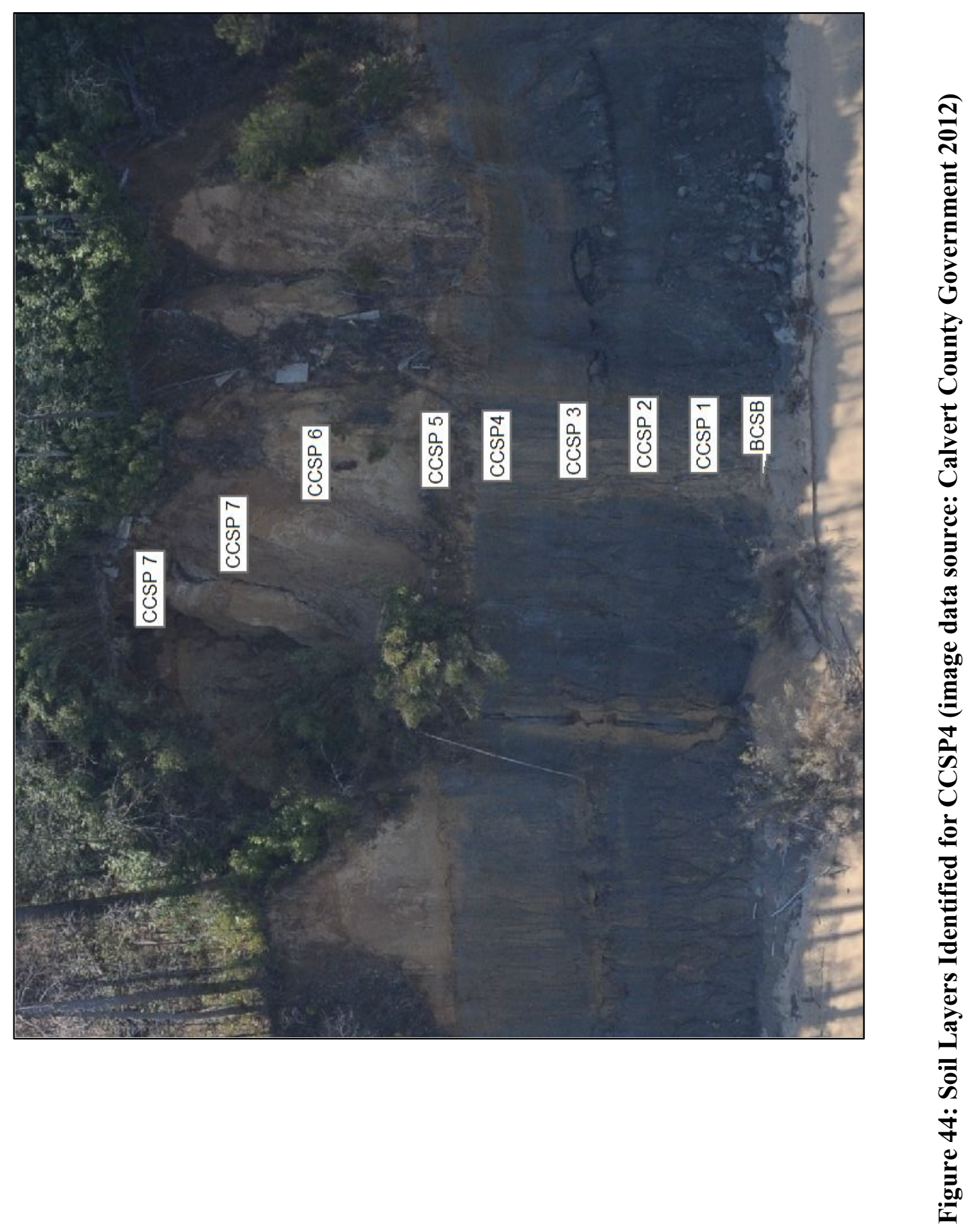

C-12 


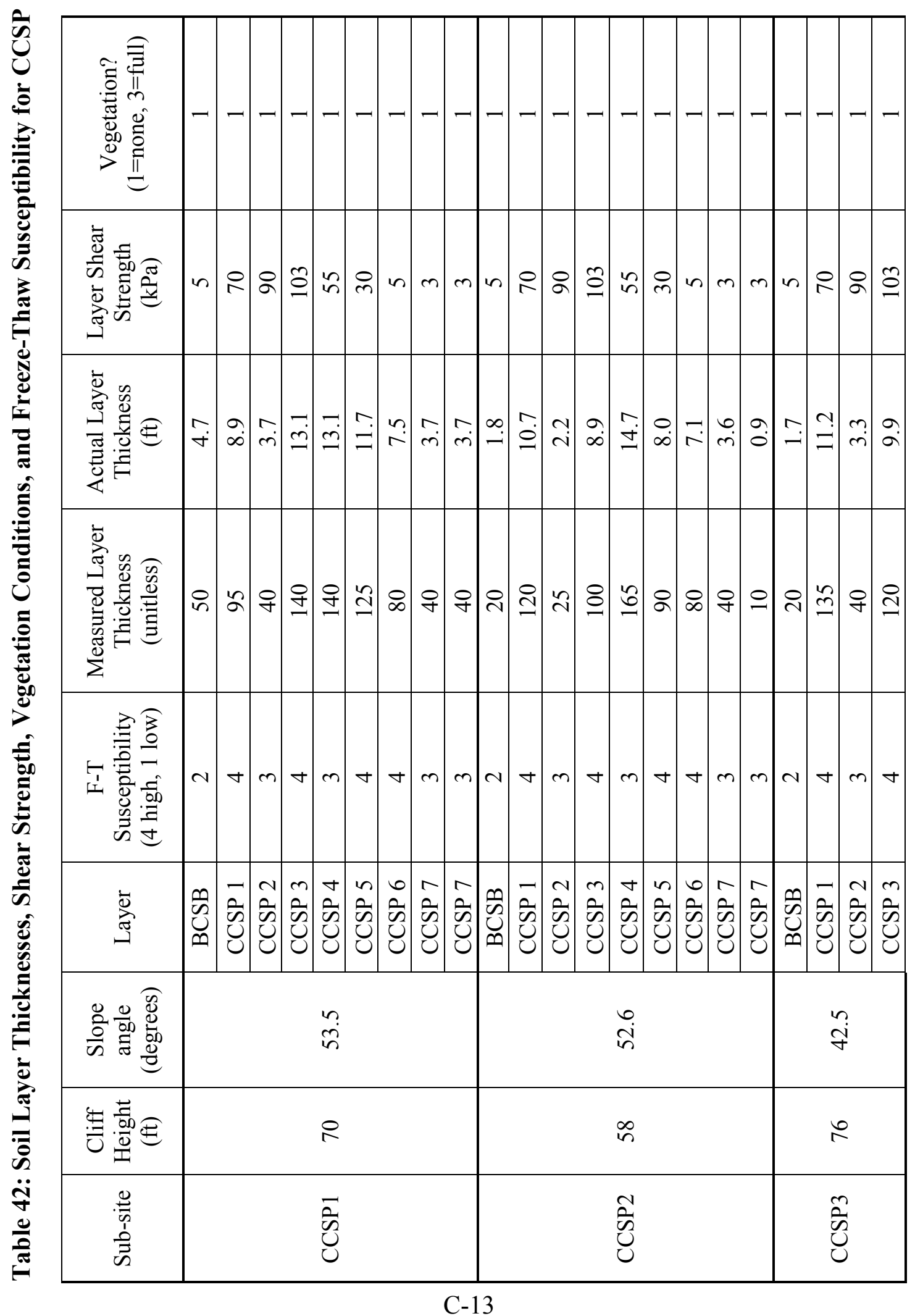




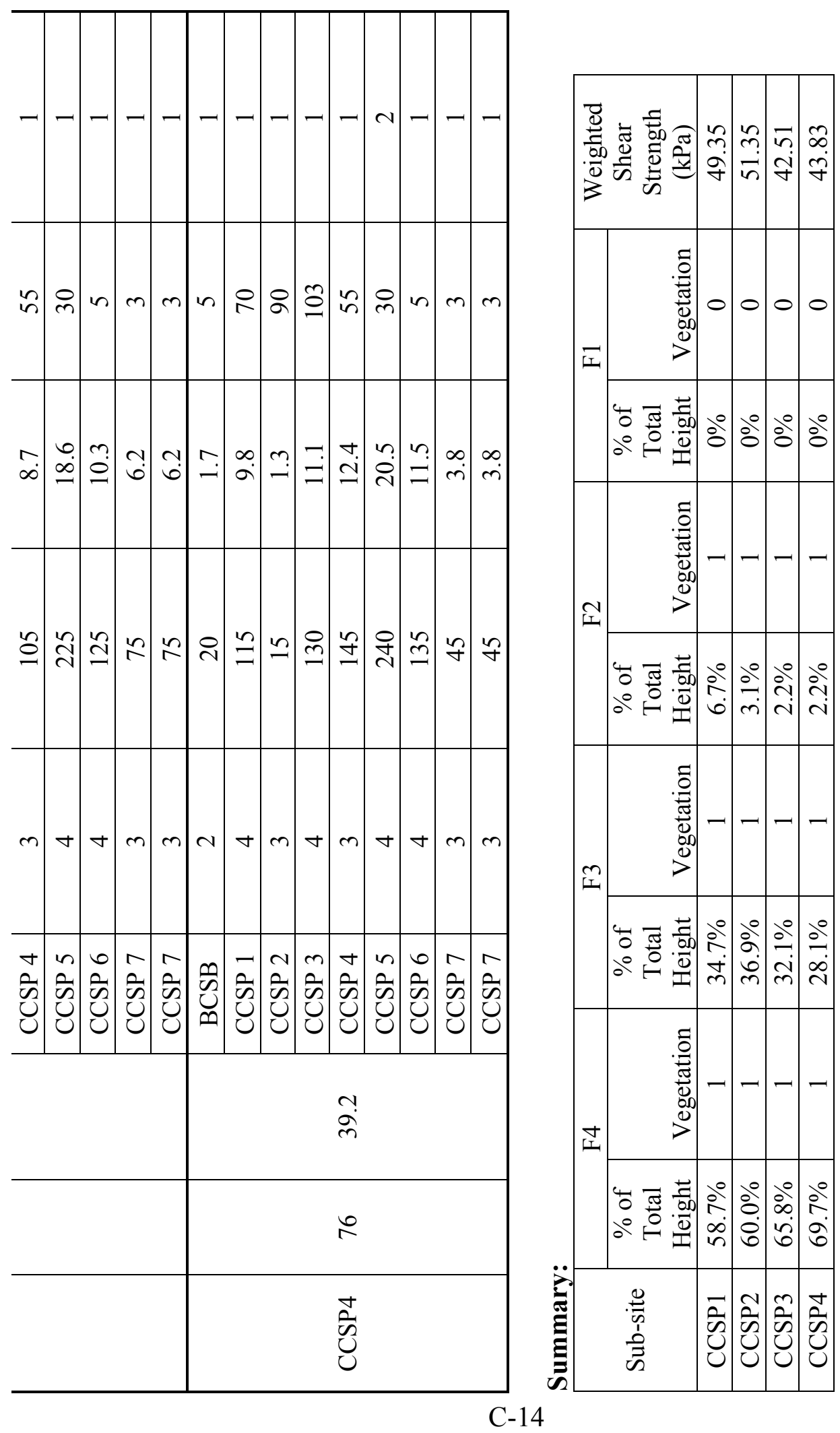




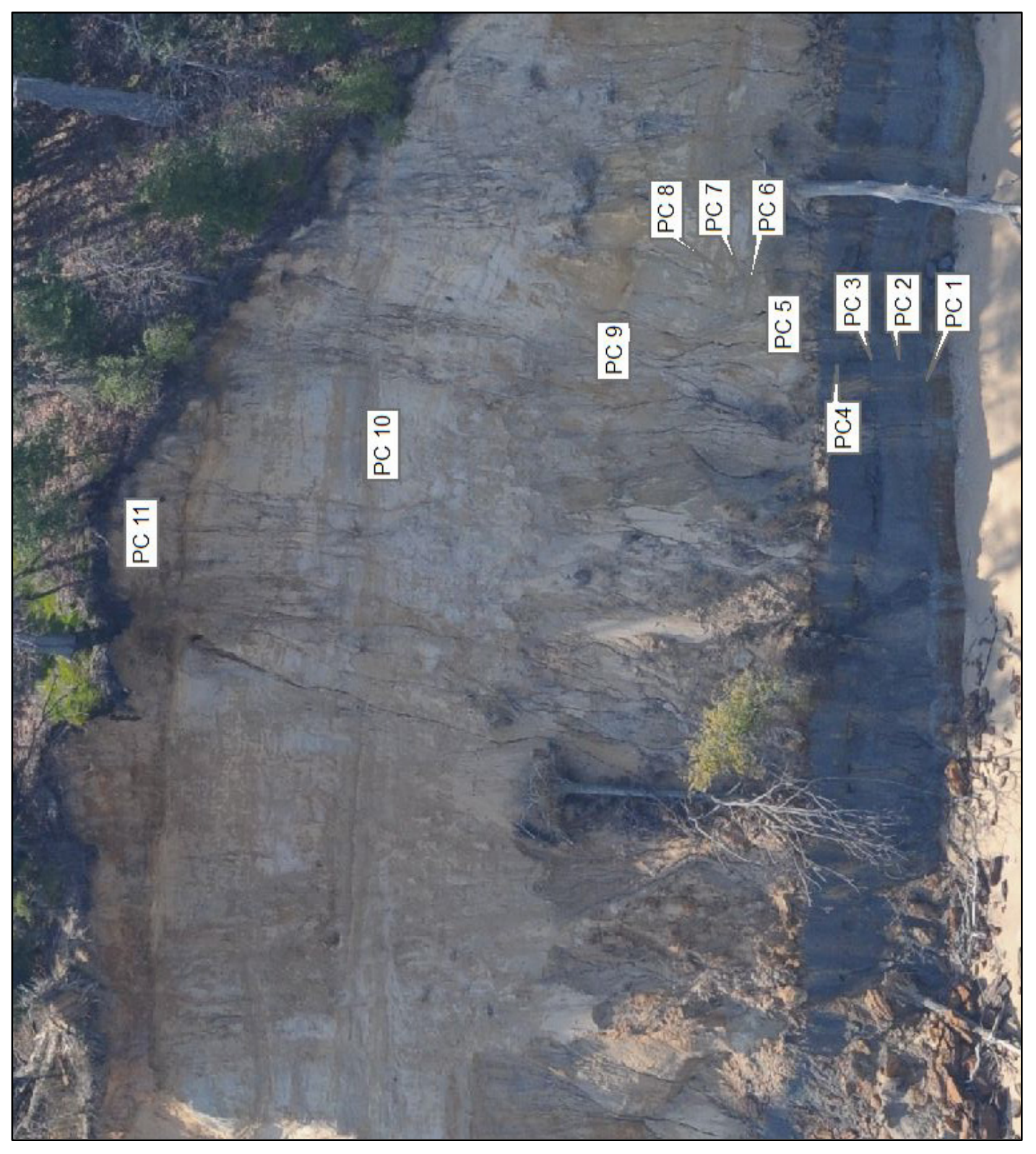

空

C-15 


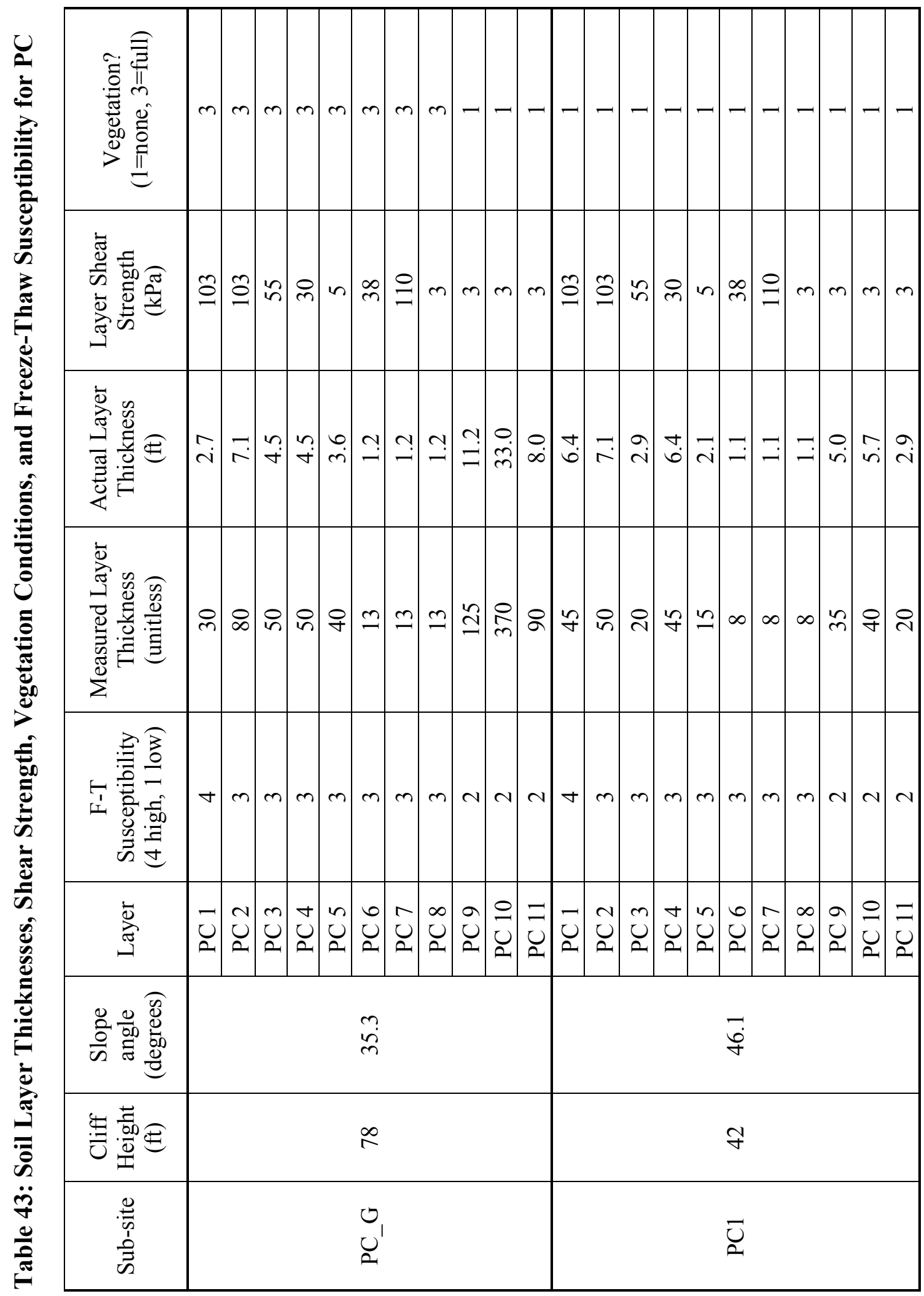




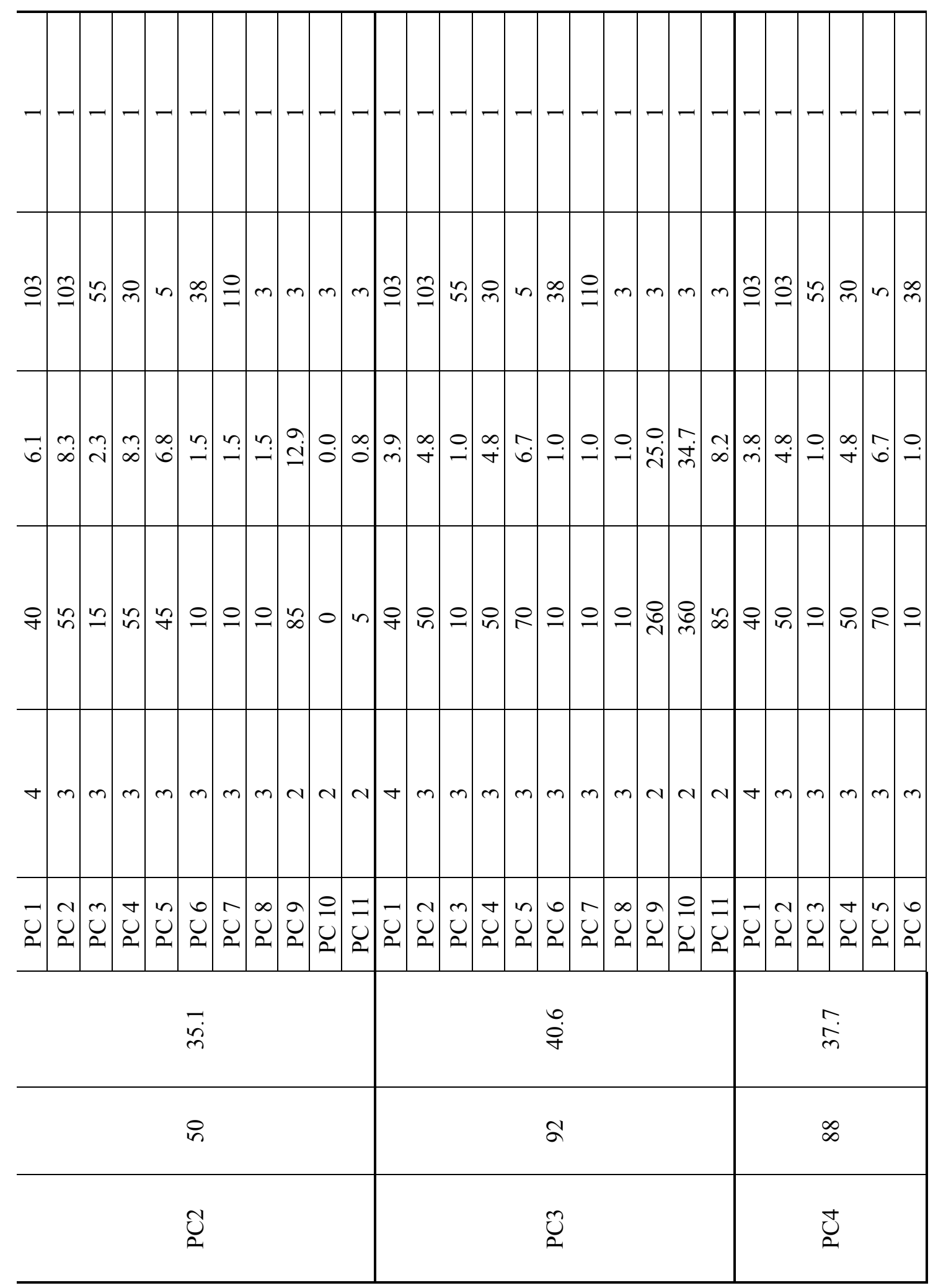




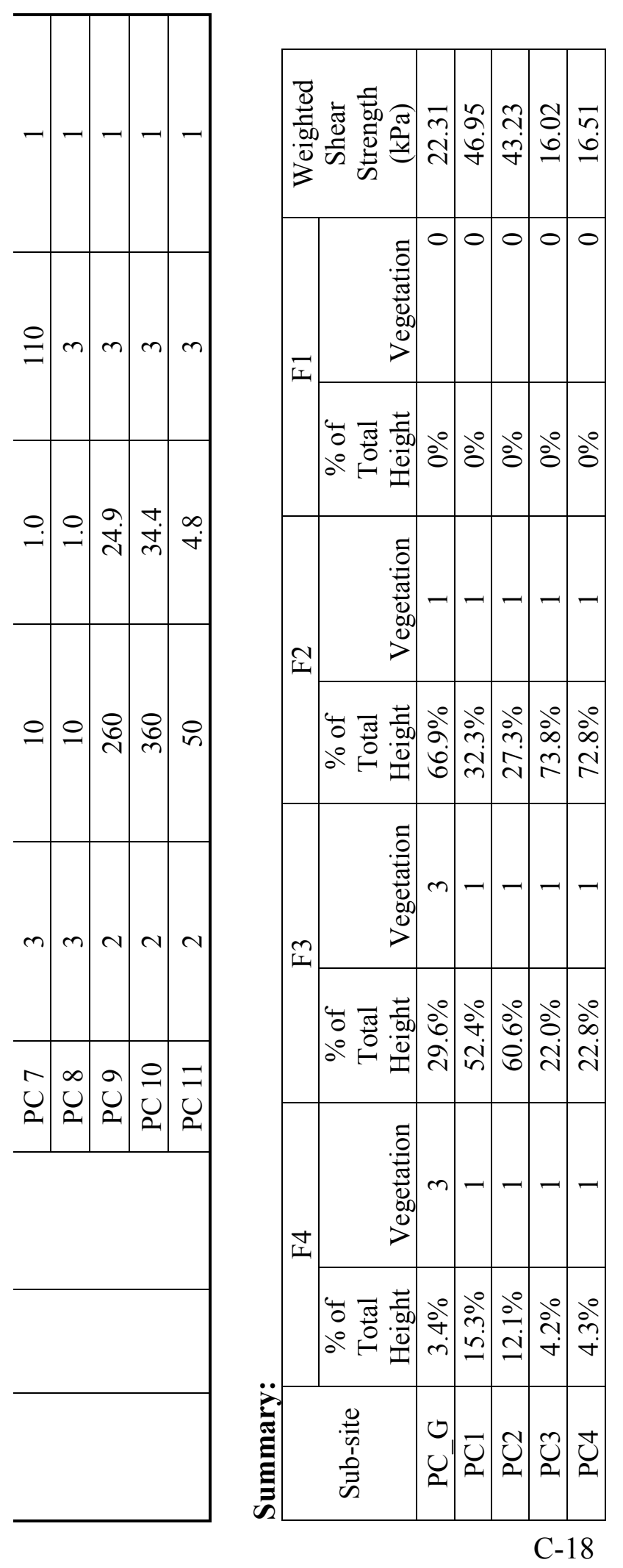




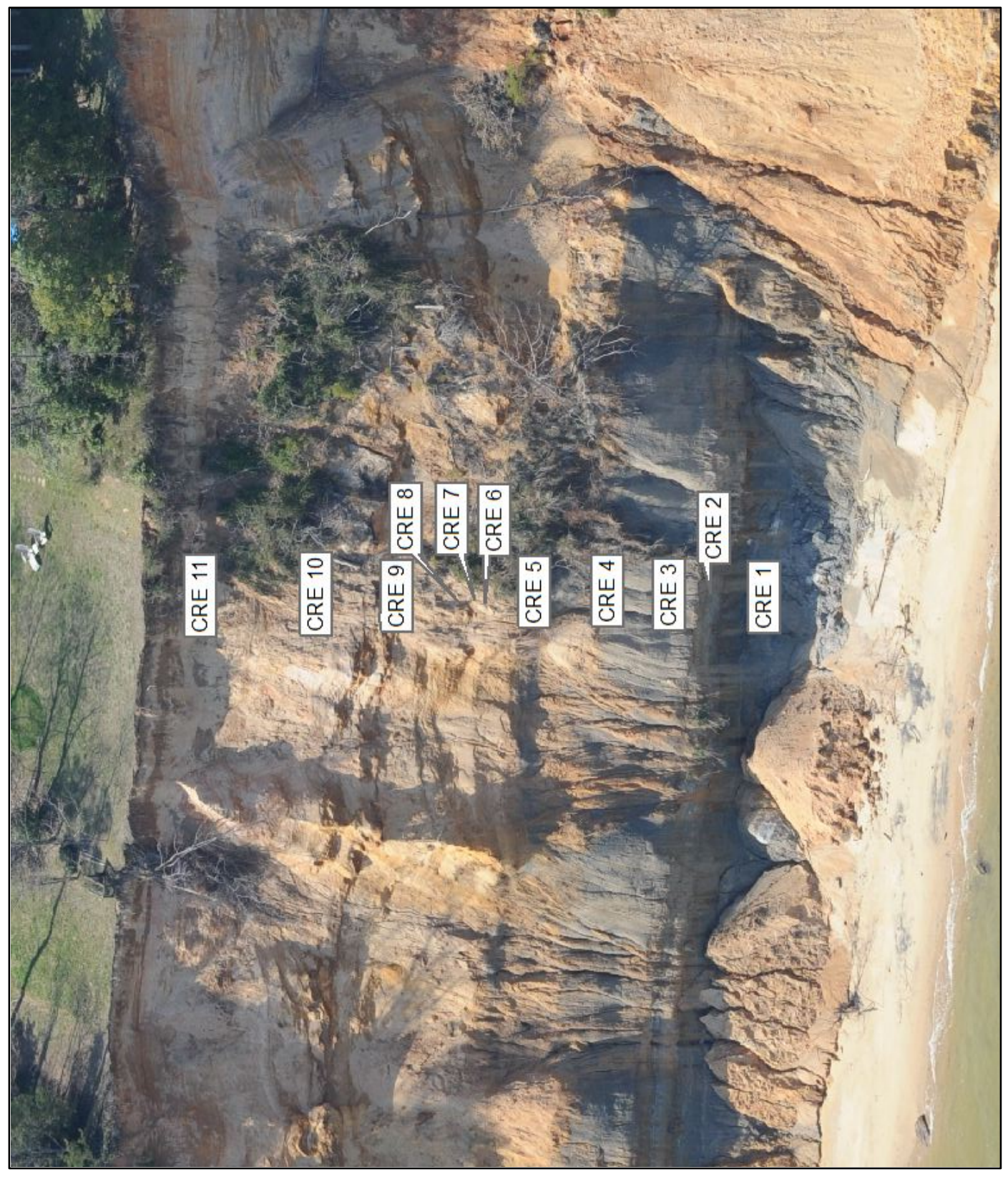

ปี

C-19 


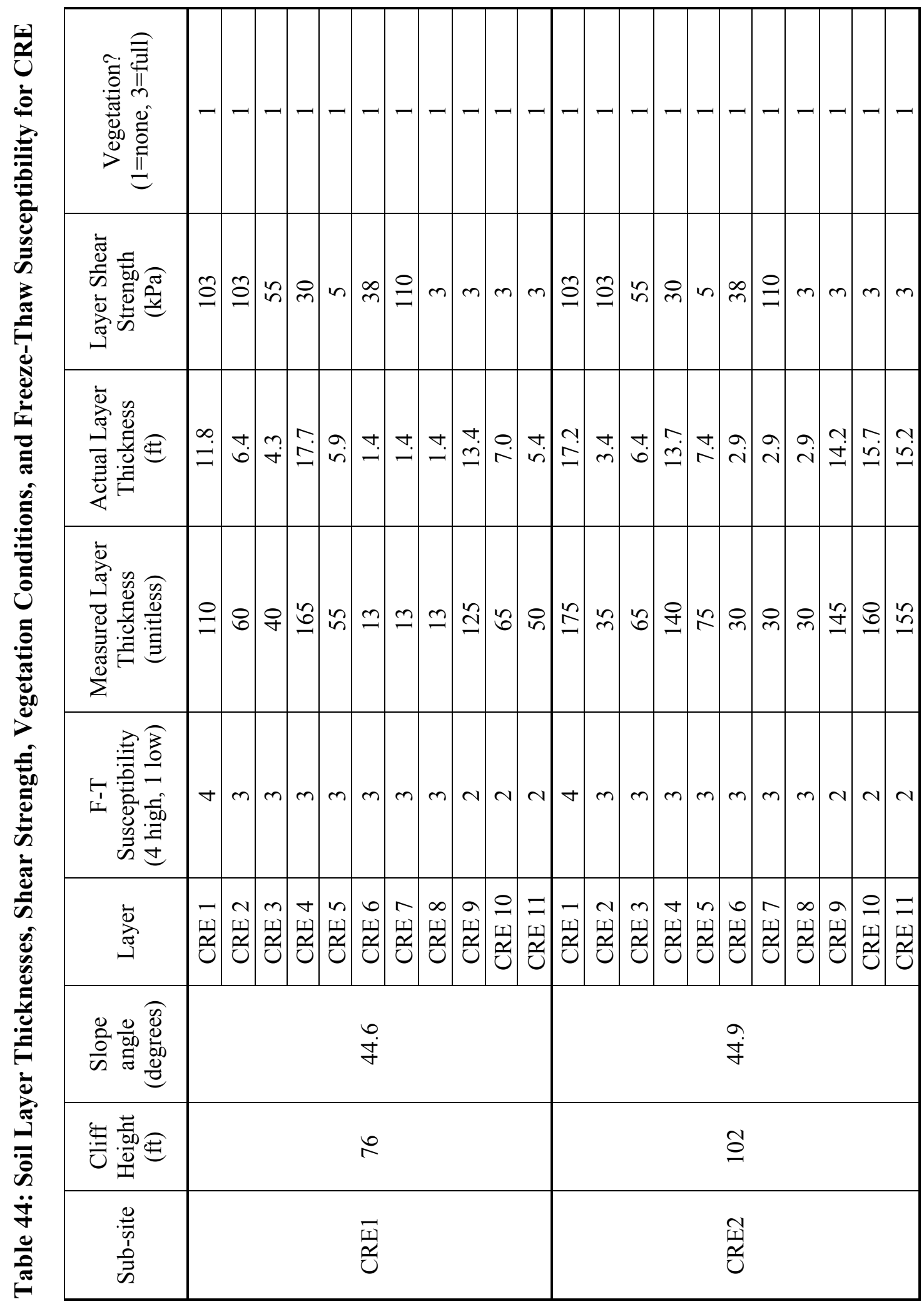




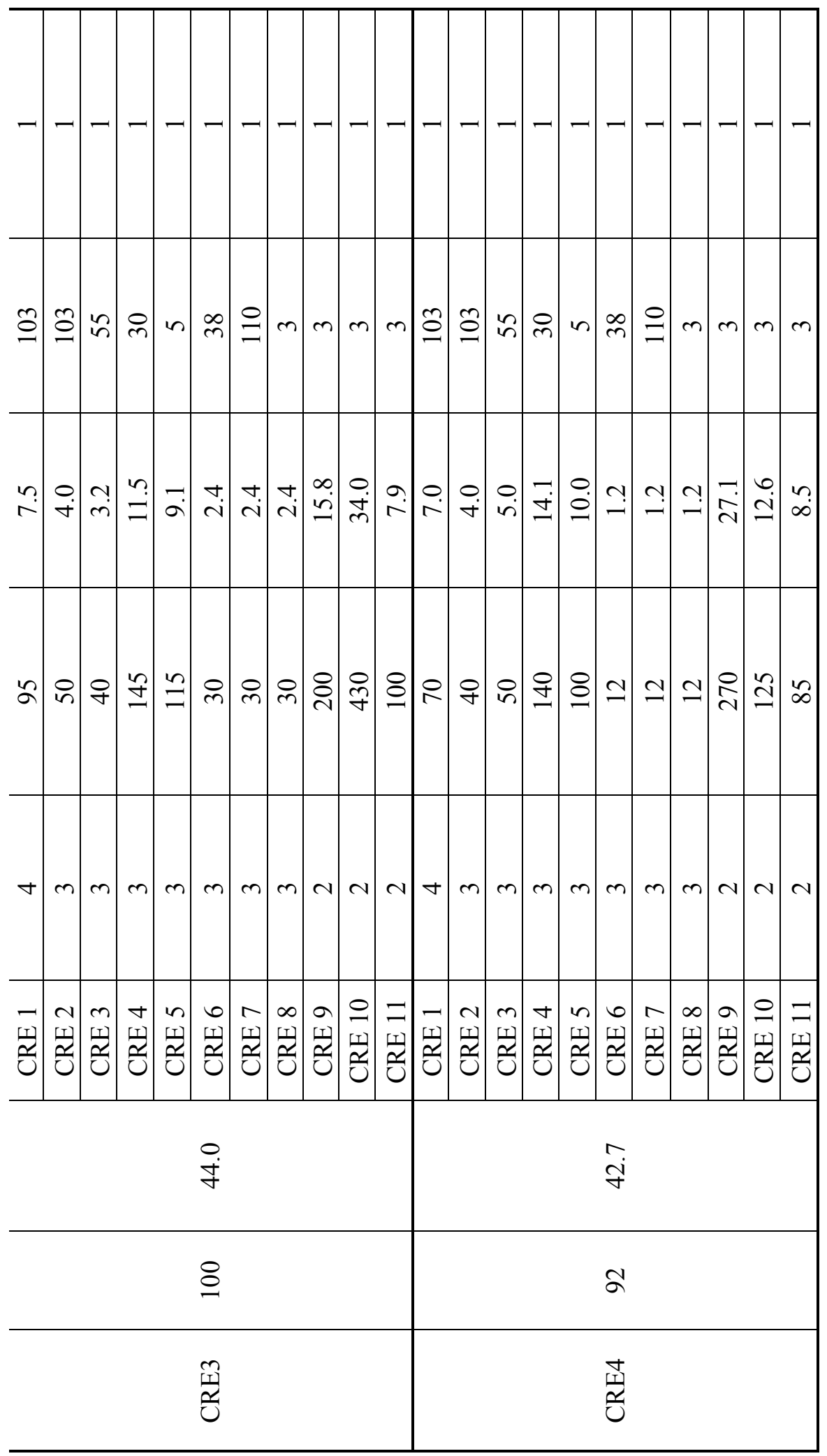

C-21 


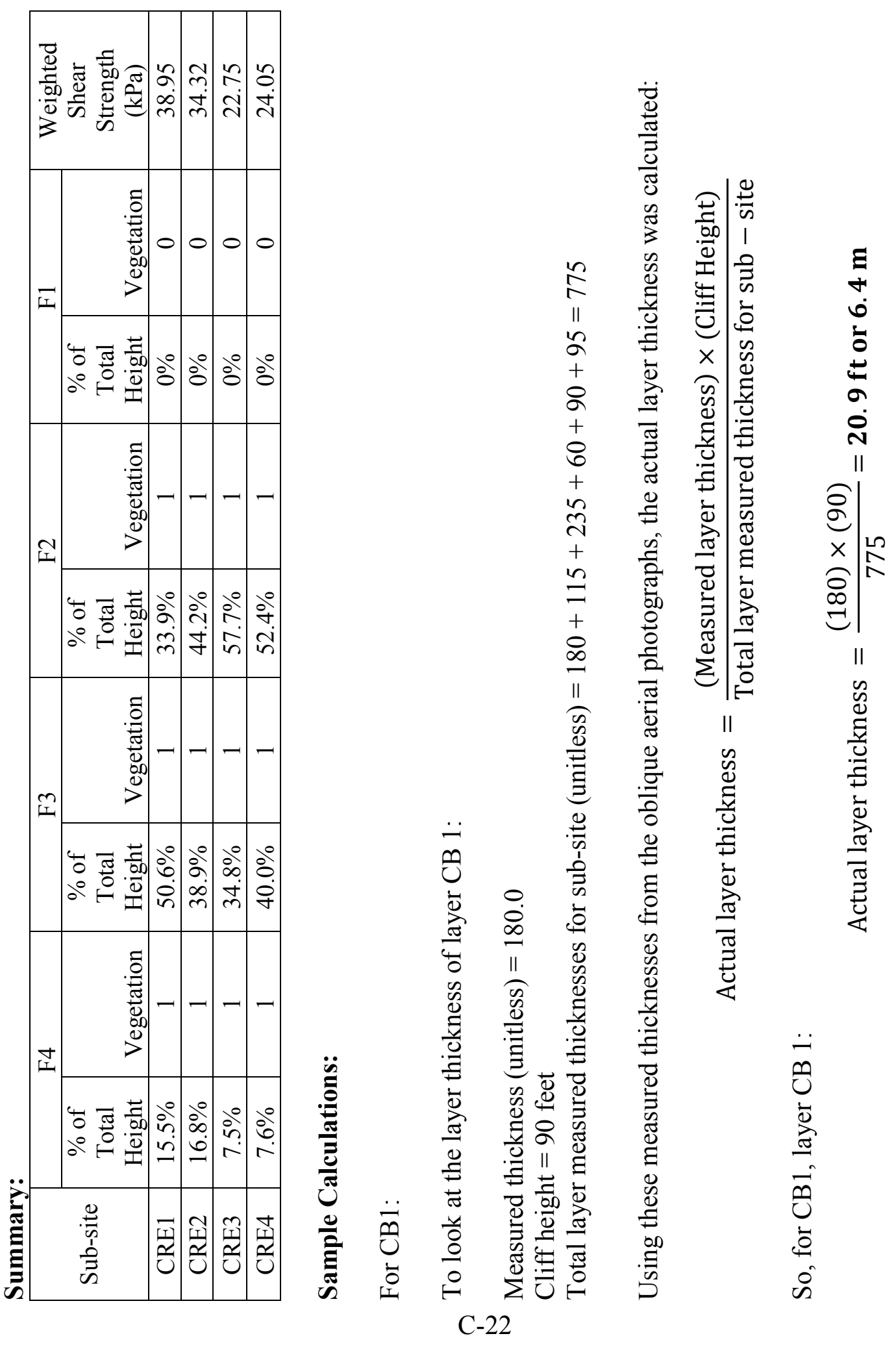




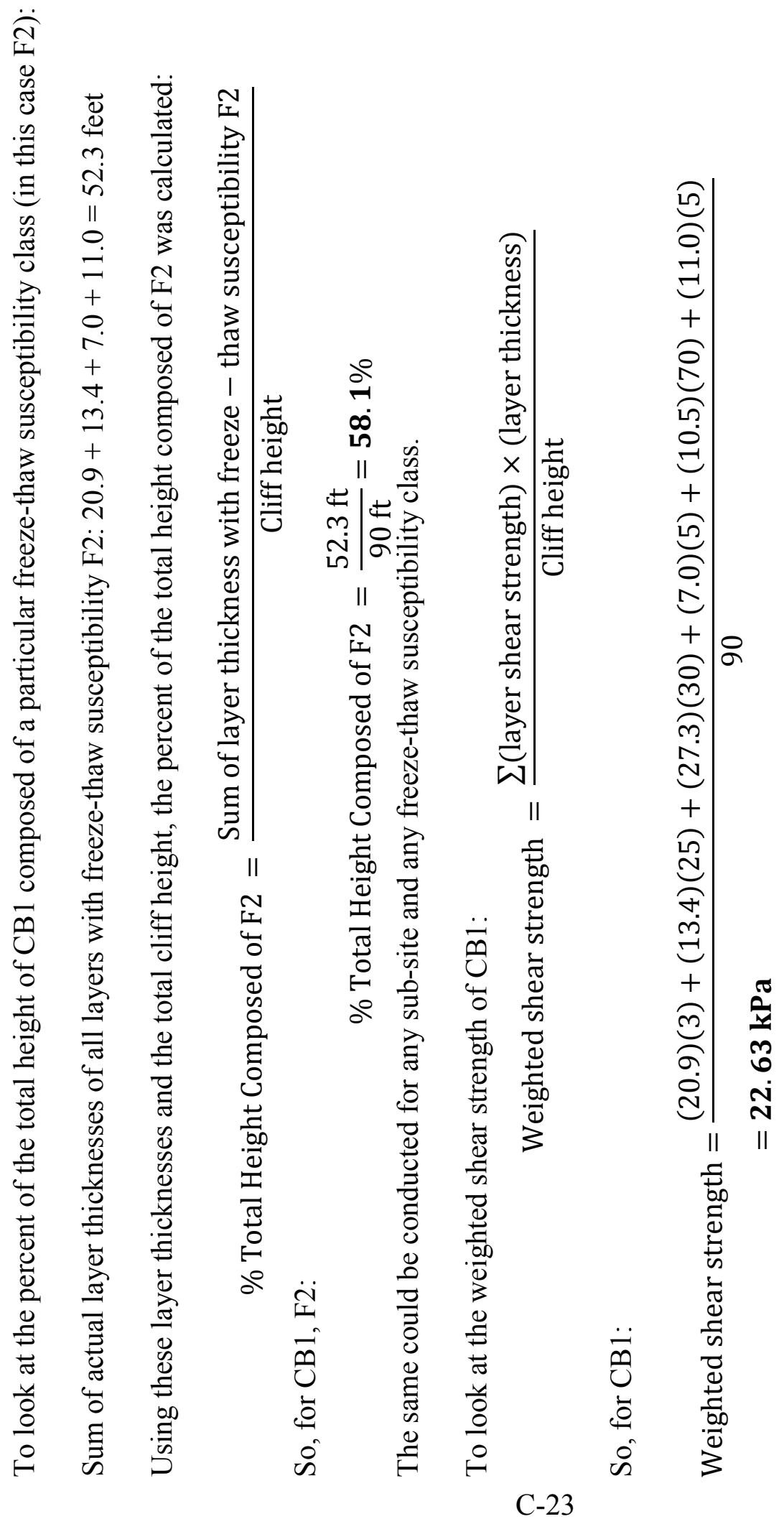





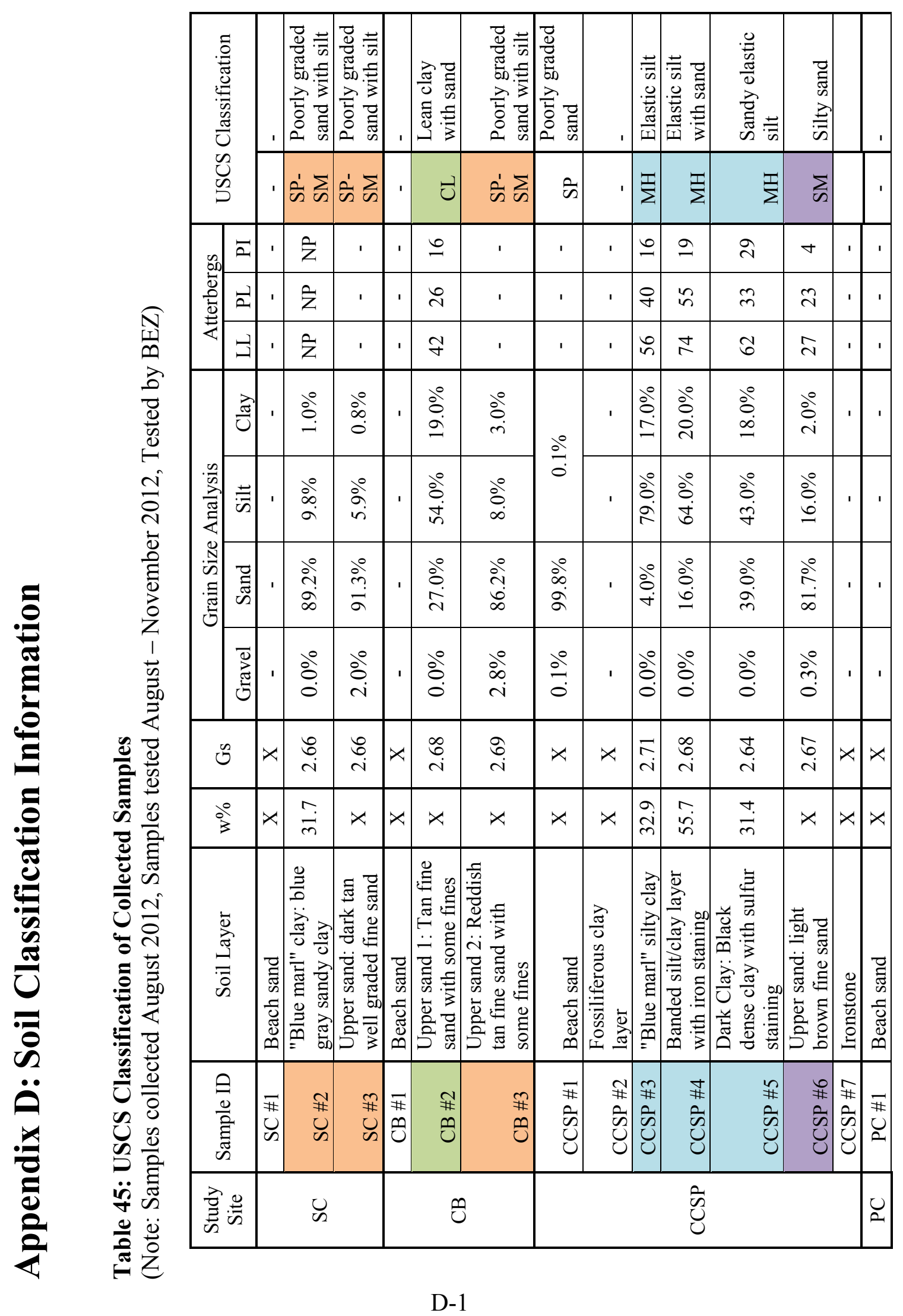




\begin{tabular}{|c|c|c|c|c|c|c|c|c|}
\hline 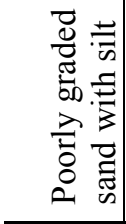 & 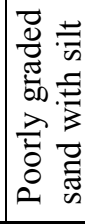 & 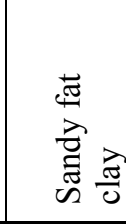 & ' & 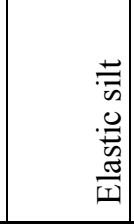 & $\begin{array}{l}\frac{\pi}{0} \\
0 \\
\frac{\pi}{\pi} \\
\Gamma\end{array}$ & 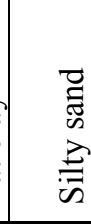 & 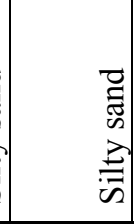 & 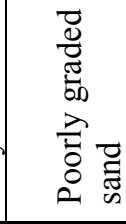 \\
\hline$\stackrel{1}{n}_{\infty} \sum_{1}$ & 宓 $\sum_{\infty}$ & $\vec{J}$ & ' & $\stackrel{\Xi}{\Sigma}$ & 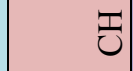 & $\sum$ & $\sum_{\infty}$ & के \\
\hline ' & ' & ৯े & ' & 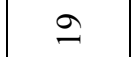 & શે & Z & 之 & ' \\
\hline ' & ' & $\widehat{\sim}$ & ' & กี & $\vec{m}$ & 吕 & 吕 & ' \\
\hline ' & ' & $\stackrel{\circ}{n}$ & ' & กี & $\nabla$ & 乙 & 㐫 & ' \\
\hline ठ̊ & $\stackrel{\text { oे }}{\text { oे }}$ & $\stackrel{\circ}{\circ}$ & ' & $\begin{array}{l}\dot{0} \\
\dot{0} \\
\dot{\theta}\end{array}$ & $\begin{array}{l}\stackrel{0}{0} \\
\dot{0} \\
i\end{array}$ & $\begin{array}{l}\text { ठे } \\
\text { ì }\end{array}$ & $\begin{array}{l}\partial_{0}^{0} \\
\infty\end{array}$ & \multirow{2}{*}{ 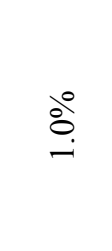 } \\
\hline$\frac{\partial^{\circ}}{6}$ & $\begin{array}{l}\stackrel{0}{0} \\
\infty \\
\infty\end{array}$ & $\frac{\stackrel{0}{0}}{\dot{n}}$ & ' & $\begin{array}{l}\dot{o}^{\circ} \\
\infty \\
\infty\end{array}$ & $\begin{array}{l}\stackrel{\circ}{0} \\
\stackrel{+}{+}\end{array}$ & $\stackrel{\stackrel{\circ}{\circ}}{\stackrel{a}{2}}$ & $\begin{array}{l}\stackrel{0}{0} \\
\dot{0}\end{array}$ & \\
\hline$\frac{\partial}{a}$ & $\begin{array}{l}\stackrel{0}{b} \\
\frac{\infty}{\infty}\end{array}$ & $\begin{array}{l}\stackrel{0}{0} \\
\text { i } \\
\text { i }\end{array}$ & ' & $\begin{array}{l}\stackrel{0}{0} \\
\circ\end{array}$ & $\begin{array}{l}\stackrel{0}{0} \\
\text { ì }\end{array}$ & $\begin{array}{l}\stackrel{0}{0} \\
\infty \\
0 \\
0\end{array}$ & $\begin{array}{l}\text { oे } \\
\text { i }\end{array}$ & $\begin{array}{l}\stackrel{0}{0} \\
\ddot{\infty} \\
\infty\end{array}$ \\
\hline @̊․ & $\begin{array}{l}\stackrel{0}{n} \\
\text { ì }\end{array}$ & $\begin{array}{l}\stackrel{0}{0} \\
0\end{array}$ & . & $\stackrel{\circ}{0}$ & $\begin{array}{l}\stackrel{0}{0} \\
0\end{array}$ & $\begin{array}{l}\stackrel{\circ}{0} \\
\stackrel{1}{1}\end{array}$ & $\stackrel{\circ}{0}$ & $\frac{\stackrel{0}{2}}{0}$ \\
\hline 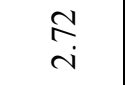 & $\begin{array}{l}\hat{b} \\
\stackrel{i}{ }\end{array}$ & $\vec{i}$ & $x$ & $\stackrel{\Re}{i}$ & $\begin{array}{l}\sqrt{6} \\
i \\
i\end{array}$ & $\begin{array}{l}\tilde{\sigma} \\
i \\
i\end{array}$ & $\begin{array}{l}\stackrel{0}{0} \\
i\end{array}$ & $\stackrel{ }{i}$ \\
\hline$\stackrel{\circ}{\stackrel{i}{~}}$ & $x$ & $\begin{array}{l}+\dot{\infty} \\
\stackrel{\infty}{\sim}\end{array}$ & $x$ & $\stackrel{N}{\stackrel{n}{n}}$ & 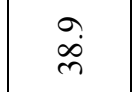 & ले & $\begin{array}{l}0 \\
\stackrel{0}{9}\end{array}$ & $\vec{n}$ \\
\hline 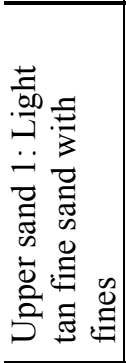 & 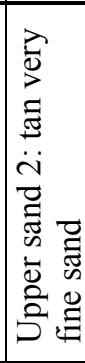 & 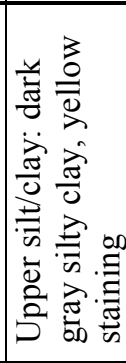 & 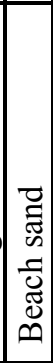 & 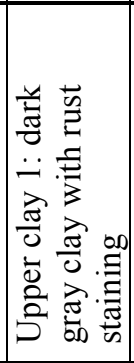 & 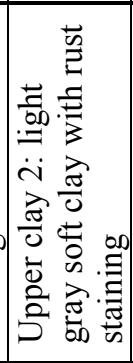 & 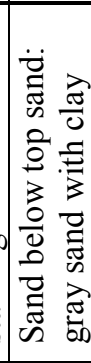 & 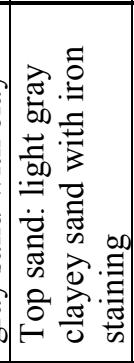 & 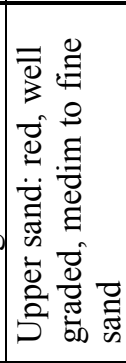 \\
\hline $\begin{array}{l}\mathbb{N} \\
U \\
0\end{array}$ & 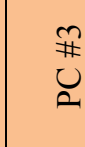 & 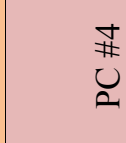 & 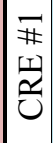 & 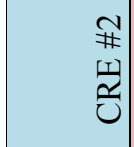 & $\begin{array}{l}\mathbb{\#} \\
\# \\
\mathbb{N} \\
\approx \\
0\end{array}$ & $\begin{array}{l}\# \\
\# \\
\text { I } \\
\text { U }\end{array}$ & $\begin{array}{l}n \\
\# \\
\text { rI } \\
\approx\end{array}$ & $\begin{array}{l}\text { I } \\
\text { 네 } \\
\text { Un }\end{array}$ \\
\hline & & & & & & $\underline{\alpha}$ & & \\
\hline
\end{tabular}

D-2 
Table 46: Geotechnical Data for Soil Layers (Adapted from Table 3.11, Miller (1995))

\begin{tabular}{|c|c|c|c|c|c|c|}
\hline \multirow{2}{*}{$\begin{array}{l}\text { Zone (based } \\
\text { on Shattuck) }\end{array}$} & \multirow{2}{*}{ Layer (based on Miller) } & \multicolumn{4}{|c|}{ Grain Size Analysis } & \multirow{2}{*}{$\begin{array}{l}\text { Cohesion c' } \\
\left(\mathrm{kN} / \mathrm{m}^{2}\right)\end{array}$} \\
\hline & & $*$ & $\%$ Sand & $\%$ Silt & $\%$ Clay & \\
\hline \multirow{3}{*}{ Zone 13} & \multirow{3}{*}{ Chione-Glossus } & $\mathrm{L}$ & 23 & 51 & 26 & 111 \\
\hline & & M & 55 & 25 & 20 & \\
\hline & & $\mathrm{U}$ & 70 & 14 & 15 & $50-115$ \\
\hline \multirow{4}{*}{ Zone 14} & \multirow{4}{*}{ KBSB } & $\mathrm{L}$ & 80 & 12 & 8 & $14-41$ \\
\hline & & M & 75 & 8 & 17 & 16.7 \\
\hline & & & 76 & 11 & 13 & 16.7 \\
\hline & & $\mathrm{U}$ & 85 & 12 & 3 & $134 * *$ \\
\hline Zone 15 & Turritella-Pandora & $\mathrm{L}$ & 58 & 27 & 15 & \multirow{2}{*}{124.5} \\
\hline Zone 16 & Turritella-Pandora & $\mathrm{U}$ & 72 & 14 & 14 & \\
\hline Zone 17 & Governor's Run Sand & & 94 & 5 & 1 & $2-5$ \\
\hline \multirow{3}{*}{ Zone 17} & \multirow{3}{*}{ DCSB } & $\mathrm{L}$ & & & & 43.1 \\
\hline & & M & 86 & 11 & 3 & 21.5 \\
\hline & & $\mathrm{U}$ & 81 & 14 & 5 & 14.4 \\
\hline \multirow{5}{*}{ Zone 18} & \multirow{5}{*}{ Mytilus } & $\mathrm{L}$ & & & & 28.7 \\
\hline & & & 75 & 12 & 3 & 39.7 \\
\hline & & M & 77 & 13 & 10 & 53.6 \\
\hline & & & 80 & 11 & 9 & 10.5 \\
\hline & & U & 77 & 10 & 13 & 19.1 \\
\hline \multirow{3}{*}{ Zone 19} & \multirow{3}{*}{ BCSB } & $\mathrm{L}$ & 84 & 8 & 8 & $3-10$ \\
\hline & & M & 90 & 5 & 5 & $2-6$ \\
\hline & & $\mathrm{U}$ & 88 & 6 & 6 & $5-8$ \\
\hline \multirow{3}{*}{ Zone 20} & \multirow{3}{*}{ Unnamed N. of Rocky Point } & $\mathrm{L}$ & 11 & 45 & 44 & $85-125$ \\
\hline & & M & 23 & 52 & 25 & 62.2 \\
\hline & & $\mathrm{U}$ & 34 & 53 & 13 & 86 \\
\hline Zone 21 & Zone 21 & & 58 & 25 & 17 & 90.5 \\
\hline \multirow{3}{*}{ Zone 22} & \multirow{3}{*}{ Zone 22} & $\mathrm{~L}$ & 0 & 54 & 46 & \\
\hline & & M & 5 & 38 & 57 & $85-120$ \\
\hline & & $\mathrm{U}$ & 20 & 35 & 54 & \\
\hline Zone 23 & Zone 23 Lower & $\mathrm{L}$ & 55 & 33 & 12 & $48-63$ \\
\hline Zone 23 & Zone 23 Upper & $\mathrm{U}$ & 80 & 11 & 9 & $4-6$ \\
\hline Zone 23 & CRE Clay & & 10 & 30 & 60 & $* * *$ \\
\hline \multirow{3}{*}{ Post-Miocene } & \multirow{3}{*}{ CRE-Sand } & $\mathrm{L}$ & 73 & 13 & 14 & \multirow{3}{*}{$2-5$} \\
\hline & & M & 91 & 4 & 5 & \\
\hline & & $\mathrm{U}$ & 94 & 3 & 3 & \\
\hline
\end{tabular}

D-3 
Table 47: USCS Classification for Freeze-Thaw Susceptibility of All Soil Layers

\begin{tabular}{|c|c|c|}
\hline $\begin{array}{l}\text { Study } \\
\text { Site }\end{array}$ & Layer & USCS Classification* \\
\hline \multirow{12}{*}{$\begin{array}{c}\mathrm{SCN} \\
\& \\
\mathrm{SCS}\end{array}$} & $\mathrm{SC} 1$ & SP-SM \\
\hline & SC 2 & Sand w/ $20 \%$ fines \\
\hline & SC 3 & Sand $w / 40 \%$ fines \\
\hline & $\mathrm{SC} 4$ & Sand w/ 30\% fines \\
\hline & SC 5 & Sand w/ 6\% fines \\
\hline & SC 6 & Sand $w / 15 \%$ fines \\
\hline & $\mathrm{SC} 7$ & Sand w/ 20\% fines \\
\hline & SC 7 & Sand w/ 20\% fines \\
\hline & SC 8 & SP-SM \\
\hline & SC 9 & SP-SM \\
\hline & $\mathrm{SC} 10$ & $\mathrm{CL}$ \\
\hline & SC 10 & SP-SM \\
\hline \multirow{6}{*}{$\mathrm{CB}$} & $\mathrm{CB} 1$ & Sand $\mathrm{w} / 6 \%$ fines \\
\hline & $\mathrm{CB} 2$ & Sand w/ 15\% fines \\
\hline & CB 3 & Sand w/ 20\% fines \\
\hline & CB 4 & SP-SM \\
\hline & CB 5 & $\mathrm{CL}$ \\
\hline & CB 6 & SW \\
\hline \multirow{9}{*}{ CCSP } & BCSB & SP-SM \\
\hline & CCSP 1 & $70 \%$ fines $\mathrm{w} / \mathrm{sand}$ \\
\hline & CCSP 2 & Sand $w / 40 \%$ fines \\
\hline & CCSP 3 & $\mathrm{MH}$ \\
\hline & CCSP 4 & Sand $w / 45 \%$ fines \\
\hline & CCSP 5 & $\mathrm{MH}$ \\
\hline & CCSP 6 & $\mathrm{MH}$ \\
\hline & $\operatorname{CCSP} 7$ & SM \\
\hline & $\operatorname{CCSP} 7$ & SM \\
\hline
\end{tabular}

\begin{tabular}{|c|c|c|}
\hline $\begin{array}{l}\text { Study } \\
\text { Site }\end{array}$ & Layer & USCS Classification* \\
\hline \multirow{11}{*}{$\mathrm{PC}$} & PC 1 & $\mathrm{MH}$ \\
\hline & PC 2 & $\mathrm{CL}$ or $\mathrm{CH}$ \\
\hline & PC 3 & Sand $w / 45 \%$ fines \\
\hline & $\mathrm{PC} 4$ & SM \\
\hline & PC 5 & $\mathrm{CH}$ \\
\hline & PC 6 & $\mathrm{CL}$ or $\mathrm{CH}$ \\
\hline & PC 7 & $\mathrm{CL}$ or $\mathrm{CH}$ \\
\hline & PC 8 & SM \\
\hline & PC 9 & SP-SM \\
\hline & PC 10 & $\mathrm{SP}$ \\
\hline & PC 11 & SP-SM \\
\hline \multirow{11}{*}{ CRE } & CRE 1 & $\mathrm{MH}$ \\
\hline & CRE 2 & $\mathrm{CL}$ or $\mathrm{CH}$ \\
\hline & CRE 3 & Sand $w / 45 \%$ fines \\
\hline & CRE 4 & SM \\
\hline & CRE 5 & $\mathrm{CH}$ \\
\hline & CRE 6 & $\mathrm{CL}$ or $\mathrm{CH}$ \\
\hline & CRE 7 & $\mathrm{CL}$ or $\mathrm{CH}$ \\
\hline & CRE 8 & SM \\
\hline & CRE 9 & SP-SM \\
\hline & CRE 10 & $\mathrm{SP}$ with $\mathrm{CH}$ \\
\hline & CRE 11 & SP-SM \\
\hline
\end{tabular}

*USCS Classification based on laboratory testing on collected samples where available; if not sample was collected, USCS classification based on Miller's (1995) testing. 


\section{References}

Abramson, L.W., Lee, T.S., Sharma, S., and Boyce, G.M. 2002. Slope Stability and Stabilization Methods. John Wiley \& Sons, Inc., New York, New York.

American Concrete Pavement Institute (ACPA). 2008. Frost-Suscpetible Soils, ACPA, Skokie, Illinois.

American Geological Institute. 1977. Glossary of Geology. American Geological Institute, Falls Church, Virginia.

Amin, S.M.N., and Davidson-Arnott, R.G.D. 1997. A Statistical Analysis of the Controls on Shoreline Erosion Rates, Lake Ontario. Journal of Coastal Research, 13(4): 1093-1101.

Andersland, O.B., and Anderson, D.M. 1978. Geotechnical Engineering for Cold Regions. McGraw-Hill Inc.

Baddeley, A., and Turner, R. 2005. Spatstat: an R Package for Analyzing Spatial Point Patterns. Journal of Statistical Software, 12(6): 1-42.

Becker, R.A., Wilks, A.R., Brownrigg, R., and Minka, T.P. 2012. maps: Draw Geographical Maps [online]. Available from http://CRAN.Rproject.org/package $=$ maps.

Bivand, R., Ono, H., and Dunlap, R. 2011a. classInt: Choose Univariate Class Intervals [online]. Available from http://CRAN.R-project.org/package=classInt.

Bivand, R., Yu, D., Nakaya, T., and Garcia-Lopez, M.-A. 2011b. spgwr: Geographically Weighted Regression [online]. Available from http://CRAN.Rproject.org/package $=$ spgwr.

Bivand, R., Altman, M., Anselin, L., Assuncao, R., Berke, O., Bernat, A., Blanchet, G., Blankmeyer, E., Carvalho, M., Christensen, B., Chun, Y., Dormann, C., Dray, S., Halbersma, R., Krainski, E., Legendre, P., Lewin-Koh, N., Li, H., Ma, J., Millo, G., Mueller, W., Ono, H., Peres-Neto, P., Piras, G., Reder, M., Tiefelsdorf, M., and $\mathrm{Yu}, \mathrm{D} .2011 \mathrm{c}$. spdep: Spatial dependence: weighting schemes, statistics and models [online]. Available from http://CRAN.R-projects.org/package=spdep.

Bivand, R.S., Pebesma, E.J., and Gomez-Rubio, V. 2008. Applied Spatial Data Analysis with R, Springer, NY.

Black, P.B. 1995. RIGIDICE Model of Secondary Frost Heave, US Army Corps of Engineers Cold Regions Research \& Engineering Laboratory, Hanover, NH.

Bowman, A., Crawford, E., Alexander, G., and Bowman, R.W. 2007. rpanel: Simple Interactive Controls for R Functions Using the tcltk Package. Journal of Statistical Software, 17(9): 1-18.

Brown, E.A., Wu, C.H., Mickelson, D.M., and Edil, T.B. 2005. Factors Controlling Rates of Bluff Recession at Two Sites on Lake Michigan. Journal of Great Lakes Research, 31: 306-321.

Buckler, W.R., and Winters, H.A. 1983. Lake Michigan Bluff Recession. Annals of the Association of American Geographers, 73(1): 89-110.

Budhu, M. 2007. Soil Mechanics and Foundations. John Wiley \& Sons, Inc., Hoboken, New Jersey. 
Calvert County Government. 2012. Aerial imagery and ArcGIS shapefile data, Prince Frederick, MD.

Calvert County, Maryland. 2013. Cliff Stabilization Advisory Committee (CSAC) [online]. Available from http://www.co.cal.md.us/index.aspx?nid=1257.

Calvert County, Maryland, Department of Natural Resources, Maryland Department of the Environment, United States Army Corps of Engineers, United States Fish and Wildlife Service, and Maryland Emergency Management Agency. 2010. Chesapeake Bay Cliff Erosion in Calvert County: Draft Steering Committee Report.

Carter, C.H., and Guy, D.E. 1988. Coastal Erosion: Processes, Timing and Magnitudes at the Bluff Toe. Marine Geology, 84: 1-17.

Clark, I., Larsen, C.E., and Herzog, M. 2004. Evolution of Equilibrium Slopes at Calvert Cliffs, Maryland: A Method of Estimating the Timescale of Slope Stabilization. Shore \& Beach, 72(4): 17-23.

CSAC-Meeting 2012. Shoreline Permit Guidebook.

Department of the Army Corps of Engineers. 1981a. Low Cost Shore Protection: A Property Owner's Guide, USA.

Department of the Army Corps of Engineers. 1981b. Low Cost Shore Protection: A Guide for Engineers and Contractors, USA.

Department of the Army Corps of Engineers Office of the Chief of Engineers. 1984. Pavement Criteria for Seasonal Frost Conditions: Mobilization Construction, USA.

Dimitriadou, E., Hornick, K., Leisch, F., Meyer, D., and Weingessel, A. 2011. e1071: Misc Functions of the Department of Statistics (e1071), TU Wien [online]. Available from http://CRAN.R-project.org/package=e1071.

Duncan, J.M., and Wright, S.G. 2005. Soil Strength and Slope Stability. John Wiley \& Sons, Inc., Hoboken, New Jersey.

Edil, T.B. 2010. Erosion, Slope Stability, Prediction of Future Recession in Actively Eroding Slopes. Geotechnical Engineering Journal of the SEAGS \& AGSSEA, 41(4).

Edil, T.B., and Vallejo, L.E. 1980. Mechanics of Coastal Landslides and the Influence of Slope Parameters. Engineering Geology, 16: 83-96.

Ferrick, M., and Gatto, L.W. 2005. Quantifying the effect of a freeze-thaw cycle on soil erosion: Laboratory experiments. Earth Surface Processes and Landforms, 30(10): 1305-1326.

Force, J.D.o.t.A.a.A. 1987. Arctic and Subarctic Construction: General Provisions, USA.

Fox, J., and Weisberg, S. 2011. An R Companion to Applied Regression. SAGE Publications, Inc., Thousand Oaks, California.

Furrer, R., Nychka, D., and Sain, S. 2012. fields: Tools for Spatial Data [online]. Available from http://CRAN.R-project.org/package=fields.

Gatto, L.W. 1995. Soil Freeze-Thaw Effects on Bank Erodibility and Stability, US Army Corps of Engineers Cold Regions Research \& Engineering Laboratory, Hanover, $\mathrm{NH}$.

Giraudoux, P. 2011. pgirmess: Data Analysis in Ecology [online]. Available from http://CRAN.R-projects.org/package=pgirmess. 
Gray, D.H., and Sotir, R.B. 1996. Biotechnical and Soil Bioengineering Slope Stabilization: A Practical Guide for Erosion Control. John Wiley \& Sons, Inc., New York, New York.

Hampton, M.A., Griggs, G.B., Edil, T.B., Guy, D.E., Kelley, J.T., Komar, P.D., Mickelson, D.M., and Shipman, H.M. 2004a. Processes that Govern the Formation and Evolution of Coastal Cliffs, U.S. Department of the Interior, U.S.A.

Hampton, M.A., Griggs, G.B., Edil, T.B., Guy, D.E., Kelley, J.T., Komar, P.D., Mickelson, D.M., and Shipman, H.M. 2004b. Introduction, U.S. Department of the Interior, U.S.A.

Hapke, C.J. 2004. The Measurement and Interpretation of Coastal Cliff and Bluff Retreat, U.S. Department of the Interior, U.S.A.

Harlan, R.L., and Nixon, J.F. 1978. Ground Thermal Regime. In Geotechnical Engineering for Cold Regions. Edited by O.B. Andersland and D.M. Anderson, Mc-Graw Hill Book Co., New York, New York. pp. 103-163.

Harris, C., and Lewkowicz, A.G. 2000. An Analysis of the Stability of Thawing Slopes, Ellesmere Island, Nunavut, Canada. Canadian Geotechnical Journal, 37: 449-462.

Harris, C., Rea, B., and Davies, M. 2001. Scaled Physical Modelling of Mass Movement Processes on Thawing Slopes. Permafrost and Periglacial Processes, 12: 125-135.

Hiemstra, P.H., Pebesma, E.J., Twenh, C.J.W., and Heuvelink, G.B.M. 2008. Real-Time Automatic Interpolation of Ambient Gamma Dose Rates from the Dutch Radioactivity Monitoring Network. Computers \& Geosciences.

Higashi, A., and Corte, A.E. 1971. Soilfluction: A Model Experiment. Science, 171(3970): 480-482.

Holtz, R.D., Kovacs, W.D., and Sheahan, T.C. 2011. An Introduction to Geotechnical Engineering. Pearson Education, Inc, Upper Saddle River, New Jersey.

Jackson, G.A. 2003. System and Method for Preventing Bluff Erosion. Edward E. Gillen Co. Milwaukee, WI (US), USA.

Kamphuis, J.W. 1987. Recession Rate of Glacial Till Bluffs. Journal of Waterway, Port, Coastal, and Ocean Engineering, 113(1): 60-73.

Kawamura, S., and Miura, S. 2011. Stability Evaluation of Volcanic Slope Subjected to Rainfall and Freeze-Thaw Action Based on Field Monitoring. Advances in Civil Engineering, 2011: 1-14.

Keitt, T.H., Bivand, R., Pebesma, E., and Rowlingson, B. 2012. rgdal: Bindings for the Geospatial Data Abstraction Library [online]. Available from http://CRAN.Rproject.org/package $=$ rgdal.

Kidwell, S.M. 1997. Anatomy of Extremely Thin Marine Sequences Landward of a Passive-Margin Hinge Zone: Neogene Calvert Cliffs Succession, Maryland, U.S.A. Journal of Sedimentary Research, 67(2): 322-340.

Kim, W.-H., and Daniel, D.E. 1992. Effects of Freezing on Hydraulic Conductivity of Compacted Clay. Journal of Geotechnical Engineering, 118(7): 1083-1097.

Knisley, C.B. 2011. Studies of Two Rare Tiger Beetles (Cicindela Puritana and C. D. Dorsalis) in Maryland, 2010, Ashland, Virginia.

Konrad, J.-M., and Morgenstern, N.R. 1980. A Mechanistic Theory of Ice Lens Formation in Fine-Grained Soils. Canadian Geotechnical Journal, 17: 473-486. 
Leatherman, S.P. 1986. Cliff Stability Along Western Chesapeake Bay, Maryland. Marine Technology Society Journal, 20: 28-36.

Lees, J.M. 2011. geomapdata: Data for Topographic and Geologic Mapping [online]. Available from http://CRAN.R-project.org/package=geomapdata.

Lewin-Koh, N.J., Bivand, R., Pebesma, E.J., Archer, E., Baddeley, A., Bibiko, H.-J., Callahan, J., Dray, S., Forrest, D., Friendly, M., Giradoux, P., Golicher, D., Rubio, V.G., Hausmann, P., Hufthammer, K.O., Jagger, T., Luque, S.P., MacQueen, D., Niccolai, A., Short, T., Snow, G., Stabler, B., and Turner, R. 2012. maptools: Tools for Reading and Handling Spatial Objects [online]. Available from http://CRAN.R-project.org/package=maptools.

Loecher, M. 2011. RgoogleMaps: Overlays on Google Map Tiles in R [online]. Available from http://CRAN.R-project.org/package=RgoogleMaps.

Manson, G.K. 2002. Subannual Erosion and Retreat of Cohesive till Bluffs, McNab's Island, Nova Scotia. Journal of Coastal Research, 18(3): 421-432.

Michalowski, R.L., and Zhu, M. 2006a. Frost Heave Modelling Using Porosity Rate Function. International Journal for Numerical and Analytical Methods in Geomechanics, 30: 703-722.

Michalowski, R.L., and Zhu, M. 2006b. Modelling of Freezing in Frost-Susceptible Soils. Computer Assisted Mechanics and Engineering Sciences, 13: 613-625.

Miller, D.S. 1995. A Field Investigation of the Controls of the Dominant Erosion Processes on the Actively Undercut, Non-Lithified Coastal Slopes of Calvert County, Maryland. PhD, Johns Hopkins University, Baltimore, MD.

Miller, D.S., Prince, N., and Miller, B.J. 2006. A Best Management Plan for the Shoreline and Slopes Along the Scientists' Cliffs Shoreline of the Chesapeake Bay, Maryland, Scientists' Cliffs Association.

Mininger, K.T., Santi, P.M., and Short, R.D. 2011. Life Span of Horizontal Wick Drains Used for Landslide Drainage. Journal of Environmental \& Engineering Geoscience, 17(2): 103-121.

National Oceanic and Atmospheric Administration (NOAA) Coastal Services Center. 2012. Lidar 101: An Introduction to Lidar Technology, Data, and Applications, NOAA Coastal Services Center, Charleston, South Carolina.

NCDC/NOAA 2002a. Air Freezing Index- USA Method (Base 32 degrees Fahrenheit), Asheville, NC.

NCDC/NOAA 2002b. Air Freezing Index Winter Season Values - USA Method (Base 32 degrees Fahrenheit), Asheville, NC.

NCDC/NOAA 2002c. Data Documentation for Data Ser 9712D (DSI-9712D): AirFreezing Index Statistics for the United States National Climatic Data Center/National Oceanic and Atmospheric Administration, Asheville, NC.

NCDC/NOAA 2012a. Integrated Surface Hourly Climate Data, Patuxent River NAS, Asheville, NC.

NCDC/NOAA 2012b. Integrated Surface Hourly Climate Data, Asheville, NC.

Neuwirth, E. 2011. RColorBrewer: ColorBrewer Palettes [online]. Available from http://CRAN.R-project.org/package=RColorBrewer.

Paradis, E., Claude, J., and Strimmer, K. 2004. APE: Analyses of Phylogenetics and Evloution in R Languate. Bioinformatics, 20: 289-290. 
Pardoe, I. 2012. Applied Regression Modeling. John Wiley \& Sons, Inc., Hoboken, New Jersey.

Pebesma, E., Cornford, D., Dubois, G., Heuvelink, G.B.M., Hristophulos, D., Pilz, J., Stoehlker, U., Morin, G., and Skoien, J.O. 2010. INTAMAP: The Design and Implementation of an Interoperable Automated Interpolation Web Service. Computers \& Geosciences.

Pebesma, E.J. 2004. Multivariable Geostatistics in S: The gstat Package. Computers \& Geosciences, 30: 683-691.

Pebesma, E.J., and Bivand, R.S. 2005. Classes and Methods for Spatial Data in R. R News 5, 2.

Price, J.C. 1980. The potential of remotely sensed thermal infrared data to infer surface soil moisture and evaporation. Water Resources Research, 16(4): 787-795.

Program, C.B. 2012. Northeastern Beach Tiger Beetle [online]. Available from www.chesapeakebay.net/fieldguide/critter/northeastern_beach_tiger_beetle [cited 27 March 2013].

R Core Team. 2012. R: A Languate and Environment for Statistical Computing [online]. Available from http://www.R-project.org/.

Resources, M.D.o.N. 2011. The Maryland Puritan Tiger Beetle Habitat Conservation Program, Annapolis, Maryland.

Ripley, B., and Lapsley, M. 2012. RODBC: ODBC Database Access [online]. Available from http://CRAN.R-project.org/package=RODBC.

Rowlingson, B., Diggle, P., Bivand, R., Petris, G., and Eglen, S. 2012. splancs: Spatial and Space-Time Point Pattern Analysis [online]. Available from http://CRAN.Rproject.org/package $=$ splancs.

Schweitzer, J.P. 1993. Observations of Soil Wash on Steep, Unvegetated Slopes: Calvert County, Maryland. Master of Science, Johns Hopkins University.

Selezneva, O.I., Jiang, Y.J., Larson, G., and Puzin, T. 2008. LTPP Computed Parameter: Frost Penetration, Federal Highway Administration.

Shattuck, G.B. 1904. Geologial and Paleontological Relations, with a Review of Earlier Investigations. In The Miocend Deposits of Maryland. Edited by G.B.Shattuck.

W. B. Clark, W. H. Dall, Maryland Geological Survey. pp. 33-94.

Sterrett, R.J., and Edil, T.B. 1982. Ground-Water Flow Systems and Stability of a Slope. Ground Water, 20(1): 5-11.

Swenson, M.J., Wu, C.H., Edil, T.B., and Mickelson, D.M. 2006. Bluff Recession Rates and Wave Impact Along the Wisconsin Coast of Lake Superior. Journal of Great Lakes Research, 32: 512-530.

Tanyu, B.F., Sabatini, P.J., and Berg, R.R. 2008. FHWA NHI 132036 Earth Retaining Structures.

The Scientists' Cliffs History Book Committee. 2010. Scientists' Cliffs Community and Context. Scientists' Cliffs Association, Port Republic, Maryland.

Thode, H.C. 2002. Testing for Normality. Marcel Dekker, Inc., New York, New York.

U.S. Fish \& Wildlife Service. 2011. Puritan Tiger Beetle [online]. Available from http://www.fws.gov/chesapeakebay/EndSppWeb/BEETLE/TigerBeetle.html.

Vallejo, L.E. 1980. A New Approach to the Stability Analysis of Thawing Slopes. Canadian Geotechnical Journal, 17: 607-612. 
Vallejo, L.E.D., Robert 1988. Bluff Response to Wave Action. Engineering Geology, 26: $1-16$.

Wang, L., Ling, X., Zhang, F., Gao, X., and Wu, L. 2009. Freeze-Thaw Stability of Slopes in Seasonally Frozen Regions of the Northeast China. In ICCTP 2009: Critical Issues in Transportation Systems Planning, Development, and Management. ASCE, pp. 951-957.

Ward, L.W., and Andrews, G.W. 2008. Stratigraphy of the Calvert, Choptank, and St. Marys Formations (Miocene) in the Chesapeake Bay Area, Maryland and Virginia. Virginia Museum of Natural History.

Wickham, H. 2011. The Split-Apply-Combine Strategy for Data Analysis. Journal of Statistical Software, 40(1): 1-29.

Wilcock, P.R., Miller, D.S., and Kerhin, R.T. 1993. Calvert Cliffs Slope Erosion Project Phase II Final Report - Processes and Controls of Coastal Slope Erosion, Charleston, SC.

Wilcock, P.R., Miller, D.S., Shea, R.H., and Kerhin, R.T. 1998. Frequency of Effective Wave Activity and the Recession of Coastal Bulffs: Calvert Cliffs, Maryland. Journal of Coastal Research, 14(1): 256-268.

Zheng, D., Hunt Jr., E.R., and Running, S.W.R. 1993. A daily soil temperature model based on air temperature and precipitation for continental applications. Journal of Climate Research, 2: 183-197.

Zurek, P.J., Narin, R.B., and Thieme, S.J. 2003. Spatial and Temporal Considerations for Calculating Shoreline Change Rates in the Great Lakes Basin. Journal of Coastal Research(Special Issue No. 38 Shoreline Mapping and Change Analysis: Technical Considerations and Management Implications): 125-146. 